\title{
POTTERY PRODUCTION, DISTRIBUTION AND CONSUMPTION IN EARLY MINOAN WEST CRETE: \\ AN ANALYTICAL PERSPECTIVE
}

Volume I: Text and Bibliography

Eleni Nodarou

Thesis submitted for the degree of

Doctor of Philosophy

University of Sheffield

Department of Archaeology

May 2003 
Tomy parents 
"... and the earth, when compressed by the air into an indissoluble union with water becomes rock. The fairer sort is that which is made up or equal and similar parts and is transparent; that which has the opposite qualities is inferior. But when all the watery part is suddenly draw w out by fire, a more brittle substance is formed, to which we give the name of pottery..."

Plato, Timaens: 60

"Does not the potter have the right to make out of the same lump of clay some pottery for notle purposes and some for common use"?

Romans 9: 21 


\begin{abstract}
This thesis investigates the provenance and technology of pottery during the earlier Prepalatial period (EM I-EM IIB) in West Crete, using an integrated approach involving stylistic examination and physico-chemical analysis.

Although the stylistic particularities of the West Cretan Early Minoan assemblages have been acknowledged since the 1960's, there has been no attempt to assess and interpret the differences, and integrate this part of Crete into the broader picture of the Prepalatial period. Due to the lack of publications and analyses, West Crete remained away from the new developments that have changed the way the Prepalatial period is considered.
\end{abstract}

As part of the GEOPRO TMR Network, this project applies an integrated methodology to the ceramic material from selected sites and investigates issues of pottery provenance and technology. The analytical techniques used comprise thin section petrography, neutron activation analysis and scanning electron microcopy with EDAX attachment. Possible locations of production for the various fabrics are suggested and technological issues, such as clay recipes, firing practices and pottery manufacturing traditions, are discussed in detail.

All pottery examined in the project appear to have been manufactured within West Crete and the majority of the fabrics are likely to have been manufactured close to their findspots. There are, however, markedly contrasting traditions of pottery manufacture, one producing relatively high-fired calcareous vessels and another noncalcareous, low-fired tradition. The stylistic correlates of these two very different forms of pottery technology are compared.

Issues concerning technological traditions, the identity and ethnicity of the producers and consumers of this pottery, and the organization of production are discussed. As the research revealed no imports from outside Crete, and this contrasts with Central and Eastern Crete, the position and role of West Crete in the Southern Aegean during the Early Bronze Age is re-assessed. 


\section{CONTENTS}

\section{VOLUME I}

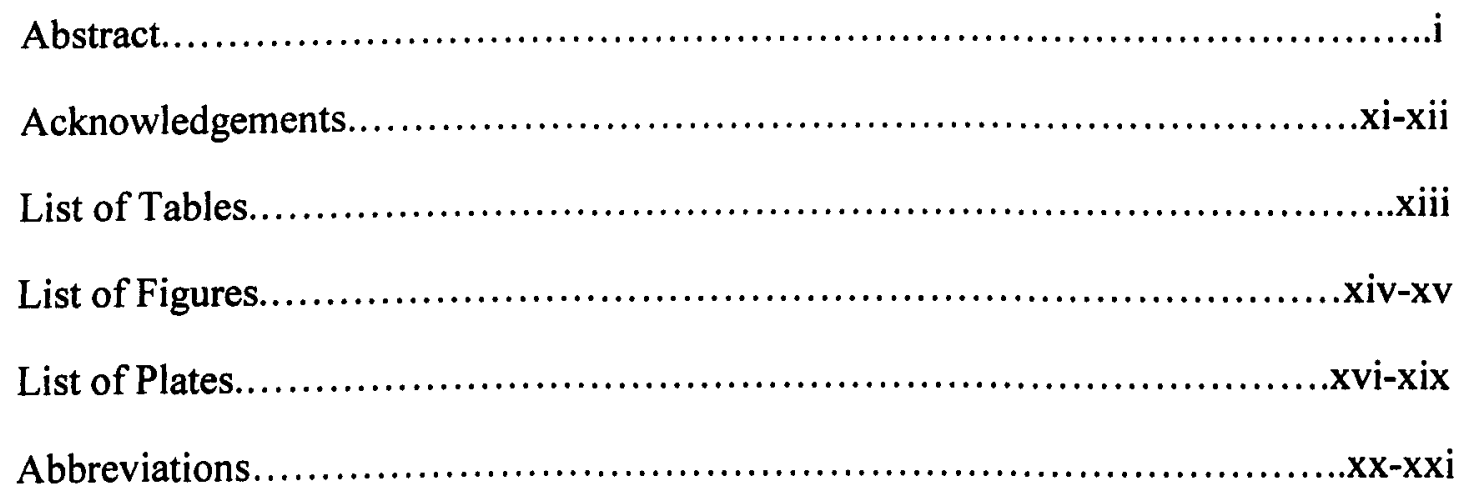

\section{CHAPTER 1}

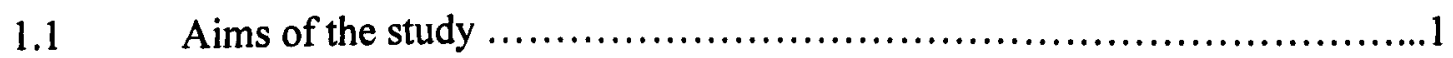

Chronological and geographical limits of the study.......................

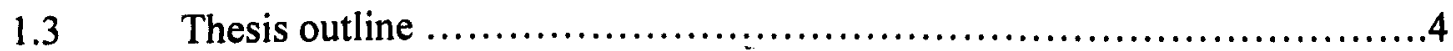

CHAPTER 2 The Prepalatial period in West Crete and the sites studied...............................................7-29

2.1 The Prepalatial period in Central and East Crete...........................

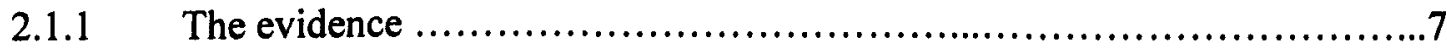

2.1.2 Major themes in the archaeology of the Prepalatial period...................8

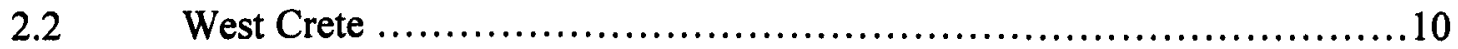

2.2.1 Background to the research in West Crete.............................. 10

2.2.2 Environment and settlement patterns................................... 12

2.2.2.1 The Final Neolithic period............................................ 13

2.2.2.2 The Early Minoan I period............................................ 14

2.2.2.3 The Early Minoan II period........................................ 16 


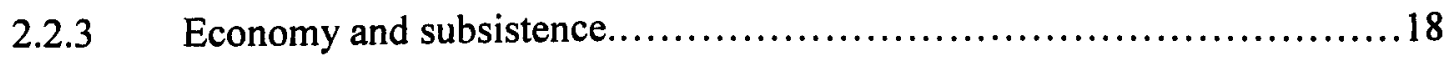

2.3 The sites included in the study: criteria of selection and brief presentation. 20

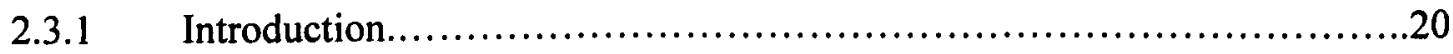

2.3.2 The sites...............................................................

2.3.2.1 Kastelli and Chania Town............................................ 21

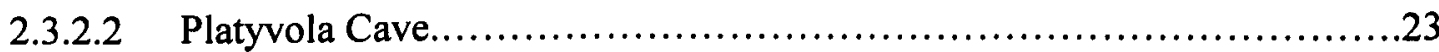

2.3.2.3 Nea Roumata/Mitatoulia...........................................24

2.3.2.4 Debla............................................................ 25

2.3.2.5 Nopigeia Kissamou.................................................26

2.3.2.6 Psathi Kydonias........................................................

CHAPTER 3 Methodology...........................................30-44

3.1 Methods and scale of analysis in ceramic studies .........................30

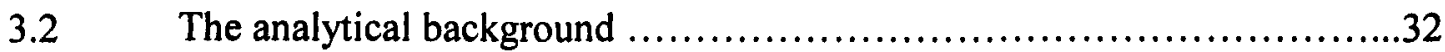

3.2.1 Chemical analysis .................................................... 32

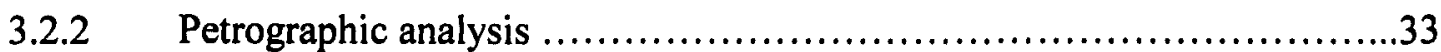

3.3 The analysis of EM pottery from West Crete...........................34

3.3.1 Typological examination and sampling of the pottery $\ldots \ldots \ldots \ldots \ldots \ldots \ldots . \ldots . \ldots . \ldots 35$

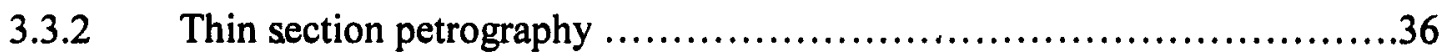

The geological sampling................................................. 38

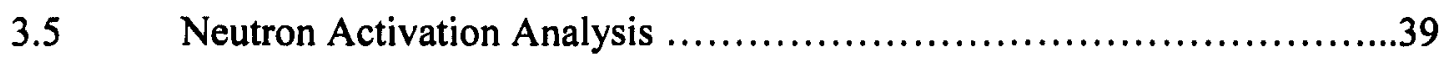

3.5.1 Scanning Electron Microscopy....................................41

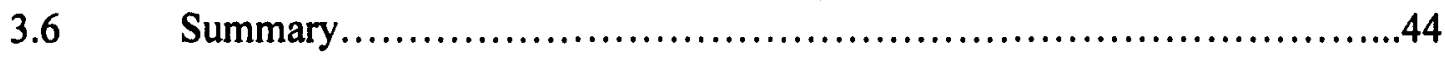




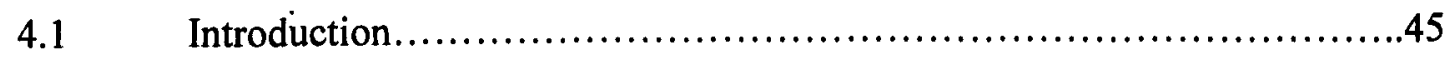

4.2 The geological evolution of Crete....................................45

$4.3 \quad$ Pre-Neogene units.................................................. 47

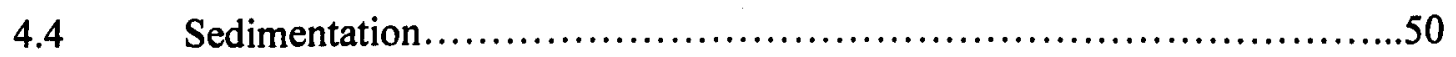

4.4.1 Neogene deposits in West Crete......................................51

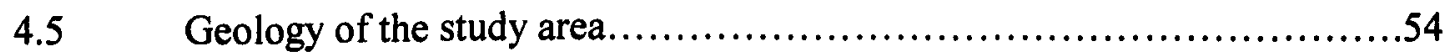

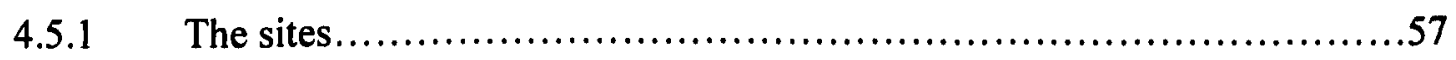

4.6 Geological variation and ancient ceramics..............................58

4.7 Clay sampling and experimental briquettes...........................61

4.7.1 The red deposits....................................................61

4.7.2 The Neogene marls................................................63

4.8 The petrology of the clay samples.....................................64

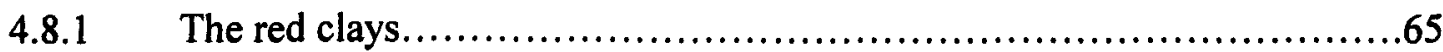

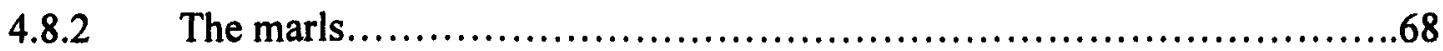

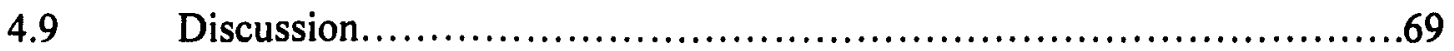

\section{CHAPTER 5 Early Bronze Age pottery from West Crete..........72-114}

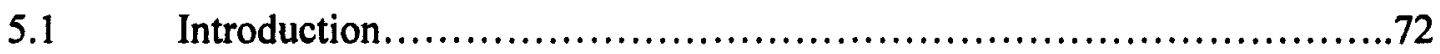

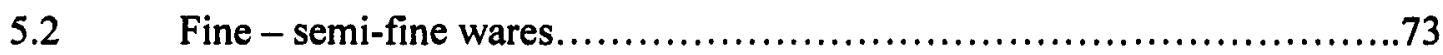

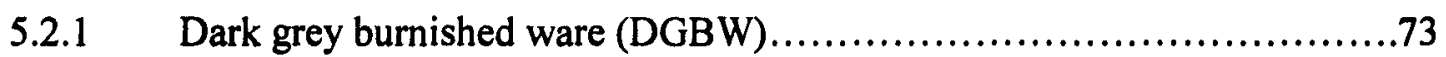

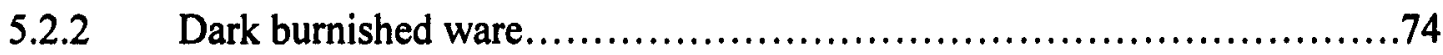

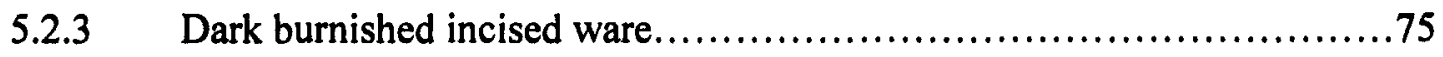

5.2.4 Black slipped ware ....................................................

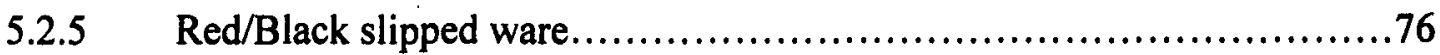




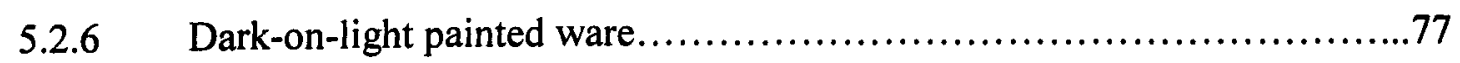

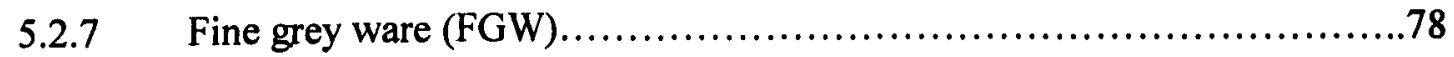

5.2.8 Mottled ware......................................................

S.3 Semi-coarse - coarse wares...................................... 79

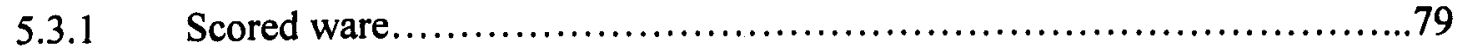

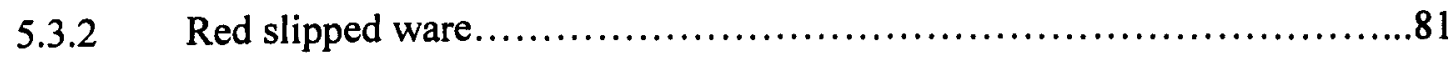

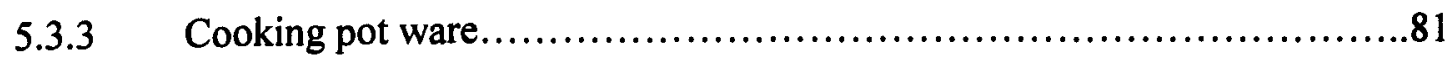

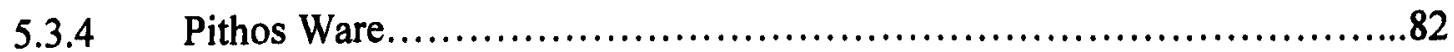

5.3 .5 Other coarse wares.............................................. 82

$5.4 \quad$ The pottery from the sites.......................................... 83

5.4.1 Debla............................................................... 83

5.4.2 Platyvola Cave......................................................... 88

5.4.3 Mitatoulia.......................................................92

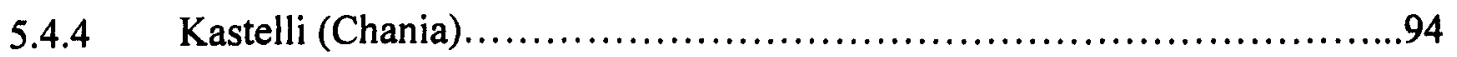

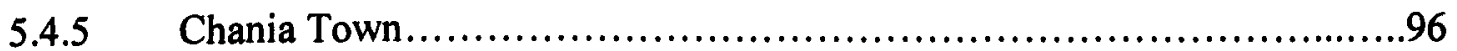

5.4.6 Nopigeia......................................................98

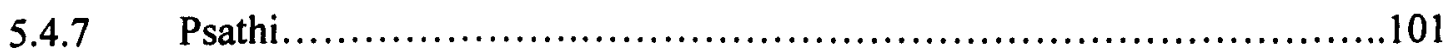

$5.5 \quad$ The Shapes....................................................... 103

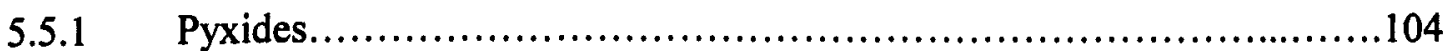

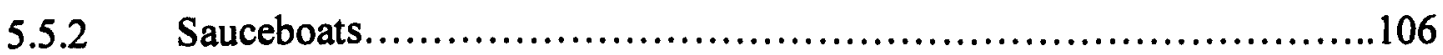

Collar-necked jars.................................................. 107

5.5.4 Stamped Hearths............................................... 108

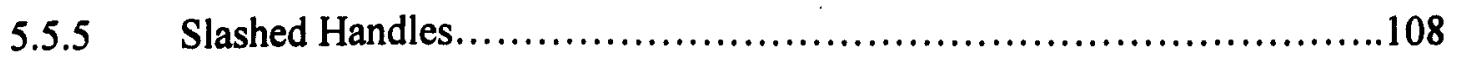




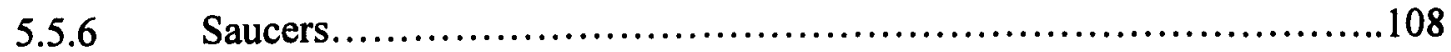

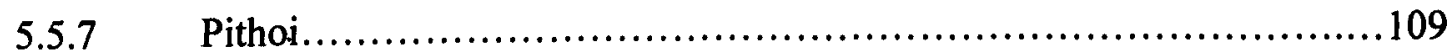

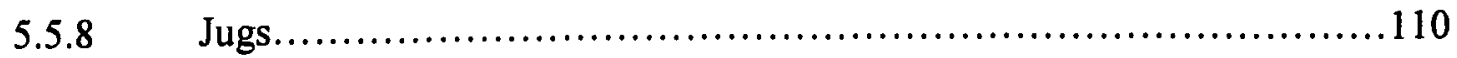

5.6 The rest of West Crete: an outline of the pottery assemblages from Stavromenos and Eleutherna in Rethymnon..........................112

$5.7 \quad$ Discussion..........................................................

CHAPTER 6 Petrographic Analysis...............................115-164

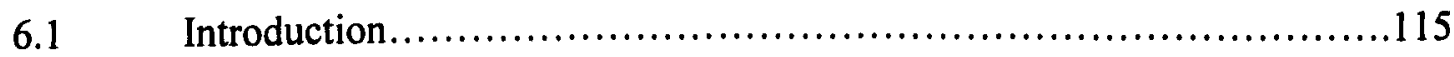

6.2 Thin section petrography............................................. 116

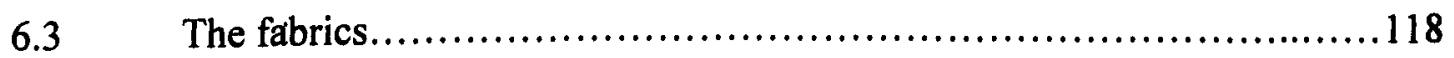

6.3.1 The establishment of petrographic groups............................118

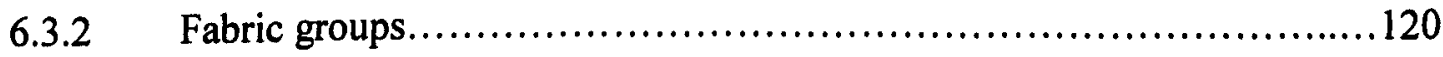

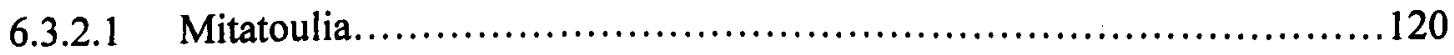

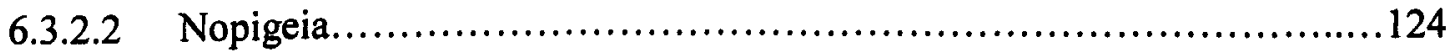

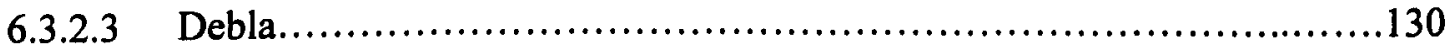

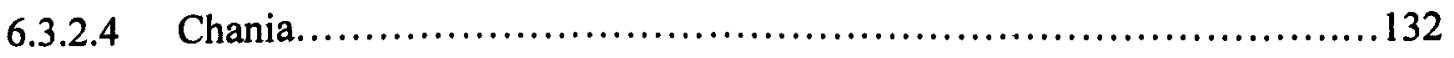

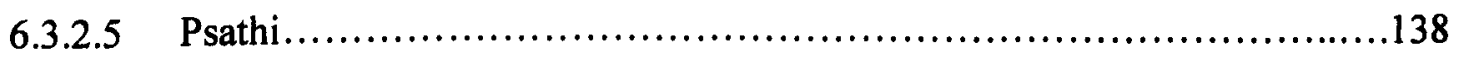

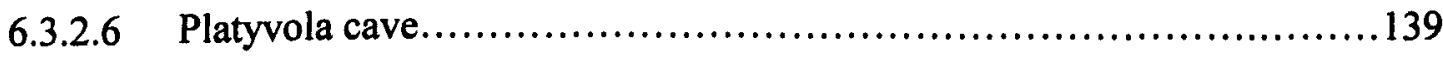

$6.4 \quad$ Discussion............................................................

6.4.1 Comment on the distribution of fabrics..............................151

6.4.2 Comment on the technology of manufacture ............................153

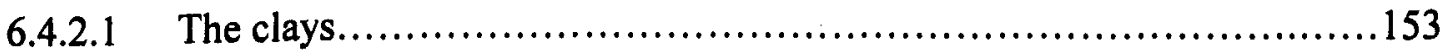

6.4.2.2 Clay recipes in EM West Crete.......................................155

6.4.2.2.1 Clay sieving ........................................................ 155 
6.4.2.2.2 Clay mixing and tempering........................................... 156

6.4.2.3 Other technological aspects of the West Cretan pottery..................160

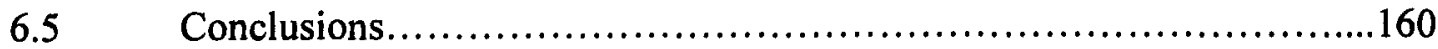

CHAPTER 7 Neutron Activation Analysis........................165-198

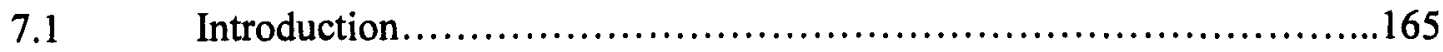

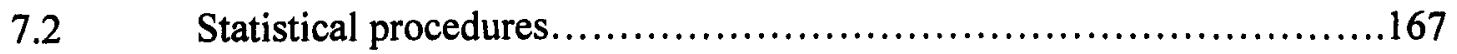

7.2.1 Some preliminary considerations...................................167

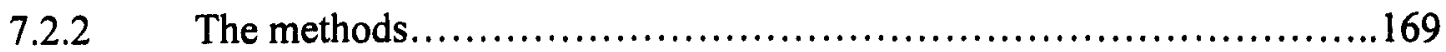

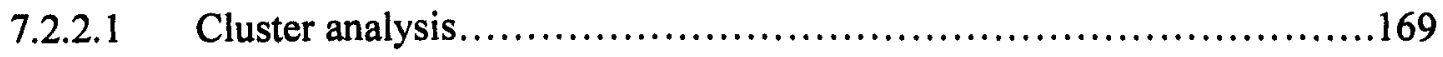

7.2.2.2 Princípal components analysis.....................................169

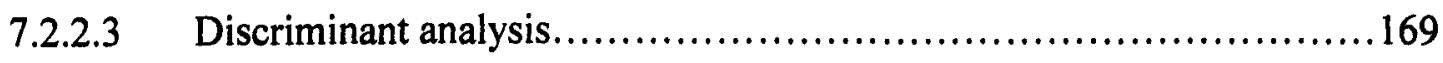

7.2.2.4 The Bonn approach.................................................. 170

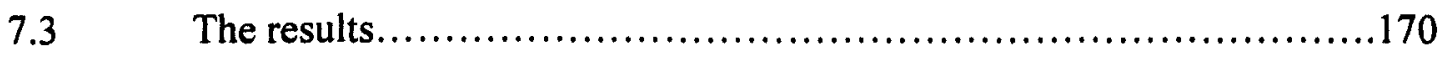

7.3.1 The entire dataset...................................................

7.3.2 The chemical groups...........................................173

7.3.2.1 Chania groups...................................................... 174

7.3.2.2 Psathi groups..........................................................

7.3.2.3 Nopigeia groups................................................. 181

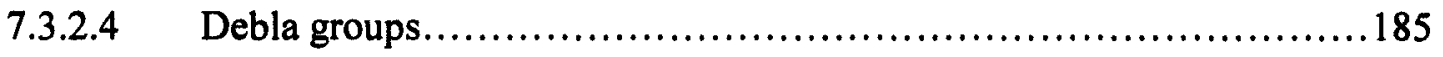

7.3.2.5 Platyvola group.................................................... 187

7.3.2.6 Mitatoulia group.................................................. 188

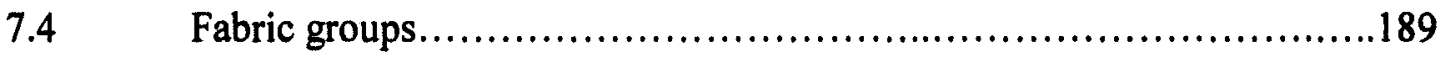

7.4.1 Fabrics with fossils................................................... 190

7.4.2 Red fabrics........................................................ 191 
7.4.3 The Helladic wares............................................. 192

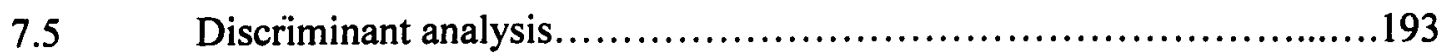

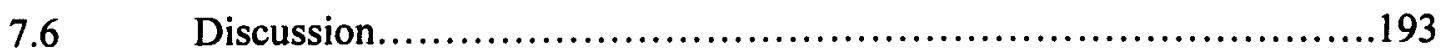

CHAPTER 8 Scanning Electron Microscopy.....................199-222

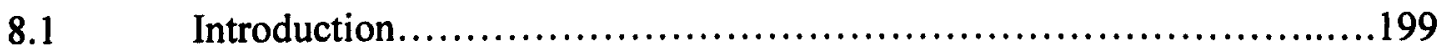

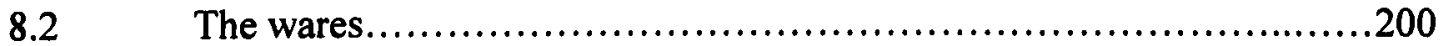

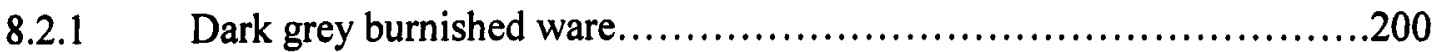

8.2.2 Red-brown/Black burnished ware ................................203

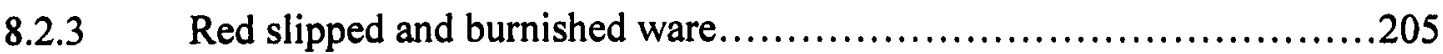

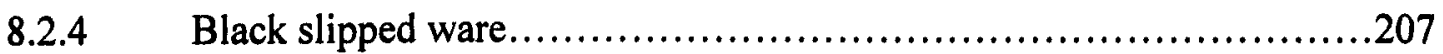

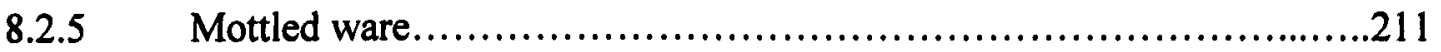

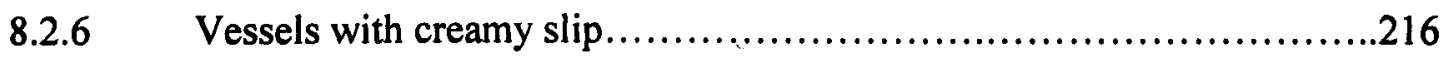

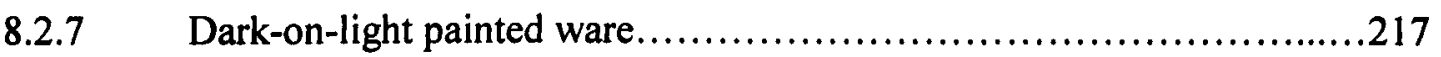

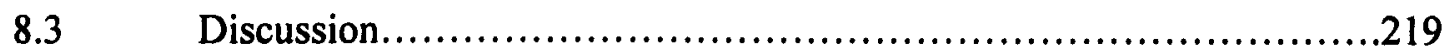

CHAPTER 9 Investigating technology, style, and ethnicity in EBA West Crete: the evidence from pottery analysis.........223-245

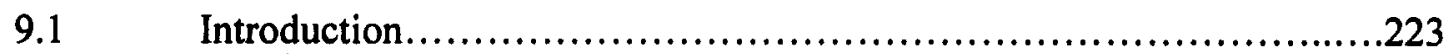

9.2 The "culture-historical" approach in the study of material culture.........224

9.3 Technological style and social meaning.............................225

9.4 "Cultures" and ethnicity in the EBA Southern Aegean..................227

9.4.1 Aegean "cultures" and the International Spirit.........................227

9.4.2 The Creto-Cycladic connection....................................228

$9.5 \quad$ Why is West Crete different?......................................229 


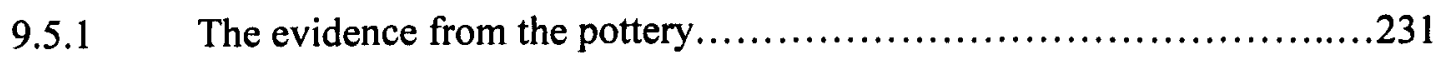

9.5.2 Divergent traditions in West Crete and two case studies................233

9.6 The Western Cycladic connection.....................................236

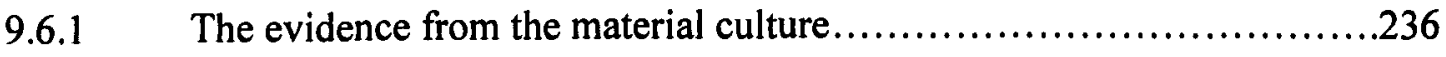

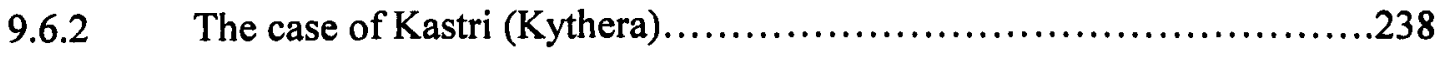

9.6.3 The Western Cycladic network..................................239

9.7 West Crete and the International Spirit.............................

\section{CHAPTER 10 Conclusions.......................................246-260}

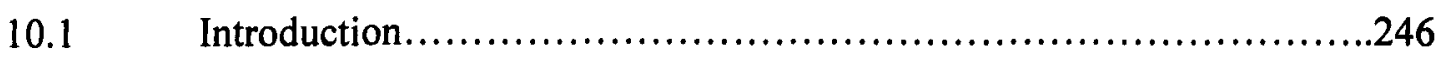

10.2 The issues addressed in the study of the EM West Cretan pottery........247

10.2.1 Specialisation in pottery production...............................247

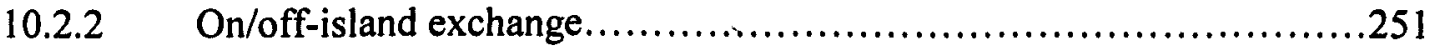

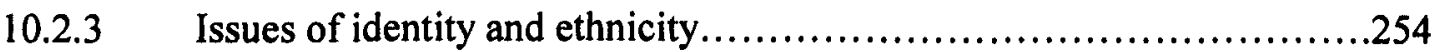

Summary of the main points in this research.........................256

$10.4 \quad$ Suggestions for future research..................................258

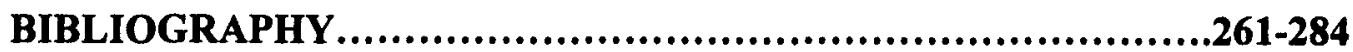




\section{VOLUME II}

APPENDICES...............................................................

Appendix I Catalogue of the pottery samples...................................

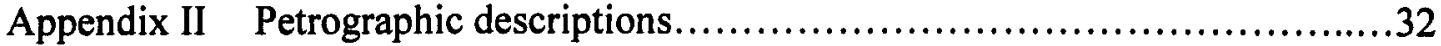

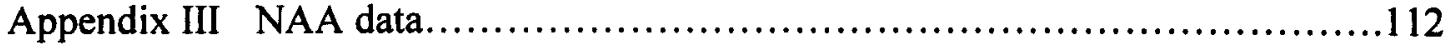

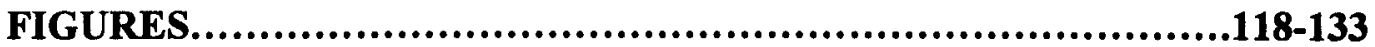

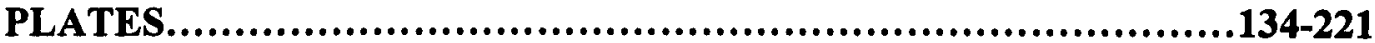




\section{ACKNOWLEDGEMENTS}

A doctoral thesis is ex principio a long and lonely process. This $\mathrm{PhD}$ is no exception, but in the four years I have been working on the material from West Crete, I had around me people who kindly offered support and advice. Moreover, I had friends who shared with me the good and bad moments of this process, making it less long and less lonely.

I am grateful to my supervisor, Dr Peter M. Day, who offered me the opportunity to join GEOPRO and undertake the research on West Crete. In Chania, he wisely guided me through the labyrinth of Early Minoan pottery; in Sheffield, he helped me with comments and advice understand the essence of pottery analysis. I thank him for everything.

Many thanks are due to Professor J. F. Cherry and Dr J. Bennet for making available to us an unpublished inventory of the Bronze Age sites in West Crete.

This project would not have been carried out without the support of the archaeologists who provided the material. I am indebted to the Director of KE' Ephoreia of Prehistoric and Classical Antiquities, Dr Maria Andreadaki-Vlasaki, who supported this project from the very beginning, facilitated the study and sampling in every possible way and entrusted me with the material from Chania Town, Nopigeia, Psathi and Stavromenos. Dr Y. Tzedakis is gratefully acknowledged for allowing me to sample the material from Kastelli (Chania), Platyvola Cave and Mitatoulia. I further thank Professor P. Warren and Professor A. Kalpaxis for permits to sample the material from Debla and Eleutherna respectively.

At Chania I benefited greatly from discussions with $\mathrm{Dr}$ B. Hallager who kindly offered me her expert knowledge on West Cretan pottery. I further thank Ms E. Protopapadaki who facilitated the sampling of the material from Platyvola and Ms L. Mandalara who facilitated the sorting of the material from Eleutherna.

I would also like to thank the personnel of the Museums at Chania and Rethymnon for their help during the study seasons. Special thanks go to the guard of the Arsenal storeroom at Chania, Mr D. Chrysos; his kind help on practical issues facilitated greatly the process and completion of the study.

In the course of the study and analysis of the material I benefited from the expertise and kind help of two people who are eminent in their fields. Professor D. E. Wilson offered valuable advice during the typological study of the material. Dr V. Kilikoglou supervised a significant part of the analysis, offered valuable help during my stay at Demokritos and discussed with me the results of NAA and SEM. They are both gratefully acknowledged.

Being a member of GEOPRO provided me the opportunity to meet other young researchers and discuss aspects of my work with them. Dr Cuco Cau offered advice on petrographic issues, Dr Anno Hein was always there for me to discuss NAA and teach me how to deal with statistics, and Eddy Faber let me benefit from his knowledge of the SEM. I thank them for their help and, above all, for their friendship.

The other GEOPRO members, Dr M. Baxter, Dr. C. Beardah, Dr. J. Buxeda, Y. Iliopoulos and Dr I. Papageorgiou are gratefully acknowledged for many useful conversations.

Most of the work has been carried out in Sheffield, in the Department of Archaeology where I have benefited from lectures by and discussions with several members of staff, namely Prof. J. Barrett, Prof. P. Buckland, Dr P. Halstead and Dr. C. M. Jackson. I thank them all. 
I would also like to express my gratitude to Dr Charles Frederick for everything he taught me in the realms of geoarchaeology and soil analysis and, above all, for being always there for me with his reassuring spirit and positive thinking.

I owe a lot to my colleagues and friends in the Research School. Many thanks to Despina Catapoti, Mihalis Catapotis, Ben Chan, Sotiria Dandou, Eddy Faber, Linda Howie, Efi Kartsonaki, Olia Peperaki, Peter Tomkins, Christina Tsoraki, Giorgos Vavouranakis, Andrea Vianello, Emma Wager, and Harriet White; many thanks also to the friends outside archaeology, namely James Hollingsworth and Vassilis Roubos. I am grateful to all of them for the serious and not so serious conversations, the practical help and moral support and, above all, for their friendship through the years. Maria Relaki shared with me all the ups and downs of the research and life in Sheffield; I thank her for the long discussions, her friendship and her optimism.

Many thanks are due to my friends in Athens, Maria Lafazani, Eleutheria Papadopoulou, Vivi Philippa, Maria Tsilimigaki, as well as Markos Sarris and the rest of the "Fontana" company, for keeping me sane by reminding me that there is life beyond archaeology and research.

Finally, Yiannis Papadatos offered me practical and moral support under the most unfavourable circumstances. He eagerly climbed the mountains with me in search of Debla, he helped with the clay sampling, and patiently read and commented on various drafts of the text. He has always been a source of strong criticism, I did not appreciate it at the time, but now I am grateful.

Last but not least, I would like to thank my parents, to whom I owe the most and to whom this work is dedicated. They discretely supported every decision I made and stood by me in every possible way.

This study was conducted for three years with the financial support of the GEOPRO Research Network, funded by DGXII of the European Commission, under the Training and Mobility of Researchers Network Programme (Contract number ERBFMRX-CT98-0165). During the fourth year, I received financial support in the form of small grants from The Sir Richard Stapley Foundation Trust, The Newby Trust Ltd and the Gilchrist Educational Trust. 


\section{LIST OF TABLES}

TABLE I Early Minoan material at Kastelli (Chania)

TABLE II Stratigraphic Scale (after Derimitzakis and Georgiades-Dikaioulia 1981)

TABLE III Petrographic fabrics and pottery styles

TABLE IV Sites and chemical subgroups

TABLE V Chemical groups from Chania

TABLE VI Chemical groups from Psathi

TABLE VII Chemical groups from Nopigeia

TABLE VIII Chemical pair groups from Nopigeia

TABLE IX Chemical groups from Debla

TABLE X Chemical group from Platyvola

TABLE XI Chemical group from Mitatoulia

TABLE XII SEM Dark Grey Burnished Ware

TABLE XIII SEM Red/Brown - Black Burnished Ware

TABLE XIV SEM Red Slipped and Burnished Ware

TABLE XV SEM Black Slipped Ware

TABLE XVI SEM Mottled Ware

TABLE XVII SEM Vessels with creamy slip 


\section{LIST OF FIGURES}

FIGURE 1 Diagram of the firing of the experimental briquettes.

FIGURE 2 Principal components analysis of the entire data set from West Crete

FIGURE 3 Principal components analysis of the entire data set from West Crete without considering $\mathrm{Ca}$

FIGURE 4 Cluster analysis of the entire data set from West Crete

FIGURE 5 Cluster analysis of the entire data set from West Crete without considering $\mathrm{Ca}$

FIGURE 6 Biplot of logged unscaled data considering $\mathrm{Ca}$

FIGURE 7 Biplot of logged unscaled data without considering Ca

FIGURE 8 Biplot of standardised (scaled) data considering Ca

FIGURE 9 Biplot of standardised (scaled) data without considering $\mathrm{Ca}$

FIGURE 10 Principal components analysis of the entire data set with emphasis on Chania Groups 1 and 4

FIGURE 11 Principal components analysis of the entire data set with emphasis on Chania Groups 2 and 3

FIGURE 12 Principal components analysis of the entire data set with emphasis on Psathi Groups 1 and 2

FIGURE 13 Principal components analysis of the entire data set with emphasis on Nopigeia Groups 1 and 2

FIGURE 14 Principal components analysis of the entire data set with emphasis on Nopigeia Groups 3, 4 and Pairs 1, 2

FIGURE 15 Principal components analysis of the entire data set with emphasis on Debla Groups 1, 2, 3 
FIGURE 16 Principal components analysis of the entire data set with emphasis on the Platyvola Group

FIGURE 17 Principal components analysis of the entire data set with emphasis on the Mitatoulia Group

FIGURE 18 Cluster analysis of the fabrics with fossils from Chania

FIGURE 19 Principal components analysis with the fabrics with fossils from Chania.

FIGURE 20 Principal components analysis with the red fabrics.

FIGURE 21 Cluster analysis of the Red Wares

FIGURE 22 Principal components analysis with the Black Slipped Wares

FIGURE 23 Cluster analysis of the Black Slipped Wares

FIGURE 24 Discriminant analysis of the major chemical groups

FIGURE 25 Discriminant analysis of the groups from Chania and Psathi.

FIGURE 26 Discriminant analysis comparing Helladic samples 


\section{LIST OF PLATES}

PLATE 1a Geographical limits of the study area

PLATE 1b Sites in West Crete included in the study

PLATE 2a Chania, the excavation at Agia Aikaterini Square

PLATE 2b Chania, the excavation at Daskalogianni Street

PLATE 2c Chania, the excavation of Kaniamos plot

PLATE 3a Platyvola Cave, the entrance

PLATE 3b Platyvola Cave, the gorge

PLATE 4a Nea Roumata, the tomb

PLATE 4b Mitatoulia, excavation plan

PLATE 5a Debla, view from SE, from the plain of Varypetro

PLATE 5b Debla, the site

PLATE 5c Debla, the site

PLATE 5d Debla, view to the north coast

PLATE 6a The gulf of Kissamos and the site of Nopigeia

PLATE 6b Nopigeia, the excavation on the hill of Troullia

PLATE 7a Psathi, the hill from SW

PLATE 7b Psathi, view to the NE

PLATE 8 General geological map of Crete

PLATE 9 Geological map of Chania and Platyvola

PLATE 10 Geological map of Psathi

PLATE 11 Geological map of Nopigeia

PLATE 12 Geological map of Debla and Nea Roumata

PLATE 13 Location of clay samples (red) at Akrotiri and Chania

PLATE 14 Location of clay samples (red) at Debla 
PLATE 15 Location of clay samples (red) at Nea Roumata and Mitatoulia

PLATE 16 Location of clay samples (red) at Nopigeia

PLATE 17 Location of clay samples (red) at Nopigeia

PLATE 18 Location of clay samples (marls) at Chania

PLATE 19 Location of clay samples (marls) at Chania

PLATE 20 Clay samples groups 1-3

PLATE 21 Clay samples group 4

PLATE 22 Clay samples group 5

PLATE 23 Clay samples groups 6-7

PLATE 24 Clay samples groups 8-9

PLATE 25 Clay samples groups 10-11

PLATE 26 Dark grey burnished ware

PLATE 27 Dark burnished ware

PLATE 28 Dark burnished incised ware

PLATE 29 Black slipped ware

PLATE 30 Red/Black slipped ware

PLATE 31 Red slipped / Red ware

PLATE 32 Dark-on-light and Mottled wares

PLATE 33 Scored ware

PLATE 34 Black slipped sauceboats from Platyvola

PLATE 35 Pottery from Mitatoulia and Nea Roumata

PLATE 36 Pottery from Nopigeia

PLATE 37 Helladic-style and Minoan vessels

PLATE 38 Petrographic Fabric Al

PLATE 39 Petrographic Fabric A2

PLATE 40 Petrographic Fabric A3 
PLATE 41 Petrographic Fabrics related to A

PLATE 42 Petrographic Fabric B1

PLATE 43 Petrographic Fabric B2

PLATE 44 Petrographic Fabric B3

PLATE 45 Petrographic Fabric B4

PLATE 46 Petrographic Fabric B5

PLATE 47 Petrographic Fabric B6

PLATE 48 Petrographic Fabric B7

PLATE 49 Petrographic Fabric B8

PLATE 50 Petrographic Fabric B9

PLATE 51 Petrographic Fabric Cl

PLATE 52 Petrographic Fabric C2

PLATE 53 Petrographic Fabric D1 (Chania and Platyvola)

PLATE 54 Petrographic Fabric D1 (Nopigeia and Debla)

PLATE 55 Petrographic Fabric D2

PLATE 56 Petrographic Fabric D3

PLATE 57 Petrographic Fabric D4

PLATE 58 Petrographic Fabric D5

PLATE 59 Petrographic Fabric D6

PLATE 60 Petrographic Fabric D7

PLATE 61 Petrographic Fabric D8

PLATE 62 Petrographic Fabric D8 (EM I group)

PLATE 63 Petrographic Fabric D9

PLATE 64 Petrographic Fabric D10 (reduced)

PLATE 65 Petrographic Fabric D10 (oxidised)

PLATE 66 Petrographic Fabric D11 
PLATE 67 Petrographic Fabrics D12-13

PLATE 68 Petrographic Fabric D14

PLATE 69 Petrographic Fabrics D15-17

PLATE 70 Petrographic Fabrics D18-19

PLATE 71 Petrographic Fabric E1a (low-fired)

PLATE 72 Petrographic Fabric Elb (high-fired)

PLATE 73 Petrographic Fabric F1

PLATE 74 Petrographic Fabrics F2-3

PLATE 75 Clay mixing

PLATE 76 Clay tempering

PLATE 77 SEM, Dark grey burnished ware

PLATE 78 SEM, Red-Brown/Black burnished ware

PLATE 79 SEM, Red-Brown/Black burnished ware

PLATE 80 SEM. Red slipped and burnished ware

PLATE 81 SEM, Red slipped and burnished ware

PLATE 82 SEM, Black slipped ware

PLATE 83 SEM, Black slipped ware

PLATE 84 SEM, Mottled ware (Chania Town)

PLATE 85 SEM, Mottled ware (Kastelli Chania)

PLATE 86 SEM, Mottled ware (Psathi)

PLATE 87 SEM, Vessels with creamy slip

PLATE 88 SEM, Dark-on-light painted ware 


\section{ABBREVIATIONS}

A66reviations in text:

AAS Atomic absorption spectrophotometry

BP Before present

CM Chania Museum

DGBW Dark grey burnished ware

D-O-L Dark-on-light (painted ware)

EBA Early Bronze Age

EM Early Minoan

FGW Fine grey ware

FN Final Neolithic

ICP-MS Inductively coupled plasma - mass spectrometry

LM Late Minoan

LN Late Neolithic

MBA Middle Bronze Age

MM Middle Minoan

my BP million years before present

NAA Neutron activation analysis

OES Optical emission spectroscopy

PCA Principal components analysis

P-Q series Phyllite-Quartzite series

ppm parts per million

REE Rare earth elements

SEM Scanning electron microscopy

XRD $\mathrm{X}$-ray diffraction analysis

Code names for the sites studied

CHT Chania Town

DEB Debla

ELE Eleutherna

KST Kastelli (Chania) 


$\begin{array}{ll}\text { MIT } & \text { Mitatoulia } \\ \text { NOP } & \text { Nopigeia } \\ \text { PLT } & \text { Platyvola } \\ \text { PST } & \text { Psathi } \\ \text { STV } & \text { Stavromenos }\end{array}$

Scanning Electron Microscopy

NV No Vitrification

IV Initial Vitrification

V Vitrified

TV Total Vitrification

Petrographic Descriptions

a-sa angular-subangular

r-sr rounded-subrounded

tcf's textural concentration features

PPL Plane polarised light

XP: $\quad$ Crossed polars

A66reviations in bibliography:

AAA Athens Annals of Archaeology

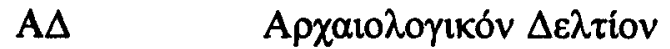

BAR British Archaeological Reports

BSA Annual of the British School at Athens

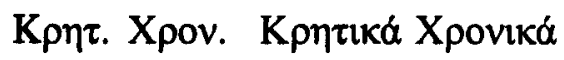

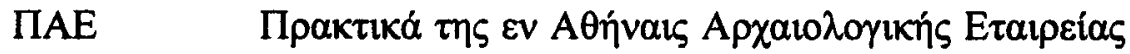




\title{
CHAPTER 1
}

\author{
Introduction
}

\subsection{Aims of the study}

This thesis examines the Prepalatial pottery from several sites in West Crete, using an integrated approach of typological classification and analysis. The research questions are set partly by the nature of the material per se and partly by the work carried out in the rest of the island and the way this work transformed our view of the period.

The Prepalatial period demarcates the beginning of the Early Bronze Age in Crete. It has perhaps received less attention than other phases of the Bronze Age, due to the lack of Palaces and other indications of elaborate socio-economic organisation. According to the prevailing concept, the Early Minoan (EM) society consisted of small, semi-autonomous and self-sufficient settlements. The organisation of pottery production was thought to be at the level of the household and its role was limited to that of a simple "precursor" of the more complex ceramic system that emerged with the Palaces during the Middle Minoan (MM) period (Branigan 1988).

However, recent analytical work and provenance studies during the 90's using an integrated approach of typology and scientific analysis explored patterns of regionalism in EM Central and East Crete (Wilson and Day 1994; Whitelaw et al. 1997). It came up with a complex network of intra-island pottery distribution as well as a network of inter-island activities involving communication with the Cyclades since the EM I (Day et al. 1998; Day et al. in press). It was suggested that the level of production was beyond that of the household and involved a degree of technical knowledge that characterises specialisation in craftsmanship (Day et al. 1997). Finally, it has been demonstrated that a combined study of style and analysis may provide significant information on issues of ethnicity and identity (Day et al. 1998). 
West Crete has stood apart from these new developments, due to a lack of published assemblages and pottery analyses. Moreover, the available evidence indicated pottery shapes and wares that contrasted markedly with that of the rest of the island. In West Crete different types of pottery seem to co-exist: there is a group comparable with the ceramic repertoire of the rest of Early Bronze Crete, which we might term "Minoan", and other vessels which seem similar to wares known from the Southern Mainland and the Cyclades. Although this discrepancy within the West Cretan assemblages was known since the early 60 's when the first excavations were undertaken, it has never been examined typologically and/or analytically and interpreted archaeologically.

This thesis is the outcome of a project undertaken as part of the GEOPRO TMR Network, in order to examine the Prepalatial pottery from West Crete, understand pottery production and distribution in this part of the island during the Prepalatial period, and integrate this area into the broader picture of Minoan Crete and the Southern Aegean in the Early Bronze Age. The project encompasses 550 samples from different types of settlement sites and a cave. It involves typological and stylistic analysis, petrographic examination, neutron activation analysis and scanning electron microscopy.

The main themes around which the research questions have evolved concern:

a) the organisation of pottery production: through the characterisation of the different wares in the ceramic assemblage, local pottery groups are established. In this way, the question of local versus imported is investigated and the clay recipes for similar or different pottery types are examined. Among the aims of this work is to characterise the pottery and suggest potential locations of production.

b) regionalism and specialisation of production: the examination of the organisation of production sets the framework for the investigation of the degree of specialisation in pottery production. It has been demonstrated that in Central and East Crete there is a considerable degree of specialisation with centres producing specific types of pottery (Wilson and Day 1994) and consumption centres acquiring pottery from more than 
one centre (Whitelaw et al. 1997). In this study, it is examined whether a similar pattern can be detected in West Crete and in what range pottery moves.

c) issues of identity and ethnicity: in Central and East Crete, the study of assemblages from tombs and cemeteries has led to a growing body of information concerning identity and ethnicity; it has been argued that through the deposition of specific items, personal and social identity are negotiated (Day et al. 1998; Papadatos 1999). In West Crete the problem is different but the approach is similar. Due to the lack of cemeteries and tombs, the basis of the research is the pottery assemblage from settlements and caves. The marked difference of style and technology of the pottery constitute the basis of the analysis. The results will provide the background for the discussion of ethnicity and identity in West Crete.

In what follows, the chronological and geographical limits of the study are presented, followed by a short outline of the thesis.

\subsection{Chronological and geographical limits of the study}

The chronological limits of the study cover the time span referred to as the earlier Prepalatial, i.e. EM I - EM IIB. The reason for selecting this specific period is that it has been identified across the island without major deviations in the stylistic sequences. Even when they were not identical, specific shapes, wares and decorative motifs have been recognised across the island, which allowed the establishment of a relative chronological sequence. In this way, it has been possible to incorporate new pottery types in the existing repertoire and evaluate the role and extent of regional variation (Wilson and Day 1994).

Moreover, in Central Crete (mainly at Knossos) there is a well-established typology, which can be used for comparative reasons (Wilson 1994). On the contrary, the later phase of the Prepalatial (EM III/MM IA) is quite problematic: pottery styles of this period have not been recognised equally in Central and East Crete and, even in sites with fairly complete stratigraphic sequences, it has been a problem to define securely the presence and the limits of this phase (Zois 1968; Watrous 1994; Momigliano 1991). In West Crete, where the pottery sequence is fragmentary and not 
well established, it is very difficult, if not impossible, to deal with the issue of the later Prepalatial. For these reasons, it is beyond the scopes of the present work to clarify the problem of the EM III/MM IA period in West Crete.

The geographical limits of the study follow the geographical configuration of the area. The western part of the island comprises the area extending west of Mount Ida and the Amari valley, which according to the administrative division of the territory includes the counties (vouoi) of Chania and Rethymnon (PI. 1a). The study concentrates mainly on the ceramic assemblages deriving from seven sites situated in Chania, which present typological and stylistic similarity. The pottery assemblages from two sites in Rethymnon were also examined typologically, sampled and studied analytically, but they present remarkable differences from the Chaniot ones and they are not included in the thesis. Some observations concerning this material are used selectively for comparative purposes.

\subsection{Thesis Outline}

Chapter 2 presents an overview of the literature on the Prepalatial period with emphasis on West Crete. It examines whether the models on settlement patterns and economy established for the EM period in Central and East Crete match the data available for West Crete. It discusses the causes that enhanced the growth of settlements and the economic development that occurred in the Early Minoan period. The sites included in the study are briefly presented with emphasis on their geographical location, architecture, and archaeological stratigraphy.

The methodology involved in the study of the EM ceramic material from West Crete is discussed in Chapter 3. The analytical techniques used for the study of provenance and technology of the West Cretan assemblage are presented with a brief overview of their use through the years in the analysis of Minoan pottery. Finally, the procedure of manufacture of experimental briquettes is discussed.

The geology of West Crete is presented in Chapter 4. In the first part an overview of the geological evolution of the island and the main rock units are 
presented. The second part of the chapter concerns the Pre-Neogene and Neogene deposits in West Crete, which constitute the geological background of the study area and have provided the raw materials for the manufacture of pottery. The geology of the sites included in the study is also presented. Finally, the third part concerns the aims and objectives of the clay sampling, as well as the criteria for the selection of specific samples. Chapter 4 is concluded with a detailed account of the deposits sampled and the results of petrographic analysis of the clay samples.

Chapter 5 presents the typological analysis of the EM pottery from West Crete. Most of the assemblages studied and sampled in West Crete are unpublished and the information available on pottery typology in this part of the island derives mainly from excavation reports and two published assemblages, namely the sites of Debla (Warren and Tzedakis 1974) and Nopigeia (Karantzali 1997). In the first part, the wares occurring in this part of the island are presented. It is attempted to construct a typological as well as chronological sequence for the EM ceramic assemblage in West Crete based on the ware types occurring in the sites examined. The establishment of the West Cretan sequence is carried out in comparison and with reference to what is known from Central and East Crete. This is followed by a detailed presentation of the wares and shape repertoire from each site and finally, in the third part, individual shapes, which present special interest, are discussed in terms of typology and parallels from Crete or the Aegean.

Chapters 6,7 , and 8 comprise the results of the analyses with a brief introduction on the use and utility of each method, along with the archaeological questions that led to the selection of the specific methods. Chapter 6 presents the results of petrographic analysis according to fabric groups. Then follows a discussion on the spatial distribution of the fabrics, the techniques of pottery manufacture as detected from the study of thin sections and a comment on the use of the fabrics in the different phases of the Prepalatial.

In Chapter 7 the results of the elemental analysis are presented, along with an overview of the statistical procedures and conventions followed for the grouping of the data that derived from neutron activation analysis. In the first part of the chapter, the 
results are presented following the groups established according to the chemical composition of the samples; at a second level, the relation and compatibility of chemical and petrographic groups is examined. Finally, there is a discussion of the results of chemical analysis, in association with the typology of the pottery and the fabric groups that derived from petrographic analysis.

Chapter 8 provides the results of scanning electron microscopy. In a technological study examining separately the body and the surface of the vessels, the results are presented according to ware groups. The chapter concludes with a discussion of the results, an assessment of the technology of pottery manufacture in EM West Crete but also with a comparison of the results from West Crete with similar analyses from Central and East Crete.

Chapter 9 provides an archaeological interpretation of the analytical results presented in the previous chapters. Going beyond classification, groups and numbers it is attempted to appreciate the social meaning of stylistic differentiation and investigate the identity of the people who produced and used this pottery. There is a short overview of the concept of culture, which has been used through the years in order to explain material culture distribution in the Aegean during the Early Bronze Age, followed by the presentation of the particularities and idiosyncratic character of the West Cretan pottery in relation to that in the rest of the island. Finally, the place of West Crete in the "International Spirit" is discussed and potential networks within the Aegean in which West Crete might have participated are suggested.

In Chapter 10 the conclusions of the research are presented. The issues discussed are the degree to which the results of the analyses answered the initial questions, whether the selection of the specific methodology was justified by the result and, finally, suggestions for future research are made.

In the Appendices can be found a catalogue of the pottery samples, which is associated with the Chapter 5, detailed petrographic descriptions accompanying the presentation of the fabrics in Chapter 6, and the raw data of chemical analysis that resulted in the chemical groups presented in Chapter 7. 


\section{CHAPTER 2}

The Prepalatial Period in West Crete and the sites studied

\subsection{The Prepalatial period in Central and East Crete}

\subsubsection{The evidence}

The evidence of the Prepalatial period in Crete is abundant but fragmentary. The major excavations of Prepalatial sites took place in the central and eastern part of the island and concentrated primarily on revealing tombs. These excavations provided the architectural evidence, along with a significant corpus of material (pottery, metal objects, stone vessels and tools) upon which the reconstruction of life and society in the Prepalatial period was based. The discovery and publication of the tholos tombs in the Mesara (Xanthoudides 1924), the burial cave of Pyrgos (Xanthoudides 1918) and the cemetery in Mochlos (Seager 1912) in East Crete constitute milestones for Minoan archaeology. Subsequent excavation of individual tombs and cemeteries comprise Kyparissi (Alexiou 1951), Krasi (Marinatos 1929), Agia Photia (Davaras 1971), and Phourni-Archanes (Sakellarakis and Sakellaraki 1997).

This concentration of interest in burial sites had two implications. First, the establishment of the ceramic sequence of the period was based on the evidence from funerary contexts. However, tombs were in many cases unstratified, or disturbed due to multiple burials and/or looting and this created problems in the establishment of local pottery sequences. Second, as recently demonstrated by research in the field of the archaeology of death (Barrett 1988; Parker-Pearson 1999), tombs and cemeteries constitute places of special significance where items of prestige are deposited and special relationships are expressed and actively negotiated. Therefore, they should not be regarded as passively reflecting every day life; the interpretation of such assemblages should consider parameters such as the status of the dead as well as the living and organisation of society at the specific period (Papadatos 1999). 
Domestic assemblages are more representative of every day life, but there are only four fully published assemblages, namely those from the settlement sites of Myrtos Fournou Koriphi (Warren 1972), Debla (Warren and Tzedakis 1974), Vasiliki (Zois 1976), and Kalo Chorio (Haggis 1996). Additional information derives from stratigraphic soundings from palatial centres (Whitelaw 1983).

\subsubsection{Major themes in the archaeology of the Prepalatial period}

Two explanatory models were constructed, based on the data deriving primarily from funerary contexts, in order to provide an integrated picture of the Prepalatial period and reconstruct life and society in this early phase: the evolutionary and the revolutionary model.

The evolutionary model was developed on the basis of two seminal works on Aegean EBA, Branigan's The Foundations of Palatial Crete (1988) and Renfrew's The Emergence of Civilisation (1972). It is suggested that the Prepalatial constitutes a period of regular and continuous development, which starts as early as the EM II (Branigan 1995: 39) and bears the traces of social complexity that led to the rise of the First Palaces. The realms that enhanced this social differentiation are different in each case; Branigan (1995: 39) suggests the increasing importance of the nuclear family and the individual, population growth, and the establishment of urban centres, whereas Renfrew (1972) puts emphasis on three sub-systems, namely agriculture, metallurgy and trade.

According to the revolutionary model, the social organisation during earlier phase of the Prepalatial period (EM I-II) was simple and development was rather slow (Cherry 1983; Watrous 1994). The appearance of the palaces was a discontinuous and sudden phenomenon, a quantum leap, which occurred in the later Prepalatial period (EM III or MM IA), probably after a short phase of great social turbulence (Watrous 1994: 753).

It is not within the scopes of this thesis to discuss the problems of the models and the critiques they have received. However, although contradictory in their theoretical framework and the way of interpreting the evidence, both models considered the Prepalatial period in the same way, i.e. in relation to the Protopalatial and the rise of the Palaces rather than in its own right (Day et al. 1997). Using the 
same evidence (deriving mainly from funerary contexts), they tried to explain the Prepalatial in terms of what came afterwards (i.e. the Palaces) and on the basis of a binary opposition (simple versus complex, etc. see Day et al. 1997). Recent work on pottery production, and patterns of regionalism demonstrated that development in EM Crete can be understood only by making the Prepalatial period itself the focus of study (Day et al. 1997).

The shift of interest from the Prepalatial period as precursor to the rise of the Palaces to the Prepalatial per se resulted in the reconsideration of issues such as organisation of production and on- and off-island exchange during the $3^{\text {rd }}$ Millennium BC. As to the former, recent analytical work contradicted the prevailing idea that pottery production was local and at the level of the household (Branigan 1988). It was demonstrated that there was specialisation in pottery production, with specific centres producing specific types of pottery (Wilson and Day 1997; Day et al. 1997) but also specialisation in pottery consumption with specific vessels being used for specific occasions as reflected in the case of the settlement at Myrtos Fournou Koriphi (Whitelaw et al. 1997).

This evidence led to new observations concerning the intra-island relationships and interaction. It was demonstrated that during the EM period Crete was not a uniform entity but there existed patterns of regionalism, with areas being involved in networks of relationships and interaction of different degree and magnitude (Wilson and Day 1994). Such an intra-island network in the EM IIA period involved movement of specific shapes and wares form the Mesara towards Knossos where they co-existed with the locally produced vessels of the north central Cretan tradition (Wilson and Day 1994). Moreover, several sites on the north coast were involved in exchange relationships with the Cyclades (e.g. Poros, see Dimopoulou 1997; Dimopoulou et al. in press). This off-island network involved mainly raw materials, obsidian, copper and silver, the sources of which can be found solely in the Cyclades. An important quantity of these materials appeared to travel towards the Mesara, suggesting that there may have been another route of exchange, involving the movement of metals and obsidian form the north coast to South Crete (Papadatos 1999).

The intensive off-island interaction and exchange is best reflected in cemeteries such as Agia Photia and Archanes-Phourni. The co-existence of Minoan 
style along with Cycladic or Cycladic-style artefacts and architecture was interpreted as the establishment of Cycladic colonies of mercantile character on the north coast of Crete (Sakellarakis 1977a; 1977b, Doumas 1976; 1979). This assumption has been challenged recently: through the re-examination and scientific analysis of the evidence from cemeteries and settlements, issues of power (Nakou 1995) and identity (Day et al. 1998; Kiriatzi et al. 2000; Papadatos 1999) in the Prepalatial period were investigated and it was demonstrated that complex social issues are reflected in the patterning of the material culture.

The reconsideration of the existing evidence in association with analytical research demonstrated that the Prepalatial period presents spatial and chronological diversity with elaborate on- and off-island networks for the exchange and movement of pottery, raw materials and finished products. However, all the research has so far been concentrated in the Central and Eastern parts of the island. In what follows it will be investigated how archaeological research evolved in West Crete and how this part of the island can be integrated in the broader picture of EM Crete and the EBA Southern Aegean.

\subsection{WEST CRETE}

\subsubsection{Background to the research in West Crete}

Archaeological investigations in West Crete did not start as early as in the rest of the island, mainly due to Evans' concentration of interest in the central and eastern parts and Pendlebury's argument that civilisation in West Crete flourished only in the LM III period, after the final destruction and decline of Knossos (Pendlebury 1939: 239). Finally, the centralised nature and interests of the archaeological authorities in Herakleion did not allow systematic investigations in West Crete before the 1960s (Tzedakis 1990; Godart and Tzedakis 1992: 17).

However, thanks to two archaeological prospections by Hood (Hood et al. 1964; Hood 1965), and to Faure's explorations since 1964, it became apparent that occupation in the part of Crete west of Mt. Ida was continuous and uninterrupted from the Neolithic and the EM period onwards. Excavations carried out mainly in the 1960s and the 1970s under the direction of $Y$. Tzedakis brought to light substantial remains of the Neolithic and EM periods. The Gerani Cave in Rethymnon provided well- 
stratified material indicating seasonal occupation during the Neolithic (Tzedakis 1970). The caves Koumarospelio (Tzedakis 1973), Perivolia (Mameloukou Trypa) (Tzedakis 1968c) and Platyvola (Tzedakis 1965b; 1965c) provided evidence for the LN, FN and EM periods. The excavation of Kastelli Hill (Chania) as well as different rescue excavations in the Splantzia region in the town of Chania proved that the EM occupation must have been extensive (Hallager and Tzedakis 1985). With further investigations and intensive survey (Moody 1987; Nixon et al. 1988; 1989; 1990), settlement distribution and patterns of occupation in West Crete were explored.

The lack of extensive systematic excavations and major publications has discouraged scholarly preoccupation with the EM period in West Crete. Debla is the only fully published excavation, while the rest of the evidence derives from rescue excavations, stratigraphic soundings and unstratified cave deposits. Kastelli (Chania), which seems to be one of the most important settlements in the area, lies beneath the LM Minoan Kydonia, which is extremely important with elaborate domestic and funerary architecture, archives with tablets, sealings and ceramic assemblages, preventing any systematic excavation of the Prepalatial strata.

Valuable information derives also from surveys. These provide information on the environment and the settlement patterns, as well as a basic typological sequence of the pottery, with special reference to coarse wares (Moody 1985). However, the dearth in fine decorated pottery and the lack of stratigraphy do not allow making fine chronological distinctions between sub-phases (e.g. FN-EM I or EM IIA-IIB) or discussing issues such as intra- and inter-island exchange.

It is not surprising, therefore, that in synthetic works West Crete was not taken into consideration with reference to specific sites but was included ex silentio in general models concerning the entire of the island (e.g. Renfrew 1972, Branigan 1988). Moreover, the recent analytical work carried out in Central and East Crete concerning the Prepalatial period could not encompass West Crete for two main reasons: a) the work was mainly based on the analysis of ceramics and there were not any analyses carried out in West Crete, and b) the pottery that was published showed a picture typologically different to what is known from Central and East Crete and, therefore, no direct analogies could be drawn. Thus, in the emerging picture of Prepalatial Crete as a period characterised by specialised production and extensive networks of interaction, the western part of the island remains terra incognita. 
In what follows, the information on settlement patterns and economy/ subsistence strategies available from various studies in West Crete is briefly presented, and, when possible, comparisons with Central and East Crete are made.

\subsubsection{Environment and Settlement Patterns}

The limited publications (namely that of Debla, Warren and Tzedakis 1974) and the surveys carried out in West Crete (Moody 1987; Nixon et al. 1988; 1989; 1990) provided significant information regarding environment and settlement patterns in West Crete. Environmental diversity has been thought to favour occupation in prehistoric times, with preference to coastal plains, natural harbours, pockets of arable land and sometimes the more mountainous terrain, which is suitable for summer pasturage (Branigan 1988; Moody 1987).

In the Neolithic period and the Bronze Age the climate was less evaporative and more wet than today and the change to more "Mediterranean" conditions seems to have developed gradually during the Bronze Age. This shift resulted in higher temperatures, less rainfall and seasonal precipitations (Moody 1987: 161). The prevailing climatic conditions were thought to be favourable to natural vegetation and agriculture. The landscape in prehistoric West Crete might have been dominated by the White Mountains in the central and southern part; woodland, perennial springs and the surrounding low hills would have favoured summer pasturage. The fertile plains of Chania and Rethymnon with the natural harbours of the northern coast, as well as the pockets of arable soil found everywhere in the fragmented landscape, would have offered the ideal background for the establishment of settlements (Branigan 1988: 8; Moody 1987: 266).

Within this differentiated landscape Neolithic and Bronze Age occupation sites emerged, the former being confined primarily to caves (Gerani and Lentaka), the latter in all sorts of environment. A recent survey in the area of Chania demonstrated that settlement visibility was severely impeded in the plain due to recent sedimentation and, therefore, more secure information could be provided by the data from Akrotiri peninsula, which was not affected (Moody 1987). 


\subsubsection{The Final Neolithic period}

The Final Neolithic (FN) period is reported to have witnessed a major increase in settlements, as indicated mainly by surveys (Moody 1987; Watrous 1994: 700; Nixon et al. 1988; 1989; 1990). Although the number of occupation sites might be due to better visibility in relation to previous periods, it seems that there is diversity in the type of FN settlements ranging from caves to coastal and open sites, on low hills, slopes and ridges (Watrous et al. 1993; Watrous 1994; Moody 1987).

The FN has not been recognised equally across the island and, where present, it is not homogeneous (Vagnetti and Belli 1978). The architectural evidence is scarce and the pottery record is fragmentary. The main type-site for the FN is Phaistos but its unique character does not allow comparison with other sites in order to construct local sequences. The lack of a complete ceramic sequence for the FN as well as the continuation of pottery shapes and wares (such as the dark burnished) into the EM I lead to confusion and uncertainty on the character of the FN ceramic types, which are often characterised as FN/EM I.

The transition from the FN to the EM I is far from clear: along with pottery types that continue, new shapes and wares are introduced in the EM I and this has been interpreted as reflecting the influx of immigrants, who caused an abrupt end to the Neolithic tradition (Hood 1990a; 1990b; Warren 1973). Although the hypothesis of invasions/immigrations has been questioned after re-examination of the evidence (Branigan 1988: 196-209), there still exists the idea that settlements were established in defensive locations in marginal environments and mixing of indigenous settlers and newcomers occurred (Watrous 1994: 704). A recent survey of remote areas near the northern and southern coast across the island brought to light a number of FN/EM I defensible "refugee" sites; they are situated on the edge of coastal plains and on low hills and are considered to reflect the impact of these invasions (Nowicki 1999). On the south coast of West Crete several such sites were discovered on small coastal plains and valleys from 30 minutes to an hour's walk from the sea, which probably continue until the EM I period (Nowicki 1999: 577-8).

The theory of immigrants cannot be substantiated by the evidence, since occupation in settlements and caves where FN is present, is uninterrupted through the EM I, without stratigraphic hiatuses or destruction levels. This is evident in West 
Crete, in caves (Platyvola) and settlements (Kastelli), where FN pottery is found in combination with EM. In most cases there is no stratigraphy and the deposits are mixed. Therefore, it is not possible to establish a local pottery sequence and clarify the chronology of the different pottery shapes. For this reason, the site of Neroukourou is of special significance, since it is the only systematically excavated and published FN site (Vagnetti et al. 1989). In terms of typology, the ceramic assemblage, although domestic, has a particular and probably local character, with no or very little parallels in the rest of the island. The occupation of the site does not continue in the EBA but there are no indications of violence or destruction. The possibility of immigrants is not envisaged by the excavators who adopt the environmental model suggested by Moody (1987), according to which the intensification of tectonic activity resulted in the collapse of caves. Therefore, due to a sudden population increase, the FN settlements were abandoned in search of more open spaces (Vagnetti et al. 1989: 90-91).

The study and publication of other assemblages from caves and settlements might provide new information on the ceramic sequence of the period and the transition to the EM I.

\subsubsection{The Early Minoan I period}

If the Neolithic is considered to be the era of cave dwellers, the EM I is reported to be characterised by a considerable increase in the number of settlements across the island, following an increase in population (Branigan 1988; Watrous 1994). This change has been explained by a progressive amelioration of climatic conditions, the establishment of olive cultivation (contradicted by Hamilakis 1996, see below) and the expansion of pastoralism. Caves were thought to be abandoned progressively, either due to community growth or environmental reasons (collapse because of tectonism or precipitation) (Moody 1987: 292-4).

However, these assumptions cannot be adequately substantiated by the data, because in the caves there does not seem to be any sign of destruction or sealed levels and occupation continues uninterrupted as in the case for Platyvola and Perivolia. As to possible change in caves function, it is not clear whether they continued being used as habitation sites; their configuration with very small spaces and narrow passages does not allow an easy living and the nature of the finds is not representative of 
domestic assemblages. It is of interest that among the caves that continue being used in the EM period, Platyvola and Perivolia contained high quality pottery, some of nonMinoan style, a large number of transport jars and prestige items such as stone vessels, sauceboats, frying pans and a Cycladic-style figurine. Such items are commonly found in burial assemblages but the human remains of Level 4 in the cave of Platyvola were reported by the excavator (Tzedakis 1968a) to be not earlier than MM, so the cave could not have been used for burials in the EM period. If this is the case, it seems that the cave of Platyvola was neither a habitation nor a burial site, but a place of special significance where ritual activities and conspicuous deposition were taking place.

Further east, in the area of Mylopotamos, there are two more caves that produced EM material; the picture from Sentoni cave contrasts drastically with what was presented for Platyvola. The pottery assemblage reflects seasonal (Gavrilaki 1998) or permanent occupation, whereas the study of the bone material indicates diversified economy and mixed herding (Hamilakis 1998). In the same area the cave of Melidoni was investigated but the material is still under study. Excavation brought to light FN/EM I pottery and human remains, which could be associated with this earlier phase of use (Gavrilaki 1992; Tzedakis and Gavrilaki 1995). If this proves to be the case, then probably the use of Platyvola for burial purposes during the EM period should also be reconsidered.

The number of settlement sites seems to increase considerably in the EM I period. In the Mesara twice as many sites as in the FN are reported, dispersed across the landscape, near water and arable lands (Watrous et al. 1993: 223-4) and the Agiopharango valley was first settled during that period (Blackman and Branigan 1977). The prevailing pattern seems to be that of the nucleated settlement, promoting the idea of communal life, as in the case of LN Knossos.

In West Crete the picture of EM I settlement pattern does not conform with the nucleated settlements in central and eastern Crete. From the Akrotiri survey data it is deduced that this part of the island was not densely settled (Moody 1987: 297-300), although former surveys came up with a substantial number of EM sites (Hood et al. 1964; Hood 1965). There are two cases where EM I structures were excavated: the settlement of Debla at Varypetro and the village of Ellenes in the Amari valley. For the latter it is reported that it consists of many houses but no further information is 
available regarding the architectural plan. Only one house was excavated which yielded EM I pottery, namely Pyrgos ware (Marinatos 1932: 177; Payne 1932: 255) ${ }^{1}$.

Another feature of the EM I period is the establishment of small sites at higher elevations occupied on a seasonal basis (Hood et al. 1964: 51; Watrous 1994). This is the case of the settlement of Debla on the foothills of the White Mountains, which provides the only information available so far on domestic architecture for the EM I-II period. The settlement lies on the rocky terrace of the summit area in an environment of woodland and with perennial springs in the vicinity. It consists of freestanding, individual buildings of rather poor construction; working, living and storage spaces were identified (Warren and Tzedakis 1974).

The second EM I settlement in West Crete is the site of Mitatoulia, situated on top of a small hill at a distance of ca. $800-1000 \mathrm{~m}$ SE from the tomb of Nea Roumata. It is not at such a high elevation as Debla, it is a foothill overlooking the valley. The material evidence derives from test pits and, therefore, no conclusions can be deduced concerning the extent or the character of the settlement.

\subsubsection{The Early Minoan II period}

As mentioned above, the Prepalatial is not a uniform period but there are significant differences in space and time. This is particularly obvious in the EM II, which displays variety across the island and a great change in style between the earlier (EM IIA) and the later phase (EM IIB). The general pattern is that in the EM II caves continue in use and there are more recorded settlement sites. In the Lasithi plain there is a movement from high mountain slopes at the edge of the plain, and in the entire island there seems to be a strong predilection for coastal settlements situated on low promontories or hills. House plans seem to follow a common pattern: continuous,

\footnotetext{
${ }^{1}$ In the literature there is a misunderstanding concerning the Ellenes settlement (with the exception of Payne 1932); Branigan (1988: 39) reports "blocks of houses (like Knossos) and one free-standing building". Warren and Tzedakis (1974: 335) present Ellenes as a comparative settlement pattern for Debla, with "individual units". Although contradictory, both arguments were based on a misinterpretation. Marinatos (1932) writes about Ellenes: "...eine fruhminoische Ortschaft aus mehreren Häusern; von diesen wurde eines freigelegt." This translates as: "...an Early Minoan settlement composed of many houses, from which only one was revealed". It seems that both scholars translated "freigelegt" as "free-standing", whereas it means "revealed, unearthened". Many thanks to Ulrich Thaler for clarifying the meaning of the german word.
} 
cellular, multi-roomed complexes, like the ones at Myrtos Fournou Koriphi, Agia Triada, Vasiliki (Watrous 1994: 705; Moody 1987: 295).

In West Crete the pattern of the north central coast, i.e. low hills in proximity of a natural harbour (for example Poros), is represented along the north-west coast with the settlements of Kastelli (Chania), Nopigeia, Psathi and Stavromenos. Kastelli is a characteristic case of a settlement on a hill situated between two natural harbours. Habitation before EM II is not represented in architecture but documented by ceramic finds of the EM I and FN periods (Hallager and Tzedakis 1985). Architectural features are preserved only from the EM II period indicating an extended settlement of considerable importance. On every occasion where excavation has reached pre-LM deposits, EM material was present and of very good quality. There are also finds from the streets around Kastelli, the Splantzia area and the modern town of Chania.

The settlements of Nopigeia, Psathi and Stavromenos were not excavated systematically and the architectural remains (when preserved) are very scarce. However, in all three cases their geographical position on a low hill in proximity to the sea is important for maritime contacts in the EM II period.

However, the EM II is not just the period of settlement expansion. The first phase (EM IIA) is characterised by intense inter- and intra- island contacts, involving communication with the Cyclades and large-scale movement of raw materials and finished products. The focus of all this activity seems to be the north coast of Crete with sites such as Poros, which may have functioned as gateways for the products arriving from the Aegean and centres of transformation of the raw materials into finished artefacts (Dimopoulou 1997; Dimopoulou et al. in press).

As to the material record, in EM IIA there is a shift in the pottery typology with emphasis on drinking and serving vessels. Whereas the EM I ceramic repertoire is dominated by large vessels considered to be used in communal ceremonies, in this period there are smaller vessels such as bowls and goblets, meant for individual use. Moreover, serving vessels such as jugs which in the EM I are characterised by globular bases, in the EM IIA acquire flat bases, which indicates change in the context of use (Wilson and Day 2000).

In West Crete this change is more dramatic because, as will be discussed later in detail, the introduction of a totally new style takes place, consisting of black slipped 
serving and drinking vessels, which share more similarities with Helladic style vessels rather with their Minoan counterparts. This is not the case of a single site but the norm in West Crete, with all the sites of the EM IIA period being characterised by the two markedly different pottery traditions, the part which presents affinities with the rest of Minoan Crete and the part that is reminiscent of Helladic and/or Cycladic prototypes.

In EM IIB the picture changes drastically and the pattern seems to be homogeneous for a great part of the island, with some new vessel shapes, such as long-spouted jars, which are present across the island. Moreover, mottled ware becomes common and in its great majority is produced in East Crete and distributed across the island. The contacts with the Cyclades seem to reach an abrupt end, along with the imports of pottery from the Mesara to north central Crete. The only centres distributing pottery seem to be east Cretan (Whitelaw et al 1997).

In West Crete the pattern is not very different; there are only a few remnants of the Helladic style vessels, the major part of the assemblage being of Minoan style as known from the rest of Crete. However, until the present study there has not been any other analytical work carried out in West Crete and mottled ware is presumed imported from East Crete (Betancourt et al.1979).

\subsubsection{Economy and subsistence}

As mentioned above, although there is almost no work carried out in West Crete concerning organisation of production, or intra and inter island exchange, this part of Crete has received a great deal of attention in the realms of natural environment and settlement patterns, as well as economy and subsistence strategies. Although these studies are not directly relevant to our project, a brief outline is presented in order to understand the character of the sites included in the study.

The surveys of Chania (Moody 1987) and Sphakia (Nixon et al. 1988; 1989; 1990) as well as the book on The Making of the Cretan Landscape (Rackham and Moody 1996) provided significant environmental information. Moreover, there exist two publications of faunal assemblages, that of Debla (Warren and Tzedakis 1974) and that of Sentoni Cave (Hamilakis 1998), and a report assessing the floral information from Debla (Greig and Warren 1974). 
Debla and Sentoni, are both of EM I-IIA date and they were considered by their excavators as seasonal shelters used by pastoralists during the summer (Warren and Tzedakis 1974; Gavrilaki 1998). More specifically, for the settlement of Debla the model of seasonal occupation serving a small agricultural community, which practiced small-scale cereal cultivation and transhumant animal husbandry, was suggested (Warren and Tzedakis 1974: 336). As to the plant species, all the information derives from chaff-tempered pottery; the organic matter used as temper reflects plants growing in the area where the specific vessels were manufactured and not necessarily Debla (the excavators argue that there was not any potting activity in Debla).

The identification of animal species showed that the entire assemblage consisted of caprine fauna of adult individuals, which led the excavators to suggest specialised herding (Warren and Tzedakis 1974: 333-4). This pattern does not conform with the diversified (mixed) animal husbandry, which is suggested for Sentoni cave and EBA Crete in general, and involves sheep/goat, cattle and pigs (Hamilakis 1998: 91-2).

From the other sites, no animal bones or plant remains were reported. However, the analysis of chaff-tempered pottery, which is highly represented in all EM sites in West Crete, would provide some insight on plant species. The main species identified in Debla were emmer wheat, barley, oats (for the first time on Crete) and brome grass (Greig and Warren 1974).

From all the above it can be concluded that West Crete followed the agricultural innovations detected in the rest of the island in terms of diversified crops and animal husbandry. Gradual amelioration of climatic conditions along with water supply and favourable soil conditions might have encouraged diversified agriculture in West Crete. The shift from wheat to barley as attested in the grain impressions from Debla reflects diversification of production, which figures among the effects of Mediterranean polyculture (Renfrew 1972: 281).

As to pastoralism, the model of transhumant herding and seasonal camps for the Neolithic and EBA has been contested and mixed herding in caves and permanent settlements was suggested (Halstead 1980). Especially in West Crete, environmental conditions would not allow large flocks of sheep because they are not well adapted in a wooded environment (Moody 1987: 296; Hamilakis 1998). Where Debla is 
concerned, the study of the bone assemblage showed that ages varied between 2 and 5 years, which indicates exploitation for secondary products (Moody 1987: 296). A model of mixed farming economy was suggested, involving herding on the uplands and grain crops at the foothills in the vicinity of Debla (Moody 1987: 296).

The picture of Prepalatial West Crete as indicated from the existing studies is mainly that of permanent and semi-permanent settlements practicing agriculture and herding; there are also caves, which are thought be used also as habitation sites. However, this is based either on survey data or on studies of individual sites.

So far there has not been any synthetic approach focussing on the ceramic material in order to investigate provenance or technology. Moreover, there has not been any attempt to combine information from more than one site in order to reconstruct the picture of West Crete in the broader context of EM Crete. In the present study it is attempted to understand the Prepalatial period in West Crete on the basis of the ceramic evidence and through a combined study of typology and analysis. The pottery selected derives from various sites in order to get a representative picture of the assemblages. In this way, it will be possible to investigate not only issues related to the pottery itself but also issues of regionalism and ethnicity.

\subsection{The sites included in the study: criteria of selection and brief presentation}

\subsubsection{Introduction}

The main aim of the project undertaken in West Crete is to identify patterns of production and distribution of pottery in the area during the EM period. In order to get a representative picture of the EM period the sites selected for study and sampling cover the different phases of the EM period (EM I-IIB), and are representative of different types of sites (Pl. 1b).

The archaeological sites of EM date in West Crete comprise primarily settlements and caves; six settlements and one cave were selected in the county of Chania: Kastelli and Chania Town, Psathi and Nopigeia are situated on the coast, Debla is on the mountains and Mitatoulia is in an upland plain. In West Crete, there is dearth in necrotaphic assemblages, the only tomb discovered being that of Nea 
Roumata (Tzedakis 1980b; 1984). Although, the material from the tomb has not been made available to us, it has been possible to study and sample the assemblage of the nearby settlement site of Mitatoulia. The cave of Platyvola was considered representative of the picture of west Cretan caves in the Prepalatial period: the reports on the excavations of Platyvola and Perivolia caves (Tzedakis 1967a; 1968a; 1968d), as well as the publication of Lera cave (Papamanoli-Guest and Lambraki 1976) have demonstrated that the assemblages from the caves display typological similarities.

Finally, two sites from the area of Rethymnon, namely Stavromenos and Eleutherna, were also studied and sampled. The typological and petrographic examination of the ceramic assemblages demonstrated that this material has closer affinities to Central rather than West Cretan assemblages. An integrated study of the Rethymnon material would necessitate a different approach than that followed for the rest of the West Cretan EM pottery, which would be beyond the scopes of this thesis. Therefore, there will be only a brief presentation of the data from these sites for comparative reasons and in relation to the West Cretan ceramic material.

\subsubsection{The Sites}

\subsubsection{Kastelli and Chania Town ${ }^{2}$}

Kastelli is a small hill in the old town of Chania, by the Venetian harbour. The site is situated on top of the hill in an advantageous location profiting from a fertile hinterland and a good harbour. The excavation constitutes a joint Greek-Swedish project and the information available derives from preliminary reports (for an account of the individual excavations carried out on the hill of Kastelli and Chania Town, see Table I, at the end of the chapter).

The excavation started from the Square of Agia Aikaterini and progressively covered parts of the adjacent plots and the area of Splantzia (below the hill) (Pl. 2a). Because of the importance of the LM occupation, excavation stopped after revealing floors and surfaces. The majority of the EM pottery derives from non-stratified

\footnotetext{
${ }^{2}$ Kastelli and Chania Town constitute parts of the same EM settlement, extending from the hill of Kastelli to the Old town of Chania. However, they were excavated, studied, sampled and analysed separately, and, therefore, they are also presented separately. In the discussion of the analytical results, they will be considered as a single site.
} 
contexts, stratigraphic tests, levelling deposits or pits in association with MM and/or LM sherds. The most representative assemblage could be considered that deriving from House I where there are architectural remains preserved and relatively clear stratigraphy (Tzedakis 1971; 1972; Hellström and Styrenius 1971; Hallager and Tzedakis 1982).

Among the architectural remains there are walls plastered with fine stucco, clay floors, hearths, and a workshop area. The finds have been reported to consist of pottery sherds of EM II date (fine and coarse wares), stone tools and a considerable amount of obsidian; in fact Kastelli is the only EM site in West Crete where obsidian remains cover all the stages of the manufacturing chain: there are cores, flakes and complete blades, whereas in most cases there are only blades (Tzedakis 1980a: 507). Moreover, it is the only site where fragments of bronze are reported (Hallager and Tzedakis 1986). The excavation on Kanevaro Street, at the foot of the hill, brought to light from EM II levels the impressions of at least two stamp seals preserved on the surface. This sealing is among the few found in Crete from the Prepalatial period (the others are found at Myrtos and Knossos) (Hallager and Tzedakis 1988).

The general picture of the Prepalatial period as reflected by stratigraphic soundings is that the occupation of the site is uninterrupted from the LN period onwards (Tzedakis 1981; Tzedakis and Hallager 1983). The EM I period is represented only by pottery without any architectural remains, whereas the quantity and quality of the EM II remains (architecture and artefacts) argues in favour of an extensive and flourishing settlement in this period.

Chania Town: The Minoan settlement of Chania expands further SE from the hill of Kastelli, on the low-lying area of Splantzia. Many individual plots were excavated and in most of them stratigraphic soundings provided a plethora of EM material with pottery, obsidian flakes and blades, along with fragmentary architecture. More specifically, evidence of EM occupation was revealed in the following plots:

Vardinogiannis-Anastasakis plot (Plastira and Apokoronou Streets): On the yellowish bedrock soil the remains of an EM wall, few EM sherds and an EM loom weight were revealed (Tzedakis 1978). 
Vasilelis plot (Daskalogianni St.): two test pits were opened. The Minoan levels provided a mixture of EM and MM pottery, obsidian blades, and a loom weight (Tzedakis 1981).

Hatzidakis - Kalamaridis plot (Katre St.): a test pit in Trench B revealed a mixture of MM and EM pottery under the LM layers (Tzedakis 1981).

Papadopoulos plot (Daskalogianni St.): The rescue excavation revealed building phases as early as EM II (Andreadaki-Vlasaki 1988).

The material studied and sampled in the present study derives from stratigraphic pits in the Kaniamos plot on Daskalogianni Street (Andreadaki-Vlasaki 1994a). This plot is situated nearby the Papadopoulos plot. Stratigraphic pits revealed a mixture of EM - MM remains, scarce architecture and mainly pottery sherds and an abundance of obsidian blades and flakes (Andreadaki-Vlasaki 1994a) (Pl. 2b, c).

The reason this specific plot was sampled for analysis is because it provides a representative picture of the EM pottery from the area of Splantzia and also for practical reasons. The material from all the rescue excavations has not been studied for publication yet, and, therefore, it remains unsorted: the number of crates with pottery range from 90 to more than 150 for each plot, with hundreds of pottery bags containing a mixture of sherds ranging in date from Byzantine-Venetian to EM. Sorting the material from all these excavations would go beyond the scope and the time limits of this study. The material from Kaniamos plot was convenient for sampling since there has been a preliminary evaluation of the chronological range of the pottery contained in each bag. We were given access to the excavation journals ${ }^{3}$, where it has been recorded which levels contained EM pottery; this facilitated greatly the process of sorting.

\subsubsection{Platyvola Cave}

The cave of Platyvola is situated ca. $25 \mathrm{Km}$ east of Chania on the plateau of Kerameia, nearby the small village of Scourachlada (PI. 3). The first investigation/ prospection of the site was conducted by Alexiou (1964); he was the first to identify Neolithic and Prepalatial pottery as well as "one sherd that is reminiscent of the

\footnotetext{
${ }^{3}$ Many thanks are due to Dr Maria Vlasaki for making the journals of the excavation available to us.
} 
Helladic sauceboat". Faure (1956) and Tzedakis (1965c) carried out on site investigation and surface collection of sherds, while systematic excavation started in 1966 by Tzedakis.

The cave is divided to four levels of different elevation; levels I and II were systematically investigated and provided a range of FN and EM pottery, among which EM I Pyrgos ware chalices, EM IIA incised pyxides, black slipped sauceboats and frying pans with Helladic and Cycladic affinities, and EM IIB mottled vessels (Tzedakis 1965b; 1965c; 1966a; 1966b; 1967a; 1968a). Unfortunately, none of the levels gave any stratigraphy (in the sense of superposed levels but for the particularities of the stratigraphy in a cave, see Zois 1998: 71-3). It is of interest that most of the finds were in pits with soil and stones, which provides implicit indications of ritual activities. Level IV contained only bones and it is suggested that during the Old-Palatial period it was probably transformed into a burial cave (Tzedakis 1968a) ${ }^{4}$.

In the area there are two more caves with pre- and mostly proto-palatial finds: a) Keramos, b) Cheilou Avlochi (Tzedakis 1965c; 1966b; 1967a). This shows that Platyvola was probably not a unique case in the area.

\subsubsection{Nea Roumata/Mitatoulia}

The area of Nea Roumata is situated SW of Chania, nearby the village of Alikianos. The site consists of a small circular tomb of the EM period (PI. 4a). This type of tomb was considered by the excavator to be of Cycladic origin and namely related to the tombs of the Keros-Syros culture (Tzedakis 1984). Moreover, it was compared to that of Krasi, near Malia, in terms of construction and chronology (Tzedakis 1984). However, both assumptions seem to be contradicted by the comparative study of the evidence. The tomb at Krasi contains multiple burials and the date of the pottery is EM I-II (Marinatos 1929), whereas the tomb at Nea Roumata contains a single burial and the date of the pottery is earlier. The argument of the early date of the tomb at Nea Roumata contradicts also the comparison with the Cycladic tombs. The latter are of EC II date, whereas the pottery from Nea Roumata is earlier (FN/EM I). A globular cooking pot and a cylindrical goblet/open bowl point towards

\footnotetext{
${ }^{4}$ In the excavation report (Tzedakis 1967a) there is no mention on structures or finds for Level III.
} 
the FN/EM I period in the form of the vessels and the handles. This date is definitely anterior to that of the Cycladic tombs.

The site of Mitatoulia is situated on the top of a small hill, south of the main road that leads to the village of Nea Roumata, and SE of the EM tomb. The hill is at a distance of ca. $800-1000 \mathrm{~m}$ from the tomb. Surface investigation provided EM sherds. Three test pits were opened and produced a considerable quantity of EM pottery, mainly coarse, a large amount of obsidian blades, stone tools, two loom weights and two fragments of rock crystal (Tzedakis 1980b) (Pl. 4b).

\subsubsection{Debla}

Debla is the name of a long E-W ridge forming one of the first foothills of the White Mountains of western Crete, above the plain west of Chania (P1. 5a). The plain reaches a height of $542 \mathrm{~m}$ and the Minoan settlement lies on the rocky terrace of the summit area (Pl. 5d). The site was known from previous explorations in the area but systematic excavation by Warren and Tzedakis revealed two EM buildings, scraps of at least two others, one building of uncertain date and part of a Hellenistic and Roman watch-tower. The EM structures consisted of free-standing houses with a single room each (Warren and Tzedakis 1974) (Pl. 5b, c).

The architectural remains consist of the following:

Building I: The Triangular House: it is well-built with unworked blocks of the local grey limestone. The floor was of packed earth, to level the uneven bedrock. On the floor a deposit of 13 vases along with obsidian blades and nine stone tools were found. Two spindle whorls, two quernstones, rock crystal and quartz were also recovered above the floor. Both the floor and the level above it produced many obsidian blades but no cores. The date of Building I is EM I-II.

Building 2: The Rectangular House: it was revealed in Trench $\mathrm{E}$ and consists of a single room. It is built against the bedrock with unworked stones. The building was almost devoid of finds, except for a pithos with scored decoration. The date for both the building and the pithos is considered by the excavators to be EM I. 
Building 3: Most of the fill and walls had been disturbed or destroyed. A possible floor level of red clay baked hard by fire was revealed. The construction seems EM, the bedrock material was EM I - the building is considered to be EM I.

Trench B: the building remains indicate a triangular structure like Building I. Four levels were distinguished but they were not stratigraphically distinct. They contained a mixture of Minoan and Hellenistic/Roman sherds.

Watch-tower/trench F: the fill of the building contained sherds of mixed date, Hellenistic/Roman and Minoan. The latter consisted of about 12 sherds of EM scored ware with a coarse, gritty, cooking-pot fabric in both levels (Phase I) and two fragments of EM IIA pyxides with incised herringbone decoration. However, the shape of the building and its architectural features (stone slab floor, thick walls) suggest that it was not part of the EM settlement.

Trench G: two poorly preserved rooms were revealed. The clay floor in the south room contained a few scraps including one good EM II herringbone incised sherd (the only diagnostic piece). The trench produced many Roman sherds, EM scored, redwash and bowl scraps.

The internal dimensions and the contents of the buildings indicate living and working spaces as reflected in the pottery, the obsidian and other stone tools. Storage is indicated by the presence of pithoi (Warren and Tzedakis 1974).

\subsubsection{Nopigeia Kissamou}

Nopigeia is a small coastal settlement on the Bay of Kissamos and belongs to the community of Drapanias (Pl. 6a). In prehistoric times, the sea covered the area of the plain to a distance of ca. $200 \mathrm{~m}$ to the south and probably reached the small hill of Troullia where the settlement was situated (Pl. 6b). The Minoan settlement covered an area of ca. $400 \mathrm{~m}$ from East to West. The earliest occupational remains date to the EM IIA (Andreadaki-Vlasaki 1991; 1994b) and the occupation of the site was interrupted before EM IIB. The hill was reoccupied in the early MM period.

The architectural remains are situated on the top of the Troullia hill, but some traces are also visible in lower parts. EM architectural remains were found only in one fully excavated trench but EM pottery was revealed in many test pits. Undisturbed EM 
groups were found buried deep, below the late MM settlement. In other areas layers of mixed EM and MM pottery were recovered; this mixture might be explained as the levelling fill in order to establish the MM floors. The EM pottery of the site bears close similarities with Helladic and Cycladic assemblages, with vessel shapes, such as hearths, that do not occur anywhere else in West Crete. Nearby the EM remains an inhumation of a child in a pithoid vessel was found, which constitutes a unique case in EM Crete so far (Karantzali 1997).

\subsubsection{Psathi Kydonias}

The site of Psathi lies $6 \mathrm{~km}$ west of the modern town of Chania, on a low coastal hill overlooking the sea, the Akrotiri area on the east and the Stalos beach on the west $(\mathrm{Pl} .7 \mathrm{a}, \mathrm{b})$. The extent of the settlement is ca $3.500 \mathrm{~m}^{2}$. Because of intensive agricultural activity no architectural structures were preserved ${ }^{5}$ but a large amount of pottery, a fragment of rock crystal and few obsidian blades were recovered (NiniouKindeli 1980: 509). The occupation of the settlement is reported to be EM IIB - MM IA and part of this pottery (deriving from three plots) is published (Mytilineou 199798).

The ceramic material studied and sampled for the present study derives from a fourth plot (Drakakis plot), which has produced a large amount of early Prepalatial pottery that remains unpublished. This assemblage belongs to the EM IIA phase and consists mainly of drinking and serving vessels in a red/black slipped and burnished and mottled ware.

Mytilineou (1997-98: 234-5) suggests that Psathi might have been a small autonomous settlement taking advantage of the close proximity to the sea and also practising agriculture. There is no evidence of any inter or intra-island contact and, therefore, it is assumed that the harbour was being used just for short-distance travels, and needs that could not be covered locally (i.e. obsidian and fine wares) would involve imports from Chania.

However, there is one element that makes Psathi a unique case: alongside the pottery more than 3,000 narrow clay strips, all fired and bearing string and thumb

\footnotetext{
${ }^{3}$ There is new evidence, yet unpublished, of architectural remains, indicating probably a workshop area (Mytilineou 2001).
} 
impressions were recovered (Mytilineou and Hallager 2000). Mytilineou and Hallager call these strips teniakia and suggest that they were used with strings as "buffers" and "stabilisers" to hold the local and poor quality pots during firing. Among the strips, a clay sealing was also found.

The "clay stripes mystery" as well as the paucity in cooking and storage vessels and the presence of the clay sealing led us to think that there must be something more about Psathi. Its favourable geographical position, on the hill overlooking the small harbour and in such close proximity to the flourishing settlement of Chania might have made Psathi a site of special importance. New evidence from recent excavations might allow a better understanding of the role of this site during the EM period (Mytilineou 2001).

The aim of this chapter was to set the background of the study by providing general information on the period, the environment, and the sites. This was considered important because, although this work is about pottery, the production and consumption of material culture is directly dependant on the time and the natural and social environment where it takes place. This is the reason why pottery is largely representative of various aspects of life in the past: through the study of their different attributes, ceramics provide information on origin, function and chronology, and allow a better understanding of social life in a specific period.

The pottery from the sites presented above constitutes the basis of this study. By using various methods of analysis, it is attempted to investigate patterns of pottery production, distribution and consumption, and at a second level shed light to the Prepalatial period in West Crete. In Chapter 3 are presented the methods used in this effect. 


\section{TABLE I}

EM Material at Kastelli, Chania

\begin{tabular}{|c|c|c|c|c|c|}
\hline Location & Stratigraphy & Material Type & $\begin{array}{c}\text { Architecture- } \\
\text { Features related }\end{array}$ & $\begin{array}{l}\text { Excavation } \\
\text { Year }\end{array}$ & Reference \\
\hline $\begin{array}{l}\text { Ag. Aik. Sq. Area } \\
\text { of Santa Maria dei } \\
\text { Miracoli }\end{array}$ & No & $\begin{array}{l}\text { Pottery: incised, } \\
\text { scored, mottled }\end{array}$ & No & 1964 & $\begin{array}{l}\text { Tzedakis 1964; } \\
\text { 1965b }\end{array}$ \\
\hline $\begin{array}{l}\text { Santa Maria, open } \\
\text { areas - Trench } 1\end{array}$ & No & FN-LM sherds & No & 1965 & $\begin{array}{l}\text { Tzedakis 1965a; } \\
\text { 1966a }\end{array}$ \\
\hline $\begin{array}{l}\text { Plot west of Ag. } \\
\text { Aik. Sq. }\end{array}$ & $\begin{array}{c}\text { Under MM } \\
\text { walls }\end{array}$ & mixed EM-MM & $\begin{array}{l}\text { MM walls and clay } \\
\text { floor (Room A) }\end{array}$ & 1966 & Tzedakis 1967 \\
\hline $\begin{array}{l}\text { Plot south of Ag. } \\
\text { Aik. Sq. }\end{array}$ & $\begin{array}{c}\text { Stratigraphic } \\
\text { test }\end{array}$ & $\begin{array}{l}\text { mixed EM-LM } \\
\text { sherds }\end{array}$ & under Room B & 1967 & Tzedakis 1968 \\
\hline $\begin{array}{l}\text { Plot further west of } \\
\text { the Ag. Aik. Sq - } \\
\text { Trench II }\end{array}$ & $\begin{array}{l}\text { Stratigraphic } \\
\text { test }\end{array}$ & $\begin{array}{l}\text { Pit with MM II, } \\
\text { EM II/III: } \\
\text { Ag.On., Pyrgos, } \\
\text { Mottled } \\
\end{array}$ & No & 1969 & $\begin{array}{l}\text { Tzedakis 1970; } \\
\text { Styrenius and } \\
\text { Tzedakis. } 1970\end{array}$ \\
\hline $\begin{array}{l}\text { Ag. Aik. Sq, west } \\
\text { part, trenches } 1,2 \text {, } \\
4\end{array}$ & Yes & $\begin{array}{l}\text { EM II on floors- } \\
\text { Vasiliki; LN, FN, } \\
\text { EM I underneath } \\
\text { until bedrock. }\end{array}$ & $\begin{array}{l}\text { EM II room (wall } \\
60 \mathrm{~cm} \text {, clayfloor, } \\
\text { sunk hearth) }\end{array}$ & 1970,1971 & $\begin{array}{l}\text { Tzedakis. 1971; } \\
\text { 1972; Hellström } \\
\text { and Styrenius } \\
1971\end{array}$ \\
\hline $\begin{array}{l}\text { Ag. Aik. Sq, small } \\
\text { space between } \\
\text { Room A (House } \\
\text { I)-MM House }\end{array}$ & Yes & $\begin{array}{l}\text { Continuation of } \\
\text { EM II floor - EM } \\
\text { II jug }\end{array}$ & EM II floor; & 1979 & $\begin{array}{l}\text { Tzedakis } 1980 ; \\
\text { Hallager and } \\
\text { Tzedakis. } 1982\end{array}$ \\
\hline $\begin{array}{l}\text { Ag. Aik. Sq Room } \\
\mathrm{G} \text { (House I) }\end{array}$ & $\begin{array}{c}\text { Stratigraphic } \\
\text { test }\end{array}$ & $\begin{array}{l}\text { Mixed EM + LM } \\
\text { sherds }\end{array}$ & MM wall? & 1979 & Tzedakis 1980 \\
\hline $\begin{array}{l}\text { Ag. Aik. Sq, } \\
\text { House I threshold }\end{array}$ & $\begin{array}{c}\text { Stratigraphic } \\
\text { test }\end{array}$ & $\begin{array}{l}\text { Below LM IA } \\
\text { layer, EM II + } \\
\text { MM pottery } \\
\end{array}$ & $\begin{array}{l}\text { Levelling or } \\
\text { foundation deposit }\end{array}$ & 1987 & $\begin{array}{l}\text { Hallager and } \\
\text { Tzedakis. } 1986\end{array}$ \\
\hline $\begin{array}{l}\text { Ag. Aik. Sq, Area } \\
\text { between Trenches } \\
\text { 3/14 }\end{array}$ & No & $\begin{array}{l}\text { EM - LM IIIA } \\
\text { material }\end{array}$ & Pits & 1978 & Tzedakis 1979 \\
\hline $\begin{array}{l}\text { Kanevaro St. } \\
\text { (rescue excav.) - } \\
\text { eastern end (621- } \\
626.5 \text { ) }\end{array}$ & $\begin{array}{l}\text { Yes: sealed } \\
\text { below EM III- } \\
\text { MM IA floors } \\
\text { and bedrock }\end{array}$ & $\begin{array}{l}\text { Pure EM II } \\
\text { deposit with frag. } \\
\text { of stone vessels + } \\
\text { obsidian }\end{array}$ & No & 1989 & $\begin{array}{l}\text { Hallager and } \\
\text { Tzedakis } 1988\end{array}$ \\
\hline $\begin{array}{l}\text { Kanevaro St. } \\
\text { (rescue excav.) } \\
(595-605)\end{array}$ & $\begin{array}{l}\text { Yes: sealed } \\
\text { below EM III- } \\
\text { MM IA floors }\end{array}$ & No finds & $\begin{array}{l}\text { EM II floor with } \\
\text { ash and charcoal. } \\
\text { Prepalatial clay } \\
\text { sealing underneath }\end{array}$ & 1989 & $\begin{array}{l}\text { Hallager and } \\
\text { Tzedakis } 1988\end{array}$ \\
\hline $\begin{array}{l}\text { Vardinogiannis - } \\
\text { Anastasakis plot }\end{array}$ & $\begin{array}{l}\text { On the yellow } \\
\text { bedrock soil }\end{array}$ & $\begin{array}{l}\text { EM sherds and } \\
\text { loom weight }\end{array}$ & $\begin{array}{l}\text { Part of Minoan } \\
\text { mudbrick wall }\end{array}$ & 1977 & Tzedakis 1978 \\
\hline Vasilelis plot & No & $\begin{array}{l}\text { Mixed EM } \\
\text { pottery }\end{array}$ & No & 1980 & Tzedakis 1981 \\
\hline $\begin{array}{l}\text { Hatzidakis - } \\
\text { Kalamaridis plot }\end{array}$ & $\begin{array}{c}\text { Stratigraphic } \\
\text { test }\end{array}$ & EM sherds & No & 1980 & Tzedakis 1981 \\
\hline \multirow[t]{2}{*}{ Papadopoulos plot } & $?$ & $?$ & $\begin{array}{l}\text { Building remains } \\
\text { EM II -LM IIIB }\end{array}$ & 1989 & $\begin{array}{l}\text { Andreadaki- } \\
\text { Vlasaki } 1988\end{array}$ \\
\hline & Yes & $\bar{?}$ & $\begin{array}{l}\text { Building } \\
\text { foundations, EM II- } \\
\text { MM III clayfloors, } \\
\text { EM II-MMIA } \\
\text { building remains }\end{array}$ & $1990-1992$ & $\begin{array}{l}\text { Andreadaki- } \\
\text { Vlasaki 1994a }\end{array}$ \\
\hline
\end{tabular}




\section{CHAPTER 3}

\section{Methodology}

\subsection{Methods and scale of analysis in ceramic studies}

The methods adopted in ceramic studies tend to alter depending on the context of application (cultural anthropology or archaeology) and the aims and objectives of the specific study. In archaeology pottery has served many purposes: it has frequently been used as a temporal sequence of shapes in order to establish chronological sequences, it has been studied for its aesthetic value within the confines of Art History, it has been analysed in its smallest components (elemental analysis) for the identification of provenance. The ultimate goal has been and still is to understand and interpret human behaviour through the production and consumption of material culture (Arnold 1985, Rice 1987).

Ethnographic studies have been at the starting point of this type of research, examining the context of production, use and discard of material culture and the meaning of style and technology in the social life of producers and consumers (the bibliography is extensive, a small selection may include Hodder 1978; 1985; Longacre and Skibo 1994). In the study of archaeological ceramics, however, the methodology of research had to be modified since the information available was rather different. In most cases, only part of the material is preserved in an integral form (a few whole vessels and many sherds), and only the context of discard is known. The location of production is known in special cases, such as kiln sites. As to the function of artefacts, it is more or less assumed. Therefore, the array of questions raised from the archaeological assemblages, along with the need for more information deriving from the objects themselves, introduced the use of analytical techniques in the study of material culture. In recent years, the questions prevailing in the study of archaeological 
ceramics are where and how pottery is manufactured, i.e. the provenance and technology.

In the Southern Aegean, pottery has been and still is the major tool for the establishment of relative chronology, due to the plethora and diversity of the material. However, the study of ceramic assemblages has gone through various stages and drastically changed in the last decades, following the new developments in ceramic studies. In Chapter 2 it was discussed how the study of the Prepalatial period evolved and changed, when it was demonstrated that a combined approach on pottery is a powerful tool in order to investigate pottery production and patterns of regionalism but also inter- and intra-island exchange and issues of identity and ethnicity.

The traditional approach was primarily interested in the typological classification of the material according to shapes and decoration, which are the best indicators for dating. This approach had implications in the way the assemblages were studied: emphasis was laid on fine and decorated wares, whereas coarse wares, which typologically are more conservative and not good chronological indicators, were overlooked and a priori considered locally produced.

A drastic change occurred when macroscopic study and classification took into account the fabric, along with shape, surface treatment and decoration. This is the case of the settlement site of Myrtos Fournou Korifi in East Crete (Warren 1972), where the fabrics of coarse and fine wares were categorised according to their colour, texture and inclusions (Warren 1972: 94-97). This study is important in that it recognised the connection between fabrics, decoration and function and put into perspective the idea of clay recipe. More specifically Warren (1972: 95) states:

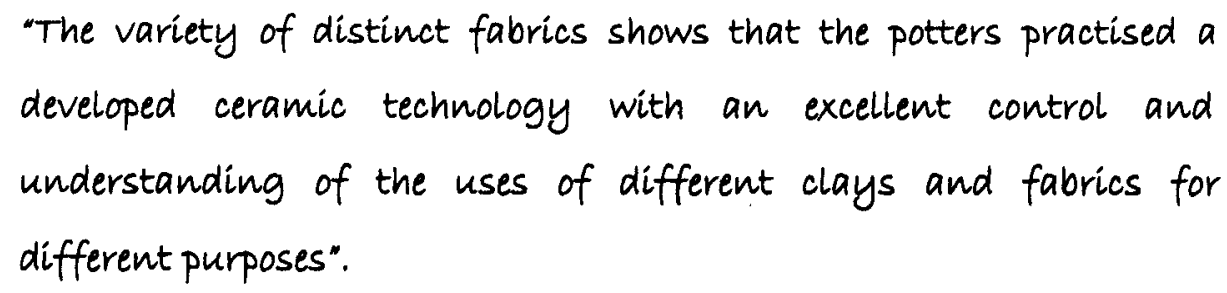

The "ware approach" was applied in the study of the EM pottery from the West Court House (Wilson 1984; 1985). The categorisation of the ceramic material was 
based on a detailed study of the wares, i.e. a combination of macroscopic observations on fabrics and surface treatment. This work is important not only because it provided a solid local sequence for EM Knossos, where other studies draw comparisons from, but also because it gave a new perspective to the study of pottery typology. Aspects such as the composition of the fabric, especially in coarse wares, might provide indications on chronology and technology of manufacture.

The investigation of issues of pottery provenance and technology evolved in two directions: the first is the "ware approach" as presented above, laying emphasis on detailed macroscopic observation and fabric description. The second involves the application of analytical techniques in ceramic studies. Both approaches had similar aims but it was only in the 1990's that they were combined.

\subsection{The analytical background}

\subsubsection{Chemical analysis}

Provenance studies in the Aegean were developed in the 1960's and were dominated by elemental analysis. The aim was to investigate large-scale pottery movement and trade in the Aegean and, therefore, research has focused around fine wares, which were considered to constitute objects of value (or containers of valuable products) and were more likely to be traded. Coarse wares were presumed a priori locally produced.

The first technique widely used in provenance studies was optical emission spectroscopy (OES) followed by atomic absorption spectrophotometry (AAS). The main question at the time was to discriminate between Cretan sites, separate them from the Mainland and, in this way, investigate the movement of pottery in the Aegean during the Late Bronze Age. The case of the inscribed stirrup jars constituted through the years an arena of debate: the schools and scholars involved developed their ways of thinking, sampling strategies and interpretations of the analytical results and suggested ways for the refinement of the procedures of elemental analysis in 
provenance studies (for detailed discussion see Catling et al. 1963; Catling and Millet 1965; Catling and Jones 1977; Catling et al. 1980).

The work on inscribed stirrup jars showed that the movement of pottery in the Aegean Late Bronze Age was beyond the level expected and that the application of a single technique was not sufficient in order to make positive statements on provenance. The outcome was the establishment of three broad compositional zones for Crete: West, Central and East Crete (Jones 1986: 256-7).

This created the need for a more integrated approach combining elemental analysis with other techniques as well as typology in order to overcome the singletechnique limitations. Neutron Activation Analysis (NAA) has been successfully used for the characterisation of archaeological ceramics, especially in cases where stylistic information, macroscopic and/or microscopic fabric characterisation were not distinctive. The work on Bronze Age pottery from Thera (Kilikoglou et al. 1990), the islands of the Southern Aegean (Kilikoglou and Grimanis 1993) and the Mainland (Attas 1977; Tomlinson 1991; 1995) has demonstrated that, with the application of NAA and statistical multivariate analysis, there can be discrimination on the basis of elemental concentrations.

\subsubsection{Petrographic analysis}

Petrographic research in Crete was pioneered by Riley who demonstrated the potential of ceramic petrography studies. He investigated temporal variation in the use of raw materials and tackled the prejudice that coarse pottery is local by definition. He demonstrated that pottery is a commodity that moves and gets traded in the Aegean Late Bronze Age (Riley 1983: 288-89).

In subsequent studies, fabric-based analyses were associated with geological prospection and addressed broader archaeological questions. Research on provenance went further than "classification, cultural/trade links and technological enquiry" and tackled more complex issues such as paste recipes, technological choices, and the organisation of pottery production (Day 1988b: 41). Petrographic analysis attempted a 
shift in the orientation of analytical studies by examining issues such as workshops and local traditions, as well as the short-distance distribution of ceramic vessels.

In later studies, individual Minoan wares have been the focus of analysis through an array of techniques in order to identify centres of production: these are the cases of Vasiliki Ware and the East Cretan White-on-Dark Ware (Betancourt et al. 1979; Betancourt 1984). More recently there has been a shift from the study of individual wares to the intra-island movement of pottery. This is illustrated by the case of the Neopalatial storage jars (Day 1988a) as well as the study of pottery production in East Crete during the same period (Day 1991; 1995). These projects demonstrated the potential of petrographic analysis to discriminate between production centres and investigate local patterns of pottery distribution. However, there were still questions that could not be tackled with petrography alone; this is the case of fine wares with no distinctive mineralogy or the discrimination between production centres using similar raw materials. This created the need for an integrated approach combining typology, petrography and chemical analysis.

This approach was applied in the case of EM Central and East Crete, where patterns of regionalism were explored using the ware approach with emphasis on macroscopic observation of fabrics in combination with petrography and SEM analysis (Wilson and Day 1994). This study shattered the prevailing assumption that Prepalatial pottery is locally produced and on a household basis. It was demonstrated that pottery production in the Prepalatial period was a specialised activity and that there existed a complex network of intra-island pottery distribution (Wilson and Day 1994; Day et al. 1997; Whitelaw et al. 1997).

\subsection{The analysis of EM pottery from West Crete}

The project on the EM pottery from West Crete draws upon previous work and experience. It is incorporated as a case study in the GEOPRO TMR Network; the main aim of GEOPRO is to develop an integrated approach of geochemical and mineralogical techniques in the study of ancient ceramics. It is, therefore, of interest to apply this integrated approach combining typological examination and analytical 
techniques in the study of pottery from an area without any history in scientific analysis for such an early period. In this way, the validity of the methodology is tested and the information acquired is of considerable archaeological significance. This study is also incorporated within the broader framework of analyses of EM pottery in Crete (see Wilson and Day 1994; Day et al. 1997; Whitelaw et al. 1997) and complements the picture of EM pottery production, distribution and consumption. The issues investigated include the provenance and technology of the specific material and at a second level the comparison with the information available from the rest of the island. In this way, there is an overview of the distribution of different wares across the island, and issues such as the provenance of wares, which are still problematic (i.e. the Knossian red wares), can be re-examined. Finally, it allows the reconstruction of a more complete picture of the Prepalatial period.

\subsubsection{Typological examination and sampling of the pottery}

The first stage of the work involved the typological classification of the ceramic material from the sites included in the study (Chapter 2) and the selection of samples for analysis. In most cases we had at our disposal the entire assemblage in order to examine the pottery and evaluate the relative frequency of wares and shapes. Only at Nopigeia, the material examined consisted of what had been sorted for publication by E. Karantzali (1997). The typological examination and classification comprised the study of shape, surface treatment, decoration and macroscopic fabric and an estimation of the chronology for the assemblage and the specific types of pottery. This examination was far from exhaustive. The aim was not to study the material in detail as if for publication (since most of it is unpublished), but to get a fairly accurate picture of each assemblage separately and of the whole in West Crete, in order to select representative samples for analysis.

The criterion according to which the sampling was designed was to get samples representative in terms of shape, ware, fabric and chronology. The examination of the pottery set also the archaeological questions. It was made clear since the beginning that the assemblages examined were quite homogeneous in the 
wares and shapes included, as much for the Minoan- as for the Helladic-style pottery. Therefore, the main themes around which the sampling was carried out were:

a) to examine whether similar wares were manufactured with similar raw materials, and, if possible, to identify whether they were produced in the same place

b) to examine whether the non-Minoan wares were imported

c) to investigate the technology of manufacture of the EM West Cretan pottery

The analytical techniques used in this effect were mineralogy and chemical analysis for the investigation of provenance, and mineralogy and microstructural analysis for the investigation of technology. For the reasons explained below, the mineralogical technique selected was thin section petrography, for chemical analysis Neutron Activation Analysis was selected and for the study of microstructure it was scanning electron microscopy (SEM). Finally, for comparative reasons a small-scale geological sampling was carried out.

\subsubsection{Thin section petrography}

Petrography has been a major tool of analysis in the prehistoric Aegean and especially in Minoan Crete, since the diversified geology of the island allows discrimination between sources of raw material. In this study thin section petrography was considered the most suitable technique for mineralogical analysis. The reason petrography was preferred to other mineralogical techniques such as X-Ray Diffraction (XRD) is twofold. Considering that a ceramic vessel is a composite object of a single or more raw materials, modified through human intervention, what is sought from analysis is to provide information on both. XRD provides accurate mineralogical information on clay minerals and added tempers (Eiland and Williams 2001) but does not give any on the ceramic paste, i.e. the fabric and the technology of manufacture.

Although XRD has been used in the characterisation of archaeological ceramics in Minoan studies, its use was for specific reasons and in combination with 
other techniques. In the case of the Kommos kiln the aim was to create a chemical reference group and an array of mineralogical and microscopic techniques was applied in order to understand the causes of compositional variability and reduce the effect of alteration and contamination (Buxeda et al. 2001). In the case of the EM pottery from West Crete, XRD would not be the most suitable technique because the material derives from consumption sites, the questions relate mainly to provenance and technology and, as mentioned above, a major target of this project is to produce results compatible with and comparable to what is available from EM sites in the rest of the island.

The stages of petrographic study involve observation of ceramic thin sections under petrological polarising microscope ${ }^{1}$, grouping and description of groups. All the stages of this process entail a degree of subjectivity and there are conventions that may vary according to the observer, the archaeological question and the material under study. These conventions include the criteria set for grouping and the attributes of the material that are considered more significant than others and "dictate" the establishment of petrographic groups. The study focuses in the examination and characterisation of the fabrics, i.e. the combination of the plastic and non-plastic components. There are certain attributes of the fabrics that were considered significant because they are related to the provenance and technology of manufacture of the pottery. These comprise the nature, quantity, texture and shape of the plastic and nonplastic inclusions, the quantity, texture and shape of the voids, the presence of organic material. These components are studied, and potential variation is assessed in order to form the groups. Finally, the groups are described and the variation between them is evaluated and, if possible, interpreted.

However, this is not the only method available for treating petrographic data. Within GEOPRO the automatic procedure of grouping was introduced, consisting in "describing" each sample according to a set of existing but easily modifiable variables (texture, optical activity, various types of inclusions). In this way, the petrographic data are expressed in a binary system of absence-presence, which can be used in mixed

\footnotetext{
${ }^{1}$ The thin sections were manufactured at the Fitch Laboratory of the British School at Athens by Mr Michalis Sakalis.
} 
mode analysis, along with the data from chemical analysis. The automatic procedure of grouping was also applied to the West Cretan assemblage but, due to the compositional homogeneity of the material, the resulting groups were not archaeologically meaningful (see also \$3.2.3).

The petrographic analysis for this study was carried out using a Leica Laborlux 12 POL $S$ polarising microscope at magnifications ranging between $\times 25$ to $\times 400$. The descriptions follow the system proposed by Whitbread for the study of ceramic thin sections (Whitbread 1989; 1995b), which was based on the terminology used for soil micromorphology (Bullock et al. 1985; Kemp 1985). By studying the plastic and nonplastic components, the pottery fabrics are characterised and linked to the geology of the area. The main advantage of this system is that it enables the description of textural concentration features and argillaceous inclusions and, therefore, of textural differences between fabrics. In this way, technological characteristics such as clay mixing and tempering can be discerned and described.

Textural information is important not only because of the technological information provided. The geology of in West Crete is homogeneous with the PhylliteQuartzite series and the Tripolis limestone dominating the landscape. It is, therefore, expected that differentiation between fabrics will depend more on textural rather than compositional variation.

\subsection{The geological sampling}

The geological sampling was carried out on a small-scale and in two seasons and had specific objectives: the aim of the first season was to collect randomly samples from Neogene marls and red deposits in West Crete, in order to get an idea of how these clays looked under the microscope. The sampling of the second season targeted similar deposits near the sites under study, in an attempt to clarify certain issues that derived after the petrographic examination of the material. Because the geology of West Crete is quite uniform, with the same units outcropping in a repetitive way, the main issue to be tackled through geological sampling was whether the same types of deposits had similar composition across West Crete. 
Outcrops of Neogene marls, red deposits and weathered phyllite deposits were selected for sampling, some in the vicinity of the sites under study. More detailed description of the sampling sites as well as the results of the geological sampling are presented elsewhere (Chapters 4 and 6). Here will be discussed the methodology followed for the treatment of clays and the manufacture of the experimental briquettes. During the two seasons of sampling, 30 clays were collected and 60 briquettes were manufactured.

The first group of clays (15 samples) were ground in a wooden mortar and drysieved under $1 \mathrm{~mm}$ sieve in order to remove organic material and gravels. Because all the briquettes of the first group were successful in drying and firing, for the second group (15 samples) the clays were ground but not sieved in order to examine their performance when containing natural inclusions. In both cases water was added for plasticity and two briquettes were manufactured from each clay (ca. $5 \times 1 \times 1 \mathrm{~cm})$. They were left to dry naturally overnight and were fired at $650 \mathrm{C}$ and $950 \mathrm{C}$. These temperatures were chosen to be representative of low and a high firing respectively. In the former case the result is an optically active matrix under the microscope, representing a non-vitrified state of the ceramic with all the clay minerals unchanged. In the latter, the matrix is optically inactive due to the vitrification of the ceramic body and compositional changes have occurred due to high temperature.

The briquettes were fired in a laboratory furnace in air (oxidising conditions) with a heating rate of $\mathrm{ca} .3 .3^{\circ} \mathrm{C} / \mathrm{min}$ and soaking time of one hour at $100 \mathrm{C}$ in order to prevent breakage. Then, they stayed at peak temperature for one hour and they cooled down at a natural rate. The firing procedure is illustrated in Fig.1.

\subsection{Neutron Activation Analysis}

Elemental analysis was considered necessary for a better understanding of the EM material from West Crete because there were issues related to nature of the material and the composition of the ceramic pastes that could not be answered by petrography. It was the case of fine wares with non-distinctive mineralogy that had to 
be analysed chemically in order to identify whether they were imported or produced locally and, if the latter, whether the raw materials used were similar or different.

The reasons NAA was specifically selected as the method of elemental analysis relate to the potential of the method and the work previously carried out in Crete. There are other techniques that measure trace elements concentrations (like Inductively Coupled Plasma-Mass Spectrometry - ICP-MS) but some of the West Cretan samples were semi-coarse and the amount of sample needed for ICP-MS is small and, therefore, might not be representative. Moreover, samples for ICP-MS need to be dissolved and incomplete or inhomogeneous dilution may result to inaccurate measurements (for further comparison between chemical techniques of analysis, see Hein et al. 2002).

The advantage of NAA is that it provides accuracy and precision and can measure a wide array of elements at major, minor and trace concentrations. Moreover, most chemical analyses carried out so far on EM material from Crete were performed with NAA (Day et al. 1999; Tsolakidou et al. 2002). Therefore, as with petrography, the data produced for West Crete had to be compatible with and comparable to the existing data bank (Day et al. 1999).

The samples for the analysis were selected to be representative of the major ware and fabric groups in the assemblage. A total of 203 samples were analysed at the Laboratory of Archaeometry, Institute of Materials Science of the NCSR Demokritos (Athens). The principles of the method are described in Perlman and Asaro (1969) and the specific procedures followed in Demokritos are described in Kilikoglou et al. (1990); Kilikoglou and Grimanis (1993); with an update in Hein et al. (2002).

In brief, from each sherd a small piece is clipped off, the surface is cleared with a carbide drill, then ground and homogenised in an agate mortar. The samples are left overnight to dry along with the standards at $120^{\circ} \mathrm{C}$. The standard used in Demokritos is the International Atomic Energy Agency Certified Reference Material Soil-7. Ceramic samples and standards weighing approximately $130 \mathrm{mg}$ are placed into polyethylene vials and heat-sealed. They are irradiated in batches of ten (eight samples-two standards) in the Demokritos swimming pool reactor and then counted 
twice. The first count takes place after seven days of cooling in order to determine the short-lived elements (As, Ca, K, La, Lu, Na, Sb, Sm, U, Yb). The second count takes place after twenty days in order to determine the long-lived elements (Ce, $\mathrm{Co}, \mathrm{Cr}, \mathrm{Cs}$, $\mathrm{Eu}, \mathrm{Fe}, \mathrm{Hf}, \mathrm{Rb}, \mathrm{Sc}, \mathrm{Ta}, \mathrm{Tb}, \mathrm{Th})$.

The statistical evaluation of the data that derived from chemical analysis was carried out using the statistical package S-Plus (Venables and Ripley 1999; 2000). Within GEOPRO an implementation of this software was developed in an attempt to integrate geochemical and mineralogical data into statistical analyses. The types of statistical analysis included aggregative hierarchical cluster analysis (average linkage), principal components, and discriminant analysis. Cluster and principal components are exploratory methods of analysis used for the evaluation of compositional data (Baxter 1994). The aim is to measure similarity within the data set in order to identify groups of samples. Discriminant analysis uses existing groups that derived through the application of other analytical methods in order to confirm that they are distinct.

Along with the implementation of S-Plus, mixed mode analysis was also developed within GEOPRO. The aim was to use the two types of data (geochemical that derived from NAA and mineralogical that derived from petrographic analysis through the automatic grouping procedure) in order to identify groups (Beardah and Baxter 2001). The West Cretan data were analysed with mixed-mode but the picture that derived was far from clear and methodological issues arose. The variables used for the petrographic grouping were not sufficient in order to cover the textural variation within the assemblage, and chemical variation did not allow any clear grouping either. Therefore, there is still work to be done on the methodology of mixed-mode analysis and this is not within the confines of the present work.

\subsection{Scanning Electron Microscopy (SEM)}

Examination of archaeological ceramics with SEM is a widely used technique for the investigation of ceramic technology. It provides a different scale of analysis than petrography and NAA. The magnification reaches $\times 2000$ and observation is at the level of clay filaments. The information achieved concerns the microstructure of the 
body, surface and slip or paint etc. Through the microstructural characterisation of the body and surface of the vessel, the degree of vitrification and the texture of the body are examined and the firing temperature is estimated. Through the semi-quantitative analysis available through EDAX, the calcium content of the clay body and the surface slip or paint is assessed.

Recent literature based on ethnographic data has questioned the validity of using firing temperature identifications in the technological interpretations of pottery, on the grounds that there is overlap in temperature range not only between firing environments but also within a single vessel (Gosselain 1992). Subsequent work based on experimental firing has demonstrated that, although it is not possible to relate a set of thermal characteristics to a specific firing procedure, ethnographic data and experimental work, combined with archaeological information, can contribute in the reconstruction and interpretation of technical behaviours (Livingstone Smith 2001).

For the reconstruction and interpretation of the original firing conditions refiring tests can be carried out, especially when testing the effect of firing in different clays or when investigating firing temperatures. Depending on the change in colour (macroscopic observation), the original firing temperature can be estimated (Rice 1987: 428). However, when SEM is available, the observation of the microstructure is a better guide for the identification of the firing temperature. Refiring can also be used in combination with SEM and XRD when dealing with problems related to compositional alteration and due to firing. However, in the case of the EM pottery from West Crete, it was clear, even by macroscopic observation, that there were two distinct types of pottery, the Helladic-style black slipped being higher-fired than the Minoan wares. As to compositional perturbations, they are not easily detected in consumption assemblages where compositional variability is a priori expected (Buxeda et al. 2001: 368).

The use of SEM, along with petrographic analysis, in the study of Early Minoan material from consumption sites has revealed aspects of the technology of manufacture of the pottery previously unknown. It has been demonstrated that the choice of clays, as well as the manufacturing techniques and clay recipes, were 
dictated by a deep knowledge of the performance of the different materials and the function of the final product. There was control of pyrotechnology both in terms of firing temperature and atmosphere in order to achieve specific vessel qualities and visual effect (Kilikoglou 1994).

In the case of the EM pottery from West Crete, SEM has been used in the investigation of certain technological aspects of the assemblage. The reason for selecting this method was not only that it has been used in the analysis of EM ceramics from Central and East Crete. It provided information that could not be obtained through other analytical techniques (XRF or NAA), namely the possibility to examine separately the body and the surface of the vessel in terms of microstructure and composition. Moreover, with the semi-quantitative elemental analysis, the content in Ca (and other elements) was assessed. In this way, it has been examined in which cases calcareous or non-calcareous clays were used and whether similar or different clays were used for the body and the slip of the vessel. Finally, through the estimation of the degree of vitrification, firing temperatures were estimated.

The main issues of the EM pottery from West Crete concerned the technological characteristics of the slipped, dark grey burnished and mottled wares. For the Minoan-style vessels it has been examined whether they shared similar technology of manufacture with their counterparts in Central and East Crete. The nonMinoan style vessels were examined in order to identify similarities and differences in the technology of manufacture between sites.

According to the above questions $\mathbf{5 5}$ samples were selected for SEM analysis. They were representative of the different wares and fabrics. Sample preparation consisted of a freshly fractured cross-section of body and slip glued with electrically conducting glue on an aluminium stage. The samples were coated with a thin layer of carbon in order to be made conductive. All the samples were examined in a Philips 515 SEM at the Institute of Materials Science of the NSCR Demokritos (Athens). The analysis was carried out with the energy-dispersive system EDAX 9900 coupled to the SEM. For the characterisation of the body micromorphology and the degree of vitrification the terminology used is the one introduced by Maniatis and Tite (1981) 
with a small differentiation in the term Total Vitirification (TV) instead of Continuous Vitrification (CV) introduced by Kilikoglou (1994: 70).

\subsection{Summary}

Recent analytical research in Central and East Crete covering a large array of sites from the Early to the Late Minoan period has demonstrated the potential of a combined approach using typology and scientific analysis. Pottery was viewed as the product of a complex process, involving natural components (raw materials) and human agency (clay recipes and technology of manufacture). The analytical work concentrated in identifying these components in the ceramic artefacts and thus interpreting human behaviour. More specifically, in the case of the Prepalatial period it has been shown that pottery production was not at the level of the household as previously believed, but was the specialised product of a restricted number of sites and was widely distributed via a network of exchange along the north axis of Central and East Crete.

In this picture of the Prepalatial period West Crete was absent. The lack of publications and scientific analysis did not allow any comparison with contemporary sites in other parts of the island. This project was undertaken in order to investigate pottery production and consumption in EM West Crete through a combined approach of typological classification and scientific analysis. Ceramics petrography, NAA and SEM have already been used in Minoan ceramic studies and it has been demonstrated that hey constitute a powerful tool for the characterisation of the pottery and the investigation of issues of provenance and technology.

In the following chapters the geological background of West Crete, the typological classification of the material, and the results of the analyses are presented. The geology of the area and the results of the clay sampling set the framework within which the analytical results are presented, whereas the chapter on typology sets the basic questions posed by the study of the material. 


\section{CHAPTER 4}

\section{The geology of West Crete}

\subsection{Introduction}

The relevance of a chapter on the geology of West Crete lies in the nature of the archaeological material under study. Ceramics are made of clay and tempering agents in varying proportions and according to recipes that also vary in time and space. Their composition has, therefore, a twofold character, reflecting the natural elements (i.e. the geology of the area where the raw materials came from) and the human agent. Pottery analysis is carried out in order to characterise the natural components, make inferences about provenance, and understand human behaviour. The study of the geology provides information on the first part of the endeavour and hints on the second.

The geological information needed in a study concerned with ceramics includes: a) the rock types that outcrop in West Crete, and b) sedimentation. The first component reflects the non-plastic inclusions in the pottery, the second the clay used for its manufacture, and the combination of the two represents production technology and resources. In this chapter, some aspects of the West Cretan geology are presented, followed by the results of a limited clay prospection, carried out for comparative reasons.

\subsection{The geological evolution of Crete}

The island of Crete lies between 23 30' and 26 20' East longitude and 34 54' $40^{\prime \prime}$ and $3541^{\prime} 34^{\prime \prime}$ North latitude. It is approximately $258 \mathrm{~km}$ long and varies between 11 and $56 \mathrm{~km}$ in width. The total land area amounts to $8287 \mathrm{~km}^{2}$, thus 
Crete comprises approximately $6.3 \%$ of the total area of Greece (Timpson 1992: $15)$.

Crete represents the exposed southern portion of the Hellenides. It consists of an orogenic overthrust belt constructed primarily during the Late Palaeogene to Early Miocene (for the Stratigraphic Scale, see Table II at the end of chapter) (Timpson 1992: 18). The southern Aegean which includes the island of Crete comprises: a) the Hellenic trench, a deep sea trench between Crete and the north African coast, b) the Hellenic Island Arc, a convergent zone extending between Greece and Turkey, and c) the Aegean Volcanic Island Arc (Hall et al. 1996; Moody 1987).

The Greek landmass, the Cyclades, and Crete emerged from the sea of Tethys during the Alpine orogeny, which began in the East during the Late Cretaceous (70 my BP) and ended in the west during the Miocene (25-10 my BP). It resulted in the formation of alternating nappes (i.e. uplifted massifs sliding from east to west on to lower and still submerged areas), which partly explains the rhythmic repetition of Cretan landscapes (Rackham and Moody 1996: 13-14) (P1. 8).

The interplay of tectonics and sedimentation has resulted in a large variety of sediment types and in rapid lithological changes both in a horizontal and vertical sense (Dermitzakis et al. 1995). The sedimentary record allows the recognition of several successive intervals from the Oligocene to Recent, which correspond to a specific combination of sedimentary pattern, tectonic movements and palaeogeographic configuration. The intervals represent periods of stability succeeded by periods of instability with submergences and upliftings resulting to the formation of the different sedimentary series, the configuration of the coast and the shaping of relief (Rackham and Moody 1996). It is also worth mentioning that these intervals do not necessarily cover exactly the same time lapse all over the island and, therefore, similar geological formations are not necessarily contemporaneous (Drooger and Meulencamp 1973). 
A short hiatus in the form of a sedimentary gap, apparent everywhere in Crete, Kasos, Karpathos, the Peloponnese and Kythera, occurred at the end of the Miocene when the Messenian "salinity crisis" of the Mediterranean took place and gypsiferous deposits were laid down. From the Late Pliocene through the Middle Pleistocene renewed faulting gave Crete its present configuration. During this period the Souda Bay graben collapsed and Akrotiri was separated from the north coast of Crete. The Mio-Pliocene terraces that form the fertile north coastal plains emerged at this time (Meulencamp 1971; Meulencamp et al. 1977; Zamani and Maroukian 1981).

The Middle Pleistocene to Middle Holocene (600,000 - 5000 years BP) was a period of relatively low tectonic activity with sea level rise and fall, which resulted in the periodic deposition of aeolianites and fluvial/colluvial sediments (red beds).

Approximately 4200 years BP Crete experienced renewed tectonic activity; according to radiocarbon dates from different strata the tectonic submergence occurred gradually from $2800 \mathrm{BC}$ to $\mathrm{AD} 400$. This is contrary to the prevailing view that the west coast of Crete has been emerging gradually since prehistoric times. According to the new data seven tectonic events have occurred since the Early Bronze Age, resulting in abrupt downward displacements of the west coastal margins of the island (Moody 1987: 20). Moreover, recent research has demonstrated that earthquakes in the Southern Aegean might have been localised phenomena with destructive effects in the immediate vicinity, but with a limited orbit of impact (Zachos 1996; Vallianou 1996).

\subsection{Pre-Neogene Units}

Crete consists essentially of a backbone of Tethyan sedimentary and igneous rocks dated as Permian to Oligocene, deformed and metamorphosed in Mesozoic and Tertiary times and overlain by post-tectonic shallow water sediments of Upper Tertiary (Neogene) age. 
The lithological units of the Pre-Neogene are separated from one another by tectonic and not stratigraphic contacts. With the exception of the Plattenkalk (whose origin is uncertain) they are all allochthonous. At least six Pre-Neogene units have been identified, all of which show evidence of Tethyan deformation. The PreNeogene units of Crete have been described in many works (e.g. Bonneau et al. 1977; Hall et al. 1996) and in brief they are as follows:

Plattenkalk Series: this series constitutes the geological core of Crete. It consists of dark grey crystalline limestones with chert horizons and calcarenites, carbonate breccias, dolomites and algal limestones. The main sequence is believed to range from Triassic to Eocene (no fossils).

Tripali Unit: this unit has been along with the phyllite quartzite series form one overthrust unit (Seidel and Okrusch 1976). It consists of shallow water limestones and dolomites and recrystallised coarse carbonate breccias. It is identified primarily in West Crete, the main outcrops occurring in the White Mountains and the Akrotiri peninsula. The only fossil evidence indicates a Liassic age (Triassic early Jurassic) (Gifford 1992).

Phyllite-Quartzite (P-Q) Series nappe: metamorphic complex of quartzites, mica schists, red limestones, marbles, gypsum and andesites with their tuffs. Sporadic fossils within the nappe indicate a Late Permian to Late Triassic age. On Crete it constitutes an external, allochthonous complex of the Hellenides and is bounded by thrust planes separating it from the underlying autochthonous (?) Plattenkalk and Tripali units and from the overlying Tripolis Nappe which is essentially unmetamorphosed. The P-Q nappe is interpreted as a melange. It consists of siliciclastics and carbonates, pyroclastic, volcanic and minor intrusive igneous rocks. All of these rocks have been deformed and metamorphosed during the Tertiary orogeny under high pressure $(\mathrm{P})$ - low temperature $(\mathrm{T})$ conditions; the grade of metamorphism varies from very low-grade zeolite/greenschist in East Crete to blueschist facies in West Crete. The P-Q series is the most enigmatic unit within the external zones of the Hellenides; there are many unsolved problems concerning 
its definition, its separation from similar rock assemblages in the neighbourhood, its age and its depositional area. It is also a matter of debate between scholars whether its metamorphism is related to subduction or to gravity sliding (for further discussion, see Greiling 1982; Krahl et al. 1983; Jacobshagen 1994, Zulauf et al. 2002).

The P-Q series in West Crete: petrological investigations in West Crete showed the following mineral parageneses:

glaucophane - pumpellyite - aragonite - albite - ferrocarpholite --- in metabasalts

quartz - muscovite - paragonite - chloritoid - lawsonite --- in metapelites

However, according to $\mathrm{P} / \mathrm{T}$ conditions and petrological investigations the most common metamorphic minerals distributed all over W. Crete are glaucophane, lawsonite and chloritoid.

Lithologically, the P-Q nappe of West Crete can be divided into an upper sequence of phyllites and quartzites and a lower sequence of phyllites and carbonate rocks, locally intercalated with evaporites and rare metabasalts (Seidel and Okrusch 1976; Greiling 1982).

Tripolis Series nappe: this consists of massive unbedded to thick-bedded limestones of Jurassic to Middle Eocene age. The massive, light grey, dolomitised limestones represent a typical shallow water, marine carbonate sequence. It is suggested that this unit was moved by nappe transport as a rigid thrust sheet, later fractured by post-orogenic block-faulting.

Pindos Series nappe: this consists of pelagic limestones with radiolarites, turbidites and thin clastics, dated from Triassic to Eocene, and represents the uppermost sedimentary nappe unit of Greece. The presence of this nappe in Crete is characterised by important variations, especially in the Asteroussia Mountains of southern Crete, that is why the term "Pindos-Ethia" Series is used for the rocks of the Cretan Pindos nappe. In the "Asteroussia nappe" occur high-grade metamophic 
and ultramafic rocks often associated with Neogene rocks and late Cenozoic faulting.

Ophiolite nappes: the uppermost part of the Cretan nappe pile comprises a heterogeneous group of rocks that may be described as a high-grade metamorphic and ophiolitic mélange. This unit includes rock types such as amphibolites, andalusite and sillimanite-cordierite-garnet-mica schists, gneisses, deformed granitic rocks, marbles and calc-silicate assemblages. The thickness of the nappe varies from $600 \mathrm{~m}$ in the Asteroussia Mountains to 4-5 m near Anogia. Within the high $\mathrm{T}$ metamorphic mélange there are ortho- and para-amphibolites. The assemblage plagioclase + hornblende \pm clinopyroxene implies the low $P$ range of the amphibolite facies.

\subsection{Sedimentation}

In Crete, phases of sea regression were followed by periods of transgression and marine sedimentation, which is reflected by the alternation of fresh-water and marine deposits. There is evidence that the fresh-water deposits are the oldest ones, which means that the area was above sea-level from approximately the Oligocene up to the Middle Miocene; these deposits are overlain by the marine Early to Middle Tortonian deposits (Freudenthal 1969). The outcome of this sedimentation process is that the post- Middle Miocene deposits are increasingly calcareous. This is of importance when analysing Minoan pottery and examining potential sources of raw materials, since it is a usual practice of the prehistoric potters to select calcareous clays.

In shallow basins, laminated marls units, rich in siliceous microfossils, accumulated in low energy environments. Evaporation led to local accumulation of thin layers of gypsum, probably connected with the Messenian salinity crisis. Although Crete was only marginally affected by high salinity environments, Messenian deposits are important because they form the basis of the great Cretan 
plains, such as the Mesara in Central Crete and the bay of Kissamos, the coastal plains of Chania and Rethymnon in the West (Gifford 1992: 20).

Throughout the Later Miocene and Pliocene only some minor parts of the area remained above sea level. Fully marine conditions were established throughout Crete in Lower Pliocene times.

During the Pleistocene several periods of deposition have occurred resulting in the formation of fluvial and colluvial terraces. From the end of the Pleistocene onwards several phases of alluviation have occurred, the earliest of which dates to the Early Bronze Age $(2500 \mathrm{BC})$. Since then human interference with the environment is considered to be the major component affecting sedimentation. Nevertheless, evidence from West Crete indicates that landforms were also modified by renewed tectonism.

\subsubsection{Neogene Deposits in West Crete}

In Crete Neogene deposits overlie with an angular unconformity PreNeogene folded rocks ranging in age from the Palaeozoic to the Eocene. The base of the Neogene sequence is composed of an irregular succession of fresh-water conglomerates, sandstones, clays, lignites and limestones. These fresh-water deposits are overlain by marine greyish marls and clays with frequently basal Heterostegina sands. These are succeeded by alternating organic limestones and marls (Meulencamp 1971).

The Neogene deposits are found in the relatively low, hilly, coastal plains along the northern coast, almost restricted to the districts of Apokoronas, Kydonia and Kissamos. .

Thick detrital sediments at the base of the Neogene are considered to be of Helvetian age. In the Rethymnon area they consist of sand, sandstone, gravel and limestone. They are lacking in the Chania province except for a small occurrence of clay on the Titiros peninsula. Overlying the coarse, detrital sediments there are blue- 
white marls and marly limestones with macrofossils. Gypsum masses, gravel and conglomerate beds are found interbedded within these marls and marly limestones. They are considered to be of Tortonian age and are present in Rethymnon but not in Chania. During the Tortonian sedimentation stopped owing to a regressive phase tectonical uplift of earlier sediments. Messenian sediments are widely distributed in the western part of Crete, e.g. the Chania province (Freudenthal 1969).

The Neogene in Crete has received much attention and several regional studies have been carried out resulting in the identification of local formations (Meulencamp 1971; Fortuin 1977; and more specifically, for Ierapetra, Dermitzakis 1969; for Siteia, Gradstein 1973, for Rethymnon, Meulencamp 1969). Analogous to these studies is the identification of eleven formations of Neogene deposits in the province of Chania, in West Crete (Freudenthal 1969). From east to west they are as follows:

1. Mesonisi Formation: red conglomerates and yellow or grey marls conformably overlying black, recrystallised Pre-Neogene limestone. This formation is overlain by the Roka Formation. The fossil record points to a fresh water environment during sedimentation. This formation outcrops mainly west of the Rodhopos peninsula.

2. Roka Formation: conglomerates, reddish-brown sands and bluish, hard organic limestones. This formation overlies unconformably black, unbedded, metamorphous limestones of Cretaceous age. Near Roka the formation conformably overlies the Mesonisi Formation at other localities it overlies shales. In the northern part of Kissamos district Roka is overlain by the Kissamos and in the southern by the Koukounaras Formation. A good example of the succession conglomerate-sandlimestone is found near Nochia. This formation reflects a near-shore, shallow water environment. The cross-bedded sands may reflect a fluviatile sedimentation.

3. Koukounaras Formation: graded beds with thin, interbedded, laminated and amorphous bluish clays. This formation overlies the Roka Formation and it is overlain by the Khairetiana Formation. The thickness of clays increases from south to north. The alternation of graded beds and amorphous clays is due to turbidity 
currents. The former are indicative of shallow water environment, the latter of quiet environment, not very shallow, which resulted to the formation of these clays.

4. Kissamos Formation: amorphous, sometimes laminated, blue or purple clays with graded and non-graded clastic intercalations (sandstones, calcarenites, organic limestones). This formation conformably overlies the Roka and it is overlain by the Khairetiana and the Khatzi Formation in different areas. Near Agia Marina Kydonias the amorphous clays are quarried for brick manufacture.

5. Khairetiana Formation: alternating layers of amorphous or laminated yellow to brown marls, sandy clays and clays. Gypsum deposits are present locally in its lower part. Graded beds are rare. This formation is underlain by the Kissamos, the Khatzi and the Koukounaras Formations in different parts, and it is most widely distributed in the Kissamos and the Apokoronas districts.

6. Khatzi Formation: two lithologic units are present; a coarsely clastic, consisting of conglomerates and subordinate marls and clays, and a finely clastic one consisting of thin graded beds and laminated clay. Gypsum deposits may be present. This formation is restricted to the eastern part of the Kissamos district, it unconformably overlies black recrystallised limestones and it is underlain by the Kissamos Formation.

7. Tavronitis Formation: white, amorphous marls which alternate with slightly graded beds. This formation conformably overlies the Khatzi Formation and it is not overlain by other Neogene deposits. The amorphous marls at the base reflect a continuous, quiet, off-shore sedimentation, comparable with that of the Kissamos Formation. Probably, the same sedimentary conditions prevailed throughout the time of sedimentation of the Tavronitis Formation. It outcrops on the north coast from Platanias to Rodhopos peninsula.

8. Agios Georgios Formation: conglomerates, sands, clays and organic marly limestones. This formation is underlain by Pre-Neogene shales and black 
recrystallised limestones. It is overlain by conglomeratic or sandy sediments of the Akrotiri Formation. It outcrops in the Agios Georgios area, south of Mournies.

9. Akrotiri Formation: organic limestones, conglomerates and sands. This formation is underlain by the blue clays of the Kissamos Formation and is overlain by the Agios Georgios Formation. It reflects a shallow environment. It outcrops in the southern part of the Akrotiri peninsula and in the plain of Souda.

10. Souda Formation: thin-bedded, dense limestones. This formation is underlain by brecciated, pre-Neogene black, crystallised limestones and is overlain by the Akrotiri Formation. It reflects fresh water deposits.

11. Kerameia Formation: thin-bedded, dense limestones, thick-bedded organic limestones and clays. There is no underlying Neogene formation, and this formation unconformably overlies pre-Neogene shales and limestones. The organic limestones resemble those from the Akrotiri Formation and therefore a similar environment is assumed. This formation outcrops in the Kerameia Basin.

\subsection{Geology of the study area}

West Crete is of major geological interest mainly in terms of structure and tectonics, since active faults and periods of increased tectonism have contributed greatly to its configuration. Shorelines reflect regressive and transgressive sequences, which have resulted in the present configuration of the coast (e.g. Zamani and Maroukian 1981; Thommeret et al. 1981; Postma and Nemec 1990). Through these studies human behaviour can be investigated, examining the reciprocal relationship of human populations with their environment (Moody 1987).

The geological background of West Crete has been discussed in geological works dealing with the orogenic evolution of the Hellenides and the position of Crete in the Southern Aegean (e.g. Drooger and Meulencamp 1973; Bonneau et al. 1977; Jacobshagen 1979; 1994; Hall et al. 1996). Emphasis has been laid on the study of the P-Q series, the major issue of debate being the different phases of 
metamorphism (e.g. Greiling 1982; Krahl et al. 1983; Seidel and Okrusch 1976). It is important that the $\mathrm{P}-\mathrm{Q}$ series in West Crete presents different tectonostratigraphic sequence than that in East Crete: the degree of alpine metamorphism of the latter is less than in the former as indicated by values of the metamorphic index of certain minerals (Zulauf et al. 2002: 1808). Therefore, even if these differences cannot be detected petrographically in ceramics, regional geological studies can provide information on the characteristics of the $\mathrm{P}-\mathrm{Q}$ series and possibly infer about provenance. For the Neogene deposits, there is the more general work on the Southern Aegean by Meulenkamp (1971), and the detailed study of the Chania deposits by Freudenthal (1969).

It is not within the scopes of this study to discuss the results of geological work dealing with rock and sediment formation processes. It is important to understand the geological background of West Crete under the prism of pottery production and the resources available on this effect. Therefore, emphasis is laid on the general composition of the different rock and sediment types, especially those that might have been used for pottery manufacture. Previous archaeological work has demonstrated that in Minoan pottery production the non-plastics were often related to phyllite and limestone rock series, whereas the main clay deposits exploited were Neogene marls and Quaternary alluvium (Day 1991). These are the types of deposits that constituted the target of study and sampling in this study.

For the present study, four maps at a scale of 1:50.000 were used (I.G.S.R. $\left.1956 ; 1969 ; 1970 ; 1971^{1}\right)$. The main deposits represented in the areas under study are the following starting from the bottom of the stratigraphic sequence:

Plattenkalk Series: crystalline limestones of Carboniferous-Permian age which outcrop at the eastern part of the White Mountains. The Carboniferous formation is older and consists of dark, fine-bedded to platy, fine to coarse

\footnotetext{
${ }^{1}$ I.G.S.R. is the abbreviation for the Institute for Geology and Subsurface Research, today known as I.G.M.E. (Institute of Geological and Mineral Explorations).
} 
crystalline limestones with bands and nodules of chert. In places these strata are intercalated with thin beds of reddish or greenish phyllite.

Phyllite-Quartzite Series: phyllites and crystalline schists cover the western part of the White Mountains and the majority of the Alikianos area in SW Crete. There are outcrops in the Kerameia Basin, SW of Galatas and to the East of Chania alluvial plain. This series is composed of graphitic, chloritic, sericitic and occasionally hematitic phyllites. Shale, sandstone, and quartzite layers intercalate in the upper and middle strata, while carbonate rocks (mostly platy fossiliferous limestones) intercalate in its lower strata. Deposits of evaporites (gypsum), bodies of mafic and ultramafic rocks (diabase, peridotites) and occasional outcrops of limonite also occur throughout the formation. The ultramafic rocks are often serpentinised and locally contain veins of asbestos.

Tripolis Series: limestones of Mesozoic age surround the carboniferous limestones of the White Mountains. There are outcrops south of Chania as well as at Akrotiri. These younger limestones are similar in lithology to the older ones, except for the absence of cherts and the fact that they are more strongly karstified. They also contain rudist fossils and are often brecciated and dolomitised.

Neogene Deposits: Miocene marls and Pliocene marly sandstones cover a large part of the north coast from Chania Plain to Kastelli and extend in the form of patches into the Tripolis limestones. The Chania marls belong to the Agios Georgios Formation. Neogene marls of considerable thickness occur also in the Varypetro area and belong to the Akrotiri Formation.

Holocene Deposits: they include mainly Pleistocene fluvial and colluvial terraces overlying Neogene deposits. They spread along the north coast from Chania to Kastelli. South of Chania there is an alluvial plain ranging in thickness (Moody 1987: 10). The Chania alluvium lies directly on top of Neogene deposits of the Akrotiri and Tavronitis formations. In the foothills there are occurrences in the form of pockets of alluvium at Akrotiri, but also in the vicinity of Platyvola (Kerameia basin) and Debla (the Varypetro alluvium). 


\subsubsection{The sites}

Chania: the site of Chania lies on the north of the coastal plain (Pl. 9). The Chania coastal plain is covered by $2-6 \mathrm{~m}$ of red alluvium. These recent sediments are bound by marly limestones to the north, south and west, by hard crystalline limestones to the south and southeast and by the Phyllite series to the east. For the most part they lay directly on top of Neogene deposits especially those of the Akrotiri and Tavronitis Formations. About $3 \mathrm{~km}$ west of Chania, outcrops of marls and marly limestones form the east side of the Galatas Highlands. These Neogene deposits belong to the Kissamos and Tavronitis formations (Moody 1987: 11).

Pleistocene fluvial and colluvial terraces overlie Neogene deposits. These terraces primarily occur along the major rivers. They are red and composed of conglomerate, sandy marl and clay. They are thought to be of torrential origin and may be equivalent of Vita-Finzi's "Older Fill" (Vita-Finzi 1969). In the Chania region this formation is best represented around the Alikianos basin. The alluvial sediments of the basin vary from brown to red and are bound by Pleistocene fluvial terraces on the south and by phyllite and Neogene formations on the north (Moody 1987).

Alluviation in the Chania plain is fairly recent and probably corresponds to Vita Finzi's "Younger Fill” (Vita-Finzi 1969). The alluvium was deposited around AD 400 and in parts it lies directly on top of Hellenistic and Roman walls, which locally rest on Neogene formations (Moody 1987: 26). This is rather important when discussing the geographical configuration of the Chania plain in Minoan times and the availability of raw materials for pottery manufacture.

Psathi: the site lies on a small promontory near the coast of Stalos, west of Chania (Pl. 10). The sediments of the area belong to the Kissamos formation and are of Miocene age. There are clays, sandstones and organic limestones rich in macrofossils reflecting near shore and deeper water environments (Dermitzakis et al. 1979). 
Nopigeia: the site lies on a small promontory near the north coast (Pl. 11). The bedrock consists of crystalline Palaeozoic limestones (marbles), sometimes dolomitic. There are occurrences of the Phyllite-Quartzite series too. In the vicinity there are Neogene marls alternating with marly sandstones and on the coast there are alluvial deposits.

Platyvola: the cave is situated in the Kerameia basin (Pl. 9). The bedrock consists of Palaeozoic and Mesozoic crystalline schists: phyllites, muscovitic, graphitic, sericitic quartzitic and chloritic schists. In places there are microcrystalline limestones, occasionally dolomitised. There are also pockets of marls and alluvium.

Debla: the site is situated on the summit of a foothill of the White Mountains in the Varypetro area (PI. 12). The bedrock consists of crystalline limestones. In the vicinity there are Pliocene marls as well as alluvial deposits of considerable thickness. There are also karstic depressions with terra rossa.

Nea Roumata/Mitatoulia: these sites lie south of Chania, at the foothills of the White Mountains (PI. 12). The bedrock consists of phyllites and shales, sandstones and layers of quartzites. Very close to Nea Roumata there are terraces of marine origin, especially in the valleys and outlets of gorges.

\subsection{Geological variation and ancient ceramics}

When studying ancient ceramics by thin section petrography, it is of importance to assess geological variation. Previous work in Central and East Crete demonstrated that pottery should not be presumed local unless geological prospection and clay sampling provide us sufficient information on local geology (Wilson and Day 1994).

Geological variation in Crete can be a factor that greatly enhances the potential of ceramic petrographic analysis. Different rock types and mineralogical and/or chemical variation compared with analytical results from related ancient 
ceramics can provide significant information on the exploitation and use of raw materials in the past. However, there are limitations to the potential of geological prospection. Although varied, the geology of Crete is quite repetitive and the same formations may occur in different places; moreover, when studying pottery the main parameter to be taken into consideration is that ceramics derive primarily (if not solely) from sites of pottery consumption (and not production) and what they represent are human choices in the selection of raw materials rather than local geology.

One part of the geological study encompasses the nature and provenance of the non-plastics, which occur in local pottery, while another part examines the nature of the clays available in the area under study. With regard to the latter, previous work in Crete has established in chemical terms three major compositional zones for the clays: the main characteristic of the West Cretan deposits is a variable, but primarily low, content in $\mathrm{Ca}$ which is due to the prevalence of the older metamorphic rocks of the $P-Q$ series (Jones 1986: 256). This is of interest when studying ancient ceramics since the analyses have shown that ancient potters use equally non-calcareous and calcareous clays, each for specific types of pottery (Wilson and Day 1994).

The picture of the Early Minoan pottery from West Crete, as drawn from petrographic observations, conforms to what would be expected in the geological background presented above. The non-plastics are associated with the PhylliteQuartzite series and the limestone/dolomite outcrops (Tripolis series). The size and density of the metamorphic rocks in the Early Minoan fabrics were considered to occur naturally in the sediment rather than being added as tempering agents (Moody 1987). However, this is not the case with the calcite fragments. Tempering with calcite appears to be a common practice during the EM I-IIA period in many parts of the island. In West Crete it is a rather widespread practice too.

As to the clays used, it is expected that a mixture of clays from red alluvial deposits and Neogene marls must have provided the base for pottery manufacture. 
Ethnographic and archaeological studies have demonstrated that the practice of clay mixing is very common; in some cases it is a calcareous and a non calcareous clays, whereas in cases of large storage vessels a grey phyllitic clay locally known as " $\lambda \varepsilon \pi \imath \delta \delta ́ \chi \omega \mu \alpha "$ (blade), might be added (Blitzer 1990: 682; Day 1991: 84).

From all the above it can be deduced that the Phyllite-Quartzite series and the Tripolis nappe might have constituted the main sources of non-plastics. As for the main clay body the deposits to be examined are the Neogene marls and the Pliocene alluvial red deposits. The problems and limitations of such a study rely on the fact that in West Crete the P-Q nappe dominates the entire south - western part of the White Mountains but also outcrops in many other parts of West Crete and the rest of the island, especially East Crete. In terms of its petrology, it is interpreted as a mélange; this means that it might be difficult or impossible to discuss provenance of raw materials on a regional level based on the nature of the metamorphic rocks. It is of importance, though, that it can be discussed on an island level; in East Crete the tectonic unit of the $\mathrm{P}-\mathrm{Q}$ series contains relatively high-grade metamorphic rocks with hornblende-epidote-plagioclase or garnet-kyanite-quartz-white mica associations (Seidel and Okrusch 1976), whereas the metamorphics in West Crete are low-grade with different combinations of minerals (see above). This differentiation allows the distinction between the same series in East and West Crete. Such differentiation is important when examining ancient ceramics, because it is not only indicative of provenance but it might also reflect human choices.

As to the Neogene marls, they are widespread near the north coast and it is probable that they were used in clay mixing. In this study, the examination of fossils in thin section and natural deposits could be of importance in the identification of types of sediments used as raw materials for pottery manufacture. The presence of a modern brick factory in Agia Marina is indicative of the availability of such suitable clay deposits.

With red soils, the situation is more complicated. It must be taken into account that the extensive alluvium in the Chania plain was deposited around AD 
400, i.e. in Roman times (Moody 1987: 26), and, therefore, the landscape must have been quite different in Minoan times. However, the geological background of the area does not change, and, even if the extent and the thickness of the deposits were different, their nature and composition remain the same. There are indications of earlier phases of alluviation, which date to the early Bronze Age (Moody 1987: 31 ), but they should be looked for elsewhere, probably in the form of pockets of red alluvium, widespread in different parts of the west Cretan landscape. Then it is a matter of sampling and analysis to investigate whether the different red deposits are discernible.

\subsection{Clay sampling and experimental briquettes}

The clay sampling carried out in West Crete had restricted aims and extent due to limitations of time. The objective was not to replicate ancient clay pastes but to clarify certain aspects of the geology of the area related to the ceramic fabrics. Two seasons of clay sampling were carried out. The first was before the petrographic analysis of the archaeological material and aimed at investigating the composition of different types of sediments, namely red deposits and Neogene marls. The second was carried out after the examination of the archaeological samples under the petrographic microscope, when it was clear most fabrics were site-specific, but also were similar in their basic petrological composition. Therefore the sampling focused on the investigation of deposits near and around the sites that were studied, in order to examine the variability between similar types of clays and, therefore, explain the variability in pottery fabrics.

\subsubsection{The red deposits}

The types of red deposits sampled are mainly of alluvial origin but there are also pockets of terra rossa and deposits of weathered limestone. The former occur primarily along the north coast and the deposits sampled include the alluvium south 
of Chania on the road to Mournies, the Platanias alluvium on the coast near Psathi and Agia Marina, and alluvial deposits near Nopigeia. The deposits of terra rossa, as well as the deposits of weathered limestone, occur mainly in karstic depressions on the Akrotiri Peninsula. This happens because the Plain of Chania is covered with the recent alluvium, whereas in Akrotiri there are relic soils of previous phases (Moody 1987).

The deposits sampled are presented here from east to west:

Akrotiri: in this area two samples were collected: one from the Tripolis weathered limestone (S7/2001; Pl. 9, 13a), which outcrops largely in the north - northwestern part of the peninsula. The sample was taken $1 \mathrm{~km}$ south of the airport (near the modern village of Kathiana). The second sample derives from a pocket of Quaternary terra rossa (S8/2001; Pl. 9), 500m west of the Agia Triada Monastery at the northernmost edge of the peninsula.

Chania: several samples derive from this area. There is one from the alluvial plain south of the modern town of Chania (S6/2001; P1. 9, 13b, c) on the modern road Chania-Mournies. Other samples derive from alluvial deposits along the north coast. Near Chania and at $2 \mathrm{~km}$ south of Psathi a red deposit was sampled originating from an alluvial terrace (S2/2001; P1. 9, 13d). Further west, in the area of Agia Marina an alluvial deposit was sampled (S15/2001; P1. 9, 13e).

Debla: the archaeological site is located on top of the highest summit in the area of Varypetro, south of Chania. The closest areas for clay sampling are the alluvial deposits of the Varypetro plain (S10/2001; Pl. 12, 14a,b), the Quaternary red formations at the base of Kastellos hill (S12/2001; Pl. 12, 14c) and the recent alluvial deposits south of the Agia Kyriaki Monastery (S9/2001; Pl. 12, 14d,e).

Nea Roumata/Mitatoulia: the tomb of Nea Roumata and the settlement of Mitatoulia are located in an area dominated by phyllites. The only red sediments available are terraces of torrential origin in the outlets of gorges. A small deposit probably of recent alluvium was sampled on the road leading from Nea Roumata to Chosti 
(S7/2000; Pl. 12, 15a,b) as well as a deposit on the road from Prases to Agia Eirini (S9/2000; PI. 12, 15c,d) south of Nea Roumata.

On the road from Nea Roumata to Prases a deposit of grey phyllitic sediment was also sampled (S8/2000; Pl. 12, 15e,f).

Nochia: this is a modern village, which had a lively potting tradition until the 1950's and ceramic production was greatly enhanced in the last years. A single sample was taken from a field in the middle of an olive grove (S6/2000; $\mathrm{Pl} .10)$ since this was the area indicated by a local potter where clay was mined. The main ceramic type of the village was (and is still produced) a water jar (Vallianos and Padouva 1986: 2223), which, according to the same potter, was the only vessel manufactured without any clay mixing. Although the clay mine used at the time was 2-3 meters below surface level, a single sample was taken in order to acquire some information of the composition of the sediments in the area.

Nopigeia: red deposits in the broad area of Nopigeia were sampled in three locations. A road cut on the north coast, between Kolymbari and Kissamos (near the modern village of Melissourgeio) (S1/2000; Pl. 10, 16a,b); this sample represents mixed deposits of weathered phyllite and marly limestone. The second sample was collected in the area south of Nopigeia near the modern village of Kaloudiana (S2/2000; P1. 11, 16c,d) representing the weathered limestone deposits. The third was collected also from a road cut on the north coast at the base of the Rodhopos peninsula (S5/2000; Pl. 11, 16e,f) representing a mixed deposit of weathered limestone and phyllite. Two more samples were taken from a road cut within Kastelli, on the way to the port (S3/2000 and S4/2000; Pl. 11, 17a,b). They represent the alluvial deposits of the area.

\subsubsection{The Neogene marls}

As was the case for the red deposits, the clay sampling of the Neogene marls aimed also at investigating the variability of the different deposits in West Crete. 
The work focused primarily on the formations on the north coast around Chania where the main body of marl deposits occurs. More specifically, the following deposits were sampled:

Chania: The deposits of the north coast west of Chania include the Platanias marls of the Neogene. One sample derives from the marls south west of Psathi (S1/2001; Pl. 9, 18b), two samples from a single section in the area of Agia Marina: the lower marl is finer grained, harder and contains very few inclusions (S3/2001; Pl. 10, 18c, d), the upper marl contains more inclusions and fossils (S4/2001; Pl. 10, 18e,f). One more sample was taken from the area, namely a grey clay from a deposit near the modern church of Agia Marina (S11/2000; PI. 10). Moreover, the marls south of Chania on the road from Mournies to Kerameia were sampled, right after the modern village of Vantes (S14/2001; Pl. 9, 19a,b). Finally, east of the modern town the marly sandstone of the Pliocene was sampled containing microfossils and molluscs (S13/2001; Pl. 9, 19c, d).

Nopigeia: east of the site and not far inland from the north coast, a deposit of Neogene marls was sampled (S5/2001; Pl. 11, 19e,f). It belongs to the Platanias Formation and is similar macroscopically to the deposit at Chania, where sample S3/2001 was taken and which belongs to the same formation. Although multiple sampling was beyond the scope and the potential of this limited clay prospection, sampling the Platanias marls at Chania and Nopigeia would provide an insight whether the same formation presents compositional variation.

Debla: the closest area for clay sampling for marls or marly-like sediments is the Pliocene deposits in the area between Debla and Kastellos hill (S11/2001; PI. 12, 18a).

\subsection{The petrology of the clay samples}

The methodology of manufacture and firing of the experimental briquettes is explained elsewhere (Chapter 3). Thin sections were manufactured from the 
briquettes, examined under petrographic microscope and grouped according to their composition and texture, in the same way as the ceramic thin sections. The groups confirmed what was suggested by the petrographic analysis of the archaeological material, i.e. that the textural variability in pottery fabrics reflects textural variability in the raw materials. An extensive project of multiple clay sampling in Central and East Crete within GEOPRO TMR Network demonstrated that there might be significant variability within and/or between sources and, therefore, it is not a straightforward procedure to assign provenance of archaeological samples to specific clay sources (Hein et al. in prep). A similar study in West Crete in the future would provide interesting information on the composition of the different deposits and their variation within and between sources.

The results of the petrographic examination of the geological samples are presented below.

\subsubsection{The red clays}

Group 1: Red with carbonates (S12/2001, Pl. 20a)

This group has a red-firing matrix and coarse inclusions, some of which are typical constituents of red clays, others are primarily found in marls. There are fragments of carbonate rock, calcite, biotite mica, some chert and metamorphic rock fragments, set in a red matrix. This clay derives from the red formations at the base of the Kastellos Hill, close to Debla. These deposits are of torrential origin and consist of sandy marls, clays, sandstones and conglomerates.

Group 2: Fine, quartz-rich with pellets and metamorphic rocks (S7/2001, Pl. 20b; S10/2001, Pl. 20c)

This group has a naturally fine-grained, red-firing matrix. It consists primarily of small quartz fragments set in the fine matrix, but there are also many clay pellets, biotite mica, metamorphic rock fragments and some siltstone (in 
S7/2001). The first sample derives from a deposit of weathered Tripolis limestone on the Akrotiri peninsula. The second belongs to the red formations of Varypetro, which are of the same torrential origin as those of Group 1, but without the carbonates.

Group 3: Semi-coarse, quartz-rich (S6/2001, P1. 20d; S2/2000, Pl. 20e)

This group has a red-firing matrix with medium-sized quartz fragments, metamorphic rocks, biotite mica and clay pellets. The first sample derives from the alluvial deposits south of Chania, the second from the weathered limestone on the road from Kissamos to Kolymbari. The compositional similarity between the two deposits can be explained by the fact that the alluvium derives from the weathering and transport of limestone.

Group 4: Coarse, quartz-rich with metamorphic rocks (S5/2000, PI. 21a; S7/2000, Pl. 21b; S9/2000, Pl. 21c; S11/2001, Pl. 21d; S1/2000, Pl. 21e)

This group has a coarser texture but is compositionally similar to Group 3. It contains large fragments of metamorphic rocks, angular quartz, biotite mica and clay pellets. The first sample derives from the base of the Rodhopos peninsula representing a mixed deposit of weathered phyllite and limestone. Samples S7/2000 and S9/2000 derive from the broad area around Nea Roumata and represent alluvial deposits. Sample S11/2001 derives from the Pliocene deposits in the area between Debla and Kastellos hill with conglomerates and marly limestones. These samples demonstrate that material deriving from different types of sources can be quite similar in composition, something also reflected in the composition of the archaeological material.

Finally, sample $S 1 / 2000$, although compatible with this group in its general characteristics, presents a slight differentiation. It derives from a phyllitic deposit on 
the road to Kissamos and differs from the rest in that it contains a large amount of phyllitic material and does not have the red clay matrix of the other samples.

Group 5: Coarse, quartz-rich (S2/2001, Pl. 22a; S8/2001, P1. 22b; S15/2001, Pl. 22c; S14/2000, Pl. 22d)

This group is characterised by well-sorted quartz fragments in a red matrix. There are also a few fragments of metamorphic rocks and some chert. Sample S14/2000 is very close to this group but it contains some carbonate rocks. All these samples derive from the Quaternary alluvial deposits around the area of Chania.

Group 6: Chert-rich (S3/2000, Pl. 23a; S4/2000, Pl. 23b)

This group is characterised by the presence of large angular chert fragments in a fine red matrix. Some of the chert inclusions grade into mudstone. The other constituents are small and medium-sized quartz fragments, clay pellets, a few metamorphic rocks and occasionally sandstone and siltstone fragments. Both samples derive from the same type of deposit in Kastelli (Kissamou). It is among the few cases where it had been possible to assign provenance of ceramic fabrics on geological grounds with a degree of certainty. This type of chert occurs in several of the fabrics at Nopigeia confirming this pottery is of local origin.

Group 7: Grey clay (S8/2000, Pl. 23c)

This sample is characterised by high packing of phyllite fragments. This type of deposit in the broad area of Nea Roumata was sampled because it seems to be used as temper in some fabrics. 


\subsubsection{The marls}

Group 8: Semi-fine with fossils (S1/2001, P1. 24a; S6/2000, Pl. 24b)

This group has a semi-fine texture and is composed of quartz, carbonates, clay pellets, biotite mica, fossils and a few fragments of metamorphic rocks. Sample S1/2001 derives from the Platanias marls near Psathi and this composition was expected. Sample $\mathrm{S} 6 / 2000$ is the one collected from the field at Nochia, but it needs further sampling in order to get a representative picture of the composition of the sediments in the area.

Group 9: Fine with carbonates and fossils (S11/2000, Pl. 24c; S4/2001, Pl. 24d; S9/2001, Pl. 24e; S14/2001, Pl. 24f)

This group has a finer groundmass but is quite similar in composition to Group 8. It is composed of quartz, clay pellets, carbonates, fossils and biotite mica. Samples S11/2000 and S4/2001 derive from the Platanias marls on the north coast. Sample S14/2001 is from the marls south of Chania and, although it was grouped with the rest of the marls due to compositional similarity, it contains more calcite and large carbonate rock fragments. This might be indicative of an alluvial origin, and considering that it was collected from the alluvial plain of Chania, it might represent the redeposition of Neogene material.

Sample S9/2001 derives from the deposits nearby the Agia Kyriaki monastery. These deposits are red and were expected to display compositional similarity with related alluvial deposits. However, the result was a marly clay with carbonates and fossils which can be explained by the fact that the area lies right on the contact between the Pliocene marls and the older Quaternary red deposits both containing conglomerates. It is, therefore, possible that the red sediment sampled was a mixture of a marl and a red alluvium. 
Group 10: Very fine with carbonates (S3/2001, Pl. 25a; S5/2001, Pl. 25b)

This group is similar to Group 9. It is from the lower part of the marl deposit at Agia Marina, which was sampled in two occasions (Agia Marina and Nopigeia) and, as expected, displays the same composition. It is finer than the upper part and contains carbonates, quartz, mica and smaller amount of fossils.

Group 11: Marly sandstone (S13/2001, P1. 25c)

This sample is quite different from the rest since it derives from a deposit of marly sandstone. Its main constituents are carbonate rock fragments, some quartz and mica and only a few fossils.

\subsection{Discussion}

This brief presentation of the geology of Crete, and more specifically of West Crete, aims to stressing two points. Firstly, that the geology of the island is varied when examining a restricted area but at the same time is repetitive on an island-wide scale. This means that, although there could be outcrops of many different rock types in a geographically small area, they are regularly repeated across the island. The second point is that the geological background of West Crete is homogeneous and dominated by the Phyllite-Quartzite and the Tripolis limestone series as well as specific types of sediment deposits (namely marls and alluvium).

The study of geological variability in an area might provide significant information within the confines of the study of ancient ceramics by petrography. In this case, the clay sampling was "designed" according to the questions that derived after the study and petrographic examination of the ceramic assemblage from West Crete. The deposits sampled were red sediments (in most cases of alluvial origin) and Neogene marls, i.e. those that, according to the archaeological and ethnographic literature, were possibly related to EBA pottery manufacture. 
It is difficult to assess geological variation in West Crete because the parent materials are the same all across the western part of the island and the different sediment deposits are macroscopically similar. By examining such similarity by petrography, it was feasible to evaluate the first results from the petrographic study of the archaeological samples. The variability of the ceramic fabrics seems to reflect variation in the geology and the raw materials.

The Neogene marls were found to be very similar in composition all along the north coast and in the plain south of Chania, but there are specific components that might be different in the various outcrops, such as the amount of micrite and fossils. The only sample where there was clear differentiation was the marly sandstone from the area east of Chania.

A similar situation is encountered with the red sediments, although these deposits are more variable in origin and composition than the marls. The main types of deposits are of alluvial origin, as well as weathered limestone and pockets of terra rossa. Their main constituents are quartz, biotite mica and metamorphic rock fragments, all related to the geological background of the area.

Clay sampling was not intended to replicate fabrics and is far from exhaustive in order to evaluate the magnitude of the variability. The results presented in this chapter are indicative of the potential of and the need for a more systematic clay sampling. However, the present data are sufficient, if not to assess geological variation per se, at least to indicate the importance of the human agent in the production of the EM pottery. By obtaining a general idea of the natural variation of the clay deposits and what is available in terms of raw materials, it is easier to apprehend the choices of prehistoric potters and interpret human behaviours. 


\section{TABLE II}

\section{Stratigraphic Scale \\ (after Dermitzakis and Georgiades-Diakaioulia 1981)}

\section{Cenozoic}

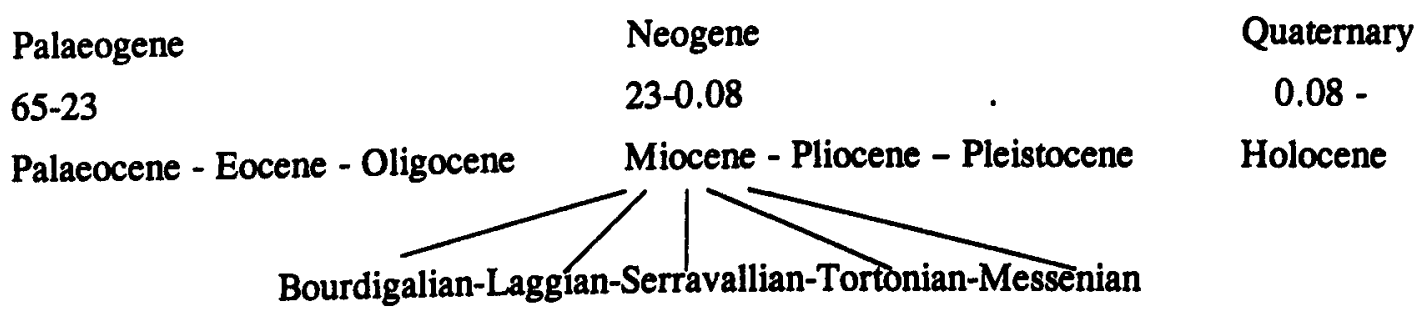

$\underline{\text { Mesozoic }}$

$\begin{array}{ccc}\text { Triassic } & \text { Jurassic } & \text { Cretaceous } \\ 230-195 & 195-140 & 140-65 \\ & \text { Liassic-Dogger-Malmian } & \text { Lower-Upper }\end{array}$

Palaeozoic

$\begin{array}{ccccc}\text { Cambrian } & \text { Silourian } & \text { Devonian } & \text { Carboniferous } & \text { Permian } \\ 600-500 & 500-400 & 400-340 & 340-280 & 280-230\end{array}$

Note: Only the eras and epochs mentioned in the text figure here. The numbers represent approx. ages in my. 


\section{CHAPTER 5}

\section{Early Bronze Age pottery from West Crete}

\subsection{Introduction}

The study of Prepalatial pottery has gone through different phases, from the construction of chronological sequences to ware- and fabric-based studies. Until the mid 1980's, typological classification constituted the focus of study and was based on shape and decoration. In his exemplary publication of the settlement of Myrtos Fournou Koriphi, Warren (1972) grouped the assemblage according to shape but he was the first to include information on fabric. Wilson's (1985) presentation of the pottery from the West Court House at Knossos followed a more integrated approach, combining ware and fabric. In this way, he managed to characterise the pottery, define the local wares, and identify possible non-local wares and fabrics. This work opened the way for a more integrated approach involving analysis, in order to explore the questions of local versus non-local wares in the Prepalatial.

More recently, stylistic information and macroscopic fabric observation have been combined with thin section petrography and scanning electron microscopy (SEM) in order to characterise the macroscopic fabrics and discuss provenance and technology (Wilson and Day 1994). At a second level, issues of pottery production have been addressed and it has been demonstrated that ceramic production at Knossos had reached a significant level of technological sophistication since this early date. Moreover, it was demonstrated that the identification of local sequences is very important for the understanding of pottery development and the establishment of local chronology, especially in cases such as the EM, where there are significant typological differences between contemporary assemblages from different regions (Wilson and Day 1994: 3). 
A similar approach has been applied to the present study. In general, West Crete seems to follow the rest of Crete in terms of chronology of the pottery and the repertoire of shapes and wares. However, the ceramic assemblages present certain consistent stylistic particularities, which range from local adaptations of known types to shapes that occur rarely in the rest of the island. The scarcity of publications (with the exception of Warren and Tzedakis 1974; Karantzali 1997; Mytilineou 1997-98) and the lack of a synthetic approach to the development of the Early Minoan pottery in West Crete make the establishment of a secure chronological and typological sequence difficult. In what follows, the main ware types that occur in West Crete will be presented, followed by a presentation of the pottery assemblages from each site separately. When possible, comparison with similar wares from the rest of the island will be made. Finally, there will be a discussion of ceramic shapes that present special interest ${ }^{1}$.

\subsection{FINE - SEMI-FINE WARES}

\subsubsection{Dark grey burnished ware (DGBW)}

This ware is characterised by a semi-fine fabric and a dark grey to black burnished surface. The burnishing may cover the exterior and/or interior of the vessel, depending on whether the vessel is open or closed. Occasionally pattern burnishing occurs (NOP 00/50). The dark grey burnished ware dates from EM I to EM IIA and occurs in almost all the sites under study (except for the material studied from Psathi). However, its representation in the assemblages is quite small, compared to other wares and to the occurrence of DGBW in the Central Cretan assemblages.

The most common shapes for the EM I period are pedestalled chalices (PI. 26) and bowls. The EM IIA shape repertoire comprises bowls with flat bases and outurned rims, stemmed goblets, and one bowl with scoring and pellet feet. Vessels

\footnotetext{
${ }^{1}$ This chapter provides only an introduction to and a brief description of the West Cretan ceramic assemblages. The terminology used is largely based on published assemblages from Central and East Crete and does not constitute the outcome of a systematic typological classification, although there has been a structured study prior to sampling (see Chapter 3, 3.3.1). The permits available cover only sampling for scientific analysis and not typological study of the material. The rights for study and publication of the pottery remain with the excavators.
} 
that occur in both periods are deep bowls and goblets, jars and jugs, and one lid with pellet foot. It seems that the development of dark grey burnished ware in West Crete follows the pattern of the rest of the island: in EM I there are large open vessels, which in EM IIA are replaced by goblets, flat-based jugs and bowls. This change has been interpreted to represent in Central Crete the shift from ceremonies where use of communal vessels occurred, to practices where shapes for individual consumption are necessary (Wilson and Day 2000: 27; Day and Wilson 2002).

It is of interest to notice the co-existence of dark grey burnishing with characteristics that occur in other wares, such as scoring, flat bases and pellet feet. This is indicative of an attempt to adapt a ware, which probably originates from other parts of the island (i.e. Central Crete), with wares that are more common in West Crete such as scored and dark burnished. This phenomenon of appropriation of pottery types by adding familiar elements is not unique to DGBW. It characterises the EM IIA period in West Crete and it occurs also in other wares such as the black slipped. It has been observed in Central Crete in scored, dark-on-light and DGBW (Wilson and Day 2000).

\subsubsection{Dark burnished ware}

This name is used for vessels with a red, reddish-brown to black burnished, and sometimes slipped surface occasionally with mottling (Pl. 27). The fabric is semifine to semi-coarse and the surface treatment consists of simple burnishing or in some cases of pattern or scribble burnishing. The burnishing may cover the interior, the exterior of the vessel, or both. This ware dates from EM I to IIA and occurs in Kastelli, Chania town, Platyvola, and Debla but not in Psathi or Nopigeia.

The most common shapes for the EM I period are pedestalled bowls, chalices and jars, which are also found in other contemporary sites in Crete, as well as small and coarse bowls. These vessels are black or red-brown burnished, sometimes slipped or mottled. In the EM IIA period there are red or black burnished and occasionally scribble burnished shallow bowls, jugs with pellet feet, lids. Shapes that occur in both 
periods are shallow and deep bowls, jugs, jars and lids, black burnished or red slipped and burnished and occasionally red scribble burnished.

\subsubsection{Dark burnished incised ware}

In this ware are included a group of pyxides (Pl. 28), which occur in most West Cretan sites such as Debla, Platyvola and Perivolia (Mameloukou Trypa) (Warren and Tzedakis 1974: Plate 55d; Tzedakis 1967a: Plate 378a; Tzedakis 1968a: Plate 376b) as well as Mitatoulia. This fabric is semi-coarse and the surface of the vessels is black or reddish-brown burnished. Often there are tubular lugs, horizontal or vertical, and the decoration consists of incised horizontal, vertical or diagonal lines, herring-bone, hatched triangles and banding. In the same category belong black burnished lids of pyxides, with incised decoration (Warren and Tzedakis 1974: 32830).

\subsubsection{Black slipped ware}

This ware is characterised by a semi-fine to fine fabric and the application on the interior, and/or exterior of the vessel of a black slip, which occasionally shows signs of burnishing (Pl. 29). In general, this ware is high-fired and sometimes the surface is mottled. In stylistic terms, the shapes are closer to the EB II repertoire; in West Crete this ware occurs with other typically Minoan EM IIA material in sites such as Debla, Nopigeia, Chania and Psathi. Although the material examined does not derive from well stratified contexts, there are shapes (namely the saucers) that continue in EM IIB. Typologically the vessels belong to two categories: the shapes that are closer to Helladic prototypes and the Minoan shapes, as known from different sites in Central and East Crete. The term used in the present work for these vessels is "Helladicising" (or Cycladicising) as opposed to "Minoan". However, the amount of this type of material in West Crete makes this term inappropriate, because it is not just the case of a few vessels imitating a non-local style, but occurs at most sites in West Crete and in considerable amounts. Due to the lack of publication, the West 
Cretan sequence of wares and shapes is fragmentary and terminology is not well established. Therefore, the terms Helladic/Helladicising will be used in order to facilitate our understanding.

In the Helladic part of the assemblage, the main shapes represented are collarnecked jars, sauceboats with low-pedestalled foot (Pl. 29a,b), ring-based saucers and askos-like jars, occasionally with double-barrelled handles. Parallels of these shapes have been found at Kythera (Coldstream and Huxley 1972), the Mainland (for Lerna and other sites see Wiencke 2000), Attica (for Raphina, see Theocharis 1952, for Agios Kosmas, see Mylonas 1959, for Rouph, see Petritaki 1980), and the Cyclades (for Agia Irini, see Wilson 1999) ${ }^{2}$. Most of the black slipped vessels are high-fired, the slip is carefully applied and occasionally burnished in order to give a shiny appearance, which is reminiscent of the Urfirnis slip (see Wiencke 2000 for the material from Lerna). Due to uneven firing there can be mottling on exterior or interior.

In the Minoan part of the assemblage, the most common shapes are different types of goblets, jugs with herring-bone incised decoration on the shoulder (PI. 29c), and small jars. The date is primarily EM IIA but seems to extend into the later phase of the period or perhaps EM IIB, especially with types like spouted jars (KST 00/7879), deep and shallow bowls. The mottled vessels occur in EM IIA shapes and may also be present in later EM II.

The black slipped ware occurs in most of the sites that have been studied, namely Kastelli, Chania Town, Platyvola, Debla and Nopigeia. It is of interest that it does not occur in the material examined from the broader area of Rethymnon, i.e. the sites of Stavromenos and Eleutherna.

\subsubsection{Red/Black slipped ware}

This ware is quite different from the Black slipped ware in the coarseness of the fabric and the surface treatment. In general, it is characterised by a semi-coarse to

\footnotetext{
${ }^{2}$ The main West Cretan shapes of the black slipped ware with parallels and comparatives are discussed
in paragraphs $6.1-6.8$ of the present chapter.
} 
fine fabric, but there are also a few coarse vessels. Surface treatment may vary from a red wash to a red burnished/polished slip on exterior, which often can be mottled (Pl. 30). There is only a small proportion of the assemblages with black slip and occurs mainly at Psathi (Pl. 31). This ware has been identified in Knossos in the EM IIA West Court House deposits (Wilson 1985: 312-17) and in EM IIB (Momigliano and Wilson 1996: 32-8; Wilson and Day 1999: 18-25). In West Crete, this ware is also represented in the EM IIA, with the early material from Debla (such as the red slipped jugs, see Warren and Tzedakis 1974: 326-7, P11-13) and in EM IIB, particularly at Chania.

The West Cretan shape repertoire comprises both Helladic and Minoan shapes. In the former are included vessels similar to those occurring in the black slipped group such as sauceboats, saucers and askoi. Typologically they are similar to their black slipped counterparts but they are larger, with thicker walls and in different fabrics.

Red/Black slipped ware is quite abundant and the Minoan-style vessels occur in all the sites. The repertoire of shapes during EM IIA comprises shallow bowls, jugs with pellet feet or cutaway spout, goblets, pyxides as well as some large coarse vessels such as jars or pithoi. More specifically, at Kastelli there are goblets with low pedestal foot, similar to the Knossian examples (Day and Wilson 2002 - KST 00/53, 54). In the EM IIB there are goblets (often mottled), deep bowls and side-spouted jars. They are represented in many sites such as Platyvola, Kastelli, Chania Town and Psathi.

\subsubsection{Dark-on-light painted ware}

This ware is largely represented in North and South Central Crete as well as East Crete and has been studied and analysed in extent (Wilson 1985; Wilson and Day 1994). It ịs characterised by a fine fabric and the application of dark painted decoration on a buff background. It appears in EM I (for the Palace Well, see Hood 1990b, for Knossos, see Wilson and Day 2000: 33-39) and continues in EM IIA (Wilson 1985: 319-30). 
In West Crete, it is very rare. There are only a few examples and they consist mainly of large, coarse or semi-coarse vessels (Pl. 32a). In their majority they are collar-necked jars or shallow bowls with inturned rim and an applied thick calcareous slip on the surface; in rare cases they have black paint on top of the slip. There are also jars and jugs, the latter with cutaway spout, and decoration of painted bands or vertical stripes. Several of the jugs have attached pellet eyes.

In most sites, there are some examples of dark-on-light painted ware, except for Nopigeia. It is of importance that the d-o-l examples from Kastelli and Platyvola are very close to the unpainted or simply slipped vessels of the assemblages.

\subsubsection{Fine grey ware (FGW)}

This ware, which appears at several sites in Central and East Crete (Warren 1972; Wilson 1985: 304-7; Wilson and Day 1994), is rare in West Crete. Wilson and Day (1994: 22) identify two possible examples of this ware in Platyvola (Tzedakis 1968a: 415-16, PI. 376b) and two possible examples in Debla (Warren and Tzedakis 1974: 326-8, P20 and P21) but it is clearly stated that these vessels do not match the shape repertoire of Central Crete.

Close examination of the vessels from Debla showed that P20, which is identified by the excavators as a goblet on a small pedestalled foot, is a sauceboat (DEB 00/32) and that both P20 and P21 (cylindrical lid) are in a grey soft fabric but do not belong in the FGW tradition. It seems that they were initially black slipped, as is the case with similar vessels in other West Cretan sites such as Kastelli and Platyvola.

The only other site where FGW is mentioned is the Cave of Lera, from where a pyxis and a small globular vase are reported (Guest-Papamanoli and Lambraki 1976: 204, fig. 7, D17, D18). However, the comparatives from Platyvola given for this material do not seem relevant either in shape and size or decoration. Moreover, the date of D18 was challenged in a later study being considered closer to Final Neolithic examples (Vagnetti et al. 1989: 86). All this makes it evident that, even if 
this ware is labelled "fine grey", it is totally different from what is known from Central Crete under the same name.

\subsubsection{Mottled ware}

Mottling is a common effect in West Cretan pottery but Vasiliki ware in its canonical form as known from East Crete (Betancourt et al. 1979) is rather rare. There are a few examples in West Crete which are referred to as being proper Vasiliki Ware. These sites include the caves of Platyvola (Tzedakis 1967a: 505), Perivolia (Tzedakis 1968d) and Lera (Guest-Papamanoli and Lambraki 1976: 204) (P1. 32b,c). The shapes represented are jugs, goblets and spouted jars respectively. However, the mottling effect appears in West Crete in EM IIA and continues throughout the EM IIB period.

\subsection{SEMI-COARSE - COARSE WARES}

In this category belong different wares comprising vessels with semi-coarse or coarse fabric and different types of surface treatment and/or decoration. The main wares presenting a fine and a coarse component are the red slipped and the dark grey burnished/incised ware, whereas the main wares in coarse fabric are scored and cooking pot wares.

\subsubsection{Scored ware}

This ware has been identified as "a monochrome pottery with a scored surface, (which) is most common in West Crete" (Betancourt 1985). It constitutes a dominant component of all West Cretan assemblages (P1. 33) but it is also present across the island in varying quantities. It is an introduction of the Early Minoan period and has no precursor in the Neolithic (Wilson and Day 2000: 51). In West Crete surface treatment consists of heavy scoring (which seems to be a characteristic mainly of EM I) and occasionally the application of red slip. Scoring can be vertical, diagonal, horizontal or combined. The most common shapes are globular jugs and 
collar-necked jars and they are found across the island (for Knossos, see Wilson and Day 2000: 39; for Palace Well, see Hood 1990b).

More specifically, in West Crete, there are numerous representatives of scored ware in all the sites studied: jugs with and without slip, deep bowls with diagonal scoring, large open bowls, lids/plates, storage jars with applied horizontal ridge below rim, pithoid jars with applied cordon and pithoi (for published examples, see Warren and Tzedakis 1974 for Debla; Alexiou 1964 for Platyvola; Guest-Papamanoli and Lambraki 1976 for Lera; Tzedakis 1968d for Perivolia).

In Central Crete the technique of heavy scoring is rarely practiced and surface treatment consists of wiping and washing. The main differences between the West Cretan scored and the Central Cretan wiped and washed ware relate to the coarseness of the fabric and the treatment of the surface. The West Cretan examples are coarser and scoring is deeper than wiping. Moreover, in West Crete, there are examples without any other form of surface treatment but scoring, whereas in the Central Cretan examples wiping is combined with the application on the surface of wash or slip (Wilson and Day 2000: 39).

In terms of date, wiped and washed ware characterises the EM I period and does not continue in EM IIA (Wilson and Day 2000: 39). In West Crete scoring occurs throughout the Prepalatial period and possibly later (Moody 1987). Heavily scored ware has been used for the relative dating of sites, since it is diagnostic of the EM I (see Warren and Tzedakis 1974: 323 for Debla). It is important that when the globular jugs of the EM changes and during the EM IIA acquire thick red slip, flat bases and pellet feet, scoring remains the prevailing type of surface treatment. It seems that scoring constitutes a West Cretan tradition that persists despite other morphological changes. That is the reason why it occurs throughout the Prepalatial period and links with other wares, namely the red slipped and the cooking pot wares. 


\subsubsection{Red slipped ware}

This ware is represented in semi-coarse to coarse vessels and combines in many cases scoring with the application of a red slip. The predominant shape is the globular jug in a red, high-fired fabric with applied red slip, which occasionally can be burnished. The best example linking jugs with red slipped ware is an EM IIA example from Platyvola (PLT 00/8) which is red slipped on exterior and the inside of neck is scored. Red slipped jugs have occasionally pellet feet (see Debla, Warren and Tzedakis 1974).

There are also other coarse vessels, such as globular deep bowls and basins with scoring on exterior and red slip on interior, exterior or both.

\subsubsection{Cooking pot ware}

This term has been used to describe a ware in a characteristic fabric rather than to suggest culinary function of the vessels (Wilson 1985: 332). The fabric is semi-coarse to coarse, reddish to dark brown and contains large angular white inclusions (calcite); at times it is also chaff-tempered (Wilson 1985: 332-33). The shapes represented serve domestic functions and the West Cretan repertoire consists mainly of deep bowls and jars, most of them with diagonal scoring on exterior. There are also baking plates, basins/lekane, tripod legs, deep bowls with thickened or flaring rim, jars with T-shaped or thickened rims, shallow bowls with everted or thickened rims, and hearth rims with Kerbschnitt decoration (Pl. 36b).

Cooking pot ware is represented in Knossos with vessels bearing a heavily wiped/scored exterior surface. The main shapes are deep bowls/open jars and baking plates, which appear in EM I but continue in EM IIA, the latter being less heavily wiped (Wilson and Day 2000: 43). In West Crete cooking pot ware is in most cases associated with scoring and is represented throughout the Prepalatial period. 


\subsubsection{Pithos Ware}

In this ware are included coarse, thick-walled pithoi and jars. Like in other West Cretan wares, there is a strong "non Minoan" component consisting mainly of vessels with calcareous slip and applied ridges or bands below the rim, which is an EB II characteristic occurring mainly in the Cyclades (for Agia Irini, see Wilson 1999: 46-47, PI. 12: II-319, 320, 322; for Thera, see Sotirakopoulou 1999: 148-49, PI. 140: 139). Other decorative motifs consist of applied cordons, impressed rope patterns and finger impressions.

The Minoan component of this ware comprises pithoi and pithoid jars in an orange to red fabric, mostly tempered with organic material or calcite. Pithoi and jars might have a ledge rim or an externally and/or internally thickened rim. In terms of surface treatment, a red slip is often applied and decoration consists of applied ridges or bands under the rim. Chronologically this ware appears in EM I and extends into the EM II period. Except for specific cases where decoration is the indicator of chronology, the absence of well-stratified contexts does not allow date pithoi with more precision.

\subsubsection{Other coarse wares}

In this category are included vessels in a red, semi-coarse fabric, characterised by small, white, calcitic inclusions. This fabric has been identified only at Chania and Platyvola and it the main vessels represented are collar-necked jars, jugs, pushedthrough handles and bowls. The vessels do not bear any decoration, except, in the cases of the collar-necked jars, a white slip.

This category comprises also coarse vessels from all the sites that do not bear any surface treatment and cannot be included in the other categories. 


\subsection{The Pottery from the Sites}

In this section, the pottery assemblages from the sites that have been studied are presented. The ceramic material is classified according to the wares established previously. In cases where publications are available and where the classificatory system is different, the presentation of the material is still according to wares, with reference to the publication. The different ware types from West Crete are discussed chronologically and in comparison to the rest of the island. Finally, the major vessel shapes are discussed, with emphasis on their stylistic development and their meaning in the Prepalatial period.

\section{The Sites}

\subsubsection{Debla}

The excavation

The assemblage from Debla is one of two fully published ceramic assemblages from West Crete (the second being that from Nopigeia) and the only one deriving from a systematic excavation (the others derive from stratigraphic soundings or rescue excavations). The study of the ceramic material from the site was carried out according to stratigraphic levels; its classification was mainly typological with emphasis on shapes, fabric and surface treatment (Warren and Tzedakis 1974). The excavators identified three phases for the prehistoric material:

Phase I comprises material from deposits above bedrock and below the floor of Building I. There is a predominance of red slipped scored ware (PI. 33a) which is characteristic of EM I levels in other sites too (Kastelli, Platyvola, Perivolia and Lera Caves). There are also examples of coarse ware, dark burnished ware (PI. 27a) and black slipped ware, which the excavators refer to as light grey ware (Warren and Tzedakis 1974: 321-3). 
Phase II comprises material from the floor deposit of Building I; thirteen vases were found, among which nine lightly burnished jugs with pellet feet (Pl. 31a,b), same coarse ware and scored or chaff-tempered vessels. There are also a few examples of grey ware and some fragments of incised pyxides. According to the excavators, the fabrics of Phases I and II are identical (Warren and Tzedakis 1974: 324-8).

Phase III is not a stratigraphic phase but comprises material from mixed upper and surface levels. It was defined as the phase of the carefully incised ware including pyxides with fine burnishing and incised decoration (Pl. 28a). Comparative material from Platyvola and similar examples from Central Crete indicate an EM IIA date for this phase (Warren and Tzedakis 1974: 328-30).

\section{The chronology}

The three phases were dated by the excavators to the EM I, EM I-IIA and EM IIA periods respectively, on the grounds of specific types pottery. More specifically Phase I is dated to the EM I period, due to the presence of large scored jugs and chaff-tempered coarse vessels, compatible with an early date. On stylistic grounds, the presence of dark burnished chalices, with parallels in many sites in Central Crete argues also in favour of an EM I date.

However, the chronology of this phase is not secure due to lack of clear EM I levels. Although chaff-tempering and heavy scoring are perfectly compatible with an EM I date, both practices continue into the EM IIA; it is also important that from the same level derive two tripod legs, one from a cooking pot and one from a pyxis, both being characteristic of an EM IIA date (Warren and Tzedakis 1974: 323). The excavators note the similarity between the material of Phases I and II considering the possibility of the deposit below the floor being earlier trodden floor material (Warren and Tzedakis 1974: 326).

The chronology of the phases in Debla has been challenged in two occasions: first by Godart and Tzedakis (1992: 26) on the grounds of an inconsistency in the publication concerning the stratigraphy of a large goblet/chalice (P5) and a 
reconsideration of the dating of the red burnished jugs. They suggest that Phase I should correspond with EM IA, Phase II with EM IB and Phase III with EM IIA. However, comparative material from other sites in West Crete as well as a recent reconsideration of the phasing of EM I period in Knossos (Wilson and Day 2000) make this dating for Debla high unlikely.

Recently Zois (1998: 56-8) challenged the early dating of Phase I on stratigraphic and stylistic grounds. The former are relevant to the mixture of the material below the floor deposit mentioned above; where the ceramic evidence is concerned, Zois argues that the absence of the characteristic EM I dark-on-light painted ware would support a single EM IIA date for Debla. However, the scarcity of dark-on-light painted ware in West Crete should not be interpreted as absence of EM I in Debla. Moreover, comparative material of EM I date in other West Cretan sites supports the existence of an EM I ceramic phase in Debla, represented primarily by large scored vessels and black burnished pedestalled bowls (P2 and B2-52) and chalices (P5). Therefore, it seems that in Debla there are two ceramic phases, representing EM I and EM IIA respectively.

Phase II is chronologically close to Phase I, the wares and fabrics are similar and is dated either to the borders of EM I to II or to the earliest EM II. The reason it was considered to be a little later than EM I but not securely EM IIA was the scarcity of scored ware and the presence of almost flat-bottomed jugs with pellet feet (Warren and Tzedakis 1974: 324-8). The presence of incised pyxides as well as tripod cooking vessels is quite compatible with an EM IIA date and as to the shape of the jugs bases, it could be interpreted as a remaining element of the EM I tradition (Zois 1998: 56-8).

Phase III is more of a stylistic rather than a chronological phase. Surface levels are likely to have been disturbed and it is difficult to define a chronological phase (Zois 1998). However, the incised ware included in this Phase by the excavators is compatible with an EM IIA date. 


\section{The wares}

Our study of the material from Debla resulted in the reconsideration of the wares suggested by the excavators (Warren and Tzedakis 1974). The wares represented in Debla are the following:

Dark burnished ware: in this category are included large vessels in a semicoarse fabric with applied red or black slip and occasionally burnished. The surface is in some cases mottled. The main shapes for this ware are pedestalled bowls (DEB/P4, B2 52, fig. 18) and footed chalices (P5) which belong to Phase I and are dated in the EM I (Pl. 27a). They have parallels in Kastelli and belong to the Pyrgos ware tradition.

Dark burnished incised ware: it comprises a large body of globular and cylindrical pyxides in a red gritty fabric (Pl. 28a) (Warren and Tzedakis 1974: 32830). They have a ledge rim and the incised decoration consists of parallel, vertical (Warren and Tzedakis 1974: Plate 56a top right) or horizontal (Warren and Tzedakis 1974: Plate 55d bottom right) incisions, herring-bone or hatched triangles and banding (Warren and Tzedakis 1974: Plates 56 top right, 55d top right, 56a low centre). There are also lids of pyxides with incised concentric circles (Warren and Tzedakis 1974: Plate 56a top left).

On stylistic grounds, there seems to be consistency in fabric, surface treatment and decoration of the EM IIA pyxides in West Crete (see examples from Platyvola, Perivolia, and Kastelli). Their counterparts in Central and East Crete are morphologically different (Wilson 1984: 277-8), and belong to a different tradition of manufacture (the Fine Grey Ware) (Wilson and Day 1994: 21-22, 79).

Red/Black slipped: in this category belong semi-coarse to coarse vessels with applied slip on the surface (preservation of slip is poor). The main component of this ware is the red lightly burnished jugs with almost flat base and pellet on the handle (Pl. 30a, b). Also present are a tripod vessel foot - probably from a pyxis (Warren and Tzedakis 1974: fig. 18 right), jars (DEB D7), an open bowl (Warren and Tzedakis 1974: fig. 18, PI. 52c, top centre), a small bowl with pierced handle (Warren and Tzedakis 1974: fig. 18, Pl. 53d, low right) and a deep bowl (DEB P20). 
A comment should be made on the typology and chronology of the burnished jugs. On typological and stratigraphic grounds, they belong to the early EM IIA period. Their bases are not completely flat but they are smaller and rather different from their round-bottomed counterparts of the EM I. They also have pellet feet, an element characteristic of the EM IIA. Zois (1998) classifies them along with the Koumasa type. It should also be noted that in the first phase (EM IIA) of Myrtos Fournou Koriphi (Warren 1972) there is a d-o-l painted jug (P57) that typologically is very close to the jugs from Debla (especially P12 and P13). It is flat-bottomed, lowbellied, with a circular handle and a not very pronounced spout. Moreover, from the same deposit derive several sherds of black slipped ware (sauceboats), which are fairly securely dated to the EM IIA.

Black slipped ware: this ware is not well represented at Debla, in comparison to other sites in West Crete (e.g. Kastelli). Black slipped ware belongs to EM IIA, the early phase of which is the main phase of occupation of Debla. The black slipped ware of Debla consists exclusively of thin-walled, pedestal-footed sauceboats, which were not identified as such by the excavators (they were considered to be goblets). Two examples of black slipped ware, a pedestal-footed sauceboat (DEB 00/32) and a pyxis lid (Warren and Tzedakis 1974, P7) are in grey fine fabric, and were interpreted by the excavators as examples of light grey ware. However, these vessels are very different from the light grey ware in Central Crete in terms of typology and decoration (Wilson 1984: 277-8) and they are closer to the black slipped ware as known from other west Cretan sites.

Scored ware: this ware comprises a large proportion of the assemblage from Debla from Phases I and II. The vessels included are in a semi-coarse to coarse fabric, mainly red slipped with heavy scoring on the surface ( $\mathrm{Pl}$. 33a). The main shapes represented are red slipped jugs, some with pellet feet, a large open bowl with horizontal scoring (Warren and Tzedakis 1974: Fig. 18, Pl. 53d top), and a large pithos. The date of these vessels is EM I to IIA with heavy scoring being perhaps an early characteristic and pellet feet being common in the EM IIA period. 
Coarse ware comprises vessels in a coarse red and occasionally chaff- or calcite-tempered fabric. In some cases they are red slipped. More specifically from Phases I and II there are thick-walled bowls, lekanai and pithoi. Comparatives for the coarse ware are found in most sites in West Crete and the rest of the island because this ware is rather conservative in its stylistic development (Warren and Tzedakis 1974 mention lekanai similar to the Debla ones from Myrtos Fournou Koriphi - EM IIA and EM IIB phases). The problems discussed above concerning mixed strata affect primarily this ware, which is not chronologically diagnostic. Therefore, due to the lack of stratigraphic information, it is difficult to determine whether specific vessels belong to the EM I or EM IIA as in the case of the tripod cooking pot which, although found in a Phase I deposit, belongs to the EM IIA period (cf. tripod cooking pots in the West Court House, Wilson 1985: 341).

\subsubsection{Platyvola Cave}

The cave of Platyvola was used for a considerable amount of time, from the Final Neolithic, through Prepalatial to the Middle Minoan period. Due to the lack of stratigraphic information, it is only through typology that a relative chronology for the ceramic sequence could be established.

The wares represented in the cave are the following:

Dark grey burnished ware: in this category belong vessels with the characteristic dark grey burnished exterior/and interior. The main shapes represented are chalices, pedestalled bowls (Pl. 26b), bowls with outurning rim, one of which has pellet feet and a scored base. The fact that a dark grey burnished vessel has pellet feet and is also scored constitutes probably an early indication of what will become obvious in other cases during the EM IIA; that many wares and shapes that originate from outside West Crete display west Cretan characteristics such as pellet feet and scoring (see the cases of frying pans, pyxides and sauceboats). The date for this ware is EM I to IIA. 
Dark burnished ware: in this category are included vessels in a semi-coarse fabric with applied red or black slip on the interior, the exterior or both. The surface is burnished and occasionally scribble burnished. Due to firing it sometimes gives the impression of mottling. The repertoire of shapes comprises large pedestalled bowls, goblets and chalices (Pyrgos type) (Tzedakis 1967a: 5046, Pl. 378c,e; Tzedakis 1968a: 415-17,. Pl. 376d,e). In terms of decoration, the join between pedestal and bowl might have horizontal ridges, which is a quite common characteristic with parallels at Kastelli and Nopigeia. This assemblage comprises large vessels characteristic of the EM I period with parallels in other west Cretan sites (such as Kastelli) and across the island (Wilson and Day 2000).

This ware continues throughout the EM IIA period with coarse and semicoarse bowls with thickened rim, jugs (some with pellet feet), hole-mouthed or collared jars and probably pattern-burnished pedestalled chalices. Where the Pyrgos type chalices are concerned, Zois (1998: 75) argues that the paucity of the type in West Crete as well as the quality of the Platyvola material argue in favour of Central or East Cretan imports. Samples were taken in order to test this hypothesis.

Dark burnished incised ware: in Platyvola there exists an important assemblage of red or black burnished incised pyxides (Pl. 28b,c) and jugs in a semicoarse orange fabric with reddish brown or black slip on the exterior. The decoration is incised and consists of hatching, herring-bone or split herring-bone (Tzedakis 1965b: 569, Pl. 719a,b; Tzedakis 1966a: 428, Pl. 465d; Tzedakis 1967a: 504, Pl. 378a; Tzedakis 1968a: 415, Pl. 376b; Tzedakis 1968c: 268, Pl. $\left.\Xi \Delta^{\prime}\right)$. The main shape of this ware is the globular and cylindrical pyxis. Comparative material from other sites in West Crete as well as the consistency of the Platyvola assemblage leads us to date the incised pyxides in the EM I-IIA period (see also Zois 1998: 80).

Red/Black slipped ware: in this category are included vessels with a characteristic red, reddish-brown to black slip applied on the surface (PI. 31b). The fabric is semi-coarse to fine, buff to orange. Due to firing the surface can be mottled. The main shapes represented are jugs with pellets on the shoulder and jars. In terms of surface treatment, this ware has links with the dark burnished and possibly with the 
red slipped scored wares, as indicated by the presence of a jug neck (PLT 00/8) with a red slipped exterior and a scored interior. The date is EM IIA and there are parallels in Kastelli, Chania town and Debla.

Black slipped ware: in this category are included vessels with applied black shiny slip on interior, exterior or both. The fabric is semi-fine to fine. The vessels are high-fired and in some occasions mottled. The shapes represented in Platyvola are of Minoan and Helladic style. The Minoan part comprises high-fired and occasionally mottled vessels such as pedestal-footed goblets and jugs with or without herring-bone incision on the shoulder.

The Helladic part consists primarily of sauceboats and one askos. The sauceboats have a lustrous slip on the exterior, which in some cases gives the impression of a Helladic Urfirnis slip (PI. 34a). Moreover, due to stacking of vessels one on top of the other during firing there are traces of uneven firing on the interior (Pl. 34b).

The presence of sauceboats is very important and their provenance caused debate since the time the first examples were collected (Alexiou 1964); Tzedakis (1967b) considered them to be EH imports; in a later study Karantzali (1996: 85) considers that the application of Urfirnis slip on the surface is a Helladic characteristic (imports from Attica or Boeotia?), whereas in other examples the shape of the vase is reminiscent of Cycladic prototypes. However, there are no exact parallels anywhere else in the Aegean.

Due to the way the bases of the sauceboats are shaped, it seems that they have closer parallels to the Mainland and Kythera (Coldstream and Huxley 1972) rather than the Cyclades. As to examples from other sites in West Crete, the closest parallels are to be found at Kastelli and, although they are high fired and covered with a lustrous black slip, they differ in some details. Those from Platyvola are more squat and probably earlier in date. It is of importance that in Kastelli, along with the sauceboats, there are other Helladic shapes such as saucers, which are totally absent in Platyvola. This may be an indication of a slightly earlier date for the Platyvola material. Furthermore, it is possible that the saucers replaced the large communal 
vessels used in earlier periods. Considering that ritual deposits in caves are in most cases EM I in date (Branigan 1988: 152-3), it seems likely that the deposits from Platyvola are EM I - early IIA. However, it is also possible that the differences in the repertoire of shapes between Kastelli and Platyvola are functional and due to the special character of the latter.

Scored ware constitutes an important part of the assemblage from Platyvola. In this ware are included coarse and semi-coarse vessels, usually in a red fabric. The surface is heavily scored with vertical or diagonal scoring on the exterior. Sometimes there is also application of a red slip, which can be burnished. The main shapes are large bowls, basins, jars and circular lids, which have parallels in the Palace Well (Hood 1990b: 372-3, figs 1-2). Special mention should be made of the large jugs with thick red slip and heavy scoring (Pl. 33a), occasionally with applied pellet on shoulder, which seem to be of EM I date and have parallels in Debla (Warren and Tzedakis 1974) and Kastelli (a few examples).

In the cave of Platyvola there are also some vessels that occur in cooking pot ware. The main shapes are globular deep bowls with outurning and externally thickened rim, shallow bowls with flaring rim and hole-mouthed jars.

Pithos ware is in many cases combined with scoring, the main shapes being collar-necked jars, globular storage jars with applied ridge below rim, pithoi with applied cordon. There are also large coarse pithoi with applied red slip without scoring. The date for the scored ware of the cave is EM I to IIA, with heavily scored coarse jugs and a circular lid being characteristic of an early date (EM I).

In the coarse wares are included vessels in a red fabric containing small, white calcitic inclusions. The main shape is the collar-necked transport jar, which can also be red slipped or covered by a thick creamy slip, but there are also jugs with cutaway spout and pushed-through handles. In a few cases there is dark-on-light decoration. Their date is taken to be EM II.

Dark-on-Light painted ware: there are only a few examples of this ware, which is rare in West Crete. The examples from Platyvola consist mainly of jars and bowls in fine calcite fabric (see above). The jars might have black slip on top of the 
thick creamy slip or red painted decoration with motifs such as cross-hatching and circles. Their date is EM II. There is one of d-o-1 painted jar from Platyvola, which has been described as an example of Agios Onouphrios decoration (Tzedakis 1966a, P1. 466c). However, this identification has been challenged by Zois (1998) arguing that it is Middle Minoan.

Mottled ware: although mottling is a common feature in west Cretan pottery, the canonical Vasiliki ware (as described in Betancourt et al. 1979) is almost absent. It is only in Platyvola that proper Vasiliki ware of EM IIB is mentioned in jugs and goblets (P1. 32b) (Tzedakis 1967a: 505, Pl. 378d).

\subsubsection{Mitatoulia}

The ceramic material from the site derives from the excavation of three trenches (Tzedakis 1980b) and it is quite homogeneous in character and date. The majority of the vessels are in an orange soft fabric and belong to the EM I period. The wares represented are the following:

Dark grey burnished ware: there are several examples of this ware (PI. 35a), namely bowls, occasionally with pellet lug, pedestalled goblets and chalices and probably a small jug. One of the chalices has six incised bands around the join, which is reminiscent of the Nopigeia examples. Both the shapes and surface treatment are compatible with the chalices from other west Cretan sites of the EM I period.

Dark burnished (and incised) ware: in this category belong semi-coarse to semi-fine vessels with applied red or black slip on the exterior and/or interior (PI. 35b). The shapes represented are pedestalled chalices, large open bowls and incised pyxides. The repertoire of shapes has parallels at Kastelli and Debla and the date for these vessels is EM I-IIA.

Red/Black slipped ware: in this ware belong semi-fine vessels with applied red slip on the exterior, which occasionally can be burnished. The main shapes are bowls jugs and pyxides (the latter probably EM IIA). 
Coarse wares: in this category are included coarse vessels with different surface treatment in the soft orange fabric that characterises the pottery from the site. There are unpainted or red slipped coarse pithoi with chaff temper, basins with mica, collar-necked jars and coarse pedestalled goblets. There are also pithoi with applied red slip and decoration, one with rope pattern, the other with applied bands bearing stamped herring-bone pattern (Kerbschnitt).

Scored ware: in this ware are included large and small bowls and jars with scoring on the surface (PI. 35c) with parallels at Debla. The main date for these wares is EM I mainly due to the presence of heavy scoring.

It is worth mentioning that the assemblage of Mitatoulia presents similarities with the other West Cretan sites, but it also has a particular (probably local) character which becomes obvious through the typology, as well as the petrographic analysis of the pottery (the latter will be discussed later). The orange fabric that characterises the pottery from Mitatoulia seems local or at least representative of a single workshop. The shape repertoire comprises vessels known from other sites such as DGBW chalices and dark burnished incised pyxides, but also many vessels in coarse ware that would appear in other sites with surface treatment, such as pedestalled goblets (unless it is only poor preservation).

In the coarse ware are also included many red slipped pithoi and pithoid jars with rope and Kerbschnitt decoration. Considering that these decorative patterns are of Western Cycladic/Helladic origin, it is of importance that they appear in the early assemblage of Mitatoulia, in the middle of the Alikianos basin, far away from the coast. It seems possible, therefore, that some of the Helladic elements, which become prominent in EM IIA, exist already in EM I, even in small settlements like Mitatoulia. A limited survey in the area produced a multitude of EM sherds (Tzedakis 1980b), which is indicative of a fairly intensive EM occupation. It would be of interest to obtain details about the character of this pottery in order to establish the extent and frequency of the non-Minoan shapes in the earliest phase of the Prepalatial period. 


\subsubsection{Kastelli (Chania)}

The site of Kastelli has been constantly inhabited since the Late Neolithic and during the entire Prepalatial period according to information provided from stratigraphic soundings (Tzedakis 1981; Tzedakis and Hallager 1983). The material from Kastelli is impressive in quantity, diversity and quality. The wares represented are the following:

Dark grey burnished ware: there are only a few examples, namely a jar and some deep bowls of the EM IIA period. Examples of this ware are not abundant in Kastelli, probably because the main phase represented in the site is EM IIA and by then EM I traditions such as the DGBW large open vessels have been replaced by new shapes for individual use. There are parallels of the ware in other West Cretan sites (such as Platyvola and Lera caves) and in Central Crete (Pyrgos cave).

Dark burnished ware: in this category are included vessels with red, redbrown or black burnished exterior and/or interior (P1. 27b). The repertoire of shapes includes large open vessels such as bowls, pedestalled bowls with internally or externally thickened rim, pedestal-footed jars. The date for these vessels is EM I.

In EM I and EM IIA there are shallow bowls with scribble burnishing, black burnished lids with cylindrical handle and small burnished bowls, which, due to uneven firing, can be mottled.

Black slipped ware: in this category are included vessels with applied black slip, which occasionally can be mottled (Pl. 29b,c). Among the shapes represented, there are pedestal-footed goblets, low-footed goblets, spouted jugs, jars with ledge rim, and jugs with herring-bone incised decoration. However, the main component of this assemblage is the Helladic style vessels, such as sauceboats with low foot, askoi and saucers. They are in a semi-fine to fine fabric, they are high-fired and in their majority they are black slipped. The slip has a shiny appearance like in Urfirnis ware. Many of these shapes have close (if not exact) parallels in EB II Mainland, but in West Crete occur with material characteristic of the EM IIA. 
However, there seems to be continuity in technology and decoration from EM IIA to EM IIB with characteristic shapes of this period such as large spouted jars occasionally with flat metallising handle with herring-bone incision, following the black slipped tradition. Among the saucers there are some that are red/black mottled and probably larger than the black slipped ones; there is also a red/black mottled jar of EM IIB date.

Red/Black slipped ware: in this category belong vessels in a semi-coarse to semi-fine fabric with a red-brown burnished exterior and/or interior (P1. 31c). The surface can in some cases be mottled. The repertoire of shapes includes Helladic and Minoan-style vessels. The Helladic component comprises large and small saucers, sauceboats with low foot and askoi. The Minoan component comprises side-spouted jars, jugs with cutaway spout and pellet eye, goblets, jars, shallow and deep bowls and one small carinated pyxis. The date for these vessels is mainly EM IIA, but the ware continues in EM IIB with side-spouted jars.

Dark-on-light painted ware: there are only a few examples of this ware in Kastelli. They are large vessels in a semi-coarse fabric. More specifically, there is a large EM I jug in orange buff clay and its decoration consists of red painted vertical stripes. There are also a large jar with thick creamy slip and traces of black painted decoration and a large shallow bowl with thick creamy slip and red painted bands on top of rim. The date for these is taken to be EM IIA and IIB(?) respectively.

Scored ware: this ware is quite common in Kastelli. A substantial proportion of scored ware vessels are in a semi-coarse red fabric, mainly red slipped. The shapes repertoire consists of jugs or collar-necked jars. The fabric is red and high-fired. These vessels do not have parallels in Platyvola where scoring is heavier and the vessels are larger. The date for the vessels at Kastelli is also EM I-IIA, probably closer to EM IIA.

There are also examples of cooking pot ware with diagonal scoring on exterior, namely collared jars and deep bowls. Other coarse vessels with scored surface might be calcite-, schist- or grog-tempered and include jugs, large jars, globular jars with vertical lug on shoulder, basins, baking plates. The date for these 
vessels is EM I-IIA. One large pedestalled deep bowl (KST 00/51) is connected with the Western Cyclades or the Mainland in terms of shape, but it seems Minoan in fabric (red fabric with angular calcitic inclusions).

Other coarse ware: in this category belong vessels in a semi-coarse red fabric with small, white, calcitic inclusions. Surface treatment consists either of applied red (and rarely black) slip on exterior /and interior or of thick calcareous slip on exterior. The repertoire of shapes comprises Minoan and Helladic-style vessels. In the former belong pedestalled bowls, deep bowls, pithoi with applied ridge, and jugs with cutaway spout. The Helladic component comprises only large open vessels, which might be saucers. They might also be shallow bowls and in that case they are Minoan. The shapes with applied calcareous slip are jugs, jars, pithoi with horizontal ridges and large shallow bowls. The date for these vessels is EM IIA.

In this category are included also coarse vessels without any surface treatment. The shapes represented are large jars with pushed-through handles, jars with externally and/or internally thickened rim, pithoi, some with applied bands or plastic rope decoration, the latter being a feature originating from the Western Cyclades or the Mainland. The date for these coarse vessels is broadly EM II.

\subsubsection{Chania Town}

The material from the town of Chania derives from the excavation of the Kaniamos plot in the area of Splantzia (Andreadaki-Vlasaki 1994a). The deposits were mixed and the early pottery was revealed through stratigraphic soundings. However, the material is quite similar in character (though poorer in preservation) with that of Kastelli on top of the hill, which is indicative of the extent of the Prepalatial occupation.

The main wares represented are the following:

Dark grey burnished ware: there are only a few examples of this ware, with a pedestalled bowl and a goblet, both black slipped and burnished. The date is EM IIIA. There are similarities with the dark burnished examples in terms of fabric and 
surface treatment. It seems that the examples from Chania town are more likely EM IIA in date, with slip and burnishing taking over dark grey burnished ware.

Dark burnished ware: in this category are included vessels with applied redbrown to black slip and burnishing on exterior and/or interior (P1. 27c). The shape repertoire comprises shallow bowls, small goblets, jugs, jars and lids with circular handle. There are parallels in the assemblage from Kastelli, which indicates the uniformity in the pottery of the Chania sites. The date is EM I-IIA.

Black slipped ware: the examples of this ware are very similar to the ones from Kastelli. There are jugs with herring-bone incision on the shoulder, saucers with black slip on exterior and/or interior and shallow bowls. The date for these vessels is EM IIA. There are also one jug and two goblets with mottled surface that probably belong to this group; for these vessels it is difficult to define within EM II, before the local sequence is better established.

In the same ware belong also some red/black slipped goblets, one with potter's mark under the base, which are EM IIB in date. As already discussed for the material from Kastelli, this ware seems to continue into EM IIB.

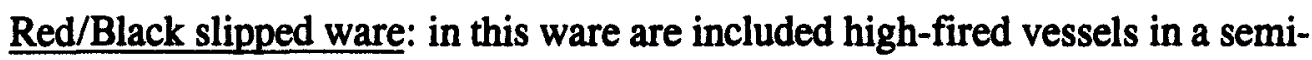
coarse to semi-fine fabric with applied red slip on the surface. The surface can often be mottled. The shapes represented are of Minoan and Helladic style, but they share the same fabric. The Minoan component consists of shallow bowls with inturned rim, large jars, and goblets. The Helladic component consists of sauceboats, most of them with an orange-black mottling. The date is EM IIB.

Dark-on-light painted ware: There are very few examples of this ware, which is a general pattern in West Crete and, additionally for this site, because the amount of material recovered from the stratigraphic sounding is limited. There exists only one example of jar in coarse ware with three painted bands of EM I-IIA date and a base of a deep bowl with calcareous slip and red paint on the exterior of late EM IIA-EM IIB date. 
Coarse ware: in this ware are included vessels in a semi-coarse, red fabric containing small, white, calcitic inclusions. The examples from Chania Town consist of a shallow bowl and jars, one collar-necked with thick creamy slip, a pushedthrough handle of a large jar and a red slipped and burnished jar. The date is EM II.

In the same ware belong also vessels in a semi-coarse to coarse fabric without any surface treatment or with slight burnishing. There are shallow and deep bowls, some straight-sided, or with everted and internally thickened rim, and baking plates. The date is mainly EM IIB.

Finally, there are also a few examples of cooking pot ware with scoring, namely a deep bowl and a pithos.

\subsubsection{Nopigeia}

The ceramic assemblage from Nopigeia has a very special character because the Helladic component of its assemblage is more prominent than in any other West Cretan site. As to the date of the site, it is published as EM IIA (Karantzali 1997), but there are also two sherds ${ }^{3}$ from pedestalled chalices of EM I date, which demonstrates that there is an earlier phase of the settlement.

Dark grey burnished ware: the EM I part of the assemblage consists of pedestalled chalices with vertical pattern burnishing on foot (Pl. 36a) (Karantzali 1997, fig. 4, nos 5-6). There are also body sherds from pedestalled goblets and chalices, indicating the Minoan character of the assemblage during the EM I period.

However, the main period of occupation seems to be the EM IIA, since the majority of the assemblage is compatible with this date. During this period the pottery is differentiated, the major part being of Helladic character.

The Minoan component of the assemblage is quite restricted in quantity. The wares represented are:

\footnotetext{
${ }^{3}$ There are two published examples of dgbw sherds (join and small part of base) from pedestalled chalices of EM I date (Karantzali 1997, fig. 4, nos 5-6). Karantzali (1997: 74) recognises the similarity with Pyrgos burnished ware but identifies them as goblet feet and dates them to EM IIA. For comparatives, see Xanthoudides (1918: Pl. B).
} 
Dark burnished incised ware: there are a few examples of this ware, namely pyxides with incised herring-bone decoration and alternating hatched triangles (Karantzali 1997: Pl. 21a). There are parallels of incised ware in almost all sites in West Crete.

Red/Black slipped ware: it comprises mainly jugs and bowls with red slip applied on the exterior, which can occasionally be burnished. This type of ware is common in other assemblages in West Crete, such as Kastelli, Chania town and Debla.

Cooking-pot ware: in this category are included baking plates and pans, deep bowls/open jars, basins (Karantzali 1997: Pl. 20b upper right) and tripod legs calciteor phyllite/schist-tempered.

Scored ware: there are scored ware bowls and pithoi with diagonal scoring underneath the rim, which is also an element of the Minoan manufacturing tradition of the EM I-IIA period (Pl. 33c). It is of importance, however, that, even in the Minoan shapes and wares, there are elements that are not compatible with Minoan traditions. Sample NOP 00/38 is a scored ware jug/jar with an applied cordon under the rim, the latter being a decorative motif of the Cyclades. In the same assemblage there is also sample NOP 00/43, a scored ware jug, like the ones that occur since the EM I in all sites in West Crete. Considering that scored ware tradition is very strong in EM West Crete and that at Nopigeia there is co-existence of purely Minoan and Helladic types, it could be suggested that the Minoan jug represents an earlier phase (EM I), before the Helladic style became predominant. This jug is taken to be EM IIA, which constitutes one more example of adaptation of an earlier Minoan tradition to the new prevailing style.

The Helladic component of the assemblage is as follows:

Black slipped ware: the vessels of this ware are characterised by a grey-buff to pink fabric and the application of black slip on the exterior (in most cases the preservation of the slip is very poor). The main shapes represented are characteristic of Helladic assemblages, namely slashed and double-barrelled handles from askoi (Pl. 36c), sauceboats, some with Urfirnis-like finish, bowls and saucers. The latter have 
ring bases and are slipped on the interior and exterior, which brings them closer to the Helladic prototypes than the ones in Kastelli or Chania town. There is also one example of a black slipped jug with incised herring-bone (Karantzali 1997: fig. 10, 41 and Pl. 22b) with close parallels at Kastelli. The date for this material is EB II.

Coarse ware: as mentioned above, it is mainly the coarse ware that belongs to the Minoan manufacturing tradition. However, there is another part, which is Helladic in character but Minoan in fabric. It is the portable hearths with impressed Kerbschnitt decoration, widely occurring in the Cyclades and the Mainland (Pl. 36b) (Karantzali 1997: 76). There are also collar-necked jars, basins with finger impressions on or below the rim, large jars/pyxides with horizontally pierced lug or external ledge rim, pithoi with applied ridges, bands or rope pattern (Karantzali 1997: Pl. 20c), all these being characteristics of Helladic or western Cycladic origin. Even the burial pithos has two applied ridges below rim, which is a Helladic characteristic (Karantzali 1997: fig. 13, Pl. 19b). A very interesting case is a pithos with rope band (Helladic characteristic) and applied red slip. It represents the combination of a Minoan shape and surface treatment with Helladic-style plastic decoration. The date for this material is broadly EB II.

In her publication of the material from Nopigeia Karantzali (1997) recognises the two-fold character of the assemblage (Minoan versus non-Minoan). For the Minoan portion parallels from the Royal Road, the West Court House in Knossos, and Myrtos Fournou Koriphi (Phase 1) are discussed. For the non-Minoan portion, there are parallels from the Cyclades, Kythera, Lerna, Tiryns. Finally, similarities with material from West Cretan sites, namely Debla, Kastelli and Platyvola Cave, are also discussed.

Although the Helladic character of a large part of the pottery from Nopigeia was acknowledged in the publication, it was not stressed that it concerned the majority of the vessels which, however, seem to be homogeneous in fabric (probably local). The significance of the Helladic character of the assemblage is considerably reconsidered after the re-study of the material in the course of the present work, during which more Helladic-style shapes were identified. Among the goblet bases of 
the initial publication there some that are in fact sauceboat bases (Karantzali 1997: fig. 4). Ring bases attributed to goblets are in fact saucer bases (Karantzali 1997: fig. 5). Moreover, rims of small vessels attributed to small pyxides (Karantzali 1997: 79, fig. 6) may be identified as saucers (D. E. Wilson pers. com.). Small pyxides do not occur in West Crete (in contrast to their large incised counterparts), whereas saucers are typical members of assemblages with Helladic-style pottery, like the ones from Kastelli and Chania town.

The amount and variety of the Helladic style material as well as the total absence of painted ware gives the assemblage of Nopigeia a Helladic, rather than a Minoan, character. Despite the opinion expressed in the publication of the assemblage that there is dearth in pouring and redundancy in drinking vessels (Karantzali 1997: 80), the identification of numerous sauceboats, jugs and teapots contradicts this statement.

\subsubsection{Psathi}

The ceramic material from the site of Psathi was revealed during the excavation of rescue trenches. The site did not produce any (Mytilineou 1997-98) or very little (Mytilineou 2001) architectural evidence; however, it produced a substantial amount of pottery with drinking and serving vessels of high quality. The particular character of the site is being discussed elsewhere but while discussing the pottery from the site, it should be taken into consideration that there is not any stratigraphic information or an overview of the entire assemblage. Even the publication (Mytilineou 1997-98) represents only part of the excavated material.

The first categorisation of the published material followed the excavated units, which corresponded to three different plot owners (Mytilineou 1997-98: 197). That material was chronologically attributed to the EM IIB-MMI periods. The material from Psathi discussed here derives from a fourth plot and it is mainly early Prepalatial (EM IIA-B). 
The main wares represented are the following:

Red/black slipped ware: this is the main type of ware represented at Psathi (Pl. 31). The surface treatment consists of the application of a thick monochrome matte red or brown to black slip on the exterior, which occasionally can be burnished or mottled. The shape repertoire comprises semi-fine serving and drinking vessels, such as footed goblets, sauceboats, saucers and jugs/jars. In all the other sites, the black slipped ware constituted a characteristic part of the assemblage, which is not the case in Psathi. The Helladic-style black slipped vessels are similar to the red slipped in terms of fabric and surface treatment. Especially in the case of the sauceboats, the difference between Psathi and other sites (such as Chania) is striking, because the examples from Psathi lack the fine walls and the shiny black slip. The date for these vessels is EM IIA but the same surface treatment continues into EM IIB with deep and shallow bowls with internally thickened rim. There are also jugs with cutaway spouts and pellet eyes that could belong to any of the two periods.

On the grounds of typology, similarities with the central Cretan red/black slipped ware (described in Wilson and Day 1999: 18) have been identified. Special mention should be made to a "metallising" strap handle of an askos with vertical incisions, which has affinities with the western Cyclades (Wilson 1999: 76, II658, P1. 68).

Dark-on-light painted ware: unlike other west Cretan sites, in Psathi there are a few examples of painted vessels (Pl. 32a). It is of interest that they are all jugs with cutaway spouts and pellet eyes or long-spouted jars. The decoration consists of black or reddish-brown linear bands and the date is EM II. There is one particular example (PST 00/21), which has parallel at the West Court House (Wilson 1985: 322, P191).

The assemblage of Psathi presents several particularities: it is quite close to the EM IIA-B phase of Kastelli with the black slipped group and characteristic shapes such as sauceboats and saucers. However, in terms of surface treatment it is closer to central Cretan examples. It is difficult to explain whether what we have at Psathi is a case of imitation or local adaptation of styles and techniques that derived from elsewhere. 
It seems that the shapes are west rather than central Cretan. As to surface treatment, it could be a continuation/adaptation of the dark burnished tradition (which does not exist in Psathi) rather than a technique deriving from Central Crete. On the other hand at Psathi there exist dark-on-light painted vessels, which are rather scarce elsewhere in West Crete. This makes the association with the central part of the island rather possible.

There is total absence of the main coarse wares, such as scored ware. It is a major drawback for the dating of the existing coarse wares that there is no stratigraphy because coarse vessels seem to be quite conservative in the Prepalatial period. Some of the jars identified by Mytilineou could be EM IIA or IIB (Mytilineou 1997-98: 209, fig. 7). Even if this is the case, the scarcity of pithoi and storage jars is indicative of the particular function of the site. According to new architectural evidence from recent excavations there could have been workshops in Psathi (Mytilineou 2001). However, this would still not explain sufficiently the amount of fine slipped and painted ware and the presence of a considerable number of sauceboats and saucers.

\subsection{The Shapes}

The EM assemblages from West Crete are characterised by the co-existence of two markedly different pottery traditions: one part is comparable with the ceramic repertoire of the rest of Early Bronze Crete (Minoan), the other presents affinities with assemblages from the Cyclades or the Mainland.

Most of the shapes of off-island origin occur in West Crete in settlements as well as caves, whereas in the Cyclades and the rest of Crete they form part of burial assemblages. Among the non-Minoan shapes there are some which are loaded with meaning and symbolism, such as frying pans and sauceboats, as well as others associated with transport within the Aegean in the $3^{\text {rd }}$ Millennium BC, such as collarnecked jars. In this part we consider the main off-island shapes found in West Crete, i.e. pyxides, sauceboats, collar-necked transport jars, stamped hearths, slashed handles, and saucers. Jugs and pithoi are also discussed. The former constitute the 
main shape of purely Minoan origin, which is also a good indicator of date and is represented in substantial amounts in West Crete. The latter are also found in many sites in West Crete and, due to their size, are considered to be locally manufactured. Moreover, coarse wares are considered to be conservative and they do not undergo stylistic changes as easily as fine wares.

\subsubsection{Pyxides}

Pyxides are shapes originating from the Cyclades but they occur largely in Crete. There are three types represented in West Crete, the large tripod example with cylindrical body the globular and the spherical one. All three types occur in Platyvola, but the cylindrical is more common and occurs also in Perivolia, Debla and Kastelli. They all share certain common characteristics such as two vertical perforated lugs, surface treatment and incised decoration.

The cylindrical pyxides are large vessels, reminiscent of tripod cooking pots due to the presence of three conical feet. The decoration consists of large horizontal ridges (CM 1996 ${ }^{4}$ ) or two groups of ridges bordering a band with deeply incised chevrons (CM 1995) (Karantzali 1996: 128, Fig. 87). They have been considered local imitations of Cycladic prototypes in stone like the one from Keros (Zapheiropoulou 1968: Pl. 332a-b). In contrast, Karantzali (1996: 128) argues that the decorative motifs are common in the Minoan repertoire (fine grey and burnished wares), which is in favour of a Minoan origin.

The cylindrical-globular pyxides are found in the caves of Platyvola (CM 2023) and Perivolia and in the settlement of Nopigeia. They are characterised by a complex profile with a low neck and a tall foot. The incised patterns consist mainly of hatched triangles, split herring-bone or alternating hatching (Karantzali 1996: 134). The same patterns occur in black slipped and burnished jugs with incision on shoulder.

\footnotetext{
${ }^{4} \mathrm{CM}=$ Chania Museum number
} 
The spherical pyxis is found in Platyvola (CM 1994). It is characterised by a cylindrical neck with everted rim. The incised patterns consist of horizontal bands of chevrons, hatching or hatched triangles (Karantzali 1996: 134).

Pyxides are considered vessels bearing specific meaning because of the importance of their content. On the grounds of their relatively small size in Central Crete and the Cyclades, they were considered to be portable containers of valuable substances, such as perfumed oil, cosmetics, medicines (Wiencke 2000: 583). However, the tripod examples from West Crete contradict the concept of the "small portable vessel" and their occurrence in domestic contexts contradicts the exclusively ritual use.

Pyxides along with other incised vessels are quite common in the rest of the island but there are considerable differences compared to the West Cretan examples. The first remark should concern the find context: in the Cyclades and the rest of Crete the majority of the incised vessels derive from burial contexts, whereas in West Crete they are found in caves and settlements. Pyxides found in north-central Crete are either in dark grey burnished or in light grey ware, whereas in west Crete they are dark burnished. The decorative motifs in Central and East Crete consist of combinations of zones and patterns with concentric semi-circles (Wilson 1984: 278), whereas in the West there are horizontal bands with incised rectilinear patterns, zones of chevrons, herring-bone and hatched triangles.

The west Cretan pyxides constitute a regional variant and probably follow a separate line of development from the ones in rest of the island and are considered to be products of a west Cretan EM IIA tradition (Wilson 1984: 278; Karantzali 1995: 457; Karantzali 1996: 128, 134). Within this framework it can be argued that the West Cretan incised ware is not an imitation of central and south Cretan prototypes (Warren and Tzedakis 1974: 329) and that the pedestalled variant (in Tzedakis 1968a, Pl. 376a) is not an import from elsewhere in the island (Wilson 1984: 278). It seems that the west Cretan variants are larger than the pyxides in the rest of Crete; the fact that in some cases they acquire feet like the cooking vessels and in others a pedestal 
like the chalices could be interpreted as an adaptation to a local trend or a tradition that seems to be extended to other vessels such as the sauceboats.

\subsubsection{Sauceboats}

Sauceboats are considered to be loaded with meaning and symbolism and along with pyxides are thought to contain valuable substances and to be used for specific ritual practices. In West Crete they occur in all the EM sites studied: Platyvola, Kastelli, Debla, Nopigeia. Sauceboats are considered to be of Cycladic or Helladic origin. The sauceboats from Platyvola and Kastelli have a low pedestalled base, they are made in a fine fabric, they are high-fired and on the surface a shiny black slip has been applied, which is reminiscent of the Helladic Urfirnis vessels. Both the slip and the shape of the body are reminiscent of Helladic examples. Petrographic analysis demonstrated that the fabrics used for the sauceboats are local and in some cases consistent with those used for coarse wares.

Moreover, both Helladic and Cycladic sauceboats present significant differences compared to the west Cretan ones: most of the Cycladic examples are shorter and the spout is longer and more pronounced (cf. with Agia Irini in Wilson 1999). As to the Helladic examples, in most cases, they have ring bases instead of pedestal, the spout is more pronounced and the body is not hemispherical and as deep as in the west Cretan ones (cf. Lerna in Wiencke 2000 and Aghios Kosmas in Mylonas 1959).

A detailed typological analysis of the Lerna assemblage and its parallels suggests that the Argolid should be excluded as a possible origin for the West Cretan sauceboats (Wiencke 2000: 590; Wilson 1984: 303); Attica or Boeotia should be considered as potential places of origin, probably via the Cyclades (Wilson 1984: 304) and the low-pedestal examples from west Crete could be considered local imitations of Helladic originals (Karantzali 1996: 148). The small calcite fabric, which is commonly used in West Crete for many types of vessels such as pyxides and in sauceboats, constitutes a typical west Cretan characteristic. 
Another characteristic of the west Cretan sauceboats is the low pedestalled foot. It is reminiscent of the footed goblet (Pl. 37a) and it is probably another case of local adaptation of a non-Minoan shape through the addition of a "familiar" element. For the same reason pyxides acquire feet like tripod vessels and frying pans acquire pellet feet like jugs (P1. 37b).

It is of importance that in Central Crete sauceboats occur in small amounts (at Knossos and Poros (Dimopoulou et al. in press), whereas in West Crete they constitute part of many different assemblages. They also occur at Kastri (Kythera) in deposit $\alpha$, either as Helladic imitations in local fabric or as imports (Coldstream and Huxley 1972: 82).

\subsubsection{Collar-necked jars}

These vessels occur primarily in the Cyclades, they often bear incised handles and their significance was recognised by Renfrew (1972) who associated them with sauceboats and folded-arm figurines. Their content is thought to be precious and socially significant (probably an alcoholic liquid) and their circulation in the Aegean could signify drinking rituals which create bonds between geographically separated communities (Broodbank 2000: 305). They are found in considerable number at Poros and constitute Cycladic imports (Dimopoulou et al. in press). In West Crete they occur in Kastelli and Platyvola in fabrics compatible with coarse wares and other typically Minoan vessels.

Except for the Cyclades, collar-necked jars with incised handles occur also in Laconia and Kythera, the latter in local fabrics. According to a recent interpretation cyclic voyages take place from the Cyclades to Crete involving a down-the-line radiation of prestige objects (Broodbank 2000: 308). This interaction through marine networks might explain homogeneity in vessel shapes, which are, though, locally manufactured. 


\subsubsection{Stamped Hearths}

Stamped hearths are not common in West Crete. They are considered a "Helladic" shape and occur only at Nopigeia (P1. 36b) along with double-barrelled and diagonally slashed jug handles (Karantzali 1997). The decoration consists of rows of impressed triangles (Kerbschnitt) and there are traces of grey-red and white slip (Karantzali 1997: 80). Impressed decoration on the rim of large vessels is quite common in the Mainland; examples of stamped hearths are reported from many sites (Zygouries, Raphina, Askitario and less frequently Lerna) and Kythera (for full catalogue and references, see Wiencke 2000). Kerbschnitt decoration occurs in the Cyclades in very limited cases, namely the hat-vases, whose function is still unclear, but they were considered to be portable hearths (Doumas 1977; Metaxa-Muhly 1984). Stamped hearths occur also in Keos in red-brown coarse ware and the decoration consists either of spirals or of the Kerbschnitt pattern (Wilson 1999).

\subsubsection{Slashed Handles}

Another Helladic type occurring at Nopigeia is the double-barrelled and the diagonally slashed jug handles (Pl. 36c) (Karantzali 1997). Both handle types occur in the Mainland (Wiencke 2000), Kythera (Coldstream and Huxley 1972) and the Cyclades and namely Keos (Wilson 1999). Rare parallels of slashed handles exist also in Central Crete, namely Knossos and Poros (Dimopoulou et al. in press); they derive from collared jars and are Cycladic imports (Wilson 1984: 305).

\subsubsection{Saucers}

Another type of vessel with western Cycladic/Helladic affinities is the ringbased saucer. It does not occur in Central and East Crete where similar functional needs are fulfilled by different types of bowls and cups. Saucers are very common in West Crete and in most of the sites that have been studied, namely Kastelli, Chania Town, Nopigeia, and Psathi. They do not occur in Platyvola or Debla, probably because these sites are earlier in date. If the saucer came in along with other 
individual vessels as a replacement of the large communal vessels of the EM I period, then it might not have reached the earlier EM IIA phase occurring in Debla and Platyvola. Especially in the latter, it has already been mentioned that the sauceboats are of different and probably earlier type than the ones of Kastelli.

In stylistic terms, the type of saucer represented in West Crete has a ring base and inturned rim and the surface treatment consists of applied black or red slip. In the sites where it occurs, it is undoubtedly associated with the group of vessels including black or red slipped sauceboats, incised jugs and goblets.

Parallels of ring-based saucers can be found in many places of the Helladic world. Published examples come from the Peloponnese, and namely Lerna (Caskey 1960: 291, Fig. 1: b, d, e; Wiencke 2000: 596-7, type 2 from period IIC - the deep entirely painted type), Tiryns and the Argolid survey (Pullen 1995), from the Mainland and namely Lithares (Tzavella-Evjen 1984) and Eutresis (Goldman 1931), and from Attica and namely Askitario (Theocharis 1953-54), Raphina (Theocharis 1952), Agios Kosmas (Mylonas 1959) Perachora (Hatzipouliou-Kalliri 1983: 374, Pl. 39, P306) and Rouph (Petritaki 1980).

Parallels occur also in Agia Irini on Keos in a red-brown semi-fine ware (Wilson 1999: 27, and P1. 45, Nos 27-36) and on Kythera (Coldstream and Huxley 1972: Pl. 17, Nos 65-67). It is of interest that the examples from Agia Irini have parallels in Lerna IIC phase, which is also the case for the West Cretan examples. This is an indication of common characteristics of this type between the Western Cyclades, the Mainland and West Crete.

\subsubsection{Pithoi}

A common characteristic of the West Cretan assemblages is the application on pithoi and jars of plastic decoration in the form of ridges, cordons, rope pattern, finger impressions and occasionally Kerbschnitt. There are also examples with incised decoration in the form of chevron pattern or hatching. Examples of jars and pithoi with plastic decoration below rim or on the shoulder exist since the EM I from 
Mitatoulia and throughout the EM IIA from Nopigeia and Platyvola with pithoi and jars with applied horizontal ridges, scoring and incision; at Kastelli there are pithoi with applied ridges, rope decoration and finger impressions in fine calcite fabric.

Plastic decoration is common in the EB II southern Aegean. There are examples from the Cyclades, namely Ayia Irini on Keos in a red-brown coarse ware (Wilson 1999: 46-47, Pl. 12: II-319, 320, 322) and from Thera (Sotirakopoulou 1999: 148-49, Pl. 140: 139); also from Kythera (Coldstream and Huxley 1972: Pl. 16: 35 , 37, 39, 40), Attica, namely Agios Kosmas (Mylonas 1959: 24, fig. 118), the Argolid, namely Lerna (Wiencke 2000) and the survey (Pullen 1995: 32-33, Figs. 25-26, 29).

In Central Crete the main type of decoration on pithoi is trickle decoration but there are a few examples of grooved and impressed motifs from Knossos (Wilson 1985: 353).

\subsubsection{Jugs}

The shapes discussed until now are typologically of off-island origin but highly represented in the West Cretan assemblages. The jug is a shape, represented in all the sites that have been studied in West Crete but also in the rest of the island. It displays morphological variability and a multitude of surface treatment and decoration. Due to its high frequency and wide distribution it is a good indicator of stylistic change and date.

The EM I period is represented in West Crete mainly in the assemblages from the caves of Platyvola and Perivolia as well as from the settlements of Debla, Kastelli and Mitatoulia. The early types are mainly in scored ware (for Debla see Warren and Tzedakis 1974: Pl. 53a-c; for Platyvola Alexiou 1964, PI. 523 top left; for Perivolia Tzedakis 1968d, Pl. 135a; for Kastelli Tzedakis 1965a: Pl. 711 bottom right). Typologically they are all large and globular like the one from the EM I Palace Well as well as Trench FF at Knossos, but there are significant differences in the way the scoring is applied (Wilson 1984: 249-50). 
In EM IIA there is a greater variety in the typology and surface treatment of the jugs. The main assemblage of jugs for this period derives from Debla from a single floor deposit with nine examples dated by the excavators at the very beginning of EM IIA. They are all in a red ware and have flat bases and pellet feet. In stylistic and chronological terms they are comparable to the ones from the West Court House (Wilson 1984: 275) but there are some features that do not exist in Knossos such as the pellet on shoulder, a diagonal row of circular hollows across the shoulder and a light horizontal groove around the shoulder (Warren and Tzedakis 1974: P6, 8-15, P10, P11, figs. 19-20). Similar vessels occur in other West Cretan sites such as Kastelli, Chania Town, Nopigeia, and Psathi. In some cases (especially in Kastelli and Chania Town) there are examples of jugs in red ware with scored surface, but scoring is not as heavy as in the previous period.

Except for the red ware jugs there is another type of the EM IIA period, namely the black slipped with incised herring-bone decoration on the shoulder. Examples of this type exist in Kastelli and Chania Town in the same ware as the black slipped (Urfirnis) sauceboats, saucers and goblets. There are no exact parallels from Central Crete, only a small distinctive group of vessels from the West Court House, among which there is one jug with herring-bone incision on the shoulder. However, this group is in a red burnished and not in a black slipped ware as is the case in West Crete.

Among the few examples of d-o-l painted ware there are several semi-coarse jugs, dating from EM I to IIB. The examples from Kastelli are typologically very close to the red ware examples, whereas the ones from Psathi are closer to Central Cretan examples. There is one example from Psathi (PST 00/21) with d-o-l banding that has parallels at the West Court House (Wilson 1985: 322, P191).

Despite regional variation and differences in ware and decoration, the jugs in West Crete follow the major changes taking place in the rest of the island in the beginning of EM IIA, namely the shift from large communal vessels to individual shapes with emphasis given to drinking and serving vessels. Among the latter are the jugs with flat instead of rounded bases. This change along with the addition of pellet 
feet indicates the shift from one type of use probably in communal ceremonies to the introduction of "table ware" and probably another type of feasting (Wilson and Day 2000: 59-60).

5.6 The rest of West Crete: an outline of the pottery assemblages from Stavromenos and Eleutherna in Rethymnon

The sites studied are located in the modern county of Chania and the comparisons of the EM ceramic material concerned this part of the island and Central and East Crete. However, according to geography and modern administrative terms, West Crete comprises not only the county of Chania but also the county of Rethymnon. Two sites from this area were studied for comparative reasons. The aim was to examine whether the pottery from this part of the island was typologically and stylistically closer to the assemblages from the far west or the central part of Crete.

The sites studied are Stavromenos on the north coast and Eleutherna south of the modern town of Rethymnon. From the typological examination of the ceramic assemblages it became clear that the disparity between the two traditions, Minoan and Helladic, that exists in the sites of the far west of the island, is not present in the sites of the area of Rethymnon.

The main wares represented are DGBW with chalices and pedestalled vessels similar to those from the Palace Well (Hood 1990b); red slipped and burnished with jugs, goblets and jars, very close to the Knossian red wares (Wilson 1985: 317-19); finally, dark-on-light, mainly with jugs with painted bands and chevrons, some with exact parallels in the West Court House (Wilson 1985: 328). As to coarse wares, there are examples of scored ware in Stavromenos that are typologically and technologically closer to the wiped and washed vessels from Central Crete and others that are closer to their counterparts from the far western part of the island. There are also jugs, jars and bowls in cooking pot ware fabric with red slip and wiping which occasionally can be patterned, similar to the EM I examples from the Early Palace Tests at Knossos (Wilson and Day 2000: 43). 
From this short outline of the pottery from the two sites in Rethymnon it is indicated that the majority of the material has closer affinities to Central than to West Cretan pottery traditions in terms of vessel wares and decoration.

\subsection{Discussion}

The typological and stylistic examination of the EM pottery from West Crete demonstrated that in EM I the wares and shapes occurring in the sites studied are compatible with those from contemporary sites in Central and East Crete. However, the presence of considerable amounts of scored ware vessels has no parallel in the rest of the island.

In EM IIA there is great discrepancy between Central and West Crete, the latter being characterised by the co-existence of two stylistically and technologically different pottery traditions: the Minoan part of the assemblage comprising wares familiar from other parts of the island and the Helladic/Cycladic part with wares and shapes known from assemblages in the Mainland and/or the western Cyclades. The assemblage from Nopigeia presents more Helladic than Minoan characteristics, whereas in all the other sites there is a mixture of Helladic style and Minoan material. It is of interest that the non-Minoan shapes display in many occasions characteristics of Minoan vessels, which was interpreted as an attempt of appropriation with the adaptation of foreign prototypes using elements of a local tradition.

The discrepancy between the two traditions is stressed by the fact that the non-Minoan vessels display a considerable typological homogeneity across west Crete. Moreover, they occur equally in settlements and caves, i.e. in contexts where different activities take place.

For comparative reasons the sites of Stavromenos and Eleutherna in the area of Rethymnon have also been studied. The ceramic material seems to be more closely related to the central Cretan pottery as known from Knossos rather than the west Cretan typology. 
Finally, the EM IIB period, although not well represented due to the lack of stratigraphic information, seems to be typologically and stylistically compatible with the ceramic assemblages from Central Crete, although some of the Helladic style vessels continue being produced. 


\section{CHAPTER 6}

\section{Petrographic Analysis}

\subsection{Introduction}

The typological examination of the Early Minoan (EM) material from West Crete provided information on the nature and variability of the pottery assemblage in West Crete and how similar or different it is to the pattern of Central and East Crete. The pivotal point around which the research revolved is the investigation of the two markedly different styles of pottery, the Minoan and the Helladic/Cycladic part of the assemblages (for the distribution of fabrics in the Helladic and Minoan style vessels, see Table III at the end of chapter).

The issues that arose after the study and typological classification of the material concern primarily the provenance and technology of the different pottery types. These issues are dealt with an integrated approach involving a combination of analytical techniques, namely thin section petrography, neutron activation analysis and scanning electron microscopy. In this and the following chapters will be presented the results of the analytical work.

Thin section petrography constitutes the main analytical technique used in the study of the EM material from West Crete and in this chapter the results of petrographic analysis are presented, examining issues such as provenance and technology. More specifically, the study of the clay pastes used for the manufacture of the pottery provides information on whether specific shapes and wares are local or imported and reveals technological aspects of the pottery such as clay mixing and tempering practices.

At a second level, it is examined whether there is connection between clay paste, shape, decoration/surface treatment and their relation to provenance. The technological characteristics and the general picture of the West Cretan pottery as 
derive from this study are compared with published assemblages from Central and East Crete.

\subsection{Thin Section Petrography}

Although only limited petrographic work has been carried out in West Crete ${ }^{1}$, previous analyses in Central and East Crete have provided valuable information on the production and distribution of pottery during the Bronze Age (Wilson and Day 1999).

Since Riley's work on Late Bronze Age material (Riley 1982) it has been demonstrated that Minoan pottery, including coarse wares, were not by definition locally produced, and that pots were exchanged across the island during the Bronze Age. On a methodological level, it was made clear that petrographic study could provide significant information on provenance.

Through the years, the archaeological questions addressed through analysis became more complex. There was a shift from questions related to provenance to issues of technology, production and distribution of pottery (Day et al. 1999). It also became apparent that there were theoretical and methodological issues to be considered, concerning the use and limitations of analytical techniques (Day 1988b; Whitbread 1995a). In order to tackle the complexity of the archaeological questions, a combination of techniques were required, along with a sound explanatory framework that would allow the researcher interpret and put in perspective the data resulting from the analyses. Pottery comprises a human-crafted material whose composition relies on many parameters, environmental as well as behavioural, which are not detectable by any single method. The study of EM pottery from Central and East Crete demonstrated the necessity of an integrated approach involving a combination of methods and techniques according to the nature of the archaeological question (Day et al. 1999).

Within this framework, there is still ongoing discussion on the quantity and quality of information that should be provided in petrographic descriptions, as well the possibility of their standardisation in order to make the results from different studies compatible and easily comparable. Relevant work carried out within GEOPRO TMR Network aimed at developing alternative methods of grouping and describing 
petrographic results, and providing a modified version of the existing methods in order to make them less subjective, less time-consuming and easily adaptable to other applications (such as mixed-mode data analysis) (Beardah and Baxter 2001).

Different systems of description have been proposed, most of them being provenance orientated and based on the existing descriptive systems used in geology (Myer et al. 1995). The latter, although descriptive for the non-plastics, contain little information on the matrix and the clay (plastic) inclusions. However, textural information can be critical when discussing ceramic fabrics, since it provides detail on the base clay used for the manufacture of the pottery in question. The properties of voids and textural concentration features are described (i.e. dimensions, shape, percentage) since the former might be indicative of provenance or forming technique, the latter might indicate provenance or tempering (Whitbread 1986).

In the case of West Crete, it was expected that, on the basis of the mineralogy of the different fabrics, it would be possible to discriminate between local and imported pottery and also examine patterns of production within West Crete. However, as will become clear in the detailed examination of the results, the grouping of the material was in several cases dictated by textural rather than compositional differentiation. The descriptions of petrographic groups, therefore, had to be in a system that would be able to reflect these differences.

In this study the descriptive system introduced by Whitbread $(1989 ; 1995 \mathrm{~b})$ is adopted. The terminology used in Whitbread's system is based on existing work on soil micromorphology (Bullock et al. 1985; Kemp 1985). The main difference with other systems is that, along with the non-plastic inclusions, the ceramic matrix is also described in order to obtain information related to the technology of manufacture. Perhaps the most important contribution for the present study is the introduction of new terminology for textural concentration features and argillaceous inclusions (Whitbread 1986).

For the visual estimation of percentages in thin sections, comparative charts were used, specifically those of Matthew et al. (1991) and Bullock et al. (1985). Detailed petrographic descriptions are presented in Appendix II.

\footnotetext{
${ }^{1}$ The existing petrographic analyses of West Cretan material comprise Chaniot stirrup jars (Day and Haskell 1995) and a comparative study of (mainly later) material from the Chania survey by $G$. Chandler (2001).
} 


\subsection{The fabrics}

The EM pottery from five settlement sites and a cave in West Crete was studied typologically and a rough repertoire of shapes and wares has been established for each assemblage. The sampling strategy aimed at selecting representative wares, shapes and macroscopic fabrics from each assemblage. The sites are Chania (Kastelli and Chania Town), Mitatoulia, Nopigeia, Debla, Psathi and Platyvola. Petrographic examination of approx. 400 archaeological samples resulted in the establishment of 27 fabric groups, some of which are related to smaller groups consisting of one or two samples with similar composition that for a variety of reasons are not included in the main group. Most groups are site-specific and it is of interest that similar fabrics occur in all sites but display compositional and textural differences. In what follows, the rationale, according to which the petrographic fabrics were established, is presented; then, the fabrics and their main characteristics are described briefly, along with a discussion on provenance and technological issues of the pottery. Finally, the results are brought together in a synthesis section.

\subsubsection{The establishment of petrographic groups}

The petrographic grouping of the EM material from West Crete is not a straightforward process, due to the nature of the material. The criteria used for the grouping were initially composition and texture. In the first phase, the samples were grouped according to their mineralogical composition. The groups that derived from this process were the tempered and the fabrics with a high frequency of a specific type of non-plastics. Due to the high proportion of a single non-plastic, the fabrics that stood out were those with calcite, siltstone and sand. It became clear that, although the calcite-tempered and the siltstone fabrics occurred at both Chania and Nopigeia (Fabrics D5, D6 and B6, B8 respectively), they were site-specific. The sand-tempered fabric (D4) occurred only at Chania. Another category that stood out after this first phase of grouping were the fine samples with fossils (Fabric D1). The fineness of the fabric along with the presence of a considerable amount of fossils led us to separate these samples. Creating sub-groups was more difficult because there were samples containing larger or smaller amounts of fossils, whereas others were finer or coarsergrained. These factors had to be evaluated at a subsequent stage. 
The above groups represented only a small proportion of the assemblage. The great majority was characterised by fabrics containing quartz, biotite mica, clay concentrations, occasionally micrite and grog, and in some cases larger or smaller amounts of low-grade metamorphic rock fragments. These fabrics were all manufactured with non-calcareous clays and the matrix was either red or grey due to oxidising or reducing firing atmosphere respectively. Due to the compositional homogeneity, other factors had to be taken into consideration for the establishment of the fabric groups: a) the amount, shape and texture of the different components might be technologically and archaeologically significant, b) the occasional occurrence of certain components, such as micrite and fossils might be indicative of different provenance in otherwise similar fabrics, and c) the non-plastic fragments might display differences related to the provenance of the fabrics.

The fabric groups derived using a combination of compositional and textural criteria demonstrated that most of the fabrics are site-specific. The Chania fabrics are characterised by a bright orange-red fabric, with medium-sized quartz fragments and occasional occurrence of micrite, which is not present in other sites. The Debla fabrics are quite similar, but the quartz inclusions are smaller, there is no micrite and the clay concentrations differ. The Nopigeia fabrics, although sharing similar broad composition with the other sites, contain more phyllite and a characteristic type of chert, which matches that observed in clay samples from the area of Nopigeia.

Finally, in the case of the fine Fabric D1, it was demonstrated that the amount of fossils was significant enough to indicate provenance, and, therefore, the samples from Chania were grouped separately from the samples from Nopigeia and Debla.

Grouping the EM assemblage from West Crete was not an easy task and involved decisions regarding similarity and dissimilarity, as well as the evaluation of factors other than mineralogical composition. The result confirms the choice of descriptive system and produces a fabric grouping that is archaeologically meaningful. 


\subsubsection{Fabric Groups}

\subsubsection{Mitatoulia (A)}

Fabric A1. Red with grog and white mica (P1. 38)

Subgroup (a)

MIT 00/ 2, 3, 5, 6, 7, 8, 10, 22, 23, 24, 26, 28, 29

KST 00/ 31

Subgroup (b)

MIT $00 / 12,14,25,30$

This is a semi-coarse to semi-fine red-firing fabric. Its main constituents are white mica, quartz, grog and textural concentration features (tcf's). There are two subgroups (a) and (b) with different matrix colour (subgroup (a) is red, subgroup (b) is yellowish grey) representing different firing atmospheres. In terms of composition subgroup (b) contains less mica than (a), but the general characteristics of the fabric are the same.

The non-plastics are not diagnostic of origin. This fabric occurs exclusively at the settlement site of Mitatoulia and may be considered broadly local. The presence of clay striations and porphyroclasts constitute evidence of clay mixing between a red clay (probably from an alluvial deposit) and a phyllitic clay, the latter containing white mica. From the limited clay sampling carried out, it has not been possible to locate any source of white mica. The fabric is clearly connected to the Phyllite-Quartzite series and most likely to a deposit of grey clay deriving from the weathering of phyllite. The deposits of grey/black phyllitic soil analysed contain predominantly phyllite but not white mica. Further geological prospection would clarify the provenance of this clay.

In clay sample S10A/2000 from Gonies in the area of Nea Roumata near Mitatoulia, the red deposit contains a considerable amount of metamorphic rocks, which are rather altered. Therefore, it could be suggested that the raw material for this pottery derived from a similar deposit and that the mica was a detrital product of weathering of metamorphic rocks. Another possibility could be that the clay used for 
the manufacture of this pottery was the product of levigation, and, therefore, the coarse fragments were removed and what remained was the fine mica.

It is the presence of white mica that differentiates this fabric from similar red fabrics from Chania. The other characteristics of the fabrics from Mitatoulia, such as the red non-calcareous matrix and the presence of grog and clay mixing are quite common in the other West Cretan sites. Most red fabrics in West Crete contain quartz, tcf's and grog, and share a similar technology of manufacture. Grog tempering constitutes a common practice in the early phases of Prepalatial (it is most frequent in EM I and EM IIA) and clay mixing is very common throughout the period.

All members of this group are from the Mitatoulia assemblage, except for one from Chania, which shares the same characteristics. However, it is not possible with petrology alone to decide whether it also shares the same origin. In terms of typology, the shapes represented are bowls, pedestalled goblets, pithoi and pithoid jars, basins and jugs. As for surface treatment, they are red slipped or scored and there are two dark grey burnished ware examples. The date for these vessels is mainly EM I with some EM IIA. The pattern is fairly common for the EM I period: there is no apparent functional or other differentiation, small and larger vessels are manufactured in the same fabric, it is only the firing conditions that change. This is also attested by the next fabric (A2), where the same characteristics are visible, the only differentiation being the addition of organic temper to the clay paste.

Fabric A2: Red with grog and organic temper (PI. 39)

MIT $00 / 4,13,15,31$

DEB 00/ 35

This fabric is very similar to the previous one (A1) in terms of composition and texture. It is also red-firing and the dominant components are white mica laths, tcf's and grog. The difference from A1 lies in the lesser amount of non-plastics and the presence of voids caused by burnt out organic matter.

The origin of the fabric cannot be assigned with certainty but it is broadly local to Mitatoulia, as is the case with $\mathrm{A} 1$. The technique of manufacture is very similar, i.e. mixing of a red and a phyllitic clay, the latter most likely being the source of the mica inclusions. It is certain that the two Mitatoulia fabrics are related with the same clay 
and grog tempering, but Fabric A2 is finer and is also tempered with organic material. This is also a quite common practice in early Prepalatial, the period to which the Mitatoulia assemblage belongs.

The majority of Fabric A2 samples belong to the Mitatoulia assemblage, along with one sample from Debla. The vessel types included are all coarse wares, mainly red or black slipped and burnished bowls, a dark grey burnished ware chalice, an incised pyxis and two pithoi. The pattern seen in Fabric A1 is repeated with the same clay paste being used for all types of pottery and vessel shapes without functional or other differentiation.

Finally, the origin of the Debla sample remains open since there are no other similarities between the two sites. It is not possible to decide on the basis of a single sample whether it derives from the same location of production as the samples from Mitatoulia, or whether similar clay sources were used in different locations.

Fabric A3: Phyllite and mica (Pl. 40)

MIT 00/17

This is a coarse, highly micaceous fabric containing large fragments of phyllite. It reflects an environment with low-grade, chloritised, metamorphic rocks. White mica present in the fabric links it to Fabrics A1 and A2. While in the previous cases a red and a grey phyllitic clay seem to have been mixed, in this fabric the predominant component is the coarse micaceous clay, derived most likely from a weathered phyllite deposit. A single sample in this fabric is a pedestalled goblet of EM I date.

\section{Related fabrics}

Fabric A4: Red with quartz (P1. 41a)

MIT 00/16

This is a small fabric group composed of two samples. It is quite close to Fabric A1, subgroup (b). It has a red-firing matrix and is composed of quartz, lowgrade metamorphic rock fragments, some sandstone and chert, but with fewer tcf's and no grog. The main difference is the absence of the long white mica laths. Its origin is 
broadly local, as is the case for the micaceous fabrics. The samples are both dark grey burnished ware (DGBW) chalices of EM I date. As at other sites in the study area, DGBW appears different from the rest of the assemblage at Mitatoulia.

Fabric A5: Red high-fired with metamorphic rocks (P1. 41c) MIT 00/20

This is a coarse, red-firing fabric. It is optically inactive, which indicates either a relatively high firing temperature or a fast firing. It is composed mainly of metamorphic rock fragments, namely phyllite and quartzite. The matrix displays higher packing than Fabric A1 and contains small quartz fragments. This sample is a dark grey burnished ware handle. All three examples of this ware (Fabrics A4 and A5) are different from the main fabric types of Mitatoulia in the dark colour of the matrix and more frequent rock fragments.

Fabric A6: Red low-fired with metamorphic rocks (Pl. 41d)

\section{MIT $00 / 18$}

This fabric is very close to Fabric A5: its main constituents are metamorphic rock fragments, the only difference being the colour of the matrix which is orange brown, most likely due to lower firing temperature. Typologically the vessel is related to the dark grey burnished ware since it is a pedestalled goblet, which is a type occurring in this ware, although in this case it is coarse and does not preserve any surface treatment. This differentiation could be due to its date, since the main date for the Mitatoulia samples is EM I whereas this sample is EM IIA in typological terms.

Fabric A7: Red with mica and organic temper (P1. 41b) MIT 00/1

This also is a semi-coarse, red-firing fabric containing white mica, small quartz, metamorphic rock fragments and a few tcf's. There is no grog but the voids indicate the use of organic tempering. This fabric is very close to the main Mitatoulia fabrics in terms of composition but there are textural differences, the packing is higher 
than in the rest of the samples and the occurrence of evenly distributed quartz fragments does not have any parallels at Mitatoulia. The vessel is a pithos.

\subsubsection{Nopigeia (B)}

Fabric B1: Coarse phyllite (Pl. 42)

NOP $00 / 5,9,10,12,17,19$

This is a coarse and relatively low-fired fabric characterised by the presence of low-grade metamorphic rock fragments, i.e. phyllite, quartzite and schist. Its origin lies in the Phyllite-Quartzite series of West Crete. It is relatively homogeneous in composition and texture and seems to be broadly local to Nopigeia. Its exact origin cannot be assigned since the Phyllite-Quartzite series outcrops all over West Crete. However, it differs from other phyllitic fabrics occurring in West Crete (Chania, Debla and Mitatoulia) mainly in texture. The Nopigeia fabric is generally coarser and lowerfired and contains less tef's.

All the samples of this group derive from the site of Nopigeia and are dated to EM II/EB II. The shapes include part of the domestic coarse wares, i.e. baking plates, one deep bowl and one collared jar. It is of importance that the same fabric is used for cooking ware and storage jars, which is not the case in Central and East Crete, where the fabrics seem to be more ware-, shape- and function-specific (Wilson and Day 1999).

Fabric B2: Coarse quartz-rich with metamorphic rocks (PI. 43)

Subgroup (a) (low fired)

NOP $00 / 1,6,11,13,20,30,32,35$

Subgroup (b) (high-fired)

NOP $00 / 3,24,29,39,40,80$

This is a coarse, red-firing fabric characterised by the presence of quartz and low-grade metamorphic rock fragments. There are two subgroups representing different firing temperatures and/or atmospheres, but compositionally and texturally 
they are very similar. This fabric is related to B1, but has fewer inclusions of metamorphic rocks and more quartz. However, both fabrics are related to the PhylliteQuartzite series with a red clay (probably of alluvial origin) mixed with a grey phyllitic clay. Deposits of the latter are common in West Crete, (see clay sample S8A/2000). In some cases, tempering with organic matter is attested by voids. This is a usual practice in EBA Crete, especially in the earlier phases of the Prepalatial (see also the fabrics from Mitatoulia).

All the samples in this fabric derive from the Nopigeia assemblage. They belong mainly to domestic coarse wares, the shapes represented being baking plates, jars (one incised), collar-necked jars, deep bowls, pithoi, a foot from a tripod cooking vessel, and two hearth rims. The pattern is similar to Fabric B1, with the same fabric being used for cooking and storage vessels. However, it should be mentioned that the tripod cooking vessel is most likely Middle Minoan, but was sampled in order to examine the use of this fabric in time. Moreover, it is significant that the hearths, which are considered Helladic and/or Cycladic style vessels and do not occur anywhere else in EBA Crete, are manufactured with the same fabric used for the usual domestic coarse wares (see also the case of the siltstone Fabric B6).

Fabric B3: Semi-coarse, quartz-rich with metamorphic rocks (P1. 44) NOP $00 / 27,51,52,54,77,79$

This is a semi-coarse fabric characterised by the presence of medium to small quartz and metamorphic rock fragments. It is a fine version of Fabric B2, the composition and texture being the same.

All the samples in this fabric derive from the site of Nopigeia. The shapes include smaller vessels than Fabric B2, namely two pyxides, two dark grey burnished pedestalled chalices, a closed vessel, and a jar. The two pedestalled vessels are EM I in date, the others are EM IIA/ EB II. It is of interest that the EM I vessels are manufactured with the same raw materials and clay recipe as the Helladic types of the EM IIA period. This indicates that it is the shape repertoire that changed, not the clay recipe. This is important when discussing the change in pottery that occurred in EM IIA, as the production of stylistically "foreign" shapes with a long established paste recipe tradition implies. 
Moreover, the fact that the DGBW, which is widespread all over Crete, is manufactured with the same fabric as other types of pottery demonstrates that it is a West Cretan product. The fabrics for DGBW are site-specific (see also Chania) and this is in contrast to what has been argued for Central and East Crete, where the DGBW vessels from different sites were found to share similar composition and technology of manufacture (Day et al. 1999).

Finally, in Fabrics B2 and B3 a pattern is revealed, which does not occur in the earlier period: there is a coarse and a fine version of the same fabric used for large and small vessels respectively, whereas in EM I there appears to be no such differentiation within our samples.

Fabric B4: Coarse phyllite with micrite and fossils (P1. 45)

NOP $00 / 15,23,36,41,47,48$

This is a coarse fabric characterised by the presence of metamorphic rock fragments, micrite/sand, biotite mica and fossils. Probably a grey phyllitic clay has been used, the metamorphic rocks being compatible with the Phyllite-Quartzite series, whereas the micrite and fossils are connected to the marls in the area around Nopigeia. This is a case of mixing of a red non-calcareous clay with a Neogene marl. There is also the possibility that, along with the phyllitic sediment, a red fabric was used that contained carbonates and fossils because clay samples such as S6A/2000 and $\mathrm{S} 12 \mathrm{~A} / 2001$ indicate that there are cases where red sediments contain such inclusions.

This fabric is related to the fabric with coarse phyllite (B1) by the type of metamorphic fragments as well as by chert fragments. The latter are present in the S3A/2000 clay sample, which was collected at Kastelli Kissamou at a short distance from Nopigeia. The presence of the same chert fragments grading into mudstone is in favour of a local origin for the Nopigeia fabrics.

All the samples in this fabric group derive from the Nopigeia assemblage. The shapes include types similar to Fabric B1, i.e. domestic coarse wares: a leg from a tripod cooking vessel, jars and bowls. The pattern is similar to that of Fabric B1, in that the same fabric is used for cooking wares and storage vessels. The date of these vessels is primarily EM/EB II, the tripod vessel, being most likely Middle Minoan in 
date.

Fabric B5: Semi-coarse with micrite (Pl. 46)

NOP $00 / 18,21,22,38,50,57$

This is a semi-coarse fabric characterised by the presence of micrite, quartz and metamorphic rock fragments. It is considered to be a finer version of Fabric B4 due to similarity in composition and texture. The main difference is the absence of coarse fragments of metamorphic rocks, perhaps due to levigation, sieving or removal by hand. The paste recipe seems to be the same as for Fabric B4, i.e. clay mixing of a non-calcareous clay and a calcareous marl. However, the samples are rather varied in the proportions of these different components: sample NOP 00/50 it contains more quartz and is compositionally and texturally close to a similar fabric with small quartz from Chania (D9). Sample NOP 00/18 has more calcite and bears similarities to the calcite-tempered fabric (B8).

All the samples of this fabric group derive from the assemblage of Nopigeia and are compatible with the local geology (see comment on Fabric B4). Except for the EM I dark grey burnished pedestalled chalice, the other shapes are EBII in date and include domestic coarse ware, i.e. bowls, a scored ware jug/jar, a dark grey burnished ware bowl and a cooking pot ware vessel. The patterning is the same as for Fabrics B2 and B3, i.e. the coarse and fine version of the same fabric being used for large and smaller vessels respectively.

Fabric B6: Semi-coarse with siltstone (P1. 47)

NOP $00 / 2,4,25,26,28,33,37,43,49,59$

This is a semi-coarse, red-firing fabric, characterised by the presence of coarse inclusions of siltstone set in a fine-grained micaceous matrix. The fine-grained chert, occasionally grading into mudstone, characterises the Nopigeia fabrics and is compatible with clay samples from the area of Kastelli. Therefore, this siltstone fabric can be considered local to Nopigeia. Another siltstone fabric occurs at Chania, but it is different in both its composition and texture.

This fabric occurs in a variety of shapes including large vessels, mainly domestic coarse wares, such as bowls, a basin, pithoi, jars and also two hearth rims. As was the case with the phyllite fabric, it is of significance that the Helladic/Cycladic 
style hearths are made in the same fabric as some of the domestic coarse wares that we would consider to belong to the normal repertoire of "Minoan" shapes. The vessels that bear surface treatment are either red slipped or scored.

Siltstone has been added to the clay paste as temper and this constitutes a common practice in Neopalatial Crete and is also known from ethnographic studies (Day 1991: 195). It is mainly used for large storage jars, one reason being probably functional, to make the clay less plastic. Ethnographic work on storage jars and pithoi demonstrated that the potters from Thrapsano temper the clays with shale and the potters from Koroni used mudstone (Blitzer 1990: 682), all these materials being similar in origin.

Fabric B7: Fine with pellets and grog (P1. 48)

NOP $00 / 16,42,44,55,56,58,60,61,62$

This is a fine, micaceous, red-firing fabric characterised by the presence of quartz, clay pellets and grog. The composition and clay matrix are similar to those of Fabrics B2 and B3. The latter were demonstrated to be local at Nopigeia (mainly due to the presence of fine-grained chert). In this fabric all the samples belong to the assemblage of Nopigeia and due to compositional similarity it could be suggested that it is also local and that the same clay recipe was used; the only difference is that the inclusions are finer and that grog was added.

The shapes include an EM I dark grey burnished ware chalice as well as jugs, jars and bowls of EM II/EB II date. In terms of surface treatment they are red/ black slipped, or scored.

Fabric B8: Calcite-/Dolomite-tempered (P1. 49) NOP $00 / 7,8$

This is a semi-coarse non-calcareous fabric characterised by the presence of angular fragments of calcite. In cases where calcite is frequent in a fabric, the issue of intentional tempering (large angular fragments) versus natural occurrence of calcite (more rounded grains) is raised (Rice 1987: 410). Calcite-tempering is a common practice in Minoan Crete (Day 1995: 164) but in this case the amount of calcite varies 
from common to very few and it is not always clear whether it was added as temper. The samples with large amounts of calcite are clearly tempered; for the ones with smaller amount there is the doubt of natural occurrence since calcite can be a minor component in red alluvial deposits. The other constituents of the fabric are quartz, some metamorphic rock fragments and biotite mica.

This fabric seems related to Fabric B5, the main difference being the absence of micrite. It does not contain the fossiliferous marl that characterises Fabric B5 but a red clay with inclusions of calcite and dolomite. As to the origin of the fabric it seems local to Nopigeia, as indicated by the presence of dolomite, which outcrops in the area and the chert grading into mudstone, which occurs in almost all major fabrics found at Nopigeia and is present in the Kissamos area. The base clay can be connected to the alluvial deposits in the area. Moreover, the presence of clay pellets with inclusions of well-rounded chert grains relates the clay paste of this fabric with that of the siltstone fabric (B6).

The shape represented is the baking plate, which occurs rather frequently in a calcite-tempered fabric in West Crete and the rest of the island (Day 1995: 164). However, it is not possible to suggest exclusive use of this fabric for baking plates and cooking ware since the coarse wares are underrepresented in the sampling of Nopigeia as the study was based on the selected material published by Karantzali (1997).

\section{Fabric B9: Chert-rich (Pl. 50)}

NOP $00 / 14,31,34$

This is a coarse, micaceous fabric characterised by the presence of large angular chert fragments along with quartz and low-grade metamorphic rock fragments. The type of chert is that found in many samples from Nopigeia (fine-grained sometimes grading into mudstone), which leaves little doubt as to the origin of the fabric. Moreover, the similarity with clay sample S3A/2000 from Kastelli (Kissamos) not only supports a local origin, but also demonstrates that a considerable amount of chert occurs naturally in the clay deposits in the area.

All the members of this fabric group belong to the Nopigeia assemblage and consist of large storage vessels of EM II/EB II date. There is one deep bowl, a pithos and a pithoid jar/basin. 


\subsubsection{Debla (C)}

Fabric C1: Red with quartz, grog and metamorphic rocks (P1. 51)

Subgroup (a): Coarse

DEB $00 / 2,9,11$

Subgroup (b): Semi-coarse

DEB $00 / 1,3,5,6,7,8,10,12,13,14,15,16,20,21,22,23,26,27,28,30,33,34$, $38,39,40,41,42,43,44$

This is a coarse to semi-coarse, red-firing fabric characterised by the presence of grog, tcf's, quartz, biotite mica and some low-grade metamorphic rock fragments. There are two subgroups representing the coarse and the semi-coarse part of the fabric. There appear to be a range of firing temperatures represented, but they all share the same compositional and textural characteristics. Clay mixing is indicated by the presence of clay striations and porphyroclasts. As already discussed for the red fabrics from Mitatoulia and Nopigeia, grog tempering and clay mixing are commonly practiced in EM Crete. As to provenance, the non-plastics are not diagnostic of origin and, although it is a West Cretan fabric with affinities to the red fabric from Chania, its specific provenance cannot be assigned. However, it differs from the fine red fabric from Chania in the absence of micrite and fossils. These two components characterise the fabrics from Chania and their absence from the fabrics in Debla points towards a different provenance for the latter.

The provenance of the vessels cannot be assigned solely on the basis of the mineralogy of the fabric, but the clay seems to derive from a red deposit. Clay samples S10A/2001 and S11A/2001 from Varypetro and Debla respectively give an idea of the red deposits in the broader area around Debla; they both derive from red formations consisting mainly of sandy marls, clays, sandstones and conglomerates. They are compositionally, and in some cases also texturally, close to the archaeological samples. This does not imply that pottery was being manufactured at Debla, but in the area of the Varypetero plain there are sediments available for pottery manufacture.

All the samples of this fabric group belong to the Debla assemblage and are of EM I-IIA date. The shapes consist of pedestalled chalices (EM I), incised pyxides, 
jugs, jars, bowls, and pithoi. In their majority they are red/black slipped and burnished, black burnished or scored. The pattern here is reminiscent of that at Nopigeia, i.e. the same fabric being used for large and smaller vessels in a coarse and a finer version respectively.

Fabric C2: Fine red with quartz and grog (P1. 52)

DEB 00/4, 24, 25

KST $00 / 52$

This is a low-fired, fine, red fabric composed of small quartz fragments, biotite mica, grog and rarely some low-grade metamorphic rock fragments. Because of its composition and texture, it can be considered the fine version of Fabric C1. Despite not having a distinct composition, it is clearly related to the red deposits that stretch along the north coast, to the west of Chania.

The samples in this fabric group are vessels from Debla with the exception of one from Kastelli. The shapes represented are two red slipped jugs in scored ware, one black burnished incised pyxis and the Kastelli vessel is an incised jug. The technology of manufacture is similar to Fabric $\mathrm{Cl}$ and it is of interest that scored jugs occur in both fabrics. Could the difference in the coarseness be indicative of chronology? One of the samples (DEB 00/24) preserves traces of the slip, which stretches along the surface of the vessels and follows the curves created from scoring (P1. 52d). This leaves no doubts about the technique of surface modification, i.e. that scoring preceded the application of slip.

As to the presence in this group of the sample from Chania, it is not possible to decide on mineralogical grounds whether it shares the same origin as the Debla vessels or is the product of a similar choice of raw materials in the broader area. In terms of typology, there are two points worth stressing: the fact that jugs and pyxides share the same fabric, although they are functionally different, and also that the different types of jugs are manufactured in a single fabric, independent of surface treatment. 


\subsubsection{Chania (D)}

Fabric D1: Very fine to semi-coarse with fossils (P1. 53, 54)

Subgroup (ai) Very fine

KST $00 / 54,55,56,57,59,60,61,63,64,66,68 \mathrm{a}, 69,70,73,74,76,77,79,82,83$, $84,86,104,137$

CHT 00/ 17, 19, 24, 25, 26 (?), 32, 33, 34

PLT 00/ 11

Subgroup (aii) Semi-coarse

KST $00 / 16,53,62,67,71,72,78,80$

CHT 00/ 14, 35

Subgroup (b)

NOP 00/ 45, 46, 53, 63, 64, 65, 66, 67, 68, 69, 70, 71, 72, 73, 74, 75, 76, 78

DEB $00 / 17,18,19,32,37$

This is a fine to semi-coarse fabric characterised by the presence of small fragments of quartz, biotite mica laths, micrite and fossils. It comprises samples from Chania, Platyvola; Nopigeia and Debla. This group is texturally broad and there are two main subgroups: (a) comprises those from Chania and Platyvola (Pl. 53), while subgroup (b) comprises the samples from Nopigeia and Debla (Pl. 54). Moreover, subgroup (a) is further subdivided in two parts, the first containing the fine-grained samples, the second the semi-coarse-grained ones. The sample from Platyvola displays compositional similarity to those from Chania, which is taken to indicate common origin. On the contrary, the Nopigeia and Debla samples, although similar in composition and texture to the samples from Chania, are discussed as a subgroup. The main difference is that in the samples from Nopigeia and Debla there is a significantly smaller amount of micrite and fossils. Since these elements characterise several fabric groups from Chania their absence is considered to be indicative of different origin for the samples of this group. 
In the samples from Chania the fossils are identified as species reflecting an environment of deep water (pelagic) ${ }^{2}$. They indicate the use of a Neogene marl for the base clay. The presence of chert and metamorphic rock fragments along with clay porphyroclasts and striations indicates clay mixing with a red clay (CHT 00/26). The fineness of the fabric is probably due to levigation or sieving.

The fabric is compatible with the fossiliferous Neogene deposits near Chania, along the north coast. Some samples in the group contain larger amounts of fossils than others, and this could create doubts about whether all the samples share the same origin. However, clay sampling in the area demonstrated that different marl deposits in close vicinity to each other might contain varying amounts of fossils: samples S3A/2001 and S4A/2001 derive from the Platanias marls and contain considerable amounts of fossils and micrite. However, from the same formation comes S11A/2000, which contains mainly biotite mica, quartz and only a few fossils; there are also samples S13A/2001 and S14A/2001 from the deposits near the modern town of Chania, as well as S1A/2001 from a marl deposit near Psathi, which have similar composition. Another argument in favour of the common origin of all the Chania samples is that several of the Chania fabrics (along with Fabric D1) contain micrite. This is also repeated in the clay samples, which in several cases are characterised by significant amounts of micrite. The presence or absence of micrite provides us with a supplementary argument in favour of a Chaniot provenance.

In the samples from Nopigeia microfossils are less frequent and micrite is absent. These are considered to be indications of different origin, although the raw materials are similar. Burial conditions seem to have affected greatly the assemblage. The surface slip is hardly visible macroscopically, whereas under the microscope the fossils are visible only under PPL as voids. The samples from Debla are very similar to those from Nopigeia compositionally and texturally but contain no fossils. This may also be considered indicative of different origin.

The repertoire of shapes in this fabric is very similar at all sites and includes mainly the Helladic style vessels of EM II date, i.e. sauceboats, saucers, incised jugs, spouted jars, footed goblets, and two askoi. The jugs and askoi contain medium-sized inclusions, the rest are in a very fine fabric. In their great majority, these vessels are

${ }^{2}$ Many thanks to Margarita Dimiza from the Dept. of Geology of the Univ. of Athens for the identification of the fossils. 
black slipped but there are a few that are red slipped or mottled (mainly saucers and goblets respectively). The fabric is very fine and is not diagnostic of origin, even in the cases of samples with medium-sized inclusions.

The difference in the fabric between Chania, Nopigeia and Debla is rather surprising considering the typological and stylistic similarity of the vessels. The black slipped ware of Helladic style is present in all settlement sites and caves and might have been expected to be the product of a single centre of production. However, the fabrics, although similar, do not support such an assumption. The compositional difference between the fabrics from the different sites might represent the existence of a few centres of production, manufacturing the same type of pottery and using similar recipes and sources of raw material. It could equally be due to chronological difference in the occupation of the sites, associated with change in the source of raw material and/or the clay mix.

Fabric D2: Fine to semi-coarse with fossils and micrite (P1. 55)

KST 00/ 9, 10, 58, 85, 103, 105, 107, 109, 111, 113, 114, 115, 116, 117, 118

CHT 00/ 13, 15, 16, 20, 21, 22, 28, 31

PST $00 / 4,8,9,10,11,12,14,28,30$

This is a fine fabric, very similar in composition to Fabric D1 described above. It is characterised by the presence of monocrystalline quartz, micrite and fossils in varying amounts reflecting the Neogene marls of the north coast around Chania. The presence of some shell fragments points towards a provenance from the Neogene marls, as indicated by the clay samples. There are also small amounts of chert and metamorphic rock fragments. The technology of manufacture seems the same as for Fabric D1, i.e. clay mixing of a marl and a red clay. Indications of clay mixing included clay striations and clay concentrations not well dissolved in the clay mixture. The samples derive mainly from Chania but also from Psathi.

The criterion that led to the separation of this fabric from D1 is primarily the presence of micrite in significantly larger quantities, as well as the occurrence of smaller amounts of chert and the lower firing temperatures for most of the samples. 
This fabric is compatible with the Neogene marl deposits at Agia Marina, just $8 \mathrm{~km}$ west of Chania on the north coast and with the marly sandstones within the area of Chania as indicated by clay samples. More specifically, it relates to samples S3A/2001 and S4A/2001 deriving from the Platanias marls, samples S13A/2001 and S14A/2001 from the deposits near the modern town of Chania. All the clay samples are close in composition to Fabric D2. They contain micrite, quartz, biotite mica and fossils. Differences between pottery and clays lie in the texture, the amount of fossils and of micrite. It is high likely, therefore, that this pottery constitutes a local Chaniot product.

The shapes represented are mainly saucers but also shallow bowls, small jugs, sauceboats, footed goblets, side spouted jars, a small pyxis and an askos. In terms of surface treatment they are red slipped and burnished; the ones from Psathi are red or black monochrome and some are mottled. All vessels are EM IIA in date, although those from Chania include also some EM IIB. Due to the lack of stratigraphic information, it is not feasible to decide with certainty whether this slightly different fabric represents also chronological difference. It could be suggested that the shapes that were mainly black slipped of EM IIA date in Fabric D1 continue in late EM IIA and IIB (with an emphasis on saucers) but are red slipped and with a slightly different fabric.

Fabric D3: Fine with fossils and grog (Pl. 56)

KST 00/22, 24, 27, 30

This fabric displays compositional similarity with Fabrics D1 and D2. It has a fine matrix and is characterised by the presence of fossils and micrite, the latter in larger quantities than in the other fabrics. There are also metamorphic rock fragments and chert in smaller quantities than in the other fabrics. It is compatible with the Neogene marls of the north coast around Chania and from the clay samples it is clear that micritic fragments occur naturally in these deposits (see S13A/2001 from the fossiliferous marly sandstones of Chania).

The presence of grog is notable: grog-tempering is a common practice throughout Crete, especially in the EM I-IIA period. In the West Cretan examples, it is the red clays that are most frequently tempered with grog. In the samples of this fabric 
group it seems that there existed a combination of techniques with clay mixing of a non-calcareous and a calcareous clay (the latter containing micrite and fossils) and addition of grog.

All the members of this group derive from Kastelli Chania and consist of red or black slipped scored ware vessels (jugs and large bowls) of EM I-IIA date. Scored ware is widespread across West Crete since EM I and constitutes one of the known local products. The fact that it shares a similar fabric with the two groups of Helladic types is important for the provenance and technology of the Helladic style vessels. Fabric D3 occurs only in scored vessels and is slightly different in composition from the other fossiliferous fabrics (D1 and D2). This compositional difference is probably related to the date of the scored ware: these vessels are a little earlier in date than those of groups D1 and D2. Moreover, the shapes represented in this group are coarser and, except for date, compositional difference might also reflect different recipes between coarse and fine wares.

Fabric D4: Sand-tempered with fossils (P1. 57)

KST $00 / 11,46,48,87,88,90,92,93,94,95,96,97,98,99,100,101,102,123,128$, $131,132,135$

CHT $00 / 38,39,40,42,43,44,45,49$

PLT 00/ 17, 18, 19

This fabric is characterised by a fine red-firing matrix with coarse inclusions consisting mainly of rounded sand grains and fossils. The other constituents are quartz, chert and some metamorphic rock fragments. The fossils were identified as deriving from a sediment source representative of a near shore environment, the most common species being Miliolidae. In sample CHT 00/42 there are Numulitae. According to the geological map, these species occur in the marly limestones that are found west of Chania (I.G.S.R. 1971).

In some samples there are indications of clay mixing in the form of clay striations and porphyroclasts as well concentrations of unmixed clay in the matrix. The red matrix is probably related to the alluvial deposits of the same area. It seems that there is mixing of a red clay of alluvial origin and a fossiliferous marl. Red/alluvial 
deposits are quite numerous in the area around Chania and there is no indication to suggest a non-Chaniot origin, especially since this fabric does not occur anywhere else in West Crete. However, the type of fossils occurring in this fabric has not been observed in any of the marls collected, although the clay sampling has not explored all sources of red and marl deposits. In cases of fabrics containing sand, the main question is whether sand occurs naturally in the sediment or was added by the potter. In this case it seems clear that the fabric is purposefully tempered, but what remains to be examined is the type of sand used. It has been demonstrated that both beach and riverine sand were used for tempering in the EBA (Wilson and Day 1994: 32), but further geological sampling is required, in order to clarify the type of sand used for this fabric.

The tradition of sand-tempering is widespread in Minoan Crete, notably in the early Prepalatial period (the case of Mesara discussed in Wilson and Day 1994: 3132). This fabric occurs only at Chania and Platyvola and seems to be local to the area around Chania. The samples from the cave were most likely brought in from Chania. The vessels represented in this fabric are of EM I-II date and consist mainly of bowls and jars; there are a few coarse vessels too, namely baking plates and pithoi. It is of importance that the collared jars from Platyvola are considered to be Cycladic /Cycladicising shapes but have a fabric common to domestic Minoan coarse wares. Moreover, the pattern seen at Nopigeia and Mitatoulia is repeated here, with cooking wares and storage vessels being manufactured in the same fabric as each other.

Fabric D5: Calcite-tempered (PI. 58)

KST 00/ 38, 40, 41, 42, 44, 45, 47, 89, 91

CHT 00/36, 37, 41, 46

DEB 00/31

This is a coarse fabric characterised by the presence of large angular fragments of calcite/dolomite, which were crushed and added as temper in the clay paste. The other constituents are quartz, chert and some metamorphic rock fragments. The base clay consists in a fine, red-firing, non-calcareous clay. The raw material seems compatible with the crystalline and sometimes dolomitic limestones that outcrop in many locations in West Crete. The red fabric may be derived from the alluvial or terra 
rossa deposits that occur throughout West Crete and the metamorphic rock fragments are compatible with the Phyllite-Quartzite series.

The practice of calcite-tempering (as well as grog-tempering, as represented in sample KST 00/38) is widespread in Crete during the Prepalatial period. In Central and East Crete it does not outlive EM IIA. In West Crete it continues until EM IIB and there are two types of calcite-tempered fabric: one occurring at Chania, the other at Nopigeia. The difference between the two lies in the presence of two types of tcf's (red and greenish brown) in the former. These are common in most fabrics from Chania, they are related to clays from alluvial deposits and indicate local origin. In the samples from Nopigeia the presence of fine-grained chert grading into mudstone is also in favour of local manufacture in the area of Nopigeia.

The samples of this group belong mainly to the assemblages of Chania, except for one from Debla. The latter is the only Debla sample that belongs to a Chania group and therefore it is not possible to decide whether coarse wares were brought in the site from Chania, whether there is some chronological significance (the site of Debla being a little earlier?) or whether they represent similar raw materials. The shapes include large coarse domestic vessels ranging in date from EM I to IIB: jugs, jars, deep and shallow bowls, and baking plates. In terms of surface treatment, in most cases they are plain but there are also scored and/or red slipped vessels.

\section{Sample PLT 00/16 (Pl. 58e)}

This sample needs to be discussed separately; it is fairly similar to the group described above in terms of composition but displays textural differences. The calcite fragments are larger than the ones of Fabric D5 and the general appearance of the fabric is coarser. The vessel is a red slipped and scored bowl of EM I-IIA date in cooking pot ware. The difference in fabric might reflect a chronological difference, the material from Platyvola being slightly earlier than that from Chania.

Fabric D6: Siltstone and fossils (PI. 59)

Subgroup (a) Coarse

KST 00/ 13, 65, 68b, 133 
Subgroup (b) Semi-coarse-Fine

KST 00/81

CHT 00/ 18

PST 00/ 34

This is a semi-coarse to fine-grained fabric characterised by the presence of angular fragments of siltstone added as temper in a fine clay groundmass. There are two subgroups, (a) and (b), representing the coarse and finer version of the fabric. The coarser version is characterised by the presence of considerable amounts of chert (for the Chania samples) whereas the fine version contains more micrite and fossils.

It is not easy to assign provenance for this fabric but the presence of fossils similar to those of groups D1-3 indicates the marl deposits on the north coast around Chania. The practice of tempering with siltstone especially for storage vessels is reported not only from EM West Crete (namely Nopigeia) but also from Late Minoan sites and contemporary ethnographic work (Day 1988a; Blitzer 1990; see also comment in Nopigeia Fabric B6).

Although a siltstone fabric is also present at Nopigeia (B6) it is rather different in texture, which is important when considering that similar raw materials were used at different production centres. Fabric D6 includes samples mainly from Chania and two samples from Psathi. The fabrics are similar in composition and texture, but the samples from Chania contain more chert and more fossils; this difference occurs also between the red fabrics of Chania and Psathi and it remains an open question whether the Psathi samples were produced in a different location, with similar raw materials and technique of manufacture.

The shapes comprise vessels of EM I-IIA date, namely two saucers, two jug handles, a lid, a large open vessel, a small bowl and a jar. The lid is black burnished, the rest are red/black slipped and burnished. It is worth mentioning that one of the jug handles (sample KST 00/68b) and the body of the vessel are made with different clays (see sample KST 00/68a). This observation is indicative of the manufacturing procedure, since it demonstrates that the handles are manufactured separately and 
attached later to the body of the vessel. The fabric used for the handles is coarser, probably because it has to be made stronger when the jug is being lifted and carried by the handle. It is also of interest that the vessels in this fabric are smaller than the ones of the siltstone fabric at Nopigeia. This supports further the argument that the pottery is locally produced in the broader area where it is found. The textural and small compositional differences of the fabrics, along with the type and size of the vessels represented argue in favour of different locations of production.

Fabric D7: Siltstone II (P1. 60)

KST 00/122

This fabric is semi-coarse and characterised by the presence of siltstone fragments and secondary calcite. It is different from Fabric D6 in the texture and quantity of the inclusions. Although this sample is semi-coarse and high-fired, it cannot be compared with the semi-coarse samples of group D6: the siltstones contain more inclusions, they seem weathered, and the amount of chert is much less than in the previous fabric. It cannot join the fine samples of group D6 either, because the amount of fossils is smaller and this fabric contains shell fragments, which is not the case for Fabric D6. Moreover, the greenish colour of the matrix indicates high firing of a more calcareous clay than that of group D6. It can, therefore, be suggested that the way of manufacture is the same, i.e. with the use of a fossiliferous marl. However, the amount of fossils and the presence of shell indicate the use of a different deposit of raw material than that used for the samples of Fabric D6.

In terms of typology, this sample is also quite different: it is a large jar with calcareous slip and painted decoration of EM II date. This type of decoration is quite rare in West Crete and this unique case is not sufficient in order to clarify whether it belongs to a different manufacturing tradition.

Fabric D8: Red with quartz, grog and calcite (P1. 61, 62)

KST $00 / 12,15,18,20,25,29,35,39,43,106,120,121$

CHT 00/ 1, 2, 6, 7, 8, 9, 29, 30, 48

MIT 00/ 9 
PLT 00/ 12

\section{EM I subgroup}

KST 00/ 2, 3, 5, 6

\section{CHT 00/4}

This is a semi-coarse to semi-fine fabric, low-fired and compositionally characterised by the presence of quartz, grog and calcite (Pl. 61). The other constituents are micrite, a few fossils and some metamorphic rock fragments. The nonplastics are of similar size-range. The general picture of the fabric is that it derives from a red firing clay mixed with a marl; the evidence of clay mixing is rather prominent in this fabric in the form of clay striations and porphyroclasts. In some cases, there is also organic tempering. The presence of micrite and fossils is related to the marly component of the clay paste. As to the calcite the amount varies and it is not possible to decide whether it is added on purpose as temper for two reasons: a) the size of the calcite fragments is significantly smaller than in the proper calcite-tempered fabric, and b) clay sampling demonstrated that calcite occurs naturally in the Neogene deposits.

It is difficult to discuss the provenance of the fabric on the basis of its mineralogical composition. It seems to reflect a type of red deposit that is common in West Crete. The main varieties of red deposits comprise alluvial formations, which are abundant all along the north coast, detrital soils from weathered limestone and pockets of terra rossa. All three types were sampled selectively and examined in thin section. The red sediments across the western part of Crete present compositional similarities. They consist mainly of quartz and biotite mica in varying amounts and, in some cases, there exist also chert and fragments of metamorphic rocks.

In some of the archaeological samples, there is indication of clay mixing with clay striations and porphyroclasts and therefore it might be suggested that there is mixing of a red and a marly clay, hence the fossils. The occurrence of metam orphic rocks is compatible with the geological background of West Crete and the consistency of the red deposits. Therefore, it can be suggested that these vessels were manufactured in the area of Chania, since the alluvial and marly deposits in the vicinity could have provided the necessary raw materials. 
The samples derive mainly from Chania but there is also one sample from Platyvola cave and one from Mitatoulia. In terms of typology the shapes represented are large and medium-sized vessels, namely shallow and deep bowls, pithoi, jars, a basin, a baking plate and a jug, all of EM I-IIA date. As to surface treatment they are scored or red/black slipped and burnished. The practices of grog and chaff tempering as well as clay mixing are known from other EM sites in Central and East Crete, but also in West Crete. Moreover, it seems that the cooking wares and storage jars are manufactured in the same fabric.

Special mention should be made of the small EM I group, which constitutes a subgroup of Fabric D8, but it is not described separately (P1. 62). Compositionally, it is very similar to the rest of the group but the amount of calcite and micrite is greater than in the rest of the group. In these samples, we could envisage the possibility of calcite-tempering, although it is not certain for the reasons mentioned above. This small group exhibits considerable homogeneity in terms of fabric and typology. All the vessels are red/black pedestalled bowls of EM I date. Therefore, it can be suggested that this fabric starts in EM I and continues into EM IIA in different wares.

Finally, the presence in this group of one sample from Platyvola Cave can easily be explained since there are other Chaniot fabrics represented there. However, the sample from Mitatoulia is a more complicated case since the red fabrics from Mitatoulia are in general quite different from those at Chania. It is not easy to suggest movement of pottery from Chania towards Mitatoulia, on the basis of a single sample, but it is still a possibility open to further research and sampling.

Fabric D9: Red with quartz, grog and pellets (P1. 63)

KST $00 / 7,8,14,19,26,28,34,37,39,119,126$

\section{CHT 00/ 23}

This is a semi-coarse to semi-fine fabric, very similar to D8. It is red-firing and its main constituents are quartz grog and clay pellets. The other non-plastics include quartzite, biotite mica, some metamorphic rock fragments some micrite, fossils and chert. The difference with Fabric D8 lies in the significantly smaller amounts of calcite, micrite and fossils and the fact that some of the samples seem higher fired. In this fabric there is also evidence of clay mixing in the form of clay striations and 
porphyroclasts. It seems likely that this represents mixing of a red alluvial clay and a marl (see comment in Fabric D8).

All the samples of this group derive from the Chania assemblages. In terms of typology they belong to EM I-IIA vessels with varied surface treatment: there are slipped and burnished shallow and deep bowls and a chalice; a black burnished lid; and two plain vessels a pithos and a baking plate. There are also scored ware bowls and jugs. Samples KST 00/7 and 00/8 are EM I and very close to the EM I subgroup of Fabric D8, without the calcite and micrite. It could be suggested that this fabric constitutes a finer and higher fired version of Fabric D8. The presence of pellets could be due to the fineness of the clay, which might have been levigated and therefore coarser tcf's must have been removed.

Fabric D10: Coarse phyllite (P1. 64, 65)

Subgroup A: coarse buff

KST 00/32, 108, 110

CHT 00/ 12

Subgroup B: coarse red

KST 00/4, 23, 49, 50(?), 51, 125, 130

CHT 00/ 5, 11

DEB 00/ 29

This is a coarse to semi-coarse fabric characterised by the presence of lowgrade metamorphic rock fragments. The other constituents are quartz, some micrite and chert. There are two subgroups: (a) contains more coarse phyllite fragments and is fired in a reducing atmosphere (P1. 64). Subgroup (b) has matrix that is deeper red, indicating oxidising atmosphere, and contains more quartzite than phyllite (P1. 65). This fabric is related to the Phyllite-Quartzite series, which outcrops widely in West Crete. The presence of occasional micrite fragments and fossils might be indicative of clay mixing with a marl but this should be considered with caution since micrite can also be a detrital component in a red sediment. Only in the case of KST/ 50 the presence of micrite is undoubtedly associated with clay mixing. 
As to clay striations and other evidence of clay mixing it can also be suggested that a red clay was mixed with a white/grey phyllitic clay.

The samples of this fabric derive mainly from Chania and there is also one sample from Debla. The shapes are of EM I-IIA date and include jugs and jars, a baking plate, a bowl, a pedestalled bowl and an askos. In terms of surface treatment, they are all red slipped and burnished, the lid is black burnished and there are also some scored ware vessels.

This fabric is in composition close to Fabrics D8 and D9, the main difference being the presence of metamorphic rock fragments. It is also interesting that these fabrics share the same vessel shapes and wares: it seems that the same vessel shapes are manufactured with different raw materials. This might be indicative of different workshops or recipes of manufacture. Sample KST 00/4 is of EM I date and seems related to the EM I subgroup of Fabric D8. It could, therefore, be suggested that it is more or less the same recipe with the use of a clay richer in metamorphic rock fragments.

The case of samples KST 00/51 and 108 is worth mentioning since the pedestalled bowl and the askos are both of Helladic/ Western Cycladic type but the fabric used for their manufacture is West Cretan and compatible with Minoan domestic wares.

Fabric D11: Coarse phyllite, sand and fossils (P1. 66)

KST 00/ 127, 129

CHT 00/ 27

This is a semi-coarse to coarse red-firing fabric. It consists mainly of quartzite, micrite and fossils (among which some shell fragments), the other components being quartz, calcite and chert. It seems that there is clay mixing of a red clay with a fossiliferous marl. It is compatible with the main components of the Chaniot fabrics.

This must also be a case of clay mixing between a red clay with metamorphic rocks and a fossililiferous marl. Where the origin of the fabric is concerned, there seems to be compatibility between the fabric and the fossiliferous marls of the area of 
Chania where occur shell fragments as shown by the clay samples and the other fossiliferous fabrics from Chania.

The samples of this group are of EM I-IIA date and belong to the Chania assemblages. The shapes include storage vessels, namely jars and one pithos. They are not decorated except for one coarse ware painted jar.

There is a compositionally similar fabric at Nopigeia (B4) used for a wider range of vessel types including jars. However, the major difference between the two fabrics is the presence of shell fragments and the lower packing of the non-plastics in the Chaniot fabric.

\section{Related Fabrics}

Fabric D12: Very fine red (P1. 67a,b)

\section{CHT 00/3}

\section{KST 00/75}

This is a very fine, red-firing fabric. It is composed of quartz, biotite mica, tcf's and a few fragments of quartzite and chert. In the first sample the slip is visible. This fabric is related to the red fabrics from Chania (D8-D9) in terms of composition and to the fine fabrics with fossils (D1-D2) in terms of typology and texture. It is fine, but does not contain any micrite or fossils, which in the case of Chania indicate the presence of a Neogene clay. The first sample is a small goblet/ bowl, the second is a jug/jar, both are black slipped and are of EM IIB date.

Fabric D13: Red with white mica (Pl. 67c)

KST 00/1

This is a semi-fine red firing fabric containing small fragments of quartz, white mica laths, tcf's, grog and some quartzite. This is among the few cases where white mica is present in the Chania material and, although connected with the PhylliteQuartzite series, its origin cannot be defined. White mica is widely present in the fabrics from Mitatoulia; more specifically this sample with small quartz fragments evenly distributed in the clay matrix is very close to the MIT 00/1 sample (Fabric A7). 
However, the sample from Mitatoulia does not contain as frequent white mica as the Chania sample. However, the date of the two vessels is compatible, since the Chania sample is a black slipped pedestalled bowl of EM I/EB I date which is also the date of most of the material from Mitatoulia. This does not in any case indicate movement of pottery from Mitatoulia towards Chania or vice versa due to the scarcity of micaceous fabrics at Chania. It is more an indication of use of similar raw materials during the same period.

Fabric D14: Red, quartz-rich, a DGBW fabric? (P1. 68)

CHT 00/ 9, 10,

KST 00/ 15, 17, 18

This is a semi-coarse, red-firing fabric. It is composed of quartz fragments, biotite mica, tcf's and grog. In terms of composition and texture it is related to Fabric D8 from Chania and more specifically to the EM I subgroup. The main difference is that in most samples of this fabric there is no calcite or micrite. This might be an indication that there is no clay mixing with a Neogene marl and that a single red clay is used, which is similar to the one used for the EM I vessels. However, sample KST $00 / 18$ contains micrite and calcite and constitutes the link between the two fabrics. It is not clear whether it is a matter of recipe or chronology that DGBW is manufactured with and without clay mixing but it seems that it is related to the EM I manufacturing traditions. All the samples of this group are dark grey burnished and in terms of shape they include a goblet, a pedestalled bowl, a jar and two bowls. Their date ranges from EM I to EM IIA.

Fabric D15: Red with micrite (P1. 69a,b)

KST 00/9, 10

This is a semi-fine red-firing fabric, composed of small fragments of quartz, biotite mica, some micrite and a few fragments of quartzite, chert, tcf's and very few fossils. It is not included in the fossiliferous fabrics from Chania because the presence of fossils is minimal, or in the red fabrics due to the presence of micrite and fossils, which indicate clay mixing with a Neogene marl. It links with sample KST 00/18 from 
the previous group (Fabric D14), which also contains small quartz fragments and micrite. The vessels of this group are both shallow bowls, of EM IIA date and the surface is red slipped with scribble burnishing.

Fabric D16: High-fired with siltstone and serpentine (P1. 69c) KST 00/33

This is a semi-fine, high-fired fabric made, most likely, with a calcareous clay since the matrix is optically inactive and displays a green colour due to firing. There are only a few inclusions, some quartz, siltstone and serpentine, along with some grains of sandstone, chert and phyllite. It is not clear whether this fabric is related to the siltstone fabrics from Chania but it seems local; although serpentine has not been identified in the EM material from Chania it might occur as a detrital mineral in the Phyllite mélange. The sample is a scored ware sherd of EM I-IIA date.

Fabric D17: Fine with ostracods (P1. 69d)

KST 00/134

This is a semi-fine fabric composed of quartz, metamorphic rock fragments, biotite mica, a few microfossils and frequent ostracods. It is related to the fabrics with fossils from Chania but in the latter ostracods occur only rarely. However, it is compatible with a. West Cretan origin and more specifically with the Neogene marls on the north coast around Chania. Typologically it is a large semi-coarse jug of EM I date with painted decoration. It is worth mentioning that it is also comparable to Fabric D7 (Siltstone II), which comprises a Minoan shape (a jar) with painted decoration and a fabric containing ostracods.

Fabric D18: Red with microfossils (Pl. 70a,b)

\section{CHT 00/26}

KST 00/ 137

This is a semi-fine, red-firing fabric composed of quartz, biotite mica, micrite, microfossils and some chert. It is connected to the fossiliferous fabrics from Chania 
due to the presence of micrite and fossils but also to the red fabrics due to the matrix with the small quartz fragments. Both samples are red slipped goblets of EM IIB date. The differentiation between this and the fossiliferous fabrics is interesting in that it demonstrates the continuation of a manufacturing practice but also adaptation to the requirements of the period - Minoan vessels and surface treatment (red slipped, as opposed to the EM IIA black slipped).

Fabric D19: Red with calcite and white mica (PI. 70c)

\section{CHT 00/47}

This is a semi-coarse, red-firing fabric. It contains large amounts of white mica, and it is not comparable to the Mitatoulia fabrics due to the amount of mica and the occurrence of other inclusions such as calcite, micrite and tcf's. It is not clear whether it is a calcite-tempered fabric since fragments of calcite and micrite might occur naturally in the red deposits. Typologically it is a deep bowl/jar in scored ware but its date is not clearly early Prepalatial, it may be later.

\subsubsection{Psathi (E)}

Fabric E1: Red with quartz and mica (P1. 71, 72)

Subgroup (a) Low-fired

PST $00 / 7,15,24,35,36$

Subgroup (b) High-fired

PST $00 / 1,2,3,5,6,13,16,17,18,19,20,21,23,25,26,27,29,31,32,33$

This is a semi-fine, red firing fabric characterised by the presence of angular fragments of quartz evenly distributed in the clay matrix. There are two subgroups representing low (P1. 71) and high (Pl. 72) fired samples. Except for the difference in firing temperature, the two groups are very similar in texture and composition. The base clay seems to be the product of clay mixing of a red clay and a fossiliferous marl although the fossils are not clearly visible (probably due to ground conditions and high firing). This fabric is reminiscent of the Chania fabrics but this is probably due to the 
similarity of the raw materials because it lacks the calcite and micrite fragments that occur constantly in the Chania fabrics. Moreover, the presence of grog and clay pellets is not as pronounced as in the Chaniot fabrics.

In terms of typology, the samples from Psathi include both Minoan and Helladic type shapes of EM IIA-IIB date: incised pyxides, jugs (some with cutaway spout), bowls, goblets, long-spouted jars, but also sauceboats and saucers. These vessels are either red/black monochrome or mottled, a jar and a long-spouted jug are dark-on-light painted.

The absence of grog tempering is probably due to the late dating of these vessels since this tempering tradition characterises the early phases of the EM period. It could also be attributed to the character of the Psathi assemblage since there does not seem to exist many coarse wares, it consists mainly of semi-coarse to fine drinking and serving vessels. It is therefore of interest to examine whether this differentiation from Chania is due to a different production location or is a matter of chronology and typology.

\subsubsection{Platyvola (F)}

Fabric F1: Red with quartz, grog and pellets (Pl. 73)

PLT $00 / 1,2,4,5,6,7,8,10,13,14,20$

This is a red-firing fabric with semi-coarse inclusions consisting mainly of quartz, tcf's, grog and a few metamorphic rock fragments. In terms of composition it is very close to the fabrics from Chania (D8 and D9) but there is one component that differentiates the Platyvola samples: there are no calcite and micrite fragments or fossils. It also differs in terms of texture since there seem to be more tcf's than in the other Chaniot fabrics. There is strong evidence of clay mixing in the form of clay striations and porphyroclasts.

The vessels that reach the cave have been produced in West Crete but it is not possible to decide whether it is at Chania or elsewhere. The main shapes represented are medium to large-sized vessel, namely jars and jugs but there are also pedestalled bowls, a pedestalled goblet, two incised pyxides and two jars. In terms of surface treatment and decoration, the pedestalled vessels are red or black slipped and 
burnished, the jugs are red slipped or scored and PLT 00/8 is red slipped on the outside and scored on the inside of neck, the collared jar is scored, the other jar is red slipped and painted and there is also one DGBW bowl. It is of interest that all these vessel types with so different decoration share the same fabric. In terms of dating, the pedestalled vessels are EM I, the rest is EM I-IIA. This seems to follow the pattern seen at the assemblage from Mitatoulia, i.e. a red fabric being used for vessels of various types and sizes.

The similarity with the Chania fabrics is quite pronounced and typologically the material from Platyvola is earlier than that from Chania; moreover, due to the repeated patterning of the EM I with a single fabric being used for various vessel types, it can be suggested that these differences in fabric between Chania and Platyvola may be chronological. It is possible that the pottery that reaches Platyvola is from Chania and that the raw materials used are similar but not the same, the absence of use of fossiliferous marls making the difference.

\section{Related fabrics}

Fabric F2: Red, quartz-rich (P1. 74a)

PLT 00/9

This is a semi-fine, red-firing fabric, the micromass is optically inactive and is composed of evenly distributed quartz fragments, biotite mica and a few metamorphic rock fragments and chert. It is related to the main group from Platyvola but the packing is higher and there are not as many tcf's (cf. PLT 00/7). The sample is a red slipped jug of EM II date.

Fabric F3: Red with metamorphic rocks (P1. 74b)

PLT 00/15

This is a semi-coarse, red-firing fabric; it is high-fired and related to the main fabric from Platyvola. The only difference is that it contains a larger amount of metamorphic rock fragments. The vessel is a jug/jar red brown slipped and scored of EM I-IIA date. 


\subsection{Discussion}

Petrographic analysis of ca. 460 archaeological and geological samples from six sites in West Crete provided interesting results regarding the provenance and distribution of the various fabrics as well as the technology of manufacture of the EM pottery. It is of importance to examine the patterning in the use of different clay pastes, in order to assess the technological characteristics of pottery wares and related production centres.

\subsubsection{Comment on the distribution of fabrics}

The fabrics identified are mostly site-specific but not unrelated to each other. This happens because in most cases they present compositional similarities between sites, but also display variation in one or two components of their composition and/or texture that differentiates them from each other. This is quite prominent in the case of the red fabrics, where the presence of calcite or micrite as well as the amount of quartz constitutes the basis for the discrimination between the different sites or even for subgrouping within sites.

Fabric distribution concerns three main categories of fabrics, namely those with fossils, the red and the phyllitic fabrics, all three reflecting the geological background of West Crete. Moreover, there are other types such as the calcite- and siltstone-tempered fabrics that occur in a number of the sites and display similar characteristics but represent local production. The geology of West Crete is dominated by outcrops of the Phyllite-Quartzite series and Neogene marl deposits all along the north coast, and deposits of terra rossa mainly in the form of alluvium, and also as relic soils. It has been demonstrated that all fabrics are connected with the West Cretan geology and are broadly local. Because the clay sampling was not exhaustive and the intention was not to replicate ancient fabrics, it has been proven extremely difficult to relate the archaeological material with specific clay sources and discuss provenance of the different fabrics in more detail than "broadly local".

The fossiliferous fabrics occur primarily, and in some cases exclusively, in Chania. They display common compositional characteristics but they differ in texture and the type of fossils contained, i.e. species indicating near shore and deep-water environment. As demonstrated by the clay samples these differences are also reflected 
in the Neogene marl Chania and the north coast. It is not surprising that there is similarity between the fossiliferous fabrics from Chania and those from Psathi, both sites being on the north coast. What is surprising is that there are textural differences between these fabrics, which reflect different deposits. This may indicate a different provenance, but may also reflect variability over time within the same source area.

The red fabrics are represented in all sites but Psathi. They reflect the variety of the different types of red sediments that occur in West Crete as indicated by geological prospection and clay samples. They all contain quartz, some metamorphic rock fragments, tcf's and grog. But the mineralogy is not distinctive of provenance. There are textural and compositional particularities in every site that differentiate between fabrics. The groups from Mitatoulia and Nopigeia are clearly different, the former being characterised by the low packing of the non-plastics and the presence of white mica, the latter from the presence of considerable amount of metamorphic rock fragments. The samples from Chania (Fabrics D8 and D9) and Debla (Fabric C1) are quite similar but the former contain calcite and micrite, which is not the case for the latter. Both these components occur naturally in the alluvial sediments of the north coast and are present in most of Chania fabrics. Therefore, their presence in the Chania red fabrics and their absence from Debla is taken as indicative of different provenance.

The phyllite fabrics are related to the Phyllite-Quartzite series outcrops in West Crete. They occur in Mitatoulia, Nopigeia and Chania and are also site-specific. The Mitatoulia sample (Fabric A3) is different from all the others due to the presence of white mica. The fabrics from Nopigeia (Fabrics B1 and B2) and Chania (Fabric D10) can be very similar in terms of firing, composition and texture especially the coarser samples (see NOP 00/12 and KST 00/30). However, there are certain aspects that differentiate them from each other: in the samples from Nopigeia there are more metamorphic rock fragments as well as chert and the latter is proven local from the clay samples. In the samples from Chania there is micrite, which is connected to the Neogene marls of the area. The red matrix is strongly reminiscent of the red fabrics from Chania with the calcite, the grog and the small quartz fragments.

For the phyllitic fabrics there are also varieties with micrite and fossils in both sites. In the fabric from Nopigeia (B4) the presence of chert favours a local origin whereas in the fabric from Chania (D11) there is calcite and grog, which link this fabric with the red fabrics from Chania. 
Calcite-tempered fabrics are also present in most sites (namely Chania, Platyvola, Debla, Nopigeia) and seem to constitute products of local workshops. The raw materials used are similar but there are textural differences. The sample from Platyvola is very similar to the ones from Chania but the size of the calcites is different which might be representative of different chronology. The practice of tempering with calcite, which is widespread all along the island is also known and practiced in local fabrics in West Crete. It is also of interest that one of the two calcite-tempered fabrics is local to Nopigeia, which indicates the existence of a production unit somewhere in the area.

The siltstone fabrics constitute a similar case, with one of the two main fabrics being local to Nopigeia and the other being local to Chania. This fabric seems to be a West Cretan characteristic probably related to the red deposits that occur all over West Crete.

The connection between all these fabric categories seems to rely on the geological background of West Crete. It has already been mentioned that the fossiliferous fabrics are related to the Neogene marls of the north coast. The phyllite fabrics are related to the Phyllite-Quartzite deposits that outcrop all over West Crete. The red fabrics contain metamorphic rock fragments, which should be detrital inclusions of the phyllite background. Finally, the mica fabrics are likely to represent the fine fraction of red alluvial or phyllite clays that have undergone levigation or sieving. All this indicates the exploitation of a multitude of sources for the procurement of the raw material.

\subsubsection{Comment on the technology of manufacture}

\subsubsection{The clays}

The petrographic examination of the EM material from West Crete provided information on the types of clay used in pottery manufacture. Due to the lack of variability in the types of rocks and sediments occurring in the area, the raw materials used are quite similar in their mineralogical composition. There are three main types of clay identified by the study of the thin sections:

i) red clay: this derives mainly from Quaternary alluvial deposits, which occur along the north coast, or from pockets of terra rossa soil, or from weathered limestone 
deposits. It is non-calcareous and contains a variety of inclusions that occur in different combinations and size ranges. The main types of inclusions are quartz, biotite mica, micrite, calcite, chert and metamorphic rock fragments. The red earth constitutes the base of every clay paste and is used by itself or in clay mixing for the manufacture of small and large size of vessels. There does not seem to be selection of raw materials according to the functional requirements, except probably the fact that it is suitable for coarse and cooking pot wares. In West Crete the red clays are used for storage jars, cooking pots, jugs and goblets.

ii) white clay: this derives from the deposits of Miocene marls that occur along the north coast. It is finer than the red clay, it is calcareous and contains medium to smallsized inclusions, the main ones being quartz, biotite mica, micrite/sand and fossils. It is used in clay mixing with a red clay mainly for the manufacture of small vessels but also some coarse wares too, mainly jars.

iii) grey/black clay: this derives from deposits of shale and is connected to the Phyllite-Quartzite series. Its main constituent is phyllite/shale and is used in clay mixing for the manufacture of coarse and semi-coarse vessels.

The use of these types of clay is also known from analyses of Late Bronze Age pottery and from ethnographic studies in Crete (Day 1991). These clays display different properties and through clay mixing the optimum result is achieved, i.e. increased plasticity, resistance to firing, strength of the vessel, interruption of crack propagation. More specifically, the ethnographic record demonstrates that the red clays are used primarily for cooking vessels; they are resistant to heat and prevent the pot from cracking. Moreover, the natural occurrence of non-plastics prevents the spread of cracks in the vessel body during firing (Day 1991: 193).

The white marly clays vary in particle size and composition and the amount of fossils also varies between the different deposits. In general these clays are more plastic, they have good workability and provide support to the vessel body during the manufacturing process. They are used in clay mix for small and large vessels.

The phyllitic clays are quite fine-grained, they contain non-plastic inclusions, which serve as natural temper, they are resistant to firing and prevent crack propagation. They increase the workability of the clay and the strength and stability of the vessel. They are oily in texture and this makes the vessels waterproof. In modern 
workshops they are used as the main temper or in clay mixes for large storage jars (Day 1991: 84; Blitzer 1990: 682).

\subsubsection{Clay recipes in EM West Crete}

The main paste recipes identified by thin section petrography in the EM pottery from West Crete involve manipulation of the raw materials prior to vessel construction and what can be inferred from the study of ceramic thin sections is clay levigation and/or sieving and more securely clay mixing and tempering. These practices are very common in Bronze Age Crete but also in modern times (Blitzer 1990).

\subsection{Clay sieving}

Levigation and/or sieving are carried out in order to purify the clay by removing the coarse fraction (pebbles and granules) and thus make it more plastic. This practice is often recorded in ethnographic studies. In Crete the dry-sieve is mentioned at Thrapsano (Voyatzoglou 1984: 133) and Kentri but recently in the latter the settling tank was introduced for this effect (Blitzer 1984: 148). In thin section the purification of clay through sieving can only be inferred by the relative amount of nonplastics occurring in relation to raw materials samples. In the case of the West Cretan pottery, sampling of raw materials was not intended to replicate clay recipes, but rather to provide an idea on the composition of different clay deposits in the area. Considering also that the sources throughout West Crete are quite similar in nature (and occasionally. in composition), there is only a limited amount of information available concerning clay manipulation for the manufacture of pottery.

The clay samples of terra rossa display compositional homogeneity, the main constituents being quartz and biotite mica with rare fragments of metamorphic rocks and chert. In the pottery fabrics, where terra rossa clay was used, the amount and/or size of chert are in most cases substantially smaller, whereas the amount of mica is higher. In the cases of the fine fabrics this phenomenon is more pronounced, since the only constituents of the fabric are quartz and mica. Considering that mica occurs naturally in the clay, as will be explained below, this is taken to be an indication of sieving in order to remove the coarse inclusions. With marl deposits it is more difficult to identify sieving in thin section since the raw material is fine by itself. 


\subsection{Clay mixing and tempering}

Clay mixing is more securely identified in thin section due to specific textural features connected with this practice, namely clay pellets, striations and porphyroclasts as well as fragments of undissolved clay. It is widely practiced in Bronze Age Crete, but also in modern times (for ethnographic parallels from the New World, see Rice 1987: 121-4). The clay pastes conform to the functional requirements of the vessels (storage of food, transport of liquids, serving of food and liquids etc.) and with clay mixing the properties of the different types of clay are exploited.

Ethnographic work on Crete has demonstrated that the main types of clay mixing involve a red terra rossa clay and a white clay (marl) in varying ratios. Sometimes grey/black clay is also added for the manufacture of large vessels (Blitzer 1984). In the ethnographic and archaeological literature there is differentiation in the recipes used for small and large vessels even within the same workshop: for the former red and white clay is used whereas for the latter two or three clays can be mixed, the third component being the grey/black clay (Day 1991: 194). The major differentiation though in clay recipes is between storage and cooking vessels. They are both large in size but the functional requirements are totally different; the latter need to be resistant to extensive and repeated heating and therefore specific care is taken in the selection of the raw materials, which in some cases is a single red clay (Day 1991: 184, 194).

As will be discussed in more detail later (Chapter 9), clay recipes and raw material sources are not related to the functional requirements of the ceramic vessels alone. They are also connected to traditions of manufacture and in most cases they are transmitted from one generation to the following. The ethnographic record has demonstrated that potters in Crete believe that clay mixing is necessary but Matson (1973) mentions that a potter from Euboea used to making jars using a single clay continued doing so in Crete.

Tempering constitutes a practice closely connected to clay mixing since it is carried out for the same purpose, i.e. to enhance the properties of the clay during manufacture, as well as the properties of the finished product. The term temper refers to all non-clay materials (non-plastics) added to the clay and it can be mineral (quartz and calcite), organic (seeds, plant fragments, bone), bio-mineral (shell, sponge spicules) or man-made (grog) (Rye 1981). The main properties of all tempering 
materials are improved clay workability through decreased plasticity, more even drying of the vessel, elimination of microcracking, reduced shrinkage, acceleration of firing schedules (Bronitsky and Hamer 1986; Kilikoglou et al. 1998). Moreover, the final product is more resistant to heavy use, contact with fire, etc.

The petrographic examination of the EM pottery from West Crete has demonstrated that both practices (clay mixing and tempering) are widely applied in pottery manufacture. Clay pellets, striations and porphyroclasts are very common in the West Cretan samples (PI. 75). In most cases, there are more than one type of clay pellets indicative of more than one types of clay. The main clay mixes identified are between red clays deriving from alluvial deposits and white clays from Neogene marls, whereas the tempering materials used include grog, calcite, sand, siltstone and organic matter (Pl. 76).

All types of clay pastes occurring in EM West Crete involve red clays. In several cases it is possible that a single raw material was used. As demonstrated by the limited clay sampling and the experimental briquettes, all the clays collected were successful in firing even in the cases where they had not been previously sieved. It should be taken into consideration that the requirement in clay plasticity is much higher in pottery manufacture than in briquettes but this is an indication that clays in West Crete display good workability. It should also be taken into account that the natural occurrence of quartz and mica in the clay constitutes by itself an effective way of increasing the toughness of the vessel and impeding crack propagation (Kilikoglou et al. 1998; Vekinis and Kilikoglou 1998).

In EM I most fabrics appear to be red and contain quartz, pellets and grog. Argillaceous inclusions help to rectify specific imperfections of the original clay and enhance the raw material's performance. Moreover, grog is stable during firing because it is already fired and possesses the same thermal expansion properties as the fabric into which it is incorporated (Rye 1981; Whitbread 1986). In West Crete red fabrics with clay pellets occur all along the Prepalatial period in all sites and are used for large and small vessels; grog tempering is attested from EM I to EM IIA and occurs in all sites. The red clays of West Crete seem to be quite suitable for pottery manufacture and they are used intensively throughout the Prepalatial period. 
In the case of Mitatoulia, where the presence of white mica is very pronounced, it seems that a red alluvial clay is mixed with a grey/black phyllitic clay but the limited clay sampling in the area was not enough to demonstrate the source of the sediment.

The second most frequently occurring tempering material is calcite. Its use spreads throughout the Prepalatial period but most of the vessels are EM II. Tempering with calcite is very common practice throughout the Bronze Age and it is used mainly for cooking ware. The benefit from using tempering material high in calcium carbonate is that it makes the clay stiffer and increases its workability. Moreover the thermal expansion of calcite is similar to that of average fired clays and, therefore, stresses due to differential expansion of clay matrix and temper are minimal when the vessels are heated and cooled during use (Rye 1981). Another advantage of limestonetempered composites is that they produce a more workable clay body, which allows for thinner and more globular vessels and a fired clay body that is more resistant to mechanical stress (Hoard et al. 1995). In West Crete calcite-tempered fabrics are found at Nopigeia, Chania and Platyvola. They are used not only for cooking ware but also in jugs, jars and large bowls.

Finally, the use of organic temper is quite frequent since the EM I mainly for large storage vessels (pithoi). Plant remains improve the plasticity of clays and reduce shrinkage. The voids resulting after the vessels have been fired impede the propagation of cracks (Rye 1981).

In the EM.II period the clay pastes involve mixing of a red clay with a marl. There are fine and coarse fabrics that combine both components. Many fine wares are manufactured by mixing a calcareous and a non-calcareous clay. The marl deposits around Chania contain varying amounts of fossils. Shell and fossils occur naturally in the sediments and it seems that they were preferred by prehistoric potters because they act as temper creating a better bond with the clay. Their rate of thermal expansion is similar to that of the clay, reducing risk from inhomogenous expansion in firing. Moreover, they need high temperatures for relatively short periods of time, which is the case for most prehistoric pottery (Bronitsky and Hamer 1986). Moreover, the 
Neogene marls of the north coast contain non-plastics such as micrite, mica, calcite and chert, which serve as natural temper.

The Helladic black slipped ware from Chania with medium to small-sized vessels constitutes the main category of pottery manufactured with a mixture of a red and a white clay with fossils (Fabrics D1 and D2). It seems that the fine black slipped ware from Nopigeia and Debla is also manufactured with similar clays although the amount of fossils is significantly smaller (probably a different deposit). This clay paste seems to be optimal for the result sought since it requires high temperatures.

At Chania there is a small fabric group (D3) where the same clay mixing is combined with grog tempering. It comprises Minoan style medium-sized serving vessels, namely jugs and a bowl.

Except for the fine wares there are cases of coarse vessels manufactured with clay mix of a red and a white clay. In Chania and Nopigeia occur fabrics with coarse phyllite and micrite/sand (D11 and B4, B5 respectively). In both cases they are used for large storage vessels but at Nopigeia they also comprise cooking and serving vessels.

Cooking and serving vessels occur also in a sand-tempered fabric. This practice is widespread in Central and East Crete but in West Crete occurs only at Chania (Fabric D4). The vessels in this fabric are mainly storage and transport jars and a few cooking vessels.

At Chania and Nopigeia occurs also a siltstone-tempered fabric of local origin (D6-D7 and B6 respectively). The vessels of the Chania assemblage are mainly smallsized whereas the variation of this fabric (D7) is a jar. It is of interest that on a jug sherd (sample KST 00/68) two fabrics co-exist, the handle being in siltstone fabric, the body being in a fine fabric with fossils (D1). At Nopigeia it occurs in domestic coarse wares and hearths (but not cooking pots). It seems that siltstone works the same way as shale and mudstone for modern potters, i.e. it turns the clay more plastic and increases its workability, that is the reason why it is used for large vessels. 


\subsubsection{Other technological aspects of the West Cretan pottery}

Except for clay pastes the study of thin sections offered some insight on forming techniques. In some cases coil joins are visible in smaller and large vessels indicating that this technique was widely used.

Finally, the different types of surface treatment serve not only aesthetic but also functional purposes. By burnishing the surface of the vessel the clay particles become oriented and permeability is reduced. The same effect is also achieved through the application of a slip which creates a non-permeable layer which vitrifies during firing (Aloupi and Maniatis 1990: 467). This is necessary for drinking vessels and vessels containing liquids. In West Crete burnished wares comprise mainly jugs, jars and smaller vessels such as saucers and bowls. Slipped wares comprise medium and small-sized serving and drinking vessels such as sauceboats, askoi, saucers and jugs.

Scoring is a very common method of surface treatment since the earliest phase of the Prepalatial period and, in most cases, is combined with burnishing. Except for reduced permeability, the roughness of the surface provides a more secure grip of the vessel, which is necessary especially when it is for transfer (Rice 1987: 232). It seems that the combination of burnishing and scoring provides the optimum result that is the reason why large vessels, namely jugs and jars are bear often this surface treatment.

\subsection{Conclusions}

The petrographic examination of EM pottery from West Crete provided significant information in two realms: provenance and technology. Before summarising the main points of the study, it is worth discussing briefly the limitations of the method in the specific study. The issue of primary interest in any petrographic study is that of provenance. In the case of West Crete it was demonstrated with a degree of certainty that the fabrics are compatible with the geology of the area, but it is difficult to assign provenance with more detail on geological grounds alone. The homogeneity in the geological background of West Crete is reflected in the ceramic fabrics in the form of compositional similarity. Moreover, the lack of stratigraphic information and of clear archaeological deposits did not allow the establishment of a chronological sequence for the different fabrics. Because some samples cannot be dated with precision, there are only indications for fabrics and clay recipes that 
continue from one phase of the Prepalatial to the other. It is also an open issue to what extent variation between similar fabrics reflects chronological difference. This is something to be addressed by future sampling. At present, it remains to examine with other techniques, including chemical analysis, whether the compositional similarity of the fabrics from different sites is also reflected in their elemental concentrations.

Despite the impediments deriving from the geology of the area and the chronology of the material, petrographic analysis demonstrated that, except for West Cretan, the pottery fabrics are in most cases site-specific and that the different fabrics are local. This means that during the EM period the manufacture of pottery was being carried out in the broad area of the sites where the finished products were consumed. This can be suggested for five out of the six sites, i.e. the settlements, because the material found in the cave of Platyvola may have been brought from Chania. Moreover, it was demonstrated that the non-Minoan types are not imported but manufactured with local clays and, in many cases, they share the same fabrics as Minoan wares.

Petrographic analysis has proved to be informative also on the technology of manufacture of the different wares. There are three types of fabrics occurring in all sites, namely red, phyllitic and fossiliferous fabrics. Petrographic analysis demonstrated that, although similar, these fabrics display variation in some their components according to the site they derive from and this differentiates them from each other. There are also smaller fabric categories occurring in one or two sites, such as the calcite-tempered and siltstone-tempered fabrics, which, however, are used for different types of vessels. All this is taken to be indicative of local manufacture.

When examining the relation between fabrics, wares and vessel shapes through time, the emerging pattern is that in the EM I period there is no differentiation between the fabrics used for large and small vessels. The main fabrics are red with natural inclusions of quartz, biotite mica, calcite and occasionally micrite and it seems that they are used independently of vessel size. In terms of wares there does not seem to be any ware-specific pattern, except for the dark grey burnished vessels. It is not clear whether this ware follows specific recipes because in some cases it is differentiated from the rest of the assemblage (as is the case at Mitatoulia) in others this is less prominent since some samples join the main fabric groups of the site (as in the case of Chania and Nopigeia). The issue of the dark grey burnished ware is very interesting in 
that it is one of the earliest wares that continue into the EM IIA period, it occurs throughout the island and has been studied extensively in Central Crete (Wilson and Day 1994). However, the lack of stratigraphy and secure chronology of the West Cretan material does not allow us follow the change in clay recipes for this ware (if any) through time. Although the variability in fabrics and elemental composition between DGBW samples has been demonstrated by petrography and chemistry, it would be interesting to analyse samples from stratified contexts in order to investigate possible changes from the EM I to the EM IIA.

In the subsequent period (EM IIA), it seems that there is clear differentiation in the fabrics used for large and small vessels but also for different wares. At Nopigeia and Chania, which are the main sites with EM IIA pottery, there are many cases of fabrics displaying differentiation between the coarse and the fine fraction used for different size vessels (Fabrics B2-B3 and D8-D9 respectively). Moreover, there is clear differentiation between the fabrics used for the Helladic type vessels in comparison to Minoan wares. Although site-specific, the fabrics used for the black slipped Helladic type ware were grouped together (Fabric D1) because they share similar compositional and textural characteristics. Moreover, the issue of the nonMinoan wares is interesting not only for the fine but also for the coarse vessels. Hearths and collared jars are the main types of Helladic/Cycladic coarse wares occurring in west Crete and it has been demonstrated that they are manufactured with similar fabrics as domestic coarse wares.

Another characteristic of the EM IIA period is that there is not any differentiation between the fabrics used for storage and cooking vessels. This must be due to the fact that the clays in West Crete display natural properties such as good workability and naturally occurring non-plastics that make them suitable for both types of vessels. Moreover, it must be said that the issue of storage versus cooking vessels has not been exhaustively investigated in this study, due to the underrepresentation of the latter type of vessels in the assemblages. Because most of the samples were selected from mixed deposits, it has not been feasible to have a full range of the cooking wares, which constitute one of the most stable wares through time in terms of typology as well as technology. Further archaeological sampling from well-stratified contexts might provide a clearer picture of the issue. 
It was demonstrated that the dominant pattern is of fabrics that are not directly related to vessel shapes, but there are some exceptions. Although no fabric is used exclusively for jars, it seems that in many instances transport jars are connected to fabrics containing micrite/sand and fossils, i.e. fabrics where there is clay mixing with a calcareous marl. There are jars in the coarse phyllite with micrite and fossils from Nopigeia (B4), in the sand-tempered fabric from Chania (D4) as well as the two single samples of jars with painted decoration from Chania, (Fabrics Siltstone II (D7) and fine with ostracods (D17) respectively).

Finally, the clay pastes reflect practices known and widespread across West Crete, even though they are not always used for the manufacture of the same types of pottery. Mixing of a red clay and a marl is quite common, as well as tempering with calcite and siltstone. However, there are fabrics that occur exclusively in a site, such as the sand-tempered fabric at Chania. All this points towards a pattern of local production, related to the settlements where the pottery would be consumed. However, typological and compositional similarity indicates that specific types of pottery are sought. This is of importance, especially in the case of the Helladic type black slipped wares, which are so similar that they seem to have been produced with similar raw materials, recipes and techniques of manufacture. This implies a widespread knowledge of the styles and techniques available during the EM period. 
TABLE III

Petrographic Fabrics and Styles

\begin{tabular}{|c|c|c|}
\hline Fabrics & Minoan & Helladic \\
\hline A1. Red w. grog + white mica & $\mathbf{x x x x}$ & \\
\hline A2. Red w. grog + org. temper & $\mathbf{x x}$ & \\
\hline A3. Phyllite and white mica & $\mathbf{x}$ & \\
\hline B1. Coarse phyllite & $\mathbf{x x x}$ & $\mathbf{x}$ \\
\hline B2. Coarse q-rich w. metam. & $\mathbf{x x}$ & $\mathbf{x x}$ \\
\hline B3. Semi-coarse q-rich w. metam. & $\mathbf{x x x x}$ & \\
\hline $\begin{array}{l}\text { B4. Coarse phyllite with micrite } \\
+ \text { fossils }\end{array}$ & $\mathbf{x x x}$ & $\mathbf{x}$ \\
\hline B5. Semi-coarse with micrite & $\mathbf{x x x}$ & $\mathbf{x}$ \\
\hline B6. Semi-coarse w. siltstone & $\mathbf{x x}$ & $\mathbf{x x}$ \\
\hline B7. Fine w. pellets and grog & $\mathbf{x x}$ & $\mathbf{x}$ \\
\hline B8. Calcite-tempered & $\mathbf{x x x x}$ & \\
\hline B9. Chert-rich & $\mathbf{x x}$ & $\mathbf{x x}$ \\
\hline C1. Red w. quartz, grog + metam. & $\mathbf{x x x x}$ & \\
\hline D1. V. fine-Semi-coarse w. fossils & $\mathbf{x x x}$ & $\mathbf{x}$ \\
\hline D2. Fine-med. w. foss + micrite & $\mathbf{x x}$ & $\mathbf{x x}$ \\
\hline D3. Fine w. fossils and grog & $\mathbf{x x x x}$ & \\
\hline D4. Sand-temp. w. fossils & $\mathbf{x x x}$ & $\mathbf{x}$ \\
\hline D5. Calcite-tempered I & $\mathbf{x x x x}$ & \\
\hline D6. Siltstone and fossils & $\mathbf{x x x}$ & $\mathbf{x}$ \\
\hline D7. Siltstone II & $\mathbf{x}$ & \\
\hline D8. Red w. quartz, grog + calc. & $\mathbf{x x x x}$ & \\
\hline D9. Red w. quartz; grog + pell. & $\mathbf{x x x x}$ & \\
\hline D10. Coarse phyllite & $\mathbf{x x x}$ & $\mathbf{x}$ \\
\hline D11. Coarse phyllite + sand & $\mathbf{x x x x}$ & \\
\hline E1. Psathi fabric & $\mathbf{x x}$ & $\mathbf{x x}$ \\
\hline F1. Platyvola fabric & $\mathbf{x x x x}$ & \\
\hline
\end{tabular}

Key to fabric codes: $A=$ Mitatoulia, $B=$ Nopigeia, $C=$ Debla, $D=$ Chania, $E=$ Psathi, $F=$ Platyvola.

Key to quantification: $\mathrm{xxxx}=$ all samples, $\mathrm{xxx}=$ most samples, $\mathrm{xx}=$ some samples, $\mathrm{x}=$ very few samples. 


\section{CHAPTER 7}

\section{Neutron Activation Analysis}

\subsection{Introduction}

Chemical analysis constitutes the most commonly used method in provenance studies of archaeological ceramics. Its development was based on the "provenance postulate", i.e. the assumption that variability among raw materials deriving from different sources is greater than variability within a single source (Harbottle.1982). In the study of pottery this signifies that variation within a ceramic group will be smaller than between two different groups. However, the degree of discrimination required in this effect is high because different ceramic assemblages might be compositionally similar. Moreover, the identification of provenance may be obscured by the manipulation that the raw materials received, i.e. levigation, mixing or tempering of clays. In the 1960's, the establishment of control groups aimed to construct groups of pottery, which were presumed local by archaeological criteria (coarse wares were considered local as opposed to fine wares considered to be traded and imported). These groups were thought to constitute the "elemental fingerprint" of a geographical area against which samples of unknown origin were compared (Jones 1986 for an overview of early work).

This approach produced successful results in distinguishing between broad geographical areas, but separation between compositional groups was compromised when the numbers of samples increased and there was need for distinction on a smaller geographical scale. Moreover, methodological issues arose, because control groups represented the sites of consumption and not necessarily the centres of production. It was demonstrated that coarse wares have been moving on a large geographical scale (Day et al. 1999), which put into question the validity of the reference groups. These 
new developments created the need for a more integrated approach on the study of ceramic material combining more than one technique.

Especially in the case of Crete, the combination of elemental analysis and petrography proved to constitute the best approach, since there are constraints that cannot be overcome by the application of a single technique. The main factors impeding clear separation are the geology of Crete and clay processing. The geology of Crete presents variation on small geographical scale and can be repetitive on a large scale. It is frequently the case that very varied deposits outcrop within a restricted geographical area but, at the same time, similar types of deposits occur regularly across the island. Moreover, the clays are processed, they can be levigated, tempered or mixed, and this affects the composition of the final product. Finally, pottery is distributed and exchanged on an intra-and inter-regional scale and this can create confusion when a given analytical programme is based on elemental concentrations or petrography alone.

In the case of the EM pottery from West Crete a combined approach of petrography and chemical analysis is applied. This is believed the best way to overcome the difficulties caused by the manipulation of the raw materials and the geology of the area. The geology of West Crete is dominated by the Phyllite-Quartzite series, the limestone of the Tripolis series, Neogene marls and red alluvial deposits, all being repeated regularly. Petrographic analysis has demonstrated that the pottery fabrics in this study are, in most cases, indicative of a West Cretan origin. In very few cases (such as Nopigeia) petrographic analysis demonstrated that the production of certain types of pottery was carried out in the broad area of consumption. There were also cases where fabrics were similar but displayed slight variation in their mineralogical composition; therefore, it has not been possible to decide whether this was representative of variation within the same source, between different sources of raw materials, or over time. Therefore, the aim of elemental analysis is not only to investigate provenance of different pottery groups (i.e. the Minoan versus the nonMinoan wares) but also differences in composition within wares. 
The samples analysed by NAA were treated using statistical procedures in order to form groups. What follows is a brief account of the statistical methods employed in this study.

\subsection{Statistical Procedures}

The grouping of the material and the statistical evaluation of NAA results were performed by standard exploratory techniques including cluster and principal components analysis. The groups that derived from these analyses were plotted against each other in discriminant analysis.

The software used for the grouping of the chemical data is the statistical package S-Plus (Venables and Ripley 1999, 2000). In addition to the above-mentioned standard exploratory techniques, another grouping procedure was applied in this study. It has been developed and used specifically for chemical compositions of ceramics (Beier and Mommsen 1994). The reasons for selecting S-Plus as the basis for the development and distribution of this software have been discussed elsewhere (Beardah and Baxter 2001).

\subsubsection{Some preliminary considerations}

Before explaining the statistical methodology, certain points on the conventions of this work should be explained. They concern data transformation, the treatment of statistical outliers and, finally, the chemical elements used in the statistical procedures.

It is usual practice to modify the data before proceeding with multivariate statistics. In most cases the data are standardised or transformed into logarithms because, if raw data were used, variables with larger values (in our case elements with higher absolute concentrations) would dominate the analysis, whereas, through transformation, each variable acquires equal weight (Baxter 2001: 685). This methodology was first proposed by Aitchinson (1986) and the aim was to standardise the values and equalise the effect of the different concentration ranges. 
For the data from West Crete log-ratio transformation was performed: all element concentrations were divided by the element concentration with the least variation and were transformed into logarithms. This was done following several studies where it was shown that the element with the least variation, was more suitable to use as divisor to equalise the different concentration ranges (Baxter and Buck 2000: 718-19; Buxeda 1999: 299-300). In this way, the elemental concentrations would shift close to an average value and the data would be normalised.

Another approach used for the normalisation of NAA data was developed in Bonn, Institut für Strahlen- und Kernphysik (Beier and Mommsen 1994). The aim was, like in Buxeda (1999), to bring concentrations close to the average but this was achieved by considering not a single element (like Buxeda 1999) but average concentrations (the best relative fit based on the average ratios of selected elements to the mean values). The two methods use different mathematic formulas and are based on different models. Recently there has been an attempt to standardise the two methods, which demonstrated that the produced results were compatible (Hein et al. 2002).

Where the treatment of missing values and statistical outliers is concerned, removal is suggested because they may cause problems to the analysis. When the aim of the analysis is the investigation of patterning in the data, obvious outliers should be identified and deleted before the final analysis. (Baxter 1999: 3345; Baxter 2001: 687; Papageorgiou et al. 2001: 579).

Finally, the elements used for multivariate analysis are $\mathrm{Ca}, \mathrm{Ce}, \mathrm{Co}, \mathrm{Cr}, \mathrm{Cs}, \mathrm{Eu}$, $\mathrm{Fe}, \mathrm{Hf}, \mathrm{La}, \mathrm{Lu}, \mathrm{Rb}, \mathrm{Sb}, \mathrm{Sc}, \mathrm{Sm}, \mathrm{Ta}, \mathrm{Tb}, \mathrm{Th}, \mathrm{U}, \mathrm{Yb}$. The elements As, Ba, Na, Nd, Ni, $\mathrm{Zn}$ and $\mathrm{Zr}$, although measured, are excluded from statistics due to poor counting statistics or natural heterogeneity. 


\subsubsection{The Methods}

\subsubsection{Cluster Analysis}

Cluster analysis is among the earlier multivariate approaches used for evaluating compositional data. The aim is to measure (dis)similarity between cases in a data matrix and subsequently to group cases on the basis of the (dis)similarity specified (Baxter 1994: 140; Baxter and Buck 2000: 705). Hierarchical agglomerative cluster analysis with average linkage is used in this study: each case is initially regarded as a single cluster and progressively amalgamated until a single group remains. Dissimilarity is defined as the average distance between all pairs of points, one from each cluster, and is measured using the mean Euclidean distance of the concentrations of the elements used for statistics. This is presented in the form of a dendrogram (Baxter and Buck 2000: 705; Day et al. 1999: 1030).

\subsubsection{Principal Components Analysis}

Principal Components Analysis (PCA) is an exploratory type of analysis for transforming the hyperspace of element concentrations and obtaining a two- or threedimensional picture of multivariate data with maximum variation. In the case of chemical compositional data it allows the establishment of groups according to chemical composition and the detection of elements, which affect the structure in the data (Baxter 1994: 48). The procedure followed with PCA in this study consists of performing log-ratio transformation of the data before the analysis (for the reasons mentioned above). Then, obvious outliers are identified and removed; well-defined petrographic or chemical groups are also removed en bloc (see also Papageorgiou et al. 2001). The outcome is a reduction of the number of samples, which however, allows the detection of more outliers and more groups.

\subsubsection{Discriminant Analysis}

In contrast to the above, Discriminant Analysis (DA) is not an exploratory technique since it uses prior assumptions about the existence of groups, which might 
have been determined by stylistic, petrographic or statistical analysis (such as cluster analysis or PCA); it is used to confirm whether the established groups are chemically distinct (Baxter and Buck 2000: 709). Applying DA constitutes a common practice in archaeometric studies since it is a convenient way of displaying results obtained via other types of analysis (Baxter 1994: 185).

\subsubsection{The Bonn approach}

As mentioned in paragraph 2.1, there is another statistical procedure developed at and used in the University of Bonn, Institut fur Strahlen- und Kernphysik. Dissimilarity between samples is measured using a modification of Mahalanobis distance (for further details see Beier and Mommsen 1994). By performing a best relative fit, a potential shift of the concentration values is taken into account; this shift may be due to experimental errors in the measurement procedure or to the pottery making process, i.e. clay tempering and/or mixing or post-burial alteration. The best relative fit is also applied in the calculation of average means and spreads in order to define better the groups of samples (for an application of the method, see Mommsen $e$ al. 2002). It has been demonstrated that this method is compatible with Buxeda's (1999) (Hein et al. 2002).

\subsection{The results}

The complete analytical data are presented in Appendix III. The raw data were transformed into log ratios, the divisor being $\mathrm{Lu}$ (according to the method suggested by Buxeda 1999 for the identification of divisors), and then cluster analysis and PCA were performed. All groups were checked by both methods (i.e. Buxeda's (1999) and the Bonn approach (Beier and Mommsen 1994) and average compositions with the respective standard deviations were calculated considering a best relative fit. The two methods provided compatible results. 


\subsubsection{The entire dataset}

The procedure followed for the statistical treatment of the West Cretan assemblage consists of plotting all the samples together using PCA and cluster analysis and then identifying groups with close chemical compositions. One obvious outlier is detected, sample DEB 00/36, with abnormally high value of $\mathrm{La}$ (most likely due to measurement error) and is removed. Then the analysis is run again and the outcome is the clustering of the samples in two main groups (Fig. 2): Cluster 1 (at the left hand side of the plot) seems tighter than Cluster 2 which could be subdivided in two smaller groups. There is also a small Cluster (Cluster 3) consisting of three samples clearly separated from the main body of samples. It is of interest that there are only a few samples at the edges of the main groups most likely as end members of the clusters. This concentration of the samples in the centre of the plot could be considered an indication of similar chemical compositions for the entire assemblage.

Before proceeding to a more detailed consideration of subgroups it is interesting to examine which elements are primarily responsible for this clustering. The initial examination of the samples belonging to each group shows that almost all sites are represented in both clusters, apart from Debla and Mitatoulia, which are not represented in Cluster 1. As to Cluster 3, all three samples are from Debla. This clustering is mainly due to the presence/absence of $\mathrm{Ca}$. It seems that in most sites a part of the assemblage is manufactured with calcareous and a part with non- or lowcalcareous clays.

This separation between calcareous and non-calcareous clays may be expected in an EM assemblage; as demonstrated by the study in Central Crete (Wilson and Day 1994) the raw materials used in this early date can be very varied. However, this constitutes mainly a technological characteristic of the pottery, indicating differentiation in clay recipes but it may or may not be indicative of provenance. Therefore, the next step is to examine the West Cretan assemblage without considering $\mathrm{Ca}$.in order to see if there are other elements separating groups and indicating difference in the source of raw material. PCA is performed again (without $\mathrm{Ca}$ and the outcome is a less clear picture with most samples concentrated in the 
middle of the plot without any clear separation (Fig. 3). At the far left the small Debla group (Cluster 3) stands out again, but there is no clear patterning, which reinforces the hypothesis of close chemical compositions for the entire data set.

Cluster analysis was performed also and the resulting dendrograms (one considering $\mathrm{Ca}$, the other without $\mathrm{Ca}$ ) are not particularly informative (Figs 4,5 ). There are some site-specific groups, but the clusters seem to share similar compositions and there is no obvious patterning in the data, which is archaeologically meaningful.

Due to the lack of clear patterning in the data set, various biplots are constructed, in order to investigate which elements are responsible for this clustering. Two types of biplots are presented, the first with logged unscaled data, the second with standardised (scaled) data. By considering scaled and unscaled data, it is attempted to get an integrated picture of chemical variation within the data set. Moreover, because it is clear from the PCA that calcium is a decisive factor for grouping in this data set, there are two biplots for each case, one considering $\mathrm{Ca}$, the other without considering Ca.

When examining the biplots of the logged unscaled data considering $\mathrm{Ca}$ (Fig. 6), it becomes clear that the left-hand side of the plot is occupied by the calcareous part of the assemblage and also that the clustering is dominated by calcium. When $\mathrm{Ca}$ is not considered (Fig. 7), the pattern is different: the upper and lower right part of the plot are differentiated by the values of the Rare Earth Elements (REE) and the alkalis respectively.

When the data are scaled and $\mathrm{Ca}$ is considered (Fig. 8), the influence of calcium is still present but not as predominant as in the case of the unscaled data. It is also clear that the upper part of the plot is characterised by the alkalis and $\mathrm{Cr}$, whereas the lower part of the plot mainly by Hf, Ta, Th and Fe. The REE occupy the right-hand side of the plot. When $\mathrm{Ca}$ is not considered (Fig. 9), the picture becomes clearer, with the upper part of the plot being occupied by samples characterised by the alkalis, whereas the lower part by samples characterised by the REE. 
The biplots provide the guidelines necessary to look for subgroups in the data set: it seems that the elements responsible for the grouping of the West Cretan material are the REE and the alkalis and in some cases probably $\mathrm{Cr}$ and $\mathrm{Fe}$.

\subsubsection{The chemical groups}

After considering the entire data set, the identification of subgroups within the main clusters is attempted by comparing average compositions and standard deviations, and considering dilution factors of selected elements ${ }^{1}$. The application of this methodology demonstrated that samples that are close in the PCA plot do not in all cases share similar concentrations. The groups presented below derived after comparing average compositions and standard deviations.

The groups that stood out are, in most cases, site-specific ${ }^{2}$. This matches the picture that derived from petrographic analysis. There are chemical groups from all the sites, although not all samples were grouped; in all sites there are samples that remained ungrouped. Statistical evaluation of the NAA data resulted in the identification of seventeen subgroups, which can be organised by site as follows (see also Table IV): four groups comprising material excavated at Chania, two with material from Psathi, four main groups and a two pairs of samples from Nopigeia, three groups from Debla and single groups from Mitatoulia and Platyvola.

\begin{tabular}{|l|c|}
\hline \multicolumn{1}{|c|}{ Site } & \multicolumn{1}{c|}{$\begin{array}{c}\text { Nr of chemical } \\
\text { subgroups }\end{array}$} \\
\hline Chania & 4 \\
\hline Psathi & 2 \\
\hline Nopigeia & 6 \\
\hline Debla & 3 \\
\hline Mitatoulia & 1 \\
\hline
\end{tabular}

1 These procedures were made possible thanks to research carried out at Demokritos as part of the GEOPRO TMR Research Network and they were added to the S-Plus package.

2 The various chemical groups were given the name of the site the samples derive from. The names Chania Group 1, 2, 3... etc. do not reflect provenance, but demonstrate the site-specific character of the groups. 


\begin{tabular}{|l|c|}
\hline Platyvola & 1 \\
\hline Total & 17 \\
\hline
\end{tabular}

Table IV Site-specific chemical subgroups that derived after the statistical evaluation of the NAA data

The two-fold character of the assemblage, with Helladic and Minoan type vessels, is confirmed by the differences in chemical compositions. In all cases, samples from "Minoan" style vessels group separately from the "Helladic" ones. It is not only the amount of $\mathrm{Ca}$ that differs (in most cases Helladic black slipped wares are calcareous) but, as demonstrated by the biplots, it is also the values of the alkalis and/or the REE. This confirms what was suggested by the petgrographic analysis, i.e. that these wares are manufactured using different raw materials. Moreover, each of the two traditions is also investigated separately and the pattern that emerges supports local manufacture with similar raw materials. The chemical variation displayed by similar wares is attributed to intra- and inter-deposit variability and also to chronological differences.

\subsubsection{Chania Groups}

The samples from Chania are clustered in four groups, which are quite compatible with the stylistic and petrographic classification. The groups that stand out are those that include fabrics with fossils and, most likely, are related to the Neogene marl deposits of the area.

\section{Chania Group 1 (Fig. 10)}

CHT/ 13, 17, 20

KST/ $53,60,61,63,65,68,74,77,79,81,82,109,137$ and probably 127,134

This group is well defined both by cluster analysis and PCA and is also compatible with petrographic and typological analysis. In terms of elemental 
concentrations, it differs from Groups 3 and 4 in the values of $\mathrm{Ca}$ and the REE and, compared to Group 2, which has similar Ca values, it displays lower concentrations for the REE and higher value for $\mathrm{Cr}$ (see also comment fro Chania Group 2). In petrographic terms, the samples belong to a fine to medium fabric with fossils (Fabrics D1 and D2), both being compatible with the Neogene marls of the area around Chania. In terms of typology, all samples belong to the Helladic portion of the assemblage, e.g. black slipped sauceboats, jugs, and saucers.

Connected with this group are two samples that belong to other fabric groups and are not black slipped. They both belong to a fabric with coarse phyllite and sand (Fabric D11) and share similar elemental values with the rest of the group, probably because this fabric is also related to the marl deposits of Chania.

Chania Group 2 (Fig. 11)

CHT/ 43,45

$\mathrm{KST} / 46,48,85,92,95,100$

PLT/ 17, 19

This group is also well-defined both in terms of chemical composition and petrography. The samples derive from Chania, with the exception of two from Platyvola, all being manufactured in a semi-coarse, sand-tempered fabric containing fossils (D4). In terms of wares and shapes there are semi-coarse and coarse vessels such as jars, baking plates, pithoi and red slipped jugs, all belonging to the Minoan repertoire. It is of interest that Chania Groups 1 and 2, although both manufactured with fossiliferous raw materials, are characterised by different clays. This is clear in petrographic and chemical analysis. The spreads of the chemical concentrations (Table V) indicate that Groups 1 and 2 differ from each other in the REE and this is taken to be indicative of a different source of raw materials (Hein et al. in preparation). 
Chania Group 3 (Fig. 11)

CHT/ 48

$\mathrm{KST} / 2,15,16,17,19,20$

NOP/ 55 (?)

This group comprises samples from a red fabric with quartz, grog and calcite (Fabric D8). NOP/ 55 belongs to a fine fabric with pellets and grog (Fabric B7). Typologically they belong to Minoan wares. There are chalices, a jar, and two scored red slipped vessels, some of EM I date. It is of interest that some of the earlier samples are grouped together with later material (EM IIA). In petrographic terms, the earlier vessels display a particular texture that separates them from later material of similar composition (Subgroup of Fabric 8).

In terms of chemical composition, this group is very different from the other three groups from Chania. It has the lower values for $\mathrm{Ca}$ and the higher for the REE (see $\mathrm{Eu}, \mathrm{La}, \mathrm{Lu}, \mathrm{Sm}, \mathrm{Tb}, \mathrm{Yb}$ ). It is high likely that this difference between Chania group 3 and the other groups from Chania reflects chronological difference. It seems that the pottery of the earlier phase (EM I) was manufactured with different raw materials.

In this group there are also some vessels in dark grey burnished ware (DGBW). The work carried out in Central Crete has demonstrated that this ware is manufactured according to specific recipes, even if it is produced in different locations (Wilson and Day 1994). In order to examine whether the same phenomenon was valid in West Crete, all the DGBW samples were analysed by NAA. The analysis showed that there does not seem to be any patterning that would allow the assignment of common provenance to all the these samples, since they do not share the same chemical composition. It is of interest that some group together (at least the ones from Chania), and it could probably be suggested that the West Cretan DGBW was produced in local workshops. As to the sample from Nopigeia, the similarity in composition with the samples from Chania may suggest either that it derives from the same production centre as the ones from Chania or that it was manufactured with similar raw materials. 
The issue of the provenance of the DGBW remains open and further sampling may provide more secure information.

\section{Chania Group 4 (Fig. 10)}

$\mathrm{CHT} / 3,11,14,28,31$

KST/ 9, 41, 91, 104, 111, 113, 114, 126

\section{NOP/ 22}

\section{PLT/ 11 (?)}

This group comprises vessels from different sites and different fabric groups. In terms of petrography, the main body of samples belongs to Fabrics D1 and D2, i.e. fine to medium with fossils. There are also samples from the calcite-tempered fabric (D5), one from a red fabric with grog and pellets (D9) and one from a semi-coarse fabric with micrite (B5).

The fossiliferous fabric, in this case, is used for shapes that belong to the Minoan tradition, i.e. bowls and goblets, a jar and a pyxis, in red or red/brown slipped ware. The fossiliferous fabric represented in the chemical group Chania 1 is used for black slipped vessels of Helladic type.

In chemical terms, this group is similar in composition with Chania Group 1. The values of the REE are similar (especially for $\mathrm{Eu}, \mathrm{Lu}, \mathrm{Sm}, \mathrm{Tb}, \mathrm{Yb}$ ) but also the values of $\mathrm{Ca}$ and $\mathrm{Fe}$. The difference lies in the values of the alkalis, which are lower for Chania group 4 (see $\mathrm{K}, \mathrm{Rb}, \mathrm{Sc}$ ). Considering that the two groups (Chania Groups 1 and 4) have in common the Helladic type vessels and fossiliferous fabrics D1 and D2, it seems that similar sources of raw materials were used, compatible with the marls of the north coast around Chania. This explains also the presence in this chemical group of the sample from Nopigeia: it is the presence of micrite that indicates the connection with the same Neogene deposits, although it is not certain whether the vessel was manufactured at Chania or the raw materials share similar chemical composition. What cannot be explained sufficiently is the presence in this chemical group of the samples belonging in the red fabrics D5 and D9, which derive from different sources, 
probably related to red alluvial deposits, but definitely not connected to Neogene marls. However, they are both tempered and this probably affects their chemical composition. When there is considerable amount of calcite in a sample, the trace elements are depleated in the analysis ( $\mathrm{Dr}$ A. Hein pers. comm.) and, when there is grog, the analysis inevitably represents partly the composition of the tempering material.

It is of interest that the black slipped sample from Platyvola shares the same composition as the Chania samples because this confirms both stylistic and petrographic observations, i.e. that the black slipped ware of the cave seems to share the same origin with the one found at Chania.

\begin{tabular}{|c|c|c|c|c|c|c|c|c|}
\hline & \multicolumn{2}{|c|}{ Chania Group 1} & \multicolumn{2}{|c|}{ Chania Group 2} & \multicolumn{2}{|c|}{ Chania Group 3} & \multicolumn{2}{|c|}{ Chanla Group 4} \\
\hline & Mean & Stdev \% & Mean & Stdev \% & Mean & Stdev $\%$ & Mean & Stdev \% \\
\hline $\mathbf{C a}$ & 4.74 & 31.6 & 5.15 & 31.1 & 1.17 & 41.7 & 3.94 & 83.1 \\
\hline $\mathrm{Ce}$ & 76.7 & 8.8 & 105.7 & 14.6 & 146.4 & 15.9 & 82.4 & 6.0 \\
\hline Co & 26.8 & 23.2 & 18.5 & 27.6 & 27.0 & 42.1 & 15.7 & 18.0 \\
\hline $\mathbf{C r}$ & 189.5 & 13.4 & 108.6 & 9.6 & 126.8 & 5.8 & 113.1 & 12.4 \\
\hline Cs & 6.85 & 10.0 & 7.10 & 16.7 & 8.95 & 13.5 & 5.66 & 18.5 \\
\hline $\mathbf{E u}$ & 1.47 & 7.0 & 2.23 & 26.2 & 3.94 & 10.2 & 1.41 & 11.0 \\
\hline $\mathbf{F e}$ & 5.00 & 5.7 & 4.49 & 11.9 & 5.60 & 11.3 & 4.95 & 9.2 \\
\hline Hf & 5.28 & 9.5 & 6.52 & 11.4 & 7.67 & 12.7 & 7.31 & 15.3 \\
\hline $\mathbf{K}$ & 2.52 & 13.4 & 1.98 & 18.4 & 2.14 & 21.2 & 1.84 & 9.2 \\
\hline $\mathbf{L a}$ & 36.2 & 6.4 & 54.0 & 12.7 & 75.8 & 11.2 & 38.2 & 10.4 \\
\hline $\mathbf{L u}$ & 0.42 & 3.4 & 0.55 & 11.5 & 0.93 & 16.1 & 0.41 & 7.0 \\
\hline $\mathbf{R b}$ & 120.4 & 9.4 & 101.5 & 13.0 & 121.4 & 9.1 & 91.7 & 9.6 \\
\hline $\mathbf{S b}$ & 1.04 & 18.6 & 1.29 & 23.3 & 1.40 & 13.5 & 1.17 & 20.7 \\
\hline Sc & 17.2 & 4.8 & 14.8 & 11.3 & 18.0 & 7.0 & 14.2 & 6.2 \\
\hline Sm & 7.03 & 6.1 & 10.5 & 18.1 & 16.9 & 15.3 & 7.05 & 8.7 \\
\hline $\mathbf{T a}$ & 1.33 & 12.7 & 1.82 & 14.2 & 2.21 & 7.0 & 1.84 & 10.8 \\
\hline $\mathbf{T b}$ & 0.87 & 11.5 & 1.26 & 28.5 & 2.14 & 11.8 & 0.83 & 9.1 \\
\hline Th & 11.4 & 3.7 & 13.9 & 9.6 & 17.4 & 7.2 & 13.0 & 7.2 \\
\hline $\mathbf{U}$ & 4.07 & 19.7 & 3.64 & 20.5 & 4.40 & 30.3 & 3.93 & 17.3 \\
\hline $\mathbf{Y b}$ & 3.32 & 3.4 & 4.55 & 15.3 & 8.05 & 17.3 & 3.36 & 5.4 \\
\hline
\end{tabular}

Table V. Chemical compositions of the Chania groups. Concentrations are given in ppm, apart from $\mathrm{Ca}, \mathrm{Fe}$ and $\mathrm{K}$, which are given in $\%$. 


\subsubsection{Psathi Groups (Fig. 12)}

From the initial stylistic study of the material, it had seemed possible that pottery from Psathi would present similar elemental concentrations as Chania, due to the geographical proximity of the two sites and the typological similarity of the assemblages. However, the Psathi samples proved to be discriminated and clustering separately from Chania.

\section{Psathi Group 1}

PST $2,9,12,15,18,19,21,22(?), 25,29,35$

This group comprises the majority of the samples from Psathi. Typologically they are similar to the Helladic black slipped ware from Chania, which is represented in Chania Group 1. The shapes include black monochrome sauceboats, saucers, jugs and one pyxis. Petrographic analysis has demonstrated that most of the samples belong to a red fabric with quartz and mica (Fabric E1). This is incompatible with the fabric of the Chania black slipped ware, which is connected with the Neogene marls and contains fossils: Moreover, the chemical compositions are different mainly in the values of the alkalis, which are lower for the Psathi samples and this is taken to indicate different source of raw material (Table VI, note especially the values of $\mathrm{K}, \mathrm{Cs}$, $\mathrm{Rb})$.

\section{Psathi Group 2}

PST/ 11, 30, 34

In addition to chemical composition (Table VI), the members of this group are different from the members of the previous also in terms of typology and petrography. The types included are a mottled jug, a black monochrome askos, (typically a Helladic-style vessel), and a jar with painted decoration. In terms of petrography, the samples belong to Fabrics D2 and D6 (fine to medium with fossils and micrite and siltstone fabric respectively); both fabrics occur exclusively at Chania and are connected with the Neogene marls of the area. However, although the Psathi samples 
belong to fabric groups from Chania, their chemical composition is different from the samples that were found in Chania (i.e. Chania Groups 1 and 2) and are also thought to have been manufactured locally. The main difference is in the values of the REE and the alkalis (the values being higher at Psathi). Therefore, even if from petrographic analysis it could be suggested that the vessels from Psathi that belong to chemical Group 2 were brought from Chania, chemical data would contradict this assumption. It is high likely, that, instead, they were produced locally to Psathi with similar raw materials, since the deposits of Neogene marls stretch all along the north coast, westwards from Psathi.

\begin{tabular}{|c|cc|cc|}
\hline & \multicolumn{2}{|c|}{ Psathi Group 1 } & \multicolumn{2}{c|}{ Psathi Group 2 } \\
\hline & Mean & Stdev $\%$ & Mean & Stdev \% \\
\hline Ca & 2.74 & 30.4 & 1.90 & 34.2 \\
Ce & 90.1 & 15.8 & 96.7 & 31.1 \\
Co & 17.3 & 27.0 & 22.0 & 41.5 \\
Cr & 120.9 & 10.7 & 132.3 & 22.4 \\
Cs & 2.10 & 29.0 & 4.16 & 38.1 \\
Eu & 1.52 & 11.6 & 1.60 & 7.9 \\
Fe & 5.66 & 8.3 & 5.36 & 1.5 \\
Hf & 8.71 & 13.1 & 7.63 & 16.6 \\
K & 0.96 & 15.8 & 1.41 & 18.7 \\
La & 41.3 & 6.9 & 41.1 & 4.4 \\
Lu & 0.44 & 7.0 & 0.47 & 5.0 \\
Rb & 38.7 & 21.2 & 65.4 & 28.1 \\
Sb & 0.95 & 29.9 & 0.76 & 8.0 \\
Sc & 15.0 & 8.8 & 14.5 & 3.0 \\
Sm & 7.59 & 9.5 & 8.06 & 7.4 \\
Ta & 2.28 & 10.2 & 2.01 & 6.4 \\
Tb & 0.91 & 9.9 & 0.9 & 9.3 \\
Th & 14.9 & 9.1 & 13.7 & 7.3 \\
U & 3.59 & 12.8 & 3.2 & 6.3 \\
Yb & 3.41 & 8.1 & 3.5 & 10.3 \\
\hline
\end{tabular}

Table VI. Chemical compositions of the Psathi groups. Concentrations are given in ppm, apart from $\mathrm{Ca}, \mathrm{Fe}$ and $\mathrm{K}$, which are given in $\%$. 


\subsubsection{Nopigeia Groups}

The assemblage from Nopigeia is of particular character in terms of typology, due to the strong Helladic affinities of the vessels. In terms of petrography, it displays a local character and this has been supported by clay sampling. The chemical groups are site-specific and are, in their majority, concentrated in Nopigeia Group 1. The remaining groups from this site are limited to 3-4 samples each.

Nopigeia Groups 1 and 2 (Fig. 13)

NOP/ $11,12,17,30,39,52,53,54,60,66,73,75,80+8,59$

NOP/ $40,68,71$

The chemical Groups 1 and 2 from Nopigeia consist of Helladic-style vessels: some have a coarse to semi-coarse phyllite fabric (Fabrics B1 and B2), the rest include black slipped ware in a fine mica fabric which petrographically is classified as a subgroup of the Chania fine fabric with fossils (Fabric D1). Nopigeia Group 2 consists of two sauceboats and a collared jar in a very fine mica fabric. These three samples are very similar to each other in terms of chemical composition and very close to those of Nopigeia Group 1, except for small differences in Ca (Group 2 displaying higher values) and the alkalis (Group 2 displaying slightly higher values) (Table VII). These differences, and especially the values of $\mathrm{Ca}$, are probably connected to the type of vessels represented in each group. Group 1 includes coarse vessels made of noncalcareous clays, whereas the vessels of Group 2 finer and probably manufactured with mixing of a calcareous and a non-calcareous clay, (hence the higher values of Ca). It is important that Nopigeia constitutes the only site with so many coarse wares in Helladic-style and that these wares share similar elemental compositions with the fine sauceboats also of Helladic style. It could be suggested that for the manufacture of the Helladic style vessels similar raw materials are used. It is still open to investigation whether the fine wares are manufactured with clay mixing, as is the case for the Chaniot Helladic-style fine vessels. 
Petrographic analysis demonstrated that the Helladic-style black slipped wares from Chania and Nopigeia share a similar fabric which, however, is not exactly the same (the samples from Nopigeia being a subgroup of Fabric D1). The values of the chemical compositions of the black slipped wares from Chania are different from those from Nopigeia: it seems that the petrographic dissimilarity is followed by elemental differentiation, which indicates different provenance for each of them.

\section{Nopigeia Group 3 (Fig. 14)}

NOP/ 4, 25, 57

This small group comprises a portable hearth, a pithos and a dark grey burnished bowl. The first two samples belong to the same petrographic fabric, i.e. a semi-coarse fabric with siltstones (B5); the dark grey burnished ware sample belongs to a semi-coarse fabric with micrite (B6). Apart from the similarity in chemical composition there does not seem to be any other obvious relation between the two fabrics. It is, though, important that the hearth, which is a vessel type of special character in terms of typology (due to the Helladic/Cycladic affinities), shares similar fabric and chemical composition with other coarse wares (such as the pithos). Chemical analysis confirmed the results of petrographic analysis: although nonMinoan in style, the hearths from Nopigeia are manufactured with local raw materials, compatible with those used for the regular domestic coarse wares.

\section{Nopigeia Group 4 (Fig. 14)}

NOP/ $15,41,56,77$

This small group comprises samples from several petrographic fabrics, namely medium with quartz and metamorphics (Fabric B3), coarse phyllite with micrite and fossils (Fabric B4) and fine with pellets and grog (Fabric B7). The shapes represented are also varied, i.e. a pyxis, two jars and one dark grey burnished bowl. As was the case with Nopigeia Group 3, there does not seem to be any archaeologically meaningful pattern in this group. 
Considering chemical compositions of the different groups interpreted to be deriving from Nopigeia, Groups 1 and 2 have higher values for the REE (Ce, Eu, La, $\mathrm{Lu}, \mathrm{Tb}$ ), whereas Groups 3 and 4 display higher values for the alkalis (especially Cs) and $\mathrm{Cr}$. Group 3 has the highest values for $\mathrm{Cr}$ and $\mathrm{Sc}$, whereas Group 4 displays some of the highest values for the alkalis and the lowest for the REE. There is no indication suggesting that the pottery found at Nopigeia was produced elsewhere, in the contrary petrographic analysis and clay sampling indicate local sources of raw material. Therefore, the differences in chemical compositions may be indicative of different sources within the Groups from Nopigeia.

\begin{tabular}{|c|c|c|c|c|c|c|c|c|}
\hline & \multicolumn{2}{|c|}{ Nopigeia Group 1} & \multicolumn{2}{|c|}{ Nopigeia Group 2} & \multicolumn{2}{|c|}{ Nopigela Group 3} & \multicolumn{2}{|c|}{ Nopigela Group 4} \\
\hline & Mean & Stdev \% & Mean & Stdev $\%$ & Mean & Stdev \% & Mean & Stdev $\%$ \\
\hline $\mathbf{C a}$ & 1.59 & 69.6 & 4.84 & 19.8 & 3.71 & 75.3 & 0.71 & 43.6 \\
\hline $\mathrm{Ce}$ & 93.5 & 7.2 & 94.0 & 5.1 & 84.6 & 4.8 & 79.8 & 16.0 \\
\hline Co & 30.6 & 18.2 & 29.0 & 0.8 & 40.0 & 11.1 & 16.6 & 28.8 \\
\hline $\mathrm{Cr}$ & 176.5 & 21.1 & 164.2 & 11.2 & 223.1 & 23.7 & 135.2 & 10.1 \\
\hline Cs & 3.23 & 36.9 & 3.51 & 26.1 & 6.49 & 12.8 & 6.23 & 26.3 \\
\hline $\mathbf{E u}$ & 1.62 & 9.4 & 1.64 & 10.3 & 1.43 & 9.3 & 1.02 & 23.5 \\
\hline $\mathbf{F e}$ & 5.44 & 8.7 & 5.96 & 3.9 & 5.26 & 4.8 & 5.22 & 5.6 \\
\hline Hf & 6.87 & 17.1 & 7.58 & 4.7 & 5.60 & 9.6 & 7.34 & 8.2 \\
\hline $\mathbf{K}$ & 1.30 & 17.0 & 1.42 & 6.9 & 1.66 & 20.1 & 1.87 & 13.6 \\
\hline $\mathbf{L a}$ & 42.0 & 10.7 & 42.9 & 2.2 & 34.4 & 8.6 & 32.6 & 16.6 \\
\hline Lu & 0.46 & 4.5 & 0.44 & 3.3 & 0.42 & 4.0 & 0.37 & 4.9 \\
\hline $\mathbf{R b}$ & 58.0 & 25.6 & 61.3 & 19.0 & 99.5 & 25.3 & 110.1 & 21.0 \\
\hline Sb & 0.91 & 25.5 & 0.98 & 5.8 & 0.89 & 13.2 & 1.25 & 25.3 \\
\hline Sc & 16.2 & 12.6 & 17.2 & 5.5 & 17.5 & 6.2 & 15.4 & 11.2 \\
\hline Sm & 7.74 & 8.7 & 7.51 & 2.8 & 7.04 & 9.7 & 5.54 & 21.9 \\
\hline $\mathrm{Ta}$ & 1.78 & 16.3 & 2.31 & 3.5 & 1.53 & 10.2 & 2.09 & 9.7 \\
\hline Tb & 0.97 & 9.7 & 0.92 & 3.2 & 0.81 & 12.7 & 0.62 & 18.2 \\
\hline Th & 13.0 & 8.4 & 14.5 & 3.9 & 12.0 & 3.5 & 13.0 & 1.0 \\
\hline $\mathbf{U}$ & 3.41 & 10.8 & 3.28 & 3.0 & 3.26 & 6.8 & 3.57 & 6.6 \\
\hline $\mathbf{Y b}$ & 3.68 & 6.1 & 3.51 & 2.4 & 3.31 & 4.2 & 3.00 & 5.5 \\
\hline
\end{tabular}

Table VII. Chemical compositions of the Nopigeia groups. Concentrations are given in ppm, apart from $\mathrm{Ca}, \mathrm{Fe}$ and $\mathrm{K}$, which are given in $\%$. 
Along with the main chemical groups, there are two pairs of samples that group together petrographically and chemically (Table VIII), (Fig. 14).

Pair 1: NOP/ 6, 20

Pair 2: NOP/ 43, 47

The first pair consists of two semi-coarse vessels, a baking plate and a deep bowl. In terms of petrography they both belong to the same coarse fabric with quartz and metamorphics (Fabric B2). The second pair includes a scored jug and a large shallow bowl in a fabric with siltstones (Fabric B3) and a fabric with micrite and fossils (Fabric B4). The two pairs are not comparable in the values of their chemical compositions, Pair 1 has higher $\mathrm{Ca}$, and REE, whereas Pair 2 has higher values for $\mathrm{Cr}$ and the alkalis. This indicates that the raw materials used are different for each of the two pairs and from the rest of the Nopigeia samples.

\begin{tabular}{|c|cc|cc|}
\hline & \multicolumn{2}{|c|}{ Nopigeia Pair 1 } & \multicolumn{2}{c|}{ Nopigeia Pair 2 } \\
\hline & Mean & Stdev \% & Mean & Stdev \% \\
\hline Ca & 1.10 & 49.9 & 0.47 & 51.4 \\
Ce & 90.3 & 12.3 & 84.8 & 1.8 \\
Co & 19.2 & 14.3 & 36.8 & 2.3 \\
Cr & 118.4 & 44.2 & 264.0 & 1.5 \\
Cs & 4.55 & 22.7 & 10.4 & 2.1 \\
Eu & 1.90 & 4.40 & 1.11 & 3.0 \\
Fe & 4.94 & 7.02 & 5.97 & 0.6 \\
Hf & 7.90 & 13.6 & 6.64 & 2.6 \\
K & 1.64 & 37.1 & 1.88 & 6.8 \\
La & 47.0 & 4.4 & 30.4 & 0.3 \\
Lu & 0.53 & 2.0 & 0.45 & 2.6 \\
Rb & 84.9 & 38.2 & 93.0 & 1.5 \\
Sb & 0.88 & 4.8 & 1.07 & 2.7 \\
Sc & 14.4 & 9.4 & 18.5 & 0.4 \\
Sm & 9.16 & 9.1 & 5.58 & 1.7 \\
Ta & 2.04 & 1.1 & 1.82 & 2.4 \\
Tb & 1.46 & 6.4 & 0.78 & 6.2 \\
Th & 12.9 & 1.2 & 13.0 & 0.09 \\
U & 3.74 & 23.3 & 3.34 & 0.7 \\
\hline
\end{tabular}




\begin{tabular}{|c|c|c|c|c|}
\hline $\mathbf{Y b}$ & 4.28 & 4.19 & 3.57 & 6.6 \\
\hline
\end{tabular}

Table VIII. Chemical compositions of the Nopigeia pair groups. Concentrations are given in $\mathrm{ppm}$, apart from $\mathrm{Ca}, \mathrm{Fe}$ and $\mathrm{K}$, which are given in \%.

\subsubsection{Debla Groups (Fig. 15)}

The material from Debla is clustered in three groups, the first two representing the main body of the assemblage, the third including the Helladic style vessels, which, as in the case of Chania and Nopigeia, are grouped separately (Debla Group 3). The rest of the samples are clustered in two groups that do not present any patterning in archaeological or petrographic terms (Table IX). Most of the material from Debla is quite homogeneous in petrographic terms and belongs to a single fabric, consisting of quartz, grog and metamorphics (Fabrics $\mathrm{C} 3$ and $\mathrm{C} 4$ : fine and coarse versions of the same fabric).

\section{Debla Groups 1 and 2}

$\mathrm{DEB} / 9,16,23,26,28,42$

$\mathrm{DEB} / 8,11,15,21,22,33,41$

The chemical Groups 1 and 2 from Debla comprise similar vessels, namely red or black slipped jugs, bowls, pyxides and one lid. The difference in chemical composition between the two groups is in the alkalis, displaying higher values for Group 1, and some of the REE (mainly La and $\mathrm{Lu}$ ), displaying higher values for Group 2. This is taken to be indicative of different source of raw materials for these two groups. Considering, though, the similarity in petrographic fabric between the two groups, it might be suggested that the type of raw material used is similar but derives from different deposits.

\section{Debla Group 3}

$\mathrm{DEB} / 17,18,32$ 
This group represents the Helladic component of the assemblage, which, although not as pronounced in terms of quantity as in other sites, is present. All samples are sauceboats and belong to the same petrographic group as the Nopigeia and Chania black slipped wares (Fabric D1). This group differs chemically from the other chemical groups from Debla, in that it is calcareous and has higher values of REE, Fe, $\mathrm{Co}$ and $\mathrm{Cr}$ (Table IX). These differences are considered indicative of a different source of raw material for these vessels compared to the rest of the Debla samples.

\begin{tabular}{|c|cc|cc|cc|}
\hline & \multicolumn{2}{|c|}{ Debla Group 1 } & \multicolumn{2}{c|}{ Debla Group 2 } & \multicolumn{2}{c|}{ Debla Group 3 } \\
\hline & Mean & Stdev \% & Mean & Stdev \% & Mean & Stdev \% \\
\hline Ca & 0.47 & 33.5 & 0.47 & 54.4 & 2.11 & 60.2 \\
Ce & 126.8 & 29.5 & 107.7 & 13.9 & 112.8 & 15.5 \\
Co & 25.9 & 6.3 & 27.2 & 28.0 & 35.2 & 28.8 \\
Cr & 111.3 & 3.0 & 141.0 & 15.7 & 179.3 & 14.3 \\
Cs & 11.2 & 11.9 & 5.86 & 22.8 & 1.60 & 126.0 \\
Eu & 1.99 & 9.6 & 2.30 & 10.5 & 2.73 & 10.4 \\
Fe & 5.48 & 4.6 & 6.05 & 10.8 & 6.30 & 14.7 \\
Hf & 7.53 & 6.0 & 8.59 & 7.7 & 8.98 & 17.7 \\
K & 2.37. & 17.3 & 1.52 & 14.0 & 1.43 & 30.1 \\
La & 38.7 & 6.3 & 47.8 & 5.5 & 57.5 & 10.8 \\
Lu & 0.49 & 5.9 & 0.52 & 5.7 & 0.60 & 13.4 \\
Rb & 99.7 & 11.9 & 78.5 & 16.6 & 45.3 & 59.3 \\
Sb & 4.05 & 15.5 & 0.97 & 25.4 & 0.93 & 24.0 \\
Sc & 16.3 & 5.0 & 16.8 & 7.5 & 17.6 & 13.9 \\
Sm & 9.82 & 8.2 & 10.7 & 7.6 & 12.5 & 8.0 \\
Ta & 2.20 & 8.0 & 2.67 & 12.8 & 2.48 & 14.7 \\
Tb & 1.14 & 12.2 & 1.21 & 8.5 & 1.48 & 14.9 \\
Th & 16.8 & 3.6 & 15.7 & 9.4 & 16.1 & 14.4 \\
U & 6.26 & 4.0 & 4.57 & 15.2 & 3.92 & 12.6 \\
Yb & 4.20 & 5.8 & 4.37 & 5.5 & 5.11 & 14.1 \\
\hline
\end{tabular}

Table IX. Chemical compositions of the Debla groups. Concentrations are given in ppm, apart from $\mathrm{Ca}, \mathrm{Fe}$ and $\mathrm{K}$, which are given in $\%$. 


\subsubsection{Platyvola Group (Fig. 16)}

PLT/ 2, 4, 5, 6, 8, 12, 14

This is a coherent group that stands out clearly in all types of analysis. It is also consistent in terms of typology and petrography. It comprises mainly red burnished vessels in a red fabric (Fabric F1), the main shapes being pedestalled chalices, pyxides, jugs and bowls, some with a scored surface. As with petrographic analysis, the chemical compositions of the samples from Platyvola are different from those of the vessels from Chania. Platyvola is not a site of production and Chania might constitute the most obvious place of origin. The closest chemical group from Chania, to which the samples from Platyvola may be compared to, is Group Chania 3, which consists of Minoan wares in a red fabric, as is the case for the chemical group from Platyvola. However, the values of the chemical composition of the Platyvola samples are in their majority lower to those from Chania Group 3 (cf. the alkalis, the REE, Fe and $\mathrm{Cr}$ ). This difference in chemical composition has a twofold explanation: it might reflect chronological difference, since the material from Platyvola comprises a large EM I portion, whereas the material from Chania is primarily EM IIA. Moreover, it might represent intra-source difference, which cannot be detected but with extensive and intra-source clay sampling.

\begin{tabular}{|c|cc|}
\hline & \multicolumn{2}{|c|}{ Platyvola Group } \\
\hline & Mean & Stdev \% \\
\hline Ca & 1.13 & 32.1 \\
$\mathrm{Ce}$ & 128.7 & 9.4 \\
$\mathrm{Co}$ & 14.1 & 29.7 \\
$\mathrm{Cr}$ & 118.3 & 8.0 \\
$\mathrm{Cs}$ & 8.12 & 19.4 \\
$\mathrm{Eu}$ & 2.13 & 9.5 \\
$\mathrm{Fe}$ & 4.17 & 19.0 \\
$\mathrm{Hf}$ & 8.78 & 9.3 \\
$\mathrm{~K}$ & 1.51 & 26.6 \\
$\mathrm{La}$ & 58.2 & 14.7 \\
Lu & 0.56 & 5.6 \\
\cline { 2 - 3 }
\end{tabular}




\begin{tabular}{|c|cc|}
\cline { 2 - 2 } $\mathbf{R b}$ & 99.7 & 13.2 \\
$\mathbf{S b}$ & 1.15 & 19.6 \\
$\mathrm{Sc}$ & 16.9 & 4.7 \\
$\mathrm{Sm}$ & 10.4 & 8.7 \\
$\mathbf{T a}$ & 2.41 & 14.6 \\
$\mathbf{T b}$ & 1.27 & 11.2 \\
$\mathbf{T h}$ & 17.3 & 7.1 \\
$\mathrm{U}$ & $4.14 \cdot$ & 7.8 \\
$\mathrm{Yb}$ & 4.56 & 6.9 \\
\hline
\end{tabular}

Table X. Chemical compositions of the Platyvola group. Concentrations are given in ppm, apart from $\mathrm{Ca}, \mathrm{Fe}$ and $\mathrm{K}$, which are given in \%.

\subsubsection{Mitatoulia Group (Fig. 17)}

\section{MIT/ 3, 13, 14, 15, 23, 31}

The samples from Mitatoulia, although presumed local by petrography because of the micaceous fabric characterising the assemblage, present diversity in the chemical composition. Most of the samples are tightly concentrated at the right end of the PCA plot. They are not compatible chemically with samples from any other sites and are all manufactured with non-calcareous clays. There is only one cluster, which contains samples exclusively from Mitatoulia. The shapes include red slipped pithoi, chalices, jars, pyxides in a red semi-coarse fabric with quartz, grog and white mica (Fabrics $\mathrm{A} 1$ and $\mathrm{A} 2$ being two versions of the same fabric, $\mathrm{A} 2$ being differentiated by the presence of organic temper). The fabrics from Mitatoulia are characterised by the presence of white mica and do not occur elsewhere in West Crete. The values of the chemical compositions of the samples from Mitatoulia are not comparable to the compositions of any other samples from West Crete either. Because the geological sampling did not produce any sample with the amount of white mica occurring in the samples from Mitatoulia, it is not possible to suggest local provenance in the vicinity of Mitatoulia. However, all the components, petrographic and chemical analysis, point towards different raw materials being used for the manufacture of this pottery than in all the other sites in West Crete. This might also be due to the early date of this assemblage and intra-source variation. 


\begin{tabular}{|c|cc|}
\hline & \multicolumn{2}{|c|}{ Mitatoulia Group } \\
\hline & Mean & Stdev $\%$ \\
\hline Ca & 0.30 & 13.3 \\
Ce & 84.2 & 13.0 \\
Co & 20.5 & 22.9 \\
Cr & 155.3 & 36.4 \\
Cs & 6.51 & 23.8 \\
Eu & 1.79 & 24.7 \\
Fe & 7.57 & 8.4 \\
Hf & 7.92 & 17.1 \\
K & 1.64 & 27.5 \\
La & 39.6 & 13.5 \\
Lu & 0.48 & 14.3 \\
Rb & 92.9 & 13.7 \\
Sb & 1.76 & 25.3 \\
Sc & 23.7 & 9.6 \\
Sm & 8.50 & 20.8 \\
Ta & 2.02 & 7.6 \\
Tb & 1.02 & 16.5 \\
Th & 21.5. & 12.4 \\
U & 4.88 & 9.8 \\
Yb & 3.81 & 17.0 \\
\hline
\end{tabular}

Table XI. Chemical compositions of the Mitatoulia group. Concentrations are given in ppm, apart from $\mathrm{Ca}, \mathrm{Fe}$ and $\mathrm{K}$ given in \%.

\subsection{Fabric Groups}

The fact that in most cases the chemical groups are site-specific may be attributed either to the use of raw materials from different locations, or to chronological differences. Moreover, chemical compositions indicate that within the assemblages there usually is clear differentiation between the Minoan- and Helladicstyle wares. These results are compatible with those from petrographic analysis: the two types of pottery are manufactured in different fabrics, most fabrics are sitespecific and in some cases there are indications for differentiation over time (the case of the EM I red wares). 
However, petrography also shows that both the fabrics used for Minoan and Helladic wares, although site-specific, bear compositional similarities between sites (in terms of their mineralogy/lithology). This is especially the case for the calcareous fine wares. It is, therefore, of interest to examine the correlation of similar fabrics from different sites in terms of elemental concentrations; similarity in chemical composition might suggest that similar sources of raw material are used for the manufacture of similar types of.pottery at different workshops. The petrographic groups considered comprise the fabrics with fossils from Chania, the red fabrics used for Minoan ware types and the fabrics used for the black slipped Helladic wares.

\subsubsection{Fabrics with fossils}

The fossiliferous fabrics from Chania (D1, D2 and D4) constitute a special case because they occur mainly, if not exclusively (like D4), in the Kastelli and Chania town assemblages and in a few samples from Psathi. Their use is restricted to Helladic type vessels (for D1 and D2) and as demonstrated from chemical analysis they cluster in three groups (Chania Group 1, 2 and 4). It has already been demonstrated that the samples from Psathi are compositionally different, but it remains to be examined whether there is any "internal" patterning of the chemical compositions within the different groups from Chania.

The result of cluster analysis is that all three types of fossiliferous fabrics from Chania are separated well from each other (Fig. 18). The first cluster in the dendrogram includes Chania chemical Group 2, the second Chania Group 4 and the third has Chania Group 1.

PCA confirms the picture presented by cluster analysis (Fig. 19). Chania Groups 1 and 4 are securely clustered, whereas Chania Group 2 is more spread, with the samples at the upper part of the plot being those from Platyvola. There is no apparent explanation why these samples present a slight "deviation" from the group, since they are clearly compatible with the rest in terms of typology and date. This compositional variation may be due to chronological difference, with the material 
from Platyvola being earlier than most of the Chania vessels, or to compositional variation in the clay deposits.

\subsubsection{Red fabrics}

The differentiation between red fabrics is not as clear as in the case of the fossiliferous fabrics for two reasons: red fabrics occur in every site examined, their use stretching throughout the Prepalatial period, and red deposits occur widely in West Crete. Petrographic analysis demonstrated that, although site-specific, the red fabrics from the different sites are very similar in composition; moreover, petrographic analysis of briquettes of raw material showed that red deposits from different sources may be mineralogically similar.

As with the fossiliferous fabrics, the chemical data corresponding to the red fabrics of Minoan style vessels were plotted using PCA and cluster analysis. PCA shows three groups that stand out in the plot (Fig. 20). The first comprises the samples from Kastelli, Chania Town and Platyvola, the second comprises most of the samples from Debla and the third includes a few samples from Nopigeia. In the middle of the plot there are sparse samples from Mitatoulia and Nopigeia, which do not cluster well. The picture is no different from what was presented in the analysis of the chemical groups: they are mainly site-specific and the values of the chemical compositions are close to each other (hence the absence of clear clustering).

In the dendrogram (Fig. 21) the same picture is repeated. The clusters are sitespecific and the values of the samples present close similarity. It is of interest that sample NOP 00/55 (a dark grey burnished chalice) clusters with the samples from Chania, whereas other samples of the same ware cluster with the rest of the Nopigeia assemblage (e.g. NOP 00/54). This might be indicative of common provenance. However, this suggestion must be treated with caution since this group displays increased variability between its members.

Although mineralogically homogeneous, the red fabrics present compositional variation, which may reflect different raw materials, chronological difference, or both. 
Chronological discrepancies constitute a major problem for the evaluation of the analytical data in terms of changes over time. Most of the EM material from West Crete cannot be dated with more precision than EM I-EM IIA. This might represent a time span of 600 (Manning 1995) to 1000 (Warren and Hankey 1989) years. Considering that clay recipes and locations for procurement of raw materials change over time and that the red deposits of West Crete are similar in mineralogical and chemical composition, it is not possible to decide on the basis of the present data set whether similarities in chemical compositions represent clay recipes of a restricted number of workshops over time or different (local) workshops.

\subsubsection{The Helladic Wares}

The last case to be examined is the Helladic black slipped wares. Due to the typological homogeneity of this ware, it was expected that there would be one centre of production manufacturing this specific kind of pottery. Petrographic analysis did not support this hypothesis and showed that there was variability in fabric between pottery of the same style fount at different sites (Fabrics D1 and D2). Chemical analysis also seems to demonstrate variation in the composition of the black slipped wares from different sites. In order to confirm this result, PCA and cluster analysis were performed.

PCA shows that the Helladic-style black slipped vessels from Chania and Platyvola are clustered together, whereas the samples from Debla stand out clearly. In addition, there is a small cluster with some samples from Psathi, whereas the rest of the samples from Psathi and those from Nopigeia are spread in the plot without any patterning (Fig. 22).

Cluster analysis (Fig. 23) confirms this result with the samples from Chania being grouped together, and some small clusters for Nopigeia and Psathi also standing out. The samples from Debla display clear differentiation from the rest. 


\subsection{Discriminant Analysis}

Using the groups identified from PCA, discriminant analysis is performed in order to compare the major site-specific groups but also similar fabrics from different sites.

In the first case, the groups plotted are Chania Group 1, Nopigeia Group 1, Debla Group 1, Psathi Group 1, Mitatoulia and Platyvola (Fig. 24). The analysis shows that some are well discriminated, especially Chania and Debla, whereas the samples from Nopigeia, Mitatoulia, Platyvola and Psathi display close compositions but are still site-specific.

Another case where discriminant analysis is used is the fabrics with fossils from Chania and Psathi. Despite the typological similarity, chemical compositions appear to be different. Discriminant analysis confirms this difference since in the resulting plot (Fig. 25) the clusters from the two sites are separated from each other.

Finally the last case where confirmation of the dissimilarity between sites was needed is the Helladic black slipped wares (Fig. 26). The groups from Chania, Nopigeia and Psathi are clearly differentiated from each other.

\subsection{Discussion}

The analysis with NAA aimed primarily at clarifying issues of provenance for the different fabrics and wares. The main issues to be tackled were the examination of the two main types of pottery, i.e. the Minoan and the Helladic style vessels but also variation within these wares, which is represented by the variation in petrographic fabrics. The results were treated statistically with S-Plus software by the application of two exploratory techniques, namely PCA and cluster analysis. The final groups were checked with discriminant analysis.

The differentiation between Minoan and Helladic style was confirmed by chemical analysis and it was demonstrated that for the Minoan wares non-calcareous clays were used, whereas the Helladic style vessels were manufactured with calcareous clays. It has been demonstrated also that the chemical groups are, in their 
great majority, site-specific and represent ware and/or fabric types from a single site. This is of particular interest in the case of the Minoan wares manufactured in red noncalcareous fabrics, the cases of the fabrics with fossils (especially those from Chania and Psathi) and the Helladic style black slipped wares. These wares appear in almost all the sites in similar fabrics, i.e. fabrics, which are related in terms of their mineralogical composition but display regional variations.

Chemical analysis has demonstrated that mineralogically similar fabrics from different sites do not share similar chemical compositions, which can be interpreted in several ways. The traditional explanation according to the provenance postulate is that different compositions reflect different production centres. However, this has been proven erroneous in several instances in the past and, recent ethnographic work had demonstrated that there can be extremely high variability within a single centre of production (Buxeda et al. 2003). The main parameters involved in compositional variability are the geology of the area, the manipulation of the raw materials, and the chronology of the pottery.

Especially in the case of West Crete, the repetitive character of the geology in the area does not facilitate the separation between similar sources of raw materials. The analysis of the pottery demonstrated that the chemical compositions are not very variable in the sense that they do not display extreme values. The different groups might have higher or lower values for the REE or the alkalis but the average compositions are close and that is the reason why in PCA (when $\mathrm{Ca}$ is not considered) all the samples group closely occupying the centre of the plot. Without extensive geological prospection and multiple clay sampling it is not possible to decide whether these values represent different deposits or variation within the same deposit.

In addition to geological and intra-deposit variability, the processing of the raw materials should be taken into consideration. Pottery making entails a great degree of clay manipulation, mainly in the form of levigation, mixing, and tempering. The chemical compositions may reflect the average composition of more than one clay and the values of some elements may be depleted or enhanced due to the presence of added materials. The work in the modern potting village of Pereruela (Spain) demonstrated 
that in some cases there might be no relation between raw materials and final products (Buxeda et al. 2003: 15). However, because of the existing variability within the archaeological assemblage in West Crete, it would be worth comparing with the local raw materials Further geological sampling and analysis providing information on the geochemistry of rocks and soils in West Crete would allow comparison between the raw materials and the average compositions of the pottery samples. In this way, even if there is no match between the concentrations of the archaeological and the geological samples, it will be possible to evaluate how representative the elemental concentrations of the pottery are and investigate the reasons of the variability and potential cases of alteration and contamination.

Finally, the issue of chronology is of importance in the discussion of chemical variability in the West Cretan assemblage. It was demonstrated by petrographic and chemical analysis that the main ware types are site- specific and this was interpreted as representing different location of production or intra-deposit variability. However, there is always the possibility of differentiation of the source of raw materials through time. Some fabrics extend over a long period of time in many sites (the red fabrics occur from EM I to IIB in all sites), whereas others occur in specific sites but with variation (like the fabrics with fossils in Chania and Psathi). Most of the West Cretan material is dated with typological rather than stratigraphic criteria and, in some cases, it is not possible to decide whether a vessel is EM I or IIA. Moreover, because most of the assemblages are not published, there does not exist a west Cretan typological sequence; therefore, it is not feasible to distinguish between the earlier and later phases of a certain period, especially for vessel or ware types that occur throughout the EM period. Therefore, the samples examined here might represent a considerable time span during which during which changes in clay recipes and sources for procurement of raw material might have occurred within the same location of production.

As was the case with the mineralogical compositions, the earlier material (EM I) displays greater variability also in chemical composition. This is due to the variety of raw materials used during this early period but also to the lack of well-stratified pottery in order to investigate the full range of fabrics and chemical compositions occurring in the EM I. The case of the dark grey burnished ware is also of particular 
interest because in similar studies from Central Crete it was demonstrated that there are several centres of production for this type of pottery following the same techniques of manufacture (Wilson and Day 1994). All the dark grey burnished ware samples from West Crete were analysed but the chemical compositions do not present any patterning and, in most cases, they remained ungrouped. The exception is the case of Chania (Chania Group 3) where they clustered together. Petrographic analysis showed that the dark grey burnished fabrics are within the broad category of the red wares, in some cases presenting slight variation from the main group (subgroup of Fabric D8). Although, most of the evidence of chemical analysis for the provenance of the dark grey burnished ware is negative, it seems that the Central Cretan pattern is repeated in the West. The West Cretan dark grey burnished ware displays similarities in the typology and fabric between the different sites of consumption and it seems that the paste recipes and way of manufacture are the same, even if the locations of production are different.

Summarising the observations from chemical analysis, it has to be stressed that these remarks refer to the part of the material that has been grouped. Before presenting a brief encounter of the results, it is important to discuss the part of the assemblage that remained ungrouped.

A significant portion of the samples analysed (ca. 35\%) were not included in any group, due to compositional variability. Although the elemental concentrations of this material did not display extreme values, variation in REE and alkalis did not allow further grouping. The samples that remained ungrouped derive primarily from Mitatoulia, Debla and Platyvola. In the case of Mitatoulia, the variability of elemental concentrations was attributed to early date of the material. It was assumed that at this early date (EM I) no standard sources of raw material were used, hence the compositional diversity. Moreover, the samples of Mitatoulia are in their majority medium coarse and it is possible that the trace elements were affected by the presence of the non-plastic inclusions. In the case of Platyvola, the number of samples taken was small due to permit restrictions. Therefore, it was attempted to provide a representative picture of the assemblage with only one or two samples for each ware. Except for the samples that grouped with the material from Chania (the Helladic style 
vessels), and the small Platyvola chemical group, the rest of the samples presented quite varied elemental concentrations, probably due to the lack of a considerable number of samples for each category. Finally, Debla was also a particular case: chronologically it seems a little earlier than Chania (EM I - early EM IIA) and in petrographic terms the fabrics are mineralogically similar but not the same as those of the Chania material. The chemical variability of the Debla material might be assigned to the early date of the pottery as well as intra- and inter-deposit variation.

Except for the specific cases of ungrouped samples, the West Cretan material presented some inherent difficulties for NAA. A considerable amount of the pottery is tempered and in NAA the elemental concentrations of the tempering materials are also reflected. Especially in cases of grog and siltstone used as temper, the concentrations of these materials might mask the elemental concentrations of the base clay, as demonstrated by analysis and experimental work (Neff et al. 1988; 1989). Several studies Moreover, petrographic analysis indicated large-scale clay mixing, most likely involving varying ratios of the different components, which also affects the elemental concentrations of the final product. The content of the West Cretan samples in quartz and fossils is elevated and this might cause depletion of the trace elements in the sample (Dr. A. Hein pers. comm.). Finally, the possibility of alteration and contamination remains to be examined but, in this effect, systematic clay sampling has to be carried out. All these components created compositional variability in the assemblage, which was reflected in the PCA plot (Fig. 2), where most of the samples are grouped in the middle of the plot but there are no clear clusters formed.

Despite the lack of obvious patterning in the data, it was made possible to identify several groups, which sustained a pattern of local pottery production, following the procedures explained in the beginning. It was demonstrated that local raw materials are used for the manufacture of specific types of pottery. NAA confirmed what was suggested by petrographic analysis, i.e. that Minoan- and Helladic-style vessels were manufactured with different raw materials. Moreover, it was demonstrated that similar wares, found at different sites, did not share similar elemental concentrations, as was the case of the red Minoan wares. It seems that 
differentiation in space, is not valid only between distant sites but also between sites located in the same geographical area, like Chania and Psathi.

This differentiation in space was probably connected with differentiation in time. It seems that in the EM I period there is not much variation in the types of raw materials used and the sources exploited are similar all over West Crete. This created a pattern of similarity in petrographic terms, which, however, is not supported by chemical analysis, the reason being the variability between deposits. The case of the dark grey burnished ware is of particular interest since it seems to follow the Central Cretan pattern with similar clay pastes and ways of manufacture in different locations of production. For the subsequent periods (EM IIA-B) the pattern is different; specific types of raw materials were used for specific types of pottery, which is reflected in the manufacture of Helladic and Minoan wares. There are also indications of pottery movement (especially in the case of black slipped ware from Chania to Platyvola). The pattern of site-specific groups is very prominent and has a two-fold interest: within sites it shows that types of particular character like the hearths at Nopigeia share the same compositions as the domestic coarse wares; between sites it implies the existence of a few locations of production where similar types of pottery are manufactured, using similar types of raw materials but different sources for clay procurement.

The chemical analysis of the West Cretan EM material did not change the picture provided by petrographic analysis but it confirmed the discrepancy between raw materials for Helladic and Minoan-style vessels and contributed to the investigation of the relation between similar wares from different sites. 


\title{
CHAPTER 8
}

\author{
Scanning Electron Microscopy
}

\subsection{Introduction}

Several technological aspects of the West Cretan EM pottery are investigated with scanning electron microscopy (SEM). The main issues concern the technology of manufacture of specific wares such as the Helladicising black slipped, but also the Minoan wares, such as the dark grey burnished, mottled, and dark-on-light painted wares. The examination includes qualitative and semi-quantitative analysis of the composition of the ceramic paste and the surface slip or paint. This information complements our knowledge from bulk chemical analysis, especially the issue of calcareous versus non-calcareous clays. With SEM it is possible to perform separate analysis on the clay paste and the paint or slip on the surface of the vessel, and examine whether the composition of the body is similar to that of the paint or slip. Moreover, observation with SEM provides information related to the manufacturing process, such as thickness of burnishing, paint, or slip, potential orientation of the clay particles of the surface, due to intense burnishing, and adherence of the paint or slip to the ceramic body. Finally, the study of the microstructure of the clay body and surface allows the estimation of the degree of vitrification and the establishment of a clear account of the firing conditions (temperature and atmosphere). In this way, the technological study covers aspects of the pottery related to the nature of the clays, the manufacture and the firing process.

The samples from West Crete studied are representative of different wares and fabrics. The results of the analysis are presented according to wares and, when possible, comparisons are made with analyses of similar wares in Central Crete (Wilson and Day 1994). There is a summary table with information from SEM and petrographic analyses at the end of each ware group. 


\subsection{The Wares.}

\subsubsection{Dark Grey Burnished Ware (PI. 77)}

In this category belong samples that are characterised by a dark grey to black surface. Representatives of this ware occur in all the sites but they vary in composition as shown by petrographic analysis. With this variability in mind and in view of previous analyses of the same ware from Central Crete, it is of interest to examine whether the West Cretan group shares similar technological characteristics and techniques of manufacture. The dark grey burnished constitutes one of the few wares that are widespread across the island and a comparative study would provide important information on the techniques of manufacture.

The samples examined are listed in Table XII. They are considered as a single group since they seem to share similar properties.

The clays used for the manufacture of the dark grey burnished group are noncalcareous. On the surface, there is a discrete layer of $15-20 \mu \mathrm{m}$, which is the result of compaction of the clay due to intense burnishing (cf. Kilikoglou 1994: 72) (Pl. 77d-f). The analysis showed that the clay body and the burnishing share the same composition, which suggests that it is the vessel surface that was burnished and there was no slip applied. The higher values of $\mathrm{Fe}$ for the burnished surface are most likely due to the compaction of the particles through burnishing. The microstructure of the body shows that all the samples are at the stage of initial vitrification (IV) (PI. 77a-c) and the estimated equivalent firing temperature is ca. $750^{\circ}-800^{\circ} \mathrm{C}$.

The colour of the surface is dark grey to black for the interior and exterior surfaces in all the samples. The colour of the clay paste (the "biscuit" of the vessel) ranges from red to black. There are two possibilities that might have led to this effect:

a) through surface treatment and variation in firing atmosphere. Near the peak temperature the oxidising atmosphere changed into reducing for a short period of time. During reduction the lack of oxygen changed the colour of the vessel from red to black. This is the technique of simple reduction and should not be confused with ironreduction, which involves re-oxidation in the final phase of firing (as in the case of the 
black slipped wares) (Kilikoglou 1994: 73). Simple reduction produces a dark colour for the surface and the clay paste. In this case, however, the clay paste, remained red probably because reduction did not last long (Kilikoglou 1994: 72-73).

b) it is a usual practice, especially for early ceramics fired in open pits to produce the black surface effect with smudging. This is achieved by covering the pots at the end of the firing process with fine material such as powdered manure or ash from the firing. This material impedes the oxygen to penetrate in the pores and carbon is deposited on the surface making the vessel black on the surface but the clay paste remains red (Rice 1987: 158).

In the case of KST/17 the colour of the ceramic core is grey, which probably indicates that the vessel was fired in a reducing atmosphere and then left to cool down at a natural rate. Most likely the burnishing of the surface did not allow the oxygen to penetrate the body during re-oxidation.

In the case of NOP/55 the part of the clay paste closer to the surface is red, whereas the core is grey, also suggesting that during re-oxidation the burnishing did not allow the oxygen to penetrate further than the area close to the surface. In both these cases it might also be suggested that the black colour of the surface is the result of smudging and carbon deposition and therefore the oxygen did not penetrate further in the core of the clay paste. Therefore, the atmosphere became locally reducing and the Fe-oxides turned into magnetite, which is responsible for the black colour (Kilikoglou and Maniatis 1993: 438). In fact, the grey-black colour of the surface and core of the vessels points towards smudging rather than a reducing atmosphere. Considering that firing was most likely carried out in an open fire, where the atmosphere is highly, if not completely oxidising, the colour to be expected at least for the core is red. Even if the DGBW vessels were kiln-fired, the atmosphere would be mixed, as indicated from the study of other wares, where firing in kiln is certain.

In the case of sample PLT/10 the colour of the clay paste is red with a grey core, which is a common phenomenon in early ceramics known as the "sandwich effect". It is a result of the firing procedure, caused either by rapid change of the 
temperature or by a reducing atmosphere near the top temperature and insufficient oxidising during cooling.

The dark grey burnished ware from the different West Cretan sites seems to share similar technological characteristics: non-calcareous clay, low firing temperature, dark-grey to black surface for the final product. This is compatible with the results of petrographic analysis, which showed that the fabrics of the DGBW samples from the different sites are local and compositionally similar but not the same. This indicates that this ware is locally produced, according to similar recipes and technology of manufacture but in different locations. The uniformity in the technology of manufacture of the DGBW, despite provenance, has already been demonstrated in Central and East Crete (Wilson and Day 1994: 75), where the DGBW is also characterised by the use of non-calcareous clays, the lack of slip and the low firing temperatures (Kilikoglou 1994: 70-73). The analysis of the West Cretan material confirms that the production of the EM I-IIA DGBW occurs in different locations but according to specific recipes of manufacture and firing in order to achieve the same visual effect in typologically similar vessels.

Table XII. Dark Grey Burnished Ware

\begin{tabular}{|l|c|c|c|c|c|c|c|c|}
\hline SAMPLE & PART & FABRIC & FIR ATM & CALC & K & Fe & VITR & TEMP \\
\hline KST 017 & paste & DGBW & R-O?-R & low & low & low & NV & ca. 750 \\
\hline KST 017 & clay & & & low & med & med & & \\
\hline KST 017 & out burnish & & & low & low/med & med & NV & \\
\hline NOP 055 & paste & Fine w. pell, grog & O-R & low & low & med & NV & ca. 750 \\
\hline NOP 055 & clay & & & low & low & low & & \\
\hline NOP 055 & out burnish & & & low & low & low & NV & \\
\hline NOP 055 & in burnish & & & low & low & med & NV & \\
\hline PLT 010 & paste & Red, q, pell, grog & O-R-O & low & low & med & NV & ca. 750 \\
\hline PLT 010 & clay & & & low & low & high & & \\
\hline PLT 010 & out burnish & & & low & low & med & NV & \\
\hline
\end{tabular}




\subsubsection{Red-Brown / Black Burnished Ware (Pl. 78, 79)}

This group comprises black and scribble burnished vessels from all the sites. The ware is widespread all over Crete and it is of interest to compare variability not only within West Crete, but also with similar types from Central Crete. The samples examined are listed in Table XIII.

This group is quite consistent in terms of composition with most of the samples belonging to related petrographic fabrics. In their majority, they are red firing clays, similar in their mineralogical composition, but with certain textural differences that suggest production in different locations. Examination by SEM shows that they share common characteristics in terms of technique of manufacture and firing (Table XIII). The clays used for the manufacture of all vessels are non-calcareous. The surface is covered with a slip made of a fine suspension of the same clay that was used for the body, as indicated by the higher concentrations of $\mathrm{Al}, \mathrm{K}$ and Fe. The thickness of the burnishing varies in the different samples between 15-25 $\mu \mathrm{m}(\mathrm{Pl}$. 79). All the samples display surface compaction of the clay particles as a result of burnishing. The black colour seems to have been produced with simple reduction and it does not show the degree of vitrification of the black slipped ware.

The firing temperatures range between $750-800^{\circ} \mathrm{C}(\mathrm{NV})(\mathrm{Pl} .78 \mathrm{a}-\mathrm{d})$. However, although the body microstructure is non-vitrified, samples PLT/04 and 05 display an area in the ceramic body exhibiting a spongy texture with small bloating pores (PI. 78e-f). This localised texture is characteristic of fast firing, i.e. a fast heating rate resulting from the positioning of the pottery during firing or from a deliberate addition of fuel during the firing process in order to produce a reducing atmosphere (Maniatis and Tite 1981: 74). This microstructure might be an indication that the red-brown surface of the vessels was intended to be black but reduction was not successful. A counter-argument would be that the firing temperature is rather low and, if black was intended, a higher temperature would have been applied (Kilikoglou 1994: 77).

The colour of the clay paste ranges from red (for KST/03) to grey (for CHT/08) suggesting the technique of simple reduction. In some cases the body is red with a grey core, which was previously interpreted as the "sandwich effect". This must 
be the result of rapid change of temperature, which created a locally reducing atmosphere.

The closest comparative material for the West Cretan black burnished ware is the analysis of a sample of black washed ware from Knossos (Kilikoglou 1994: 74). There are some technological characteristics in common, i.e. the clay used is noncalcareous, the distribution of $\mathrm{Fe}$ on the black surface is heterogeneous, the microstructure of the wash is coarser. The quality of manufacture seems lower when compared to the painted wares for the Central Cretan examples (Kilikoglou 1994: 74), and to the black slipped ware for the samples from West Crete. However there are also differences between the West and Central Cretan black burnished examples since the latter exhibit vitrification of Vc- stage, corresponding at $800-900^{\circ} \mathrm{C}$, whereas the samples from West Crete are lower-fired. Finally the most important difference lies in the production of the black colour since in the Central Cretan examples the ironreduction technique is used, whereas for the West Cretan examples it seems to be simple reduction.

Table XIII. Red-Brown / Black Burnished ware

\begin{tabular}{|l|c|c|c|c|c|c|c|c|}
\hline SAMPLE & PART & FABRIC & FIR ATM & CALC & K & Fe & VITR & FIR TEMP \\
\hline CHT 008 & paste & Red, q, grog, calc & R & non/low & low & med & NV & $<750$ \\
\hline CHT 008 & clay & & & low & low & low & & \\
\hline CHT 008 & out burnish & & & non/low & low & low & & \\
\hline DEB 007 & paste & Grog, q, phyll & 0 & non/low & low & med & IV & $750-800$ \\
\hline DEB 007 & clay. & & & non & med & low & & \\
\hline DEB 007 & out burnish & & & non & med & low & NV & \\
\hline DEB 007 & in burnish & & & non & low & low & NV & \\
\hline DEB 010 & paste & Grog, q, phyll & 0 & non & low & low & NV & $<750$ \\
\hline DEB 010 & clay & & & non/low & high & high & & \\
\hline DEB 010 & out burnish & & & non & low & med & NV & \\
\hline DEB 010 & in burnish & & & non & low & low & NV & \\
\hline KST 003 & paste & Red, q, grog, calc & R & low & low & low & NV/IV & $750-800$ \\
\hline KST 003 & clay & & & low & high & high & & \\
\hline KST 003 & out burnish & & & low & med & high & IV & \\
\hline KST 006 & paste & Red, q, grog, calc & O-R?-O & low & low & med & IV & $750-800$ \\
\hline
\end{tabular}




\begin{tabular}{|c|c|c|c|c|c|c|c|c|}
\hline KST 006 & clay & & & low & low & low & & \\
\hline KST 006 & out burnish & & & low & low & high & NV & \\
\hline KST 009 & paste & F-M, micr, foss. & 0 & non/low & low & low & NV/IV & $750-800$ \\
\hline KST 009 & clay & & & non/low & med & low & & \\
\hline KST 009 & out burnish & & & low & med & med & NV & \\
\hline KST 009 & in burnish & & & non/low & low & low & NV & \\
\hline KST 014 & paste & Red, grog, pell & $\mathbf{R}$ & low & low & high & IV & $750-800$ \\
\hline KST 014 & clay & & & low & low & low & & \\
\hline KST 014 & out burnish & & & low & med & low & NV & \\
\hline KST 014 & in burnish & & & low & low & med & & \\
\hline MIT 006 & paste & Red, grog, w. mica & 0 & non & low & med/high & NV & $<750$ \\
\hline MIT 006 & out burnish & & & non & low & med & NV & \\
\hline MIT 007 & paste & Red, grog, w. mica & $\mathbf{0}$ & non & low & high & NV & $<750$ \\
\hline MIT 007 & clay & & & non & med & high & & \\
\hline MIT 007 & out slip & & & non & low & high & NV & \\
\hline MIT 007 & in slip & & & non & low & high & NV & \\
\hline MIT 011 & paste & & O-R-O & non & med & high & NV & $<750$ \\
\hline PLT 001 & paste & Red, q, grog, pell & O-R-O & low & low & med & IV & $750-800$ \\
\hline PLT 001 & clay & & & low & low & med & & \\
\hline PLT 001 & out burnish & & & non/low & low & low & NV & \\
\hline PLT 004 & paste & Red, q, grog, pell & O-R-O & non/low & low & low & IV/V & $800-900$ \\
\hline PLT 004 & clay & & & low & low & high & & \\
\hline PLT 004 & out burnish & & & low & low/med & low & NV & \\
\hline PLT 005 & paste & Red, q, grog, pell & 0 & low & low & low & IV/V & $800-900$ \\
\hline PLT 005 & clay & & & low & low & low & & \\
\hline PLT 005 & out slip & & & low & low & low & NV & \\
\hline PLT 005 & in slip & & & low & low & low & NV & \\
\hline
\end{tabular}

\subsubsection{Red Slipped and Burnished Ware (Pl. 80, 81)}

In this category belong samples from all the sites characterised by a red slipped and burnished surface, which in some cases might also be scored. The samples that have been analysed are listed in Table XIV. This group of vessels is quite consistent in composition, all the samples belonging to related petrographic fabrics. In terms of mineralogical composition they are also similar to the Red-Brown/Black Burnished ware. They all consist of a red firing clay with similar, but not always the same, 
mineral and rock components (Table XIV). The main aim in examining this group by SEM is to compare the red slipped and burnished ware in different West Cretan sites and also with the other burnished wares.

As was the case with the black burnished ware, the clays used for the manufacture of these vessels are non-calcareous. The analysis of the surface showed that the slip was also made of a fine suspension of the same clay as the body. The thickness of the burnishing in the different samples ranges between $15-25 \mu \mathrm{m}$ and it is well compacted (P1. 81). This compaction of the fine particles is responsible for the dark hue of the red colour (Kilikoglou and Maniatis 1993: 439).

The firing temperatures are quite low, ranging between $750-800^{\circ} \mathrm{C}(\mathrm{NV})$ (Pl. $80 \mathrm{a}-\mathrm{b}$ ) and $800-900^{\circ} \mathrm{C}$ (IV) (Pl. 80c-d). Firing technology does not seem to be very consistent either between sites or among samples deriving from the same site.

The colour of the clay paste of the samples from Mitatoulia is red, indicating an oxidising atmosphere, whereas in the cases of KST/20, 31, 34 and PLT/20 the part of the body near the surface is red and the core is grey. In the cases of MIT/23 and KST/34 there are indications of fast firing (PI. 81a-b). This indicates that the firing procedures are very similar to those described for the Black Burnished ware examined above.

Considering that the two wares are contemporary (EM I-IIA) and they are both burnished, it could be suggested that they share the same tradition of manufacture. The fact that a red burnish finish is also associated with other techniques of decoration, namely scoring of the vessel, might be associated with functional along with aesthetic reasons. Burnishing reduces permeability and a rough surface (achieved through scoring) provides a more secure grip of the vessel, especially when it is for transportation (Rice 1987: 232). In this case the vessels represented are mainly (if not exclusively) jugs and jars and therefore the combination of burnishing and scoring would provide the optimum result. 
Table XIV. Red Slipped and Burnished Ware

\begin{tabular}{|c|c|c|c|c|c|c|c|c|}
\hline SAMPLE & PART & FABRIC & FIR ATM & CALC & $\mathbf{K}$ & $\mathrm{Fe}$ & VITR & FIR TEMP \\
\hline CHT 002 & paste & Red, q, grog, calc & O-R-O & med & low & med & NV & $<750$ \\
\hline CHT 002 & clay & & & med & high & high & & \\
\hline CHT 002 & out burnish & & & low & low & med & NV & \\
\hline CHT 002 & in burnish & & & low & low & med & NV & \\
\hline DEB 040 & paste & Coarse, $q$, grog, phyl & 0 & non & low & med & NV/IV & $750-800$ \\
\hline DEB 040 & out burnish & & & non & low & med & NV & \\
\hline KST 020 & paste & Red, q, grog, calc & O-R & low & low & low/med & NV/IV & $750-800$ \\
\hline KST 020 & clay & & & med & low & low & & \\
\hline KST 020 & out burnish & & & low & high & high & NV & \\
\hline KST 020 & in burnish & & & low & med & high & NV & \\
\hline KST 029 & paste & Red, q, grog, calc & 0 & low & low & med & IV & $750-800$ \\
\hline KST 029 & clay & & & low & med & high & & \\
\hline KST 029 & out burnish & & & low & med & low & NV & \\
\hline KST 031 & paste & Red, grog, w. mica & O-R & non/low & low/med & med & NV/IV & $750-800$ \\
\hline KST 031 & clay & & & non/low & med & low & & \\
\hline KST 031 & out burnish & & & non/low & med & med & NV & \\
\hline KST 031 & in burnish & & & non/low & med & med & NV & \\
\hline KST 034 & paste & Red, w. grog, pell & O-R & non & low & med & Vc & $850-1050$ \\
\hline KST 034 & clay & & & low & low & med & & \\
\hline KST 034 & out burnish & & & non & low & low/med & NV & \\
\hline MIT 023 & paste & Red, grog, w. mica & 0 & non & low & high & IV/V & $750-850$ \\
\hline MIT 023 & clay & & & non & non & low & & \\
\hline MIT 023 & out burnish & & & non & med & med & NV & \\
\hline MIT 024 & paste. & Red, grog, w. mica & 0 & non & low & med & NV & $<750$ \\
\hline MIT 024 & clay & & & non & low & low & & \\
\hline MIT 024 & out burnish & & & non & low & med & NV & \\
\hline PLT 020 & paste & Red, q, grog, pell & O-R-O & non/low & low & low & IV & $750-850$ \\
\hline PLT 020 & clay & & & low/med & low & low/med & & \\
\hline PLT 020 & out burnish & & & low & low & med & NV & \\
\hline
\end{tabular}

\subsubsection{Black Slipped Ware (PI. 82, 83)}

This is a well-defined group in terms of typology including vessels, which, in terms of shape repertoire, are considered to be closer to the Helladic "Urfirnis" ware than to Minoan prototypes. Like the "Urfirnis" vessels, they are characterised by the 
application on the surface of a black slip always with a metallic sheen. It is also a quite consistent group in terms of petrography, all the samples belonging to the same fabric group (Table XV). It is therefore of importance to examine the technology of manufacture, especially the composition and structure of the black slip in order to compare it with the Helladic black slip, which is characterised as "iron black". Emphasis is laid on the technology of manufacture of the black surface, since there are more than one method of creating the same effect on pottery (Noll et al. 1975).

The samples examined are listed in Table XV. All the samples are similar in shape and, although the Nopigeia samples preserve little or no trace of black slip due to ground conditions, they are considered as a single group.

The clays used for the manufacture of this ware are calcareous with high Fecontent. In contrast, the analysis of the black slip showed low concentrations of $\mathrm{Ca}$ and increased amounts of $\mathrm{Fe}, \mathrm{Al}$ and $\mathrm{K}$. These concentrations can be interpreted in two ways: a) they constitute natural enrichment of the clay, as a result of the fine fraction having been suspended in water before being used for the slip (Aloupi and Maniatis 1990: 461), and b) a different non-calcareous clay was used for the slip, which did not become porous with firing.

The surface slip is visible only in the samples from Kastelli and Platyvola; it has a thickness range of $15-25 \mu \mathrm{m}$ and is vitrified with a few fine bloating pores (PI. $82 \mathrm{a}-\mathrm{c})$. The technique of manufacture of the metallic black slip is that of ironreduction. This technique was first described by Binns and Frazer (1929) and consists of an oxidising-reducing-oxidising firing cycle. During reduction, the Fe-oxides turn into magnetite or wustite, which are black, and therefore the colour of the clay becomes black. In the following re-oxidising state the body becomes red again but the sintering of the fine-grained slip on the surface does not allow the oxygen to penetrate and the surface remains black (Kilikoglou 1994: 73).

In studies of Minoan ceramics, iron black decoration has been studied by many techniques, especially the metallic black slips of Middle Minoan Kamares Ware (Noll et al. 1975; Noll 1982; Faber et al. 2002). In Early Minoan Crete it has been identified in the Knossian fine painted and dark-on-light painted ware (Kilikoglou 1994: 73-75). 
It is important that the slip used for the production of the black colour is fine-grained and therefore not porous so that the visual effect would be shiny black and not brown or red-brown, which is the result of partial re-oxidation (Aloupi and Maniatis 1990: 467). In the case of the West Cretan black slipped ware, the slip is fine-grained, which allows reducing conditions to be achieved at relatively low temperatures. The quality of the black slip indicates that there was good control of the firing atmosphere, reducing conditions being fully achieved.

Colour differentiation on the black slipped sauceboats from Platyvola constitutes indirect evidence of the iron-reduction technique and reveals the way the vessels were placed in the kiln. The circular red imprint inside the bowl of the sauceboats indicates that they were stacked one inside the other. During the phase of reduction, the area in the bowl of the sauceboat occupied by the foot of the vessel stacked on top is covered and, therefore, is not affected by the formation of the black colour, leaving this red imprint.

The microstructure of the body shows vitrification, although not always to the same degree as the slip. The estimated firing temperature for KST/59 is $900-1000{ }^{\circ} \mathrm{C}$ (Vc) (Pl. 82d), whereas for KST/77 it is slightly lower, around $800^{\circ} \mathrm{C}$ (V-) (PI. 83a). The sample from Platyvola is very similar to those from Kastelli, the firing temperature being estimated at $850-1050{ }^{\circ} \mathrm{C}(\mathrm{Vc})(\mathrm{Pl} .83 \mathrm{~b})$.

In the case of KST/59 and PLT/11 the colour of the clay paste ranges from grey to red, which might be an indication of incomplete re-oxidation. In the case of $\mathrm{KST} / 77$ the body is grey, which also indicates lack of re-oxidation.

The group of black slipped ware from Nopigeia presents similar technical characteristics. The clay used is also calcareous but, as the surface is not preserved, there is no indication for the composition of the slip. The microstructure of the body displays relative vitrification for all samples; samples NOP/72, 74 have an estimated firing temperature of ca. $800-900{ }^{\circ} \mathrm{C}$ (V-) (Pl. 83c). Sample NOP/65 displays total vitrification with large rounded bloating pores, due to an estimated firing temperature of above $1100^{\circ} \mathrm{C}(\mathrm{Vc}+)(\mathrm{Pl} .83 \mathrm{~d}$ ) (cf. Maniatis and Tite 1981: 64; Fig. 6). It is obvious 
even from macroscopic observation that this vessel was a failure in terms of firing, but it is of interest that it was found in a domestic context, in spite of being discarded.

As to firing atmosphere, the colour of the body of NOP/72 is red, whereas that of NOP/74 is red near the surface, the core being grey. This along with the over-fired sample NOP/65 might be an indication of incomplete re-oxidation and unstable kiln conditions.

In the Late Bronze Age material from Akrotiri it has been observed that the black slip was mostly associated with drinking vessels; it was suggested that its use on the specific vessels served functional as well as aesthetic purposes. The slip deriving from a finer suspension of the clay due to polishing and vitrification produced a nonpermeable layer on a porous body that was necessary for drinking vessels (Aloupi and Maniatis 1990: 467). In West Crete the black slip is associated mainly with sauceboats and jugs which are also vessels related to liquids and the same connection could be possible. However, the importance of the sauceboat in terms of morphology and the visual effect it produces has been stressed by the existence of gold examples, a double sauceboat from the Great Treasure at Troy (Schmidt 1902: 230, no. 5863), one in the Louvre and one in New York, the latter ones probably being products of Argive workshops (Wiencke 2000: 592). It has long been observed that the potters are aware of the products of metalworkers and that they imitated them (Renfrew 1972: 335-37). It is, therefore, possible that the application of the black slip is in imitation of metal.

The study of black slipped ware with SEM revealed some interesting aspects of the technology of manufacture of this ware. Petrographic analysis demonstrated that the black slipped vessels are West Cretan products and share similar mineralogical composition among sites, with some differences that point to different locations of production. SEM analysis demonstrated that, except for the fabric, they also share the same technology of manufacture. This is important because the black slipped ware is confined to specific types of vessels that occur constantly in all the sites, with considerable typological and stylistic similarity. The fact that they share also the technology of manufacture points towards a few locations of production across West Crete. 
The second point refers to the particularities of the manufacturing technique. It seems that black slipped ware constitutes one of the few cases where calcareous clays and the iron-reduction technique are used for the manufacture and firing. In EM West Crete non-calcareous clays are selected for most types of pottery and the firing process is restricted to oxidation or simple reduction. This raises the issue of clay recipes and specific types of raw materials associated with specific types of pottery. The typological links of the West Cretan black slipped ware with the Helladic "Urfirnis" vessels raises the issue of pottery traditions in the Aegean and the distribution of the technological know-how.

Table XV. Black Slipped Ware

\begin{tabular}{|l|c|c|c|c|c|c|c|c|}
\hline SAMPLE & PART & FABRIC & FIR ATM & CALC & K & Fe & VITR & FIR TEMP \\
\hline KST 059 & clay & v. fine w. foss & R-O? & high & med & low & Vc & $900-1000$ \\
\hline KST 059 & out burnish & & & low & high & med & V & \\
\hline KST 077 & paste & & R & high & low & low & IV-/V- & 800 \\
\hline KST 077 & clay & & & high & low & high & & \\
\hline KST 077 & out burnish & & & low & med & low & V & \\
\hline NOP 065 & paste & v. fine w. foss & R & med & low & med & Vc+ & $>1100$ \\
\hline NOP 065 & clay & & & high & low & med & & \\
\hline NOP 065 & creamy slip & & & med & med & low & & \\
\hline NOP 072 & paste & v. fine w. foss & 0 & high & low & high & V- & $800-900$ \\
\hline NOP 072 & clay & & & high & low & low & & \\
\hline NOP 074 & paste & v. fine w. foss & O-R & med & non/low & med & V- & $800-900$ \\
\hline NOP 074 & clay & & & med & low & med & & \\
\hline PLT 011 & paste & v. fine w. foss & R-O & med & low/med & low/med & Vc & $850-1050$ \\
\hline PLT 011 & clay & & & med & med & low & & \\
\hline PLT 011 & out slip & & & low & med & med & V & \\
\hline
\end{tabular}

\subsubsection{Mottled Ware (PI. 84, 85, 86)}

Mottled ware constitutes one of the earliest ceramic types in Crete with more than one colour on the surface of the ceramic body: the mottled effect consists of interwoven black red and orange colours on a hard and lustrous surface, with no deliberate syntax. This ware was found in quantity at the site of Vasiliki, hence the 
name "Vasiliki Ware". It is a well-defined ceramic style in Central and East Crete and has been studied typologically as well as analytically because of its particular character and technique of manufacture. It was demonstrated that its origin is in East Crete, but it gets traded across Central and East Crete (Betancourt et al. 1979).

Examination by SEM of different samples from East Crete showed that there was no patterning in the microstructure of the ware, which would allow tracing in detail the procedures of manufacture. The general appearance of the vessels was suggested to depend on many variables, among which were raw materials and firing (Betancourt et al. 1979: 11). Microscopic analysis in the same study showed that the slip applied on the surface is uniform in composition, made of a fine fraction of the same clay as the body. It was also demonstrated that there is variation in the microstructure of the mottled areas; the black can be more vitrified than the surrounding areas and in some cases might display a spongy texture (Betancourt et al. 1979: 9-10). Mottling is an effect caused by variation in the kiln atmosphere during firing but there is no definite answer concerning the details of the firing process or an adequate explanation of the variability of the mottled decoration (for an account on the different reconstructions of the technology of mottling until the late 70 's, see Betancourt et al. 1979: 14-16).

In the case of West Crete the issue of mottled ware presents a two-fold aspect. Its provenance is of interest because of its rare occurrence and the assumption that everything was imported (Betancourt et al. 1979: 27). Petrographic analysis has shown that mottled ware in West Crete is produced in the same fabric as the black slipped ware, i.e. a fine calcareous clay, which may derive from the Neogene deposits of the north coast near Chania (Table XVI). The second issue concerns the technology of manufacture and whether the West Cretan examples share the technological characteristics of the "canonical" Vasiliki Ware as occurring in the East Cretan examples. The samples examined are listed in Table XVI.

All samples examined were found to be manufactured with calcareous clays but the microstructure of the clay and surface slip is not in all cases the same. Therefore, they are discussed separately. Sample CHT 00/34, is the closest to the 
canonical Vasiliki ware ${ }^{1}$. Macroscopically it displays three distinctive colour areas on the surface, black, red and orange, all of which have been examined separately. The slip is quite thick $(12-22 \mu \mathrm{m})$ all along the section and from its content in $\mathrm{Al}, \mathrm{K}$ and $\mathrm{Fe}$ it seems to have been made of the fine suspension of the clay that was used for the body (cf. also the Vasiliki Ware in Betancourt et al. 1979: 6).

As to the microstructure of the surface, the black area is vitrified with fine bloating pores, which is reminiscent of the iron reduction technique used for the production of black slip (PI. 84a). The red area is not as vitrified as the black and displays a compact texture (P1. 84b). This happens because the surface of the vessel was burnished prior to firing and therefore areas that are not well vitrified display the characteristics of burnished wares. Warren (1972: 129-31) identifies macroscopically monochrome red or brown burnished jugs that were manufactured in a similar way as the mottled ware but were fired in a single, oxidising episode ("pseudo-Vasiliki").

Finally, the orange area displays the typical texture of the canonical Vasiliki ware, i.e. a spongy texture with very fine bloating (PI. 84c). There is no definite explanation for the orange colour or this microstructure the only suggestion being that the atmosphere was not strongly reducing but there was not sufficient oxygen either to allow a full red colour to develop (Betancourt et al. 1979: 9; Faber et al. 2002).

The body displays vitrification ( $\mathrm{Vc} / \mathrm{Vc}-$ ) and the estimated firing temperature is ca. $800-1000^{\circ} \mathrm{C}$ (Pl. 84d). The colour of the clay is red towards the exterior surface and grey towards the inside of the vessel, probably as a result of incomplete reoxidation. The major issues concerning this ware are whether the mottling effect is deliberate or accidental, as well as the details of the firing process. The examination of several samples from East Crete demonstrated that the decorative motifs, the colours as well as the microstructure of the body and surface are quite varied. This indicates that the raw materials as well as the technique of manufacture and the firing process can be very different between sites, even within samples found in a single site. This is

\footnotetext{
'Except for Betancourt et al. (1979) there is no other SEM study of Vasiliki ware published. However, there is such work in progress at the Laboratory of Archaeometry of the NCSR Demokritos, which showed that there is structural difference between the black, red and orange areas (Dr V. Kilikoglou,
pers. comm.)
} 
the case in the West Cretan examples too. Except for the sample from Chania examined above, the other samples do not display any orange colour and the microstructure, as well as firing temperature, are different.

Sample KST/70 is different in appearance and microstructure. The mottled decoration displays only two colours, black and red; the former has a thickness of ca. $20 \mu \mathrm{m}$ without the fine bloating of the previous sample (Pl. 85a). The red area has also a thickness of ca. $20 \mu \mathrm{m}$ and shows compaction with fine pores (Pl. 85b). The estimated firing temperature is a little lower than for the previous sample, ca. $800-850^{\circ}$ $\mathrm{C}(\mathrm{Vc}-)$ ( $\mathrm{Pl} .85 \mathrm{c})$. The colour of the clay paste is red with a reduced core, displaying the "sandwich effect" due to insufficient oxidising during cooling (Kilikoglou and Maniatis 1993: 438).

Sample KST/86 also displays two colours on a mottled surface, i.e. black and red and is lower fired than the samples described above. Clay filaments are hardly visible on the body and the degree of vitrification is lower (IV). The estimated firing temperature is $750-800^{\circ} \mathrm{C}(\mathrm{Pl} .85 \mathrm{~d})$. The mottled areas are ca. $18 \mu \mathrm{m}$ thick, they are not vitrified and they display the compaction of burnished surfaces (Pl. 85e-f).

Finally, sample PST/11 is fired at a temperature lower than all the others; it is not vitrified (NV) and the estimated firing temperature is below $750^{\circ} \mathrm{C}(\mathrm{Pl} .86 \mathrm{a})$. The two areas (black and red) have a thickness of ca. $15 \mu \mathrm{m}$ and show the compaction of burnished wares (Pl. 86b,c). The colour of the clay paste is red towards the exterior surface and grey towards the interior of the vessel probably as a result of incomplete re-oxidation.

From the examples of mottled ware examined by SEM it seems that all the West Cretan samples share a common technology of manufacture. In all cases the clays used are calcareous with the composition of the surface being close to that of the body. As to the firing process, despite slight differences in the degree of vitrification and the estimated firing temperature, all the samples seem to have been produced with an oxidising-reducing-oxidising procedure.

Typological studies of mottled ware from different sites in Crete underline the variation in appearance of the mottled decoration, in terms of colours and syntax of the 
decoration on the vessel surface; this is discussed in detail for the case of Myrtos with macroscopic observation (Warren 1972: 129-31) and technological characterisation (Whitelaw et al. 1997: 271). This was also the case for the West Cretan samples and examination with SEM studies demonstrated that variation in the appearance of the final product reflects that in the microstructure of the ceramic body and the technique of manufacture.

Compared to the mottled wares from Myrtos, the West Cretan examples present similarities in terms of technology of manufacture and differences in provenance; they are both manufactured using calcareous clays from Neogene deposits, they have a burnished surface finish and the firing temperatures vary between $750-950^{\circ}$ C. However, the Vasiliki Ware of Myrtos is compatible with geological samples and fine wares known to derive from the Isthmus of Ierapetra (Whitelaw $e t$ al. 1997: 268), whereas the fabrics of the West Cretan mottled ware are compatible with the Neogene marls of the north coast around Chania and the black slipped wares of Helladic style. It is of importance that the black slipped is the only other ware type manufactured with the same firing technique of oxidation-reduction-oxidation.

Finally, a short comment should refer to comparison with other burnished wares, since it was demonstrated that in certain cases the structure of the surface of mottled and burnished wares presents common characteristics. This may simply be the effect of the act of burnishing since all the other characteristics are different. In West Crete all burnished wares are manufactured with non-calcareous red clays and fired either in oxidised atmosphere or with the technique of simple reduction (see above).

Decoration with mottling is a widespread phenomenon across the island in EM IIB and in several cases (like Myrtos and West Crete) also present in EM IIA. The technological study of the West Cretan examples confirmed this by demonstrating that technological similarity does not necessarily imply common provenance as was assumed for the mottled ware found in West Crete. It seems that there is a common "technological recipe" applied more or less successfully aiming at the same visual effect for the final product. 
Table XVI. Mottled Ware

\begin{tabular}{|l|c|c|c|c|c|c|c|c|}
\hline SAMPLE & PART & FABRIC & FIR ATM & CALC & K & Fe & VITR & FIR TEMP \\
\hline CHT 034 & paste & v. fine w. foss & R-O & med & low & med & Vc-/Vc & $800-1000$ \\
\hline CHT 034 & clay & & & med/high & med & med & & \\
\hline CHT 034 & grey area & & & non/low & low & med & V? & \\
\hline CHT 034 & black area & & & non/low & med & med & V & \\
\hline CHT 034 & red area & & & low & low & med & V? & \\
\hline CHT 034 & orange area & & & non/low & med & med & V (FB) & \\
\hline KST 070 & paste & v. fine w. foss & O-R-O & high & low/med & low & Vc- & $800-850$ \\
\hline KST 070 & clay & & & high & med & high & & \\
\hline KST 070 & red area & & & low & low/med & low & NV/IV & \\
\hline KST 070 & black area & & & high & high & med & V & \\
\hline KST 077 & paste & v. fine w. foss & R & high & low & low & IV-/V- & 800 \\
\hline KST 077 & clay & & & high & low & high & & \\
\hline KST 077 & out burnish & & & low & med & low & V & \\
\hline KST 086 & paste & v. fine w. foss & O & high & med & low & IV & $750-800$ \\
\hline KST 086 & clay & & & high & med/high & med & & \\
\hline KST 086 & red area & & & low & med & med & NV & \\
\hline KST 086 & black area & & & low & med & low & NV & \\
\hline PST 011 & paste & f-m, micr, foss & O-R & low/med & low & low/med & NV & $<750$ \\
\hline PST 011 & clay & & & med & low & high & & \\
\hline PST 011 & red area & & & med & high & high & NV & \\
\hline PST 011 & black area & & & low & low & med & NV & \\
\hline
\end{tabular}

\subsubsection{Vessels with creamy slip (Pl. 87)}

In this category belong semi-coarse to coarse vessels whose surface is covered with a thick, buff, creamy slip. Most of these are collar-necked jars, a vessel shape compatible with Western Cycladic rather than Minoan origin (Wilson 1999: 87). Along with the black slipped ware (sauceboats, saucers etc.) these vessels constitute the non-Minoan portion of the EM IIA assemblages in West Crete. Collared jars are of special interest because they are coarse wares, associated with transport and are found in almost all domestic sites and Platyvola cave. Petrographic analysis shows that they all belong to the same fabric group (Table XVII), which is compatible with a Chaniot origin. Examination with SEM provides information on the composition and 
technology of manufacture of this ware. The samples analysed are listed in Table XVII.

In all the samples the clay and slip are medium to low calcareous. It seems that the production of the creamy slip is the result of a white firing clay (Pl. 87a). The microstructure of the body shows initial vitrification (NV/IV) (P1. 87b-d) and the estimated firing temperature is $750^{\circ}-800^{\circ} \mathrm{C}$. In all cases the colour of the body is red indicating an oxidising atmosphere.

All the samples share the same characteristics in terms of raw materials used and technology. of manufacture. They are manufactured with a medium to low calcareous clay, are low-fired and in this respect they are not differentiated from other coarse wares such as the burnished wares. As mentioned in the case of the red slipped and burnished ware, the application of slip is significant in the case of transport vessels because it makes the surface impermeable (Rice 1987: 232). However, the creamy slip of the collared jars constitutes a non-Minoan characteristic that gives these vessels a special character probably alluding to the Western Cyclades and the transport of liquids with which collared jars are associated (Wilson and Day 2000: 58-59).

Table XVII Vessels with Creamy Slip

\begin{tabular}{|l|c|c|c|c|c|c|c|c|}
\hline SAMPLE & PART & FABRIC & FIR ATM & CALC & K & Fe & VITR & FIR TEMP \\
\hline CHT 043 & paste & sand-temp+fos & 0 & low & low & low & NV/IV & $750-800$ \\
\hline CHT 043 & clay & & & non/low & med & med & & \\
\hline CHT 043 & creamy slip & & & low & low & high & & \\
\hline CHT 044 & paste & sand-temp+fos & O-R?-O & med & low & low & NV/IV & $750-800$ \\
\hline CHT 044 & clay & & & low & low & low & & \\
\hline PLT 017 & paste & sand-temp+fos & 0 & med & low & low & IV & $750-800$ \\
\hline PLT 017 & clay & & & med & high & high & & \\
\hline PLT 017 & creamy slip & & & low & med & low & IV? & \\
\hline
\end{tabular}

\subsubsection{Dark-on-Light painted Ware (Pl. 88)}

This ware is widespread in Central and East Crete but quite rare in West Crete. Extensive analytical studies carried out in the EM material from Knossos indicated 
that a large portion of the dark-on-light painted ware consumed in north central Crete is imported from the Mesara (Wilson and Day 1994). The very few examples of darkon-light painted ware from West Crete that were examined by petrography proved to be local West Cretan products. However, the fabrics used are not exclusive to this ware: in some cases they are compatible with the geology of the north coast around Chania (Neogene marls) in other cases they are compatible with red fabrics used for other types such burnished wares. Due to the condition of the material, it was possible to examine only one sample of this ware belonging to the first fabric category, i.e. related to the north coast deposits. The sample examined is CHT/27, a jar with three painted bands on the surface.

The body of the vessel is manufactured using a medium calcareous clay and on the surface was applied a fine red paint/slip; the composition of the latter showed low value for $\mathrm{Ca}$ and high values for $\mathrm{Fe}, \mathrm{Al}$ and $\mathrm{K}$. It is not clear whether the paint/slip was different from the clay used for the body or just a fine suspension of the same clay. The microstructure of the body and surface brings this vessel close to the other coarse wares (i.e. burnished). It is low fired, both the body and slip are non-vitrified (NV) (PI. $88 \mathrm{a}-\mathrm{b}$ ) and the estimated firing temperature is ca. $750^{\circ} \mathrm{C}$; the slip is very thin and does not show the compaction of the burnished samples. The body paste is coarse and its colour is red, which indicates an oxidising atmosphere.

Comparative d-o-l material derives from Knossos, but is very different. The clays used for the body and the paint are calcareous and the firing temperatures are higher (Kilikoglou 1994: 73-75). Even in the cases of semi-fine/semi-coarse pottery where low or medium clays were used the clay paint is calcareous and the firing temperatures are higher. This indicates that the Knossian material, which was produced primarily in the Mesara, does not have similarities with the West Cretan dark-on-light which seems to be a local product. 


\subsection{Discussion}

The examination of selected samples of EM pottery from West Crete by SEM provides significant information concerning the technology of manufacture of the different wares. In addition, it allows comparison with similar wares from Central Crete.

Technological analysis confirmed what has already been argued by the typological study and petrographic analysis concerning pottery production in West Crete. There are two distinct traditions of pottery manufacture that co-exist: the first is represented by the burnished wares, which are produced locally with similar raw materials and techniques. The second is represented by the black slipped and mottled wares, which also are local and share similar raw materials and techniques of manufacture.

More specifically, there are two main technological categories in the West Cretan pottery: the wares manufactured with calcareous and those manufactured with non-calcareous clays. They are different in the raw materials used for their manufacture, the shapes represented and firing technology.

Burnished wares are manufactured with non-calcareous clays. They occur widely and comprise vessel types that we termed "Minoan" since they are represented in many EM contexts across the island. The wares examined are dark grey burnished, red-brown/black burnished and red slipped and burnished. Except for the same type of clay, they also share other technological characteristics such as firing conditions. Examination by SEM showed that all types of burnished wares are fired at low temperatures ranging from $750^{\circ}-800^{\circ} \mathrm{C}$. The surface of the vessel is burnished or slipped and the colour is achieved either by oxidation or simple reduction.

However, the firing procedures and conditions can be reconstructed only to a certain degree. Recent studies involving ethnographic and experimental work have demonstrated that firing procedures and temperatures are more complex than is able to be assessed from an estimated firing temperature and that different parameters may 
lead to the same effect on the final product (Gosselain 1992; Livingstone Smith 2001). This is especially the case of open versus kiln firing, where the average duration of the firing is similar for both types of procedures, whereas the range of temperatures achieved can be quite varied in both structures (Livingstone Smith 2001: 998).

In the case of the West Cretan EM pottery this applies to the dark grey burnished ware. This ware seems differentiated in the way the black surface is produced when compared to the other burnished wares; it is among the earliest wares (it begins in EM I) and it is high likely that the firing took place in open pits and black decoration was produced through carbon deposition ${ }^{2}$. The red-brown/black and the red slipped and burnished wares were fired in kiln structures with controlled atmosphere.

With this cautionary note in mind, it should be stressed that the homogeneity in manufacturing procedures becomes more important when considered that there is compatibility in petrographic fabrics. Petrographic analysis demonstrated that all burnished wares belong to similar fabric types, which, however, are site-specific. This means that there are similar clay recipes, similar procedures of vessel forming and firing, it is just the raw materials that are slightly different due to regional geological variation.

The black slipped and the mottled wares are very different from the burnished wares. Typologically they comprise vessels that are reminiscent of Helladic and Cycladic rather than Minoan prototypes. Petrographic analysis shows that they share the same fabric, which is compatible with the Neogene marls of the north coast near Chania. Finally, SEM analysis demonstrated that they are manufactured with a calcareous clay and fired using the iron reduction technique in higher temperatures than the other wares. The range of firing temperatures achieved, the use of the oxidation-reduction-oxidation technique and the appearance of the final product indicate the presence of highly skilled potters with a good grasp of pyrotechnology.

These observations present a two-fold interest: first, that the black slipped ware is technologically as well as typologically different from the other wares but it seems

\footnotetext{
${ }^{2}$ Kilikoglou (1994: 72-3) considers the Central Cretan DGBW samples to be kiln-fired. Purther analysis of this ware would provide a clearer picture of the firing conditions.
} 
that it is produced in a more than one centre; secondly, mottled ware, which is a Minoan phenomenon and is widespread across the island, seems to have developed parallel with or as a follow up of the black slipped ware, which occurs only in West Crete and is considered of Helladic origin.

The semi-coarse ware with creamy slip seems to be restricted to transport collar-necked jars which are vessels occurring mainly in the western Cyclades. All the samples examined share the same technological characteristics: they belong to the same fabric, which is compatible with the Neogene deposits of the north coast near Chania, they are manufactured with a low to medium calcareous clay and fired in fairly low temperatures. This vessel is of special character, since it is connected with the transport of liquids.

Finally, dark-on-light painted ware is very rare in West Crete and it is not clear within which manufacturing tradition it belongs but most likely it is closer to the burnished wares. A medium calcareous clay is used and the firing temperature is rather low but this is probably due to the size and coarseness of the specific vessel. Moreover, petrographic analysis demonstrated that none of the dark-on-light examples is imported but are all produced locally.

Technological differences between wares, such as the ones between the burnished and black slipped wares in West Crete, occur in Central Crete too. Petrographic and SEM analysis of EM material from Knossos showed that a similar division occurs with non-calcareous clays being connected with burnished wares and North Central Cretan traditions and calcareous clays being connected with painted and fine grey wares deriving from the Mesara (Wilson and Day 1994: 75-76). This typological and technological division, therefore, proved to be indicative of different centres of production manufacturing specific types of pottery.

The most evident interpretation for the discrepancy in fabric and manufacture technology between the main wares in West Crete would, therefore, be different traditions, and perhaps different provenance. In West Crete it is difficult to assign wares to production centres on the basis of their mineralogy, since the geology in West 
Crete is rather repetitive and fabric types occasionally overlap. However, this difference between the burnished non-calcareous wares and the slipped or painted calcareous ones is very prominent. It seems that the burnished wares follow the pattern of their counterparts in the rest of the island, one reason probably being that these wares continue from the EM I into EM IIA. On the contrary, the black slipped ware along with the non-Minoan vessels appear in EM IIA.

The difference in raw materials used for the manufacture of the Minoan and non-Minoan wares has been demonstrated by petrographic and elemental analysis. Examination by SEM provided information on the technology of manufacture of these wares and confirmed the existence of two markedly different pottery traditions. It also indicated similarities and differences with related wares in Central and East Crete. It remains to examine what these differences mean when considered in relation to the people who produced and consumed this pottery and within the framework of the Early Bronze Age Southern Aegean. 


\section{CHAPTER 9}

Investigating technology, style and ethnicity in EBA West Crete:

the evidence from pottery analysis

\subsection{Introduction}

This chapter provides a synthesis of the archaeological and scientific information derived from the study of the EM pottery from West Crete, along with an integration of the ceramic assemblage in the broader context of the EBA Southern Aegean. The main points of discussion focus on the stylistic character of West Cretan pottery in the EM IIA period and its relation to the assemblages in the rest of the island and the Southern Aegean.

The stylistic particularity of the EM pottery from West Crete is not a recent discovery. Since the first excavation reports (Alexiou 1964; Tzedakis 1965b) to recent publications of EBA ceramic material from West Crete (Karantzali 1996; 1997), the main observation concerned the non-Minoan character of the assemblages. As indicated by the typological study in West Crete, there co-exist two markedly different types of pottery. The part of the assemblage termed "Minoan" consists of vessels and wares compatible with similar types in other parts of the island: dark grey burnished and pattern-burnished chalices, scored ware jugs and bowls, red/black slipped ware jugs and goblets. The other part of the assemblage, here termed "Helladic", consists of wares more familiar in Early Helladic or Early Cycladic contexts: black slipped sauceboats and incised pyxides, red and black slipped saucers, hearths and collarnecked jars.

This two-fold character of the West Cretan ceramic assemblage, although detected since the 60 's, has never been discussed and interpreted sufficiently. The existing studies are either in the form of excavation reports (Alexiou 1964; Tzedakis 1968a;b) or publication of site assemblages (Karantzali 1997). The only synthetic work (Karantzali 1996) is concerned with the presentation and typological 
classification of EBA pottery from different sites in the Cyclades and Crete and is geographically too broad to discuss the West Cretan material in detail. The existing interpretative suggestions range from the manifestation of the Creto-Cycladic connection (Tzedakis 1984) to the adaptation of foreign (i.e. Cycladic) prototypes in West Crete (Karantzali 1996). However, these are individual approaches, in most cases based on evidence from a single site and were not placed within an explanatory framework.

This work, based on an integrated approach combining typology and analysis in order to investigate issues of provenance and technology, demonstrates that the West Cretan pottery is locally manufactured, although in most cases it is not feasible to assign more specifically the location of origin. It has been demonstrated also that the technology of manufacture of some of the "Helladic style" wares is significantly different from that used for the Minoan wares.

In order to comprehend and interpret the character and distribution of the material culture in West Crete during the EBA, it is important to integrate the EM material into a broader spatial perspective, that of Minoan Crete and the Southern Aegean in the $3^{\text {rd }}$ Millennium BC. In what follows we examine briefly how the present picture of the EBA Crete was constructed through years of study, considering parameters such as the culture-historical approach and following criticisms and the theoretical framework upon which the interpretation of our results will be based.

\subsection{The "culture-historical" approach in the study of material culture}

Aegean prehistory was developed during the 1960's and was largely affected by the so-called "culture-historical" approach, which was based on the identification of cultural entities occupying specific geographical locations; the ascription of an entity as "culture" relied on the identification of common traits in the material culture which were arbitrarily regarded as diagnostic (Jones 1997: 16). The spatial distribution of the "diagnostic" material culture in a specific geographical area would demarcate the extent of the culture, whereas potential discontinuities in the distribution of the material would be considered as indicators of cultural boundaries (Barth 1969: 9; Shennan 1989). Common traits between cultures were interpreted as trade and exchange, influence or imitation. 
This approach led to a series of assumptions regarding human behaviour since cultures were viewed as bounded geographic entities and the movement of materials (and people) was constrained by arbitrarily established geographical boundaries. Moreover, it led to oversimplifications concerning the existence of ethnic groups ascribed to the different cultures.

In the last decades the culture-historical approach has been heavily criticised, the main argument being that cultures can be efficient methodological tools when used to describe entities but they cannot be considered as reflections of group territoriality and human behaviour (Shennan 1989: 14). As to the material culture, the spatial distribution of artefacts is not always regular and conforming to preconceived patterns (Jones 1997: 108). The presence or absence of artefacts in specific places and specific times is related to the concurrence of a number of factors prevailing in the specific time (Jones 1997: 109). Therefore, the study of the material culture should be made independently of cultures and always in correlation with the specific spatial and temporal context.

The culture-historical approach and the criticisms it received are important factors when discussing the EBA in the Southern Aegean, because the interpretation of the material culture was largely based on the separation of the area into three major cultures (Minoan-Helladic-Cycladic). However, before examining how West Crete fits into the "culture framework" of the $3^{\text {rd }}$ Millennium BC, it is of essence to examine the use of technological style as a means of communicating social status and identity, since the major issue in the study of the EM West Cretan assemblage is the coexistence of two technologically different pottery styles.

\subsection{Technological style and social meaning}

The role of style as an indicator of social messages and identity is a recurrent theme in the study of material culture. It is the notion of "emblemic" style introduced by Wiessner (1983) that expresses intentionality in decoration aiming at communicating a message to the users of artefacts. It was first the role of decoration and decorative motifs that was apprehended as bearer of social meaning, ideas and identities. Patterned decoration was suggested to represent the mnemonic visual 
expression of beliefs and identities and therefore to persist through time (David et al. 1998: 378).

Thanks to recent ethnographic work it was demonstrated that except for decoration technological style is also a cultural phenomenon reflecting social relationships, power structures, social production and reproduction (Dobres and Hoffman 1994: 212).

By technological style we define the technical processes involving the manufacture of artefacts and in the case of pottery that we examine here, these processes range from the technological choices (i.e. raw materials selection, clay manipulation, firing) to the motor habits of forming and shaping (chaînes opératoires), the tools and techniques (Gosselain 1998). The consistency of choices and techniques for the manufacture of every day goods forms the basis of technological traditions, "the way things are always done" (Wiessner 1984: 161, 195). This knowledge constitutes the result of a learning process, which becomes internalised and passes from one generation to the next. Ethnographic work demonstrated that people are not keen to modify their habits and thus technological style remains more stable through time than other aspects of artefact production such as decorative style (Gosselain 1998: 91; 2000: 192). Therefore, technological style reflects conscious and unconscious elements of technical choices and because it is resistant to change it also communicates social information such as identity and boundaries (Stark 1999: 29).

Although revelative of the meaning that might be embodied in and reflected by technological style, this view encompasses only one aspect of technology, that of the passive transmission of existing techniques and social relationships. However, there is another aspect, equally, if not more, important, that of the active use of style and technology. Technology is inextricably linked to socio-temporal frameworks and human agents. Through the process of material culture production and consumption there is social interaction between human groups of historically specific contexts; this means that the symbolisms related to social identity that are embedded in style and technology are negotiated through every day practice and are shaped and transformed according to the prevailing concepts of each society at specific temporal context (Dobres and Hoffman: 214-15). 
Social identity and boundaries are the characteristics that are under constant negotiation and redefinition par excellence and like technology and style they constitute the product of specific spatial and temporal contexts (Shennan 1989: 17). Therefore, it would be a mistake to interpret stylistic variation as passively reflecting different ethnic identity. Rather, they should both be examined as dynamic and interacting social practices that condition cultural behaviour and are critical to social reproduction.

\section{4 "Cultures" and Ethnicity in the EBA Southern Aegean}

\subsubsection{Aegean "cultures" and the International Spirit}

The Southern Aegean is among the regions where the culture-historical approach was applied due to the plethora, diversity and wide distribution of the material culture. The typological study and classification of the material resulted in more subtle chronological divisions within the Bronze Age (Early - Middle - Late with several divisions for each one) and three main spheres of interaction were identified: Crete (Minoan culture), the Cyclades (Cycladic culture) and the Mainland (Helladic culture). Different types of artefacts were considered "diagnostic", and the three geographical areas were pronounced cultures. The application of this approach was accompanied by an ex principio identification of three different ethnic entities according to the geographic location they occupied. However, further excavation demonstrated that the cultural boundaries were not as strict as initially thought since artefacts that were diagnostic of one culture were found across the Aegean in conjunction with artefacts of another culture.

In his seminal work The Emergence of Civilisation Renfrew (1972) attempted a re-examination and re-evaluation of the data available and provided an alternative explanation to the cultural development witnessed in the Aegean during the Third Millennium BC. This work was influential for the development of Aegean studies in the sense that it envisaged development in the Aegean as an internal process and suggested a new model considering the action and interaction of the environmental, economic and social factor. Within this framework Mediterranean polyculture, metallurgy, and communication and trade within the Aegean transformed the modus 
vivendi in the Southern Aegean during the EB 2 period and led to the appearance of the first palaces in the MBA.

Communication and trade were considered the "causes" for the co-existence in many sites of artefacts deriving from different "cultures". It is mainly the case of metal objects thought to be deriving from the Cyclades either in the form of raw materials or as finished products, as well as Cycladic figurines recognised as "prestige" objects, which were circulating within the Aegean during the $3^{\text {rd }}$ Millennium BC. The frequency of this co-existence and the wide distribution of certain types of artefacts led to the characterisation of the EBA 2 period as the era of the International Spirit (Renfrew 1972). The main characteristic of the period was considered to be the movement of people, goods and ideas and the establishment in the Aegean of longdistance trade networks. Circulation seemed to be more intense on the route CycladesNorth Crete (Renfrew 1972: 451-5).

\subsubsection{The Creto-Cycladic connection}

Since the first investigations in Crete it became evident that there was a close connection between Crete and the Cyclades from the Neolithic periods onwards, the first commodity traded being Melian obsidian found in the lowest Neolithic strata of Knossos (Evans 1964). The culture-historical approach offered different interpretations on the way this inter-island network functioned and the kinds of relationships between the two ends of the trade line. Two of the main case studies on which the culture-historical approach was based are the cemeteries of Agia Photia in East Crete (Davaras 1971; Doumas 1976) and Archanes- Phourni in Central Crete (Sakellarakis 1977). In both cases Cycladic and Cycladic-style objects were found in combination with artefacts of Minoan origin and their occurrence was interpreted as reflecting the existence of Cycladic colonies of mercantile character on Crete (Sakellarakis 1977), or as extensive trade between the Cyclades and Crete (Branigan 1988).

However, recent research combining typological examination, analytical techniques and a sound explanatory framework shattered the colony assumption and demonstrated that there is a more complex network of artefact movement and social relations. In the case of the Agia Photia cemetery the discussion focused on the co- 
existence of Cycladic and Minoan elements as a conscious expression of group identity; it has been argued that it is not the presence or absence of artefacts that reflects ethnic groups rather than the association of artefacts and contextual information (Day et al. 1998: 140). In the case of Archanes (and other funerary contexts in North Central Crete), although a great part of the assemblage is Cycladic (or Cycladicising), the context is Minoan; moreover it seems that in many cases the raw materials are imported and transformed locally and thus appropriated according to Minoan traditions. It is therefore suggested that the material culture acquires in Crete different significance and symbolism than in the Cyclades and does not always indicate ethnic but other kinds of social identity (Papadatos 1999).

Finally, it. has been demonstrated that, except for long-distance maritime communication, in the EB 2 period there are several intra-island networks with specific routes through which artefacts and people circulate. The investigation of pottery regionalism in Central Crete revealed the links between Mesara and Knossos through the production and consumption of specifc types of pottery respectively (Wilson and Day 1994). The study of the assemblage of Tholos tomb $\Gamma$ in Archanes demonstrated the existence of a network between sites on the north coast (such as Archanes and Poros) and south Crete regulating the movement of raw materials deriving from the Cyclades and the related artefacts manufactured in Central Crete (Papadatos 1999).

This is of particular interest when discussing the EM West Cretan ceramic assemblage because this is one more case of the EBA 2 period where artefacts belonging to two typologically and technologically different traditions (Minoan Helladic/Cycladic) co-exist. However, West Crete is different not only in the nature and character of the material but also in the context of its discovery. This has major implications for the interpretations regarding the symbolisms and the social meaning that the material culture embodies.

\subsection{Why is West Crete different?}

The evidence from North Central Crete indicates that the expression of social identity, emulation and, in general, social reproduction goes through channels related 
to funerary practices. Tombs are the places par excellence where the identity of the living as well as the dead is being negotiated (Papadatos 1999; Soles 1988).

Moreover, cemeteries constituted the most prominent places for the manifestation of personal and social identity through the conspicuous consumption, display and ritual deposition of imported artefacts and items of prestige. In the latter belong the metal artefacts, which occur primarily in funerary contexts and are considered to be items of importance and status, embodying not only the value of the exotic form but also that of their technology and function as expressions of power (Nakou 1995).

The picture of West Crete in the $3^{\text {rd }}$ Millennium BC appears to be different. The absence of tombs ${ }^{1}$ and burials as well as metal artefacts in general (the only exception being the fragments found at Kastelli - Tzedakis and Hallager 1983) leaves us rely on material culture from domestic contexts and caves and almost exclusively on pottery. Nevertheless, it should be stressed that it is difficult to believe that the absence of tombs in West Crete is coincidental and due (only) to bad recovery. If we consider that funerary architecture created landmarks and that mortuary deposits were an investment for the manifestation of status and identity in Central and East Crete (Papadatos 1999; Soles 1995), it is high likely that there was no such investment in West Crete probably because the identity to be manifested/ negotiated was different and was reproduced through other channels.

In order to obtain a picture of West Crete in the EBA 2 period, the basis of research has to be evidence deriving mainly from settlements and some caves. Although the latter are considered places of ritual, the former represent every day practices and no special meaning is attributed to the material culture associated with them. In what follows the evidence from the pottery will be presented and we will discuss the meaning of and the social dynamics behind the production and consumption of material culture within the confines of settlement sites.

\footnotetext{
'The tomb of Nea Roumata is the only example of funerary architecture in West Crete. It is a unique and problematic case, because, as already mentioned (chapter 2), the excavator considered it "Cycladic" with parallels at the Keros-Syros group (EC II). However, the pottery of the tomb is earlier (FN/EM I).
} 


\subsubsection{The evidence from the pottery}

The EM pottery from West Crete was studied typologically and analytically in order to investigate issues of provenance and technology. The general pattern seems to be following what is the case in the rest of Crete, with the EM I displaying pottery types continuing from the Neolithic and new types emerging. EM IIA witnesses a sudden rise in imported or new types, whereas the EM IIB shows a certain homogeneity and standardisation. However, the pottery types that create this pattern in West Crete are quite different from those in Central and East Crete.

In the EM I the pottery types that are familiar from the Neolithic are red and black burnished wares, whereas the dark grey burnished Pyrgos ware which is widespread all over the island occurs -fairly rarely- also in all sites in West Crete. Scored ware seems to be a West Cretan product, in the sense that it is widespread, whereas it is rather rare in the rest of the island. In terms of provenance all the samples examined are local but their technology of manufacture is similar to the wares known from the rest of Crete. The main techniques are calcite- and grog-tempering and there is no differentiation in the clays used for small and large vessels.

In the EM IIA the ceramic assemblage changes radically due to the presence of the Helladic style wares. The Minoan types as known from the EM I continue (dark grey burnished, scored, coarse wares) but the black slipped medium sized vessels such as sauceboats, pyxides and saucers have no parallels in Central and East Crete. Similar types with black slipped surface occur in the Mainland but typologically they are not exact parallels.

In West Crete there are two main types of non-Minoan vessels: The black slipped semi-fine to fine which belong to serving and drinking vessels and coarse wares such as hearths and collar-necked jars. The former occur in caves and settlements, the latter in some sites, namely Nopigeia (the only site with hearths), Kastelli and Platyvola. The case of Platyvola is also of special interest because it is the only site where Minoan and non-Minoan types are encountered along with frying pans and figurines which do not occur anywhere else. It is of interest that the non-Minoan types are typologically unique and appear to be local adaptations of foreign prototypes with the addition of elements of a local/Minoan tradition: the pyxides acquire three feet like the cooking pots, the frying pans have pellet feet and decorative motifs 
occurring on pyxides and jugs, the sauceboats have the same type of foot as footed goblets.

These observations are confirmed by petrographic and chemical analyses; it is demonstrated that the black slipped wares as well as non-Minoan coarse wares are west Cretan in provenance and the distribution of fabrics is site-specific. This is of significance especially for the black slipped wares: they display typological similarity between sites and have been manufactured with similar techniques, although the fabrics are site-specific. This was considered as an indication of more than one workshop producing similar types of pottery. The picture we get therefore is that shapes and wares that in Central and East Crete are considered imported or imitations of foreign prototypes in West Crete occur in all sites, caves as well as settlements, in quantities comparable to the Minoan types. On the other hand the latter also occur in all the sites in the same shapes.

Considering that settlements are sites of everyday use where practices like cooking, eating and storing are performed on a regular and a rather ordinary basis (in contrast to ritual practices taking place in specific locations and on specific occasions) it seems that the Minoan and Helladic types are of equal "status", at least when we consider their distribution and representation in the different sites. It is debatable whether any special value of prestige or exotic is attributed to the latter but what cannot be argued is that they bare the value of the "rare". Petrographic analysis demonstrated that all fine black slipped vessels share similar fabrics and manufacturing techniques, which, however, are quite different from the ones used for the Minoan wares. However, the coarse Helladic type vessels share in many cases the same fabric as their Minoan counterparts. It seems, therefore, that the Helladic wares are as much "at home" in West Crete as the Minoan wares.

Finally, for the EM IIB period not much can be said due to the lack of stratigraphic information. The evidence derives from the settlements of Chania and Psathi and the cave of Platyvola. Most of the wares encountered in EM IIA continue, with Minoan and non-Minoan types, the only difference being that there are more saucers and less sauceboats, and that there is a change from black to red slipped. Moreover, mottled vessels, which appear in EM IIA, become more common but petrographic analysis showed that they are local and examination under SEM 
demonstrated that they do not share the same technique of manufacture as the canonical East Cretan Vasiliki ware.

\subsubsection{Divergent traditions in West Crete and two case studies}

The implications of the culture-historical approach, although challenged in the rest of Crete, still prevail in the study of the West Cretan material culture because until now there has not been any synthetic work that would put the data from different sites into perspective. From the typological classification and scientific analysis of the material it becomes clear that the two ceramic traditions that co-exist are also technologically different ${ }^{2}$. Moreover, their occurrence in the EM IIA period coincides with what has been described as the International Spirit (Renfrew 1972), i.e. an intense movement of people, goods and ideas in the Aegean. According to the culturehistorical approach the non-Minoan style vessels could be explained either as imports from the Mainland/Cyclades (Alexiou 1964, Tzedakis 1966a) and/or as local imitations of Cycladic/Helladic prototypes. As to cases like the settlement of Nopigeia where the non-Minoan types prevail, they could have been considered colonies of nonMinoan people on the north coast of Crete.

These interpretations are contradicted by the analytical data. Petrographic analysis of archaeological material and clay samples as well as chemical analyses demonstrated that the black slipped Helladic style vessels are West Cretan manufactured in local fabrics according to specific recipes. Coarser Helladic or Cycladic type vessels share similar fabrics with their Minoan counterparts. Moreover, the assumption of colonies cannot be substantiated for many reasons: because the Helladic style vessels are typologically similar to those from other sites, because they are manufactured with local raw materials and in some cases share the same fabrics as the Minoan vessels and because there is nothing in the assemblage indicative of a foreign establishment.

Having eliminated the options of imports and colonies, the last possible explanation is related to ethnicity and its manifestation through style and stylistic variation. Although direct correlation between material culture and ethnic groups has

\footnotetext{
${ }^{2}$ This is mainly the case of the Helladic style black slipped ware, which constitutes the major part of the non-Minoan portion of the West Cretan assemblage. The Helladic style coarse wares are in many cases manufactured in the same fabrics as the Minoan wares (see Chapter 6).
} 
been challenged (Shennan 1989: 5), ethnographic and archaeological work demonstrated that the presence or absence of objects can be indicative of ethnic or social identity only when considered in association to the general archaeological context (Day et al. 1998: 140).

Because the case studies from Central Crete derive from funerary contexts it would be of interest to examine cases of co-existing pottery traditions from settlements. There are two case studies from the Mycenaean world that are worth mentioning, one in Central Macedonia, the other in Italy. In Macedonia there are two markedly different pottery traditions, the handmade and the wheelmade. As is the case in West Crete, they are both locally made but with different fabrics and different manufacturing techniques. The former comprises all sorts of domestic coarse wares, the latter is made with more elaborate manufacturing techniques and is restricted to serving and drinking vessels (Kiriatzi et al. 1997: 364). The interpretation of this "symbiosis" is based on the suggestion that the handmade pottery represents the familiar aspect of the assemblage, whereas the wheelmade, although produced locally, bears an elaborate technical knowledge coming probably from a distance; it has, therefore, special significance and is associated with elites and special occasions of feasting and social display (Kiriatzi et al. 1997: 365-66). Furthermore, the different roles of the two manufacturing traditions seem to sustain and reproduce the social roles and identities of those producing and consuming the pottery (Kiriatzi et al. 1997: 366).

In the Italian case study the end of the Bronze Age is also characterised by the presence of two markedly different pottery traditions: the familiar local wares and the Aegean type pottery. It is of interest that according to the first interpretations the Aegean material was considered imported from Mycenaean Greece and there were also suggestions of Mycenaean settlement in peninsular Italy (Vagnetti and Jones 1988: 336). A typological study combined with scientific analysis demonstrated that both types are locally produced. The suggested interpretation rejects the previous assumptions and proposes a broader explanatory framework including more complex networks with the circulation of craftspeople, goods, technology and ideas (Vagnetti and Jones 1988: 347).

The two case studies, although spatially very distant, share a common characteristic: the "foreign" or not familiar part of the assemblage is considered by its 
form and technology of special significance and is related to contacts and movement, either directly in the form of circulation of people and artefacts (the Italian case study), or indirectly in the form of distant knowledge (the Macedonian case study). This argument of the familiar versus the non-familiar part of the assemblage has already been presented as a major issue in the study of the West Cretan material. It remains to be examined whether the non-Minoan wares are of special significance and subsequently whether they reflect the distant and exotic. But before that it is of importance to examine whether the West Cretan case is unique in Minoan Crete.

The co-existence of markedly different pottery traditions in West Crete does not constitute a unique case in the EBA Aegean, the most obvious examples being the burial sites in Central and East Crete that contain a mixture of Minoan, Cycladic and Cycladicising material such as Archanes- Phourni, Agia Photia, and Krasi. Recently, new evidence deriving from Poros adds significantly to our knowledge on the relationship between the Cyclades and the north coast of Crete. The presence of imported vessels from the Cyclades as well as evidence for in situ transformation of raw materials deriving from the Cyclades (namely metals and obsidian) gives new dimensions to the Creto-Cycladic connection (Dimopoulou 1997). Among the Cycladic vessels represented at Poros it is worth mentioning the existence of dark-onlight sauceboats and transport collar-necked jars (Dimopoulou et al. in press). Finally, the occurrence of Minoan vessels with exact parallels in South Crete strengthens the links between the north coast of Central Crete and the Mesara.

In the light of the evidence from the Mycenaean world and EBA Crete it remains to examine a) whether the west Cretan Helladic-style material bears special meaning and $b$ ) whether its patterning conforms to what is known from Central Crete. As to the first issue, there are indications in favour of the special character of the nonMinoan part of the assemblage but also arguments against it. The particular significance of the Helladic type black slipped ware is stressed by the fact that all the examples share similar typology, and have been manufactured with fabrics and manufacturing techniques rather different from those used for the Minoan wares. It appears that there are only a few centres producing this pottery and according to specific recipes; this suggests that both producers and consumers sought this stylistic uniformity because the form is associated to the use, which might have been of importance. Moreover, the fact that this ware is regularly found in caves, which are 
places of ritual activity, and consists of drinking and serving vessels also alludes to special occasions of feasting. Finally, the occurrence at Nopigeia of two examples of sauceboats clearly over-fired but not discarded as kiln wasters speaks in favour of the special significance of the black slipped ware.

There are two points that might be argued against the special character of the Helladic-style vessels. The first is that this part of the assemblage does not consist entirely of black slipped serving and drinking vessels but also of coarse wares such as hearths and jars which are occasionally manufactured in the same fabrics as their Minoan counterparts. Moreover, the occurrence of these pottery types in settlement sites as well as caves and in substantial amounts suggests that they are not exotic or rare objects but are widespread and can be easily acquired. This observation does not deny that the Helladic-style wares may be special but transposes their significance into a different realm: it seems that what matters is not the rare and distant, but it is the form, the style and probably the occasion(s) for which the vessels are used.

This leads directly to the answer of whether the patterning of the material culture in West Crete is similar to that in Central Crete. The symbiosis of the pottery traditions seems to be on a rather different basis. In West Crete the major component of non-Minoan vessels is of Helladic rather than Cycladic style and, most important, there are no imports; all the fabrics are local and the shapes constitute adaptations rather than imitations of Helladic prototypes. As to intra-island connections, the absence of dark-on-light and fine grey ware, i.e. the main products of the Mesara, indicates that this network does not reach West Crete most likely because of the participation of this part of the island in different networks.

\subsection{The Western Cycladic connection}

\subsubsection{The evidence from the material culture}

Considering the particularities of the West Cretan case, it would be of interest to locate sites with similar characteristics elsewhere in the Aegean. The issue is not to find typological parallels but patterns in the character and distribution of the material culture similar to those in West Crete. The closest examples are in the Mainland (Lerna), the East coast of Attica (Askitario, Agios Kosmas, Raphina) and south Euboea (Manika). It has already been demonstrated that the pottery from these sites 
has not only the closest typological parallels for the West Cretan Helladic-style vessels but there are other indications linking West Crete with the cultures of and around the western Cyclades.

In these sites the ceramic repertoire comprises vessels of similar character than the West Cretan ones, such as Urfirnis sauceboats and saucers. At Manika the presence of dark-on-light pottery is very scarce and there are frying pans, pyxides and sauceboats manufactured in local fabrics (Sampson 1988: 117). Moreover, there are figurines that do not have typological parallels in the Cyclades and are produced locally. Cycladic type objects of local manufacture occur also at Ayios Kosmas, Palia Kokkinia etc., and, according to Sampson (1988), there are only "a few genuine Cycladic burial goods in graves on the Greek Mainland". In this way we can explain why the sauceboats typology in West Crete is unique and why the frying pans have pellet feet. As to the figurine from Platyvola it seems to belong to the Koumasa variety $^{3}$, which, according to Renfrew (1969) constitutes an imitation of Cycladic prototypes. However, as has been recently argued, the prototypes of the South Cretan figurines might have derived from North Crete (Papadatos 1999). Considering the evidence from the pottery, it should be examined whether the specimen from Platyvola does not imitate a Cycladic prototype but rather figurines from other parts of Crete or the Aegean.

All these elements bring the sites of the western Cyclades, Attica and Euboea very close to West Crete. It seems that these places share similar material culture with a multitude of artefacts locally produced and morphologically adapted to the local tastes and traditions. The main material expression of this connection is pottery, which contrasts with what we know from Central and East Crete, i.e. metals and stone artefacts. At this point it does not matter any more where the prototypes come from and how style is transmitted. It might have started as reproduction of something familiar, or as imitation of something foreign. This repeated pattern shows that the forms are appropriated and integrated in the local repertoire without losing their evocative power, i.e. their quality to being reminiscent of something familiar to all those who are using the artefacts, even if they are in fairly distant places.

\footnotetext{
${ }^{3}$ The closest parallel for the figurine from Platyvola is Xanthoudides (1924) No 126 (1924: Pl. XXI), However, the holes on the neck and chest considered by Renfrew (1969: 19) as a Cretan customdo not exist on the example from Platyvola.
} 
It seems that there is a conscious attempt to "remember" and reproduce what is common. The material culture constitutes a common language with local manifestations, which are not based on the foreign and exotic, rather on what is familiar and consciously or unconsciously appropriated. It could therefore be suggested that the western Cyclades, Attica, Euboea and West Crete belong in the same cultural network, where the material culture is shared and individually appropriated.

\subsubsection{The case of Kastri (Kythera)}

It has been argued that the similarity in the material culture between the western Cyclades, the east coast of Attica and south Euboea (Manika) is the result of the "easier" maritime routes that connect these places in contrast to the open sea that connects them to Crete (Broodbank 2000: 307). Within this framework the case of Kastri on Kythera should be examined as a stepping-stone linking West Crete with the western Cyclades.

The settlement of Kastri is characterised in its earlier levels by Helladic pottery styles but in the EB 2 period a sudden change seems to have taken place, with Helladic types being substituted by Minoan style material, typologically similar to the West Cretan shapes. This was interpreted as the establishment of a Minoan, and namely West Cretan, colony on Kythera (Coldstream and Huxley 1972: 275-77), although there was no evidence of violence and destruction, which might have followed such an expedition. Moreover, the theory on colonies and the Creto-Cycladic connection has dramatically changed since Kastri was pronounced a colony, and the interpretation of the material culture became associated with issues of ethnicity.

It is only recently that the evidence from Kastri has been re-evaluated and it has been suggested that the site of Kastri "represents the coalescing of West Cretan people at a key point on the indirect northward passage to the west Cyclades" (Broodbank 2000: 317); this interpretation points to a maritime route that passes from the north coast of West Crete via Kythera towards the south coast of the Peloponnese and the western Cyclades. Until now the material evidence to support such a model was scarce: there are scatters of Cycladic artefacts and namely figurines occurring in 
the Peloponnese as well as jars with incised handles in Laconia (Cavanagh et al. '1996) and Kythera, the latter in local fabrics (Broodbank 2000: 308).

However, the evidence from West Crete changes our view on the existence of such a network. Considering how strong the Helladic component is in cases like Nopigeia (but also in most sites in West Crete) it can be suggested that the two areas share the same population. The Helladic style vessels that appear and become immediately widespread in West Crete are counterbalanced by the Minoan shapes in Kythera. The typology of the vessels at Kastri is very close, although not identical, to that in West Crete (sauceboats, collared jars, hearths) and in each case local fabrics are used. It seems that the material culture is shared and each place has its own potential of appropriating influences and transforming "foreign" into "familiar" forms; typological variations are just local manifestations of the same concept in different contexts.

\subsubsection{The Western Cycladic network}

In order to explain the lack of material evidence in the western Cyclades, Broodbank (2000: 260-61) discusses different patterns of interaction and detects a "disproportion" in the number and size of centres of activity. Some islands present evidence of intensive local networks and seem to have been involved in major zones of activity, whereas others seem to have participated in low-density networks. Due to the absence of material culture, the western Cyclades belong to the latter. For such cases it has been presumed that, except for the possibility of still undiscovered sites, these zones of low maritime activity might have been composed of different practices of communication.

The evidence from West Crete is crucial to this model because what is scarce and fragmentary in the western Cyclades is more abundant and complete in West Crete. Sauceboats.and (recently) jars with incised handles are considered the artefacts par excellence that move within the Aegean and their presence is associated with drinking rituals (Broodbank 2000: 305-6) ${ }^{4}$. Sauceboats and jars occur widely in West Crete and, as in the case of Kastri, they are manufactured in local fabrics. Moreover,

\footnotetext{
4 Along with sauceboats and jars with incised handles also figurines with folded arms are mentioned (Broodbank 2000: 305-6) but in West Crete there is only one example, that from Platyvola.
} 
the black slipped ware comprises, along with sauceboats, other vessels connected to serving and drinking practices such as jugs and saucers.

Broodbank suggests that these drinking rituals "may have been a means of creating bonds between leading people in widely separated communities" (Broodbank 2000: 306). With the evidence from West Crete we can go beyond the level of the rare and exotic items that are reserved for the leading people. The presence of whole ceramic sets for eating and drinking in domestic as well as ritual contexts might have been related to specific occasions and/or ceremonies of feasting where anybody could participate. With or without being prestige items they would have been used to stress social similarity rather than differentiation. The fact that they are reminiscent of or related to similar types from the Mainland but not religiously copied demonstrates that what is sought is not a simple reflection of the distant and the exotic but an active negotiation of common identity. The realisation of this "commonness" opens the debate of what is the International spirit in West Crete.

So far we have considered the elements of the material culture that stress commonness but there are two points that deserve attention: in the western Cyclades, Attica and Euboea there is abundance in metal artefacts as well as evidence of obsidian working with cores, and by-products (at Manika a workshop has been identified, see Sampson 1985: 93), whereas in West Crete the evidence of metals is very scarce, limited to a few small pieces at Kastelli (Tzedakis and Hallager 1983). As to obsidian, although present since the EM I (Mitatoulia, Tzedakis 1980b) and in every site examined, it occurs only in the form of finished products (namely blades). Only at the site of Kastelli there is scarce evidence of obsidian working in the form of flakes and possibly a few cores as well as metal-working (Tzedakis and Hallager 1983; Hallager and Tzedakis 1988).

Moreover, the absence of any published work on this material does not allow any inference on its provenance, which might have been the Cyclades (at least for the raw materials). Sites like Kastelli, Psathi and Nopigeia, situated on the north coast, might have been nodal points to the maritime route and the western Cycladic network. The role of Kastelli seems to be outstanding, although the evidence is still scarce. The possibility of a metal and an obsidian workshop along with the sealing evidence make Kastelli a site with special function and significance during the EBA. The full publication of the site may provide further insight on its role. 


\subsection{West Crete and the International Spirit}

The role and degree of involvement of West Crete in the maritime networks taking place in the Aegean during the $3^{\text {rd }}$ Millennium BC are still unclear. The themes around which the International Spirit developed are metals, conspicuous consumption and long-range interaction. For the former, the evidence in West Crete is rather scarce; the absence of any EB II burial assemblages and the rescue character of most excavations do not allow us to assess properly the role of metals. A workshop for metallurgical activity is reported at Kastelli (Tzedakis and Hallager 1983) on the basis of a few pieces of metal; this constitutes only indication and not secure evidence of metalworking. It is of importance that metal artefacts have not been reported from contexts rich in other types of material evidence (pottery, obsidian etc.) like the caves of Platyvola and Perivolia, which could also have functioned as places of ritual deposition and social display. There are three possible explanations for the paucity in metals in West Crete: that the metallurgical revolution did not reach this part of the island; that the demand for metals was not as high in West Crete as in the rest of Crete; that metals are connected mainly with funerary assemblages and, because in West Crete there is not. any indication of investment in funerary architecture, there is no investment in metal artefacts either.

However, the geographic configuration of the north coast and the establishment of settlements like Kastelli and Nopigeia are quite compatible with the model of similar centres in central Crete involved in maritime activities. The presence of obsidian since the EM I not only in coastal but also in remote settlements like Mitatoulia and Debla implies maritime activity and also a system of distribution, the latter being attested through survey data, with obsidian appearing less frequently with distance (Moody 1987). Moreover, the presence of "Helladic" and "Cycladic" artefacts in West Crete along with the Cretan evidence from Kythera are indicative of maritime contacts and connection with other areas in the Aegean. Other criteria which are thought to reflect the "International Spirit" and against which the position of West Crete could be compared to (after Broodbank (2000: 279) are: a) expansion of settlements, b) usage of plough, c) monumental building, d) seals and sealings, e) existence of local hierarchies, $f$ ) increased crafting, $g$ ) investment in the funerary sphere, and $h$ ) new drinking practices. In a nutshell, the situation in West Crete is as follows: 


\begin{tabular}{ll}
\multicolumn{1}{c}{ Criteria } & West Crete \\
expansion of settlements & yes (Moody 1987) \\
usage of plough & possibly \\
monumental building & possibly (only scarce evidence - Kastelli) \\
seals and sealings & yes (Vlasaki and Hallager 1995) \\
local hierarchies & $?$ \\
increased crafting/elaborate objects & yes \\
investment in the funerary sphere & no \\
new drinking practices & yes
\end{tabular}

Although the architectural evidence (secular and funerary) is scarce and fragmentary, the expansion of settlements has been identified through intensive survey and different settlement patterns were suggested (Moody 1987; see also Chapter 2). As to the usage of plough, the evidence for diversified agriculture and different species of plants implies that the plough must have been introduced in West Crete during the EBA as in the rest of the island. The extent of the EM settlement in Chania as reflected from the excavations at Kastelli and the town of Chania implies -although with scarce evidence- that there was potential for monumental architecture. The well-built rooms at Kastelli, as well as the few walls at Nopigeia show that the techniques of construction were quite elaborate.

Seals and sealings constitute an important and scarce type of material evidence for West Crete: from the early Prepalatial period there are two instances of seal use in Chania and one probable seal impression on the base of a jar from Platyvola (Vlasaki and Hallager 1995: 258). The first of the finds from Kastelli derives from the base of a hand-made open vessel that was found in a LM III pit, and therefore, its chronology is uncertain (Fig. 13). The second is a clay sealing of irregular shape, poorly preserved (Vlasaki and Hallager 1995: 265-6). At Platyvola was found a tall jar with scored decoration, which has a seal impression or potter's mark at the base. The motif stands out in relief and consists of a triangle filled with dots; outside of the triangle there is 
another dot (probably accidental) (Fig. 15). The impression was designed before the pot was fired (Vlasaki and Hallager 1995: 267). As to the date of the vessel, Godart and Tzedakis (1992: 48ff., Pl. XLIII,2) consider it Final Neolithic, whereas Vlasaki and Hallager (1995) consider it "a little later", which seems more conform with the typology.

As to the interpretation of the sealing evidence, Vlasaki and Hallager (1995: 268) agree that the sealings from Kastelli and Platyvola suggest some sort of control and organisation of production, especially the case of the jar since the seal impression was not supposed to be visible. Seal impressions could also be explained as control within private household economy or as the expression of some kind of administrative control within a Prepalatial community. The material available at present does not allow more than conjectural hypotheses; it is difficult to envisage the way sealings were used and how they were applied on the relevant items in order to secure the integrity of their content. It was therefore suggested that they might have been used to identify ownership or authority (Vlasaki and Hallager 1995: 270).

At this point it should be stressed that Kastelli and Platyvola are not conjectural sites; Kastelli occupies a strategic point in terms of geographical location, on a low hill overlooking two harbours and also seems to be part of an extended EM settlement. It would not, therefore, be surprising if it were involved in trading activities. In such context, seals and sealings must have been used for administrative purposes. Looking at the map with Prepalatial sites with evidence for use of seals (Vlasaki and Hallager 1995: 251, fig. 1) it is of interest that most sites are coastal (mainly on the north but also on the south coast) except for Archanes and Platyvola. The coastal sites must have used seals in their trading activities possibly as indicators of provenance or type of merchandise, although the evidence is still too scarce to be certain. As to the non-coastal sites, the importance of Archanes for the Prepalatial Central Crete and more specifically the importance of seals as indicators of rank and status in Phourni cemetery (Karytinos 1998), lead us to attribute similar significance to the sealing impression from Platyvola.

The presence of the jar with the seal impression (or potter's mark) in Platyvola is quite intriguing although not unexpected. The entire assemblage from the cave is surprising for its variability, the elaboration of manufacture and its special character. What is interesting though is what would a sealing impression be used for, if it would 
not be visible (at the base of a jar that would be quite heavy when full)? For a storage jar of these dimensions it is quite reasonable to suggest that its presence in the cave was due to its (valuable?) content. In that case, a possible explanation for the sealing would be that of the ownership, signalling the person who made the offer and not the potter.

One more piece of evidence concerning the relations of power and display attested in Platyvola derives from a sherd with an incised double axe (Alexiou 1964). The sherd belongs to a coarse vessel with deep scoring on the surface, which is characteristic of the west Cretan pottery tradition. As in the case of the jar with the sealing impression, we cannot be certain on the purpose of the engraving but it cannot be decorative since the scoring is too deep to allow any other sort of decoration. This leaves open the option of indication of ownership or identity of the person who made the offer.

The above evidence, although limited and fragmentary, implies the existence of social relations in West Crete. The material evidence from settlements and caves indicates a complex system of activities and before the EM IIA. The presence of obsidian in all sorts of environments (even in the remote settlement of Mitatoulia) implies an organised network for the procurement of raw material most likely via a maritime route and probably another one for the distribution of finished products.

The assemblages from the caves of Platyvola and Perivolia reflect continuous practices of deposition since EM I. The amount of collar-necked jars and sauceboats imply import into the cave of liquid and foodstuffs for (conspicuous) feasting and drinking. The presence of frying pans, stone vessels and a figurine imply ritual deposition of prestige objects. This is indicative of some type of social organisation, probably a local hierarchy, which was responsible for the organisation and/or the realisation of these events. The sealing impression and the sherd with the incised double axe reflect relations of power and display manifested during deposition practices.

The shift from large open vessels such as chalices and large pedestalled goblets in EM I to individual cups, small bowls and footed goblets during the EM II is indicative of the shift of emphasis from the communal to the individual. This shift was 
witnessed in other places in Crete and was interpreted as a change in the local hierarchies and social practices (Wilson and Day 2000). 


\title{
CHAPTER 10
}

\author{
Conclusions
}

\subsection{Introduction}

The aim of this thesis has been the investigation of the Prepalatial period in West Crete through the study of ceramics from selected sites, combining typological classification and scientific analysis. The methodology used has already been applied successfully in Central and East Crete and drastically changed the existing view of the Prepalatial (Wilson and Day 1994). The scope was to apply it in an area with no previous record in analytical work in order to address issues of pottery production, distribution and consumption within West Crete and investigate the technology of pottery manufacture for the different wares. Moreover, by making the data comparable to and compatible with those available from other sites on Crete it has been made possible to investigate whether West Crete follows a similar pattern of development as the rest of the island during the EM period.

The main themes around which the study of the Prepalatial has evolved during the last decade are: a) the specialisation of pottery production, b) the identification of networks of on- and off-island exchange, and c) issues of identity and ethnicity. These issues have been addressed also in the present work in order to understand pottery production and shed light on various aspects of social life and activity during the EM period in the western part of Crete. 


\subsection{The issues addressed in the study of the EM West Cretan pottery}

\subsubsection{Specialisation in pottery production}

The analysis of the EM material from West Crete shows a picture of production dominated by site-specific pottery, which may vary technologically, but seems to be produced locally. There is evidence for similar raw materials and clay recipes being used in several sites for the manufacture of similar types of pottery. This picture makes the West Cretan pattern of production different from those in Central and East Crete, where, in addition to local production, there are specific centres manufacturing specific types of pottery that get distributed across the island (Wilson and Day 1994; Whitelaw et al. 1997).

It is not a matter of the present work to discuss the validity of the concept of specialisation in the study of archaeological ceramics, but, because it is this notion that changed the traditional view of the Prepalatial period, it is considered worthwhile examining whether the criteria that define specialisation can be applied on the material from West Crete.

There are two significant papers dealing with the identification of specialisation in pottery production. First is the pioneer study by Rice $(1981 ; 1991)$ who set the variables and criteria to be met in order to recognise (a degree of) specialisation in a pottery assemblage. In brief, the criteria refer to specialisation in raw materials (Resource specialisation), vessel function (Functional or product specialisation), location (Site specialisation) and craftsmanship (Producer specialisation). In a later study, Costin (1991) suggested other parameters for the identification of specialisation. Each criterion is defined by two components ranging from non-specialised to specialised production. Costin's criteria are context (independent or attached producers), concentration (dispersed or nucleated units of production), scale (small, kin-based or large factory production), and intensity (part- or full-time). The two approaches offer different possibilities and are constructed on a different basis; Rice's approach is connected with parameters related to the products (such as raw materials, function etc.); Costin's is related to the units of production. In archaeology, there are only limited cases of preservation of production sites (such as 
kiln structures). In most cases there exist consumption sites and the final products (the pottery).

For this reason in Central and East Crete the criteria used were these set by Rice, since the information available was indirect and derived from sites of consumption and the analysis of the ceramic assemblages (Day et al. 1997). The West Cretan sites are also sites of consumption and Rice's criteria are considered better suited. A first assessment of specialisation of pottery production in West Crete is as follows:

Resource specialisation: in the EM West Cretan pottery there is some evidence on resource specialisation, since there seem to be specific clay recipes for specific types of pottery. This does not happen throughout the Prepalatial period but it is a phenomenon of the EM II phase. It is the case of calcareous and non-calcareous clays used for the manufacture of different types of pottery. The former are used for the Helladic-style black slipped ware, the rare dark-on-light and the mottled wares. The latter are used for the Minoan-style wares. This differentiation in clay selection is consistent and widespread across West Crete, and as indicated by the analyses, in different centres of production.

Functional/Production specialisation: in order to identify this type of specialisation Rice defined four individual criteria to be sought when examining a ceramic assemblage: compositional standardisation, decorative, morphological and technological homogeneity. The EM assemblages from West Crete display a certain degree of functional specialisation. The Helladic-style black slipped ware comprises exclusively serving and drinking vessels, which display compositional standardisation, all being manufactured with calcareous clays. Moreover, morphologically they are similar as much in terms of shape as in surface treatment. The sauceboats, saucers and jugs from all the sites display typological similarity and technological homogeneity: they are manufactured with similar raw materials and, as demonstrated by SEM analysis, the black slip is achieved in all cases through the iron-reduction technique.

This picture is in marked contrast with Central and East Crete, where the main technological differentiation is in the use of calcareous clays for the manufacture of 
jars and jugs and non-calcareous clays for cooking pot ware (Day et al. 1997; Whitelaw et al. 1997). This does not occur in West Crete in any phase of the Prepalatial. In the case if the non-calcareous wares, the same fabrics are used for jugs, cooking and storage vessels, while, in the case of Nopigeia, the same fabric has been used for the manufacture of semi-coarse vessels of Minoan and Helladic style.

Site specialisation: this parameter concerns patterns of production and is primarily connected to production locations. Therefore, when dealing with consumption assemblages, it is only through the study of distribution of the final product that site specialisation can be assessed.

In the West Cretan assemblages there does not seem to exist large-scale movement of pottery with specific production units distributing pottery towards various consumption centres. On the contrary, the fabrics are in their majority sitespecific and the picture is that of local production.

Through its morphological consistency, the black slipped ware was initially expected to represent the product of a single source. However, the analytical data did not confirm these expectations; despite their technological homogeneity, the black slipped vessels from the sites examined display different mineralogical and chemical composition, which was interpreted as different provenance.

Therefore, the pattern of site specialisation in the form of a production centre manufacturing a specific type of pottery which then gets distributed across the island cannot be substantiated in West Crete. It seems that there are many locations producing different types of pottery, most likely in the broader area of the consumption centres.

Producer specialisation: the concept of producer specialisation is related to the technological procedures of pottery manufacture. In the case of the West Cretan assemblage, the wares represented display a broad range of morphological and technological differences. This implies different labour investment, level of skill and technology of manufacture, and, therefore, different production units. 
The black slipped ware is the most prominent indication of technological advance. The black slip is the product of the iron-reduction technique, which requires a built kiln, good control of firing conditions and high firing temperatures. The level of technical expertise required for the achievement of this high-quality pottery argues in favour of producer specialisation. Although there are no kiln structures preserved, the traces of the firing on the sauceboats due to stacking imply, not only the presence of the kiln, but possibly a repetitive process involving large-scale production.

Moreover, there are significant differences between the forming and decoration techniques represented in the EM I and EM IIA wares. The elaboration attested in the dark burnished incised and red slipped and burnished wares of EM IIA is not present in the earlier phase of the Prepalatial. However, when the practices change (EM II) the new technologies and techniques are applied uniformly across West Crete and at different centres of production. This results in what seems to be a shared style and technology in this part of the island.

In a nutshell, the evidence from the typological study and the analyses of the EM material from West Crete point towards a degree of specialisation in pottery production. Even when not all the parameters are present, it should be stressed that specialisation is not a single phenomenon but a continuum (Day et al. 1997: 276) and therefore, it is possible than only some aspects are valid and/or archaeologically visible. In West Crete the consistency in the selection of specific raw materials for specific types of pottery, the occurrence of functionally distinct types of pottery in specific wares, and the broad range of technologies used for pottery manufacture are indications of specialisation.

This picture is markedly different from the patterns suggested for Central and East Crete, stressing even further the discrepancy between West Crete and the rest of the island. It also shows that the discussion of specialisation, especially when dealing with archaeological ceramics, is as complex as every ceramic assemblage, and requires more than the application of a set of criteria. What is of importance, after all, is to assess specialisation according to the character, the chronology and the context of each assemblage. 


\subsubsection{On/off-island exchange}

The discussion of specialisation in pottery production raises inevitably the issue of exchange. It is of interest to examine whether West Crete fits into the picture of exchange networks as those operating in Central and East Crete. It is important that on the north coast of West Crete there does not seem to exist nodal sites that take advantage of maritime communications and regulate the movement of raw materials and artefacts arriving from the Aegean. Although Chania appears to be a major harbour settlement during the Prepalatial period, it does not display the ceramic characteristics of similar sites in North-Central Crete (such as Poros) with large numbers of transport jars and Western Cycladic sauceboats (Dimopoulou et al. in press).

Contrary to the networks functioning in Central and East Crete, in West Crete there are only a few indications of pottery movement. Petrographic and chemical analysis demonstrated that the pottery examined is site-specific and broadly local. This absence of large-scale pottery exchange is not restricted only to the West Cretan wares. The analyses demonstrated that the pottery produced in the Mesara and distributed across Central and East Crete in the EM IIA, did not reach West Crete. This is the certainly the case of the fine grey and dark-on-light wares; the former is absent in West Crete, the latter is very rare and, when present, is locally produced. Moreover, Vasiliki (mottled) ware, which in EM IIB was produced in East Crete and distributed to Central Cretan sites, did not reach West Crete either' ${ }^{1}$. Unlike fine grey and dark-on-light wares, mottled ware occurs frequently in West Crete, but it is locally produced.

Finally, there is no certain indication of imports from the Southern Aegean and the Mainland, although part of the pottery in West Crete displays strong typological similarities with material from the Mainland and the Cyclades. It is mainly the case of the black slipped sauceboats and saucers, which have close affinities with the Urfirnis

\footnotetext{
This conclusion refers to the pottery analysed during the present study from different sites in West Crete. However, in the Chania Museum, there is a long spouted jar, which is very similar to the East Cretan examples of Vasiliki Ware. It remains to confirm or contradict the presence of East Cretan Vasiliki Ware with the analysis of more samples.
} 
vessels. Even some of the coarse ware (such as hearths and pithoi with rope decoration) is characteristic of non-Minoan assemblages. However, it has been demonstrated through petrographic analysis that the non-Minoan vessels seem to be manufactured with local raw materials. In some cases such as Nopigeia, local production has been confirmed by clay sampling. Moreover, the coarse, non-Minoan style vessels of Nopigeia are manufactured with the same raw materials as the Minoan ones.

The lack of evidence for pottery movement poses two questions: a) whether this phenomenon is restricted to the far western part of the island, and b) why West Crete does not participate in the general movement attested in the EM IIA.

The typological and stylistic analysis of the assemblages of Stavromenos and Eleutherna in Rethymnon were revealing in that respect. The shapes and wares represented in these assemblages display close similarities with assemblages in Central Crete: there exist dark-on-light painted vessels such as jugs, which are common in Central and East Crete, and red wares, in some cases with exact typological parallels at Knossos. Petrographic examination has demonstrated that some fabrics are related to West Cretan sources (mainly of metamorphic nature), as known from the analysis of the main assemblages, but there are also fabrics unknown in the rest of West Crete, some possibly from the Mesara. These are only preliminary observations and there is further analytical work to be carried out in order to confirm possible imports or imitations of Central Cretan prototypes. However, even from this restricted examination, it becomes clear that the patterns of pottery distribution and consumption are different in the sites of the Rethymnon area, in comparison to those in Chania and it is an issue for future research to examine potential patterns of pottery production.

Having established the discrepancy not only between West Crete and the rest of the island but also between the regions of Chania and Rethymnon within West Crete, the remaining question is why there is no evidence for large-scale pottery movement in this part of Crete. This has to be examined in relation to the absence of funerary evidence and the distribution of the non-Minoan style vessels (see also Chapter 9). 
The evidence from Central and East Crete demonstrated that pottery exchange, as well as inter- and intra-island communication, are related to the conspicuous deposition and display of specific ceramic types and metal artefacts in tombs. In West Crete, there are no funerary sites and the presence of metals is scarce. Through the use of exotica, i.e. items of special significance, rare or imported, social meanings are transmitted and identity is manifested or negotiated (Kiriatzi et al. 1997; Papadatos 1999). That is the reason why metals are found in cemeteries, where social status is displayed, and are connected with relations of power (Nakou 1995). The absence of tombs and the scarcity of metals are, therefore, not coincidental; this probably reflects a different system of values, a different way of expressing social status and identity. There is no investment in the funerary sphere (architecture, artefacts, etc.) because the identity to be expressed or negotiated is transmitted through other channels.

West Cretan assemblages are characterised by two typologically and technologically markedly different pottery traditions, the Helladic-style black slipped ware representing the special part of each assemblage. The distribution of this high quality pottery is interesting. Unlike the "luxury" wares in the rest of Crete, which occur largely in cemeteries, the West Cretan black slipped vessels occur in all the sites, equally in settlements and caves, and in large quantities. In some cases, the range of the non-Minoan vessels goes beyond the black slipped drinking and serving vessels and includes coarse wares (as is the case at Nopigeia).

Considering the stylistic and technological homogeneity within the body of the black slipped vessels, it seems that this ware does not represent the rare and exotic. On the contrary, it is something familiar that occurs in special and every day sites (caves and settlements respectively) and is accessible to all. Moreover, the typological similarity of these vessels, along with the fact that the same clay recipe and technology were used for their manufacture indicate that this specific visual effect is sought by producers and consumers. It could be suggested that the mere presence and wide distribution of the black slipped ware may explain why western Cycladic sauceboats are not imported, as is the case at Poros and Knossos. Considering that the "luxury" wares in Central and East Crete comprise primarily drinking and serving vessels, in West Crete this need might have been covered by the black slipped ware. Another 
hypothesis is that, because the tradition of this ware is so strong, there is no "space" for a new one that could substitute it. The black slipped ware is probably reminiscent of a tradition deriving from elsewhere (the Mainland?) that needs to be kept and preserved, probably a common link, a bond with other people living at a distance. It may be a material manifestation of common identity.

\subsubsection{Issues of identity and ethnicity}

Issues of ethnicity and identity constitute recurring themes in the study of the Prepalatial period but, like in the case of artefact exchange, they are in most cases connected with funerary assemblages. In West Crete the manifestation of identity was traced through typological and stylistic similarity in the Helladic-style pottery. It has been suggested that through the preservation of a common style, a common identity is also preserved and, even if pottery was not get exchanged, style and technology were clearly transmitted over space. Technological style is resistant to change (Stark 1999: 29) and the consistency in choices and techniques observed in the West Cretan ceramics might indicate an attempt to preserve and communicate identity.

The fact that pottery from the rest of the island does not reach the westernmost part of Crete might also be related to identity and ethnicity. A characteristic of the West Cretan pottery is the addition of Minoan elements on non-Minoan shapes. Prominent examples are the footed sauceboat, the foot being a characteristic of the goblet, the tripod pyxis, which is reminiscent of the tripod cooking pot and the frying pan with pellet feet, the latter being characteristic of jugs (Pl. 37). This phenomenon can have a twofold explanation: it either indicates an attempt of appropriation, of the transformation of non-familiar shapes with the addition of familiar elements, or it is an attempt to reproduce something remembered, which, inevitably, acquires elements of the current fashion.

Whatever the reason behind it, this perseverance in morphology regardless of fabric indicates an attempt to express commonness within West Crete and probably with other people producing and using similar types of pottery, even if they are living at a distance. There do not exist exact typological parallels for the Helladic-style 
pottery from West Crete, but sites with similar patterning in the material culture (i.e. artefacts of non local origin that are locally produced and occasionally slightly transformed in their morphology) occur in Kythera, the Western Cyclades, Attica and Euboea. On the grounds of these observations, it has been suggested that West Crete participates in a different network than that proposed for Central and East Crete. There is no sufficient material evidence to confirm this hypothesis, due to the lack of published material and analysis. However, there is scarce evidence, such as the occurrence of sauceboats and incised transport jars, which, in cases like Kastri where analyses have been carried out, are in local fabrics (Broodbank 2000: 305-6). The survey on Kythera and the ongoing study of the material might clarify certain aspects of this network.

In the era of the International Spirit, when the movement of people, goods and ideas is strong, West Crete must have played a role, though not as prominent as other places. Most of the criteria, set by Broodbank (2000: 279) and thought to reflect archaeologically the International Spirit, are fulfilled. The expansion of settlements is best represented at Chania: the EM occupation extends from the hill of Kastelli to the modern city. Moreover, there are examples of monumental building (although scarce due to restricted recovery), evidence for seals and sealings (Vlasaki and Hallager 1995), increased crafting represented by the high-quality black slipped ware, and new drinking practices represented by the wide distribution of black slipped sauceboats.

Although, the evidence does not allow the evaluation of the role of metals in the West Cretan society during the Prepalatial, the level of technological expertise observed in ceramics constitutes indirect evidence that there was investment in technology. Moreover, the scarce remains of metals at Kastelli Chania (Tzedakis and Hallager 1983) indicate that probably there was small-scale metallurgical activity. The fact that not all centres display intensive local networks has been interpreted by Broodbank (2000: 260-1) as reflecting low-density networks, and among these centres are the Western Cyclades. Having explained the potential relationship between the Western Cyclades and West Crete, it is possible that the latter might have participated in such a network. It would not be surprising if within the confines of the International 
Spirit there were several networks functioning simultaneously, even competing with each other, and involving different groups.

\subsection{Summary of the main points in this research}

This work has demonstrated that an integration of typology and analysis constitutes the best approach in the study of EBA ceramics. Moreover, it was made clear that a single analytical technique may not be sufficient to cover issues related to pottery characterisation, provenance and technology.

In the case of the EM assemblage from West Crete, typological examination has provided the first questions and dictated the way to proceed with sampling. The different wares have been identified and broadly dated and it has been made clear since the beginning that the main research questions would concentrate around the discrepancy between the Minoan- and the non-Minoan-style wares.

Petrography provides valuable information regarding paste recipes and techniques of manufacture. Along with the limited clay sampling, it is possible to assign a West Cretan provenance to all the samples examined. Moreover, the analysis provides indications of the site-specific character of the assemblages, although the geology alone often does not allow further provenance assignment. The main problem is that the pottery manufactured with red clays presents similar mineralogical composition, as is the case for pottery manufactured with Miocene marls. This is due to the repetitive character of the geological formations occurring in West Crete. Geological sampling confirms this observation and in some cases (such as the specific type of chert identified in the pottery and the clay samples of Nopigeia) provenance is assigned with a degree of confidence to the broad area of consumption.

Petrography and clay sampling are complemented by NAA. Elemental analysis is used for the examination of fine wares and it confirms the site-specific character of the West Cretan assemblage. It has also been demonstrated that the elemental composition of the clays is quite varied; and thus a significant number of samples remains ungrouped. 
Finally, SEM is used in order to investigate technological issues and evaluate the technology of manufacture of the different types of pottery within West Crete and in comparison to the rest of the island. Moreover, it provides a comparative measure in order to evaluate the degree of technical expertise of prehistoric potters in this part of the island.

The combined study of the typological and analytical information provides a new perspective on the EM period in West Crete. It has been demonstrated that West Crete follows the same development as the rest of the island in the EM IIA, which changes in EM IIB. In the era of the International Spirit a new type of pottery is introduced and becomes widespread; it is the high-quality black slipped ware, which seems to be produced in more than one site and includes serving and drinking vessels. The repertoire of shapes alludes to western Cycladic and Helladic contexts, although it is typologically unique. This information along with the absence of evidence for pottery movement within West Crete or imports from outside has led to the investigation of the reasons of this divergence from the pattern known from Central and East Crete.

It has been suggested that West Crete participates in a different network including Kythera, the Mainland, and possibly the Western Cyclades. The role of the black slipped ware is considered of importance in the manifestation of identity due to the prominent perseverance in the morphology. It is considered as a means to maintain the commonness and the bond with the other people who produce and use similar pottery.

Finally, it has been suggested that the network in which West Crete seems to participate is characterised by different systems of value. 


\subsection{Suggestions for future research}

The study of the EM pottery from West Crete through a combined approach of typology and analysis has provided several useful answers, some suggestions and created new questions.

The main issues concerning the pottery per se are related to the lack of contextual information and chronology. The study and publication of well-stratified assemblages would clarify issues of chronology and change in style occurring within the sub-phases of the Prepalatial. In this way, it would be feasible to establish a local sequence, which would allow archaeologists to date more accurately and securely pottery from rescue or old excavations. Moreover, it would provide a major tool for the investigation of the development of wares and styles through time.

The analytical work carried out indicates the directions for future research in the field of analysis. In the realm of geology, further geological sampling is necessary in order to evaluate difference between deposits of the same nature/character (alluvial deposits between them, marls between them). Such work should also encompass multiple sampling of each deposit, since previous research has demonstrated that there can be substantial compositional inhomogeneity within a single deposit (Hein et al. in prep.).

In the field of petrography, there are many routes that future research could follow. Different information would derive from the analysis of on- or off- island pottery. The analysis of further EM pottery from well-stratified contexts in the county of Chania would complement the existing data and would probably provide more secure information on provenance. Also within West Crete, a shift of interest to the area of Rethymnon would complement the picture we have of the Prepalatial period in this part of the island. The preliminary investigations showed the potential of such a research. The pottery from the sites of Eleutherna and Stavromenos displays significant typological similarities with assemblages from Central Crete, this connection being also confirmed by petrography. However, there seems to be a part of these assemblages that could be linked to the westernmost part of Crete and the study of this material typologically and analytically would clarify how "Western" or 
"Central Cretan" the character of these assemblages is. It would be of importance to investigate whether the area of Rethymnon receives pottery from other parts of the island (which seems to be the case) and whether the patterns of production, distribution and consumption have more affinities with Central rather than West Crete.

The petrographic analysis of pottery deriving from on-going work at sites outside West Crete, namely the western Cyclades and Kythera, will contribute greatly to an understanding of ceramic production in a broader scale. The analysis of Mainland deposits and comparison with existing NAA databases would also provide significant information on the potential relationship between West Crete and the Mainland.

Moreover, is should be stressed that the Prepalatial period does not end in the EM IIB. The present research concentrated on EM I-II because the EM III is a highly contested phase of the Prepalatial. It would be interesting to investigate the presence of EM III and MM IA pottery in West Crete. However, for the realisation of such a work, it would be imperative to have well-stratified contexts.

The research on the EM pottery should constitute the beginning for a more diachronic study of fabrics and clay recipes. The settlement of Chania (Kastelli and Chania Town) provided a range of fabrics and clay recipes. It has already been established through survey that there are fabrics which continue over time (Moody 1986) and it would be worth pursuing this research with material from stratified contexts. This research would provide valuable information on the longevity of clay recipes and the stability in the potters' choices. The petrographic study of the inscribed stirrup jars could be a link towards that direction (Day and Haskell 1995: 91). Their fabric, characterised by the presence of low-grade metamorphic rocks and argillaceous rock fragments, clay pellets, silt and mudstone, is similar to EM fabrics from Chania (Fabrics D8, D9), which demonstrates the potential of a diachronic study of clay recipes.

Finally, this research has demonstrated the potential of an approach combining typology, petrography, NAA, and SEM. In the case of West Crete we dealt with an assemblage quite different from what was already known, not only in terms of 
typology but also in terms of composition. The application of an integrated methodology covered many aspects of the assemblage and enabled us to suggest production locations and discuss clay recipes and pottery manufacturing traditions. In brief, it contributed towards a better understanding of the pottery, its provenance and its technology. Light has been shed on the Prepalatial period in West Crete in a synthetic way, using the information from the analysis in the discussion of the people and the ideas involved in the making and the consumption of pottery. 


\section{BIBLIOGRAPHY}

Aitchinson, J. 1986 The Statistical Analysis of Compositional Data. London: Chapman and Hall.

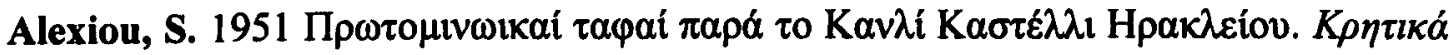

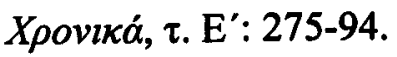

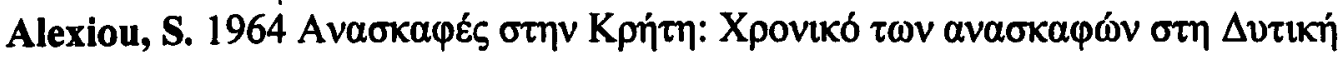

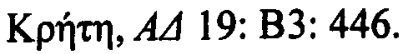

Aloupi, E. and Y. Maniatis 1990 Investigation of the technology of manufacture of the local LBA Theran pottery: the body and pigment analysis. In D. A. Hardy, C. G. Doumas, J. A. Sakellarakis and P. M. Warren (eds.) Thera and the Aegean World III: Proceedings of the Third International Congress, Santorini, Greece, 3-9 September 1989: 459-69. London: Thera Foundation.

Andreadaki-Vlasaki, M. 1988 Sunk Adyton or Lustral Basin in Chania, $A A A$ XXI: 56-76.

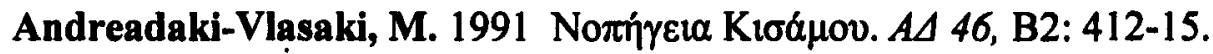

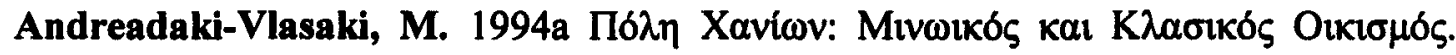

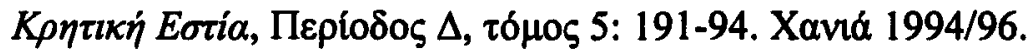

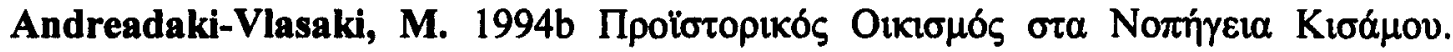

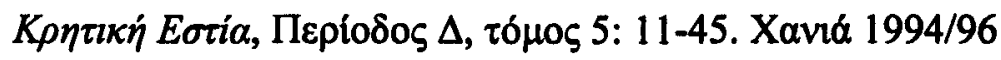

Arnold, D. E. 1985 Ceramic Theory and Cultural Process. New Studies in Archaeology, Cambridge: Cambridge University Press.

Attas, M. 1977 Neutron activation analysis of Early Bronze Age pottery from Lake Vouliagmeni, Perakhora, Central Greece. Archaeometry 19: 33-43.

Barrett, J. C. 1988 The living, the dead and the ancestors: Neolithic and Early Bronze Age mortuary practices. In J. C. Barrett and I. Kinnes (eds.) The Archaeology of Context in Neolithic and Bronze Age: Recent Trends: 30-41. Cambridge. 
Barth, F. 1969 Introduction. In F. Barth (ed.) Ethnic Groups and Boundaries. The Social Organization of Culture Difference. Bergen-Oslo: Universitets Forlaget.

Baxter, M. J. 1994 Exploratory Multivariate Analysis in Archaeology. Edinburgh: Edinburgh University Press.

Baxter, M. J. 1999 Detecting multivariate outliers in artefact compositional data, Archaeometry 41, 2: 321-38.

Baxter, M. J. 2001 Multivariate Analysis in Archaeology. In D. R. Brothwell and A. M. Pollard (eds,) Handbook of Archaeological Sciences: 685-94. John Wiley \& Sons, Ltd.

Baxter, M. J. and C. E. Buck 2000 Data Handling and Statistical Analysis. In E. Ciliberto and G. Spoto (eds.) Modern Analytical Methods in Art and Archaeology: 681-746. Chemical Analysis Series, Vol. 155. John Wiley \& Sons, Inc.

Beardah, C. C. and M. J. Baxter 2001 Grouping ceramic compositional data: an SPlus implementation. In Z. Stancic and T. Veljanovski (eds.) Computing Archaeology for Understanding the Past: CAA 2000: 53-59. BAR Int. Series 931. Oxford: Archaeopress.

Beier, T. and H. Mommsen 1994 Modified Mahalanobis filters for grouping pottery by chemical composition. Archaeometry: 36: 287-306.

Betancourt, P. P. 1984 East Cretan White-on-Dark Ware: Studies on a Handmade Pottery of the Early to Middle Minoan Periods. Philadelphia: University Museum Monograph 51.

Betancourt, P. P. 1985 The History of Minoan Pottery. Princeton.

Betancourt, P. P., T. K. Gaisser, E. Koss, R. F. Lyon, F. R. Matson, S. Montgomery, G. H. Myer and C. P. Swann 1979 Vasilike Ware, an Early Bronze Age Pottery Style in Crete. Göteborg.

Binns, C. F. and A. D. Frazer 1929 The genesis of the Greek black glaze, American Journal of Archaeology 33: 1-9. 
Blackman, D. J. and K. Branigan 1977 An archaeological survey of the lower catchment of the Ayiofarango valley, BSA 72: 13-84.

Blitzer, H. 1984 Traditional pottery production in Kentri, Crete: Workshops, materials, techniques and trade. In P. P. Betancourt (ed.) East Cretan White-on-Dark Ware: Studies of a Handmade Pottery of the Early to Middle Minoan Periods: 143-57. University Museum Monograph 51, Pennsylvania.

Blitzer, H. 1990 Koronaika: Storage jar production and trade in the traditional Aegean. Hesperia 59, 4: 675-711.

Bonneau, M., J. Angelier et M. Epting 1977 Réunion Extraordinaire de la Societé Géologique de France en Crète, Bulletin de la Societé Géologique de France XIX, 7: 87-102.

Branigan, K. 1988 [1970] The Foundations of Palatial Crete: a survey of Crete in the Early Bronze Age, in R. F. Willetts (ed.) States and Cities of Ancient Greece. Amsterdam: A. M. Hakkert.

Branigan, K. 1995 Social transformations and the rise of the state in Crete. In R. Laffineur and W. D. Niemeier (eds.) POLITEIA: Society and State in the Aegean Bronze Age: 33-40. Aegaeum 12. Liège.

Bronitsky, G. and R. Hamer 1986 Experiments in ceramic technology: the effects of various tempering materials on impact and thermal-shock resistance. American Antiquity 51 (1): 89-101.

Broodbank, C. 2000 An Island Archaeology of the Early Cyclades. Cambridge: Cambridge University Press.

Bullock, P., N. Fedoroff, A. Jongerius, G. Stoops and T. Tursina 1985 Handbook for Soil Thin Section Description. Wolverhampton: Waine Research Publications.

Buxeda I Garrigós, J. 1999 Alteration and Contamination of Archaeological Ceramics: The Perturbation Problem. Journal of Archaeological Science 26: 295-313. 
Buxeda I Garrigós, J., V. Kilikoglou and P. M. Day 2001 Chemical and mineralogical alteration of ceramics from a Late Bronze Age kiln at Kommos, Crete: the effect on the formation of a reference group. Archaeometry 43, 3: 349-71.

Buxeda I Garrigós, J., M. A. Cau Ontiveros and V. Kilikoglou 2003 Chemical variability in clays and pottery from a traditional cooking pot production village: testing assumptions in Pereruela. Archaeometry 45, 1: 1-17.

Caskey, J. L. 1960 The Early Helladic Period in the Argolid. Hesperia 29: 285-303. Catling, H. W. and A. Millet 1965 A study of the inscribed stirrup jars from Thebes, Archaeometry 8: 3-85.

Catling, H. W. and R. E. Jones 1977 A reinvestigation of the provenance of the inscribed stirrup jars found at Thebes, Archaeometry 19, 2: 137-46.

Catling, H. W., E. E. Richards and A. E. Blin-Stoyle 1963 Correlations between composition and provenance of Mycenaean and Minoan Pottery, BSA 58: 94-115.

Catling, H. W., J. F. Cherry, R. E. Jones and J. T. Killen 1980 The inscribed stirrup jars and West Crete, BSA 75: 49-113.

Cavangh, W. G., J. H. Crouwel, R. W. V. Catling and G. Shipley 1996 Continuity and Change in a Greek Rural Landscape: the Laconia Survey II. Archaeological Data. British School at Athens Suppl. Volume 27. London: British School at Athens.

Chandler, G. M. 2001 Comparative petrographic analysis of sherds from five Minoan sites in Western Crete. In Y. Bassiakos, E. Aloupi and Y. Fakorellis (eds.) Archaeometry Issues in Greek Prehistory and Antiquity, Hellenic Society for Archaeometry: 379-96. Athens: Society for Messenean Archaeological Studies.

Cherry, J. F. 1983 Evolution, revolution and the origins of complex society in Minoan Crete. In O. Krzyszkowska and L. Nixon (eds.) Minoan Society: 33-45. Bristol: Bristol Classical Press.

Coldstream, J. N. and G. L. Huxley 1972 Kythera: Excavations and Studies. London: Faber and Faber. 
Costin, C. L. 1991 Craft specialisation: issues in defining, documenting and explaining the organisation of production. In M.B. Schiffer (ed.) Archaeological Method and Theory 3: 1-56.

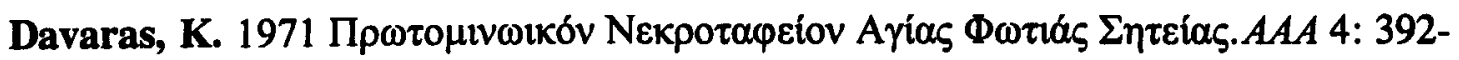
97.

David, N., J. Sterner, and K. Gavua 1998 Why pots are decorated, Current Anthropology 29, 3: 365-79.

Day, P. M. 1988a The production and distribution of storage jars in Neopalatial Crete. In E. B. French and K. A. Wardle (eds.) Problems in Greek Prehistory: 499-508. Bristol.

Day, P. M. 1988b Ceramic analysis and pottery systems: the case of Minoan Crete. In R. E. Jones and H. W. Catling (eds.), New aspects of archaeological science in Greece: 39-45. Fitch Laboratory Occasional Paper 3. Athens: British School at Athens.

Day, P. M. 1991 A Petrographic Approach to the Study of Pottery in Neopalatial East Crete. Unpublished PhD Thesis. University of Cambridge.

Day, P. M. 1995 Pottery production and consumption in the Siteia Bay area during the New Palace period, in M. Tsipopoulou and L. Vagnetti, Achladia: Richerche grecoitaliene in Creta Orientale. Rome.

Day, P. M. 1997 Ceramic Exchange between Towns and Outlying Settlements in Neopalatial East Crete. In R. Hägg (ed.) The Function of the "Minoan Villa", Proceedings of the Eighth International Symposium at the Swedish Institute at Athens, 6-8 June 1992:. 219-28. Stockholm: Paul Àstroms Förlag.

Day, P. M. and H. W. Haskell 1995 Transport Stirrup Jars form Thebes as Evidence of Trade in Late Bronze Age Greece. In C. Gillis and C. Risberg (eds.) Trade and Production in Premonetary Greece: Aspects of Trade. Studies in Mediterranean Archaeology and Literature. Jonsered. 
Day, P. M., D. E. Wilson and E. Kiriatzi 1997 Reassessing specialisation in Prepalatial Cretan ceramic production. In R. Laffineur and P. P. Betancourt (eds.) TEXNH: Craftsmen, Craftswomen and Craftsmanship in the Aegean Bronze Age: 275-90. Liège: Aegaeum 16.

Day, P. M., D. E. Wilson, and E. Kiriatzi 1998 Pots, Labels and People: burying ethnicity in the cemetery of Aghia Photia, Siteias. In K. Branigan (ed.) Cemetery and Society in the Aegean Bronze Age: 133-49. Sheffield: Sheffield Academic Press.

Day, P. M., E. Kiriatzi, A. Tsolakidou and V. Kilikoglou 1999 Group Therapy in Crete: A Comparison Between Analyses by NAA and Thin Section Petrography of Early Minoan Pottery. Journal of Archaeological Science 26: 1025-36.

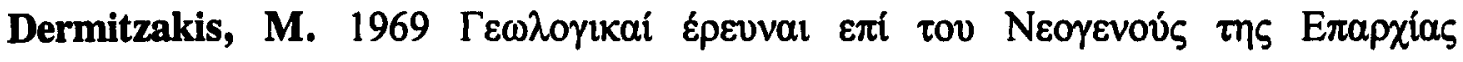

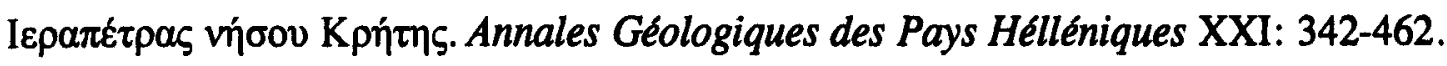

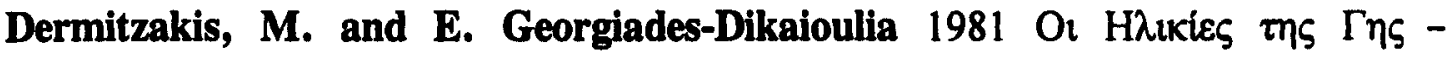

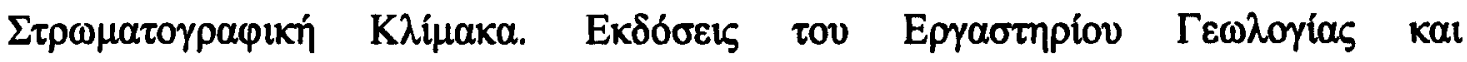

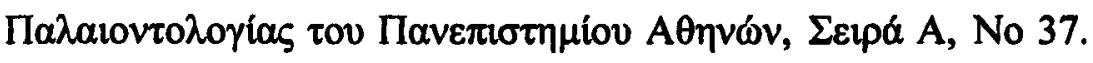

Dermitzakis, M., E. Georgiades-Dikaioulia and R. Mirkou 1979 Palaeoenvironmental observations based on the fauna assemblages from the Miocene deposits of Psathi Section (Stalos, Kydonias, W. Crete) Bulletin of the Geological Society of Greece, XIV, I: 85-93.

Dermitzakis, M., V. Karakitsios and E. Lagios 1995 Neotectonic and Recent Deformations of Crete, Proceedings of the $7^{\text {th }}$ International Conference on Cretan Studies, A1: 197-212. Rethymnon.

Dimopoulou, N. 1997 Workshops and craftsmen in the harbour town of Knossos at Poros-Katsambas. In R. Laffineur and P. P. Betancourt (eds.) TEXNH: Craftsmen, Craftswomen and Craftsmanship in the Aegean Bronze Age: 433-38. Aegaeum 16. Liège: Université de Liège. 
Dimopoulou, N., D. E. Wilson and P. M. Day in press. The earlier Prepalatial Settlement of Poros-Katsambas: craft production and exchange tat the harbour town of Knossos. In P. M. Day (ed.) Metallurgy in the Early Bronze Age: new evidence for production and consumption. Sheffield Studies in Aegean Archaeology.

Dobres, M. A. and C. R. Hoffman 1994 Social Agency and the Dynamics of Prehistoric Technology. Journal of Archaeological Method and Theory, 1, 3: 211-57.

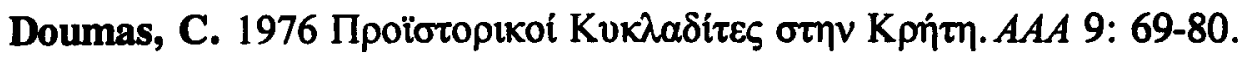

Doumas, C. 1977 Early Bronze Age Burial Habits in the Cyclades. Studies in Mediterranean Archaeology, vol. VLVIII. Göteborg: P. Ástroms Vörlag.

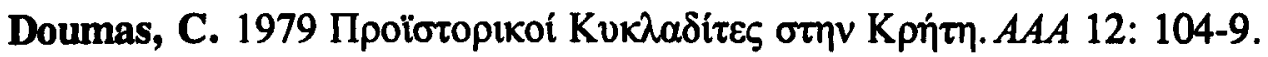

Drooger, C. W. and J. E. Meulencamp 1973 Stratigraphic contribution to geodynamics in the Mediterranean area: Crete as a case history. Bulletin of the Geological Society of Greece 10: 193-200.

Eiland, M. L. and Q. Williams 2001 Investigation of Islamic ceramics form Tell Tuneinir using X-Ray Diffraction. Geoarchaeology 16, 8: 875-903.

Evans, J. 1964 Excavations in the Neolithic settlement at Knossos. BSA 59: 132-241.

Faber, E. W., V. Kilikoglou, P. M. Day and D. E. Wilson 2002 A Technological Study of Middle Minoan Polychrome Pottery from Knossos, Crete. In V. Kilikoglou, A. Hein and Y. Maniatis (eds.) Modern Trends in Scientific Studies on Ancient Ceramics, Papers presented at the $5^{\text {th }}$ European Meeting on Ancient Ceramics, Athens 1999: 129-41. BAR Int. Series 1011.

Faure, P. 1956 Grottes Crétoises. Bulletin de Correspondance Héllénique 80: 95-103.

Fortuin, A. R. 1977 Stratigraphy and Sedimentary History of the Neogene Deposits in the Ierapetra region, Eastern Crete. GUA Papers in Geology. Amsterdam.

Freudenthal, T. 1969 Stratigraphy of Neogene deposits in the Khania province, Crete, with special reference to foraminifera of the family Planorbulinidae and the genus Heterostegina. Utrecht Micropalaeontological Bulletin, 1. Utrecht: Schotanus \& Jens Inc. 


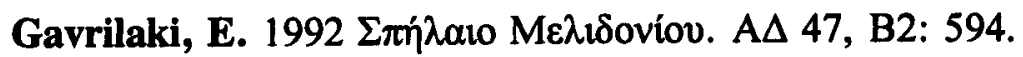

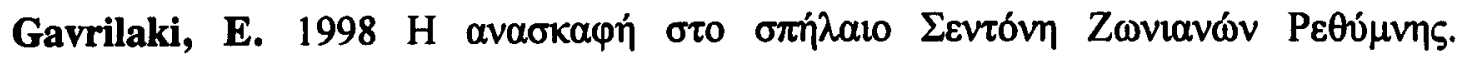

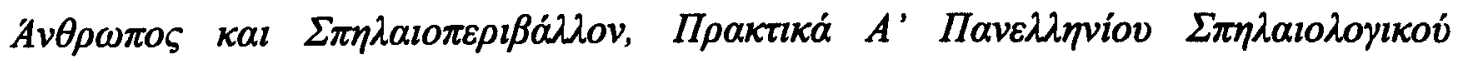

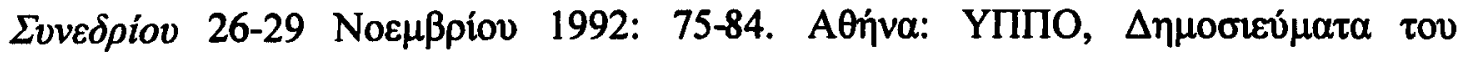

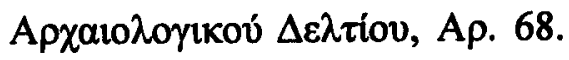

Gifford, J. A. 1992 The Geomorphology of Crete. In J. W. Myers, E. E. Myers and G. Cadogan (eds.) The Aerial Atlas of Ancient Crete: 17-25. University of California Press.

Godart, L. et Y. Tzedakis 1992 Témoignages Archéologiques et Epigraphiques en Crète Occidentale du Néolithique au Minoen Récent IIIB. Roma: Gruppo Editoriale Internazionale.

Goldman, H. 1931 Excavations at Eutresis in Boetia. Cambridge, Mass.

Gosselain, O. P. 1992 Bonfire of the Enquiries. Pottery Firing Temperatures in Archaeology: What for? Journal of Archaeological Science, 19: 243-59.

Gosselain, O. P. 1998 Social and Technical Identity in a Clay Crystal Ball. In M. T. Stark (ed.) The Archaeology of Social Boundaries: 78-106. Washington and London: Smithsonian Institution Press.

Gosselain, O. P. 1999 In Pots We Trust: The Processing of Clay and Symbols in SubSaharan Africa. Journal of Material Culture, 4, 2: 205-30.

Gosselain, O. P. 2000 Materialising Identities: an African perspective. Journal of Archaeological Method and Theory 7, 3: 187-217.

Gradstein, F. M. 1973 The Neogene and Quaternary deposits in the Sitia district of Eastern Crete. Annales Géologiques des Pays Hélléniques 25 (1972): 527-72.

Greig, J. R. A. and P. Warren 1974 Early Bronze Age Agriculture in Western Crete. Antiquity 48: 130-32.

Greiling, R. 1982 The metamorphic and structural evolution of the Phyllite-Quartzite Nappe of Western Crete. Journal of Structural Geology 4, No 3: 291-97. 
Haggis, D. 1996 Excavations at Kalo Khorio, East Crete. American Journal of Archaeology 100: 645-81.

Hall, R., M., G. Audley-Charles and D. J. Carter 1996 The significance of Crete for the evolution of the Eastern Mediterranean, In J. E. Dixon and H. F. Robertson (eds.) The Geological Evolution of the Eastern Mediterranean: 499-516. Geological Society Special Publication No 17. London: The Geological Society.

Hallager E. and Y. Tzedakis 1982 The Greek-Swedish Excavations at Kastelli, Chania (1978 and 1979) AAA XV: 21-30.

Hallager, E. and Y. Tzedakis 1985 The Greek-Swedish Excavations at Kastelli, Khania (1984) $A A A$ XVIII: 9-29.

Hallager E. and Y. Tzedakis 1986 The Greek-Swedish Excavations at Kastelli, Chania (1987) AAA XIX: 11-26.

Hallager, E. and Y. Tzedakis 1988 The Greek-Swedish Excavations at Kastelli, Khania $A A A$ XXI: $15-55$.

Halstead, P. 1980 Counting sheep in Neolithic and Bronze Age Greece. In I. Hodder, G. Isaac, and N. Hammond (eds.) Patterns of the Past: 307-339. Cambridge: Cambridge University Press.

Hamilakis, Y. 1996 Wine, oil and the dialectics of power in Bronze Age Crete: a review of the evidence. Oxford Journal of Archaeology 15, 1: 1-32.

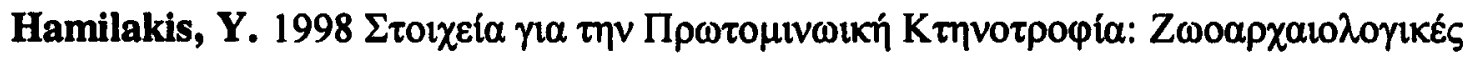

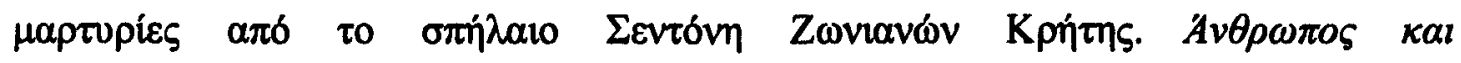

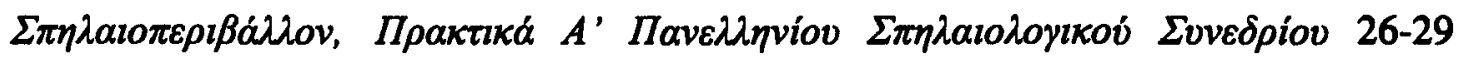

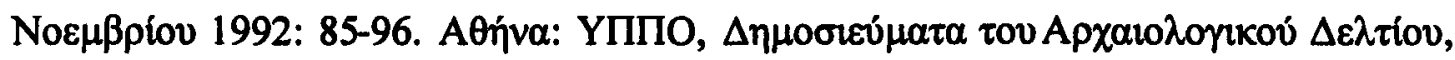
Ap. 68.

G. Harbottle 1982 Provenience studies using Neutron Activation Analysis: the role of standardisation. In J. S. Olin and A. D. Franklin (eds.) Archaeological Ceramics: 6777. Washington: Smithsonian Institution Press. 
Hatzipouliou-Kalliri, E. 1983 An Early Helladic II tomb by lake Vouliagmeni, Perachora. BSA 78: 369-75.

Hein, A., A. Tsolakidou, I. Hliopoulos, H. Mommsen, J. Buxeda I Garrigós, G. Montana and V. Kilikoglou 2002 Standardisation of elemental analytical techniques applied to provenance studies of archaeological ceramics: an inter laboratory calibration study. The Analyst 127: 542-553.

Hein, A., P. M. Day, P. S. Quinn and V. Kilikoglou in prep. Geochemical diversity of Neogene clay deposits in Crete and its implications for provenance studies of Minoan pottery.

Hellström, P. and C.-G. Styrenius 1971 Excavations at Chania 1970. AAA IV: 22324.

Hoard, R. J., M. J. O'Brien, M. G. Khorasgany and V. S. Gopalaratnam 1995 A materials-science approach to understanding limestone-tempered pottery from the Midwestern United States. Journal of Archaeological Science 22: 823-32.

Hodder, I. 1978 The maintenance of group identities in the Baringo district, W. Kenya. In D. Green, C. Haselgrove and M. Spriggs (eds.) Social Organisation and Settlement: Contributions from Anthropology, Archaeology and Geography. Part i: 4773. B.A.R. International Series (Supplement) 47 (i).

Hodder, I. 1985 Boundaries as Strategies: an Ethnoarchaeological Study. In S. W. Green and S. M. Perlman (eds.) The Archaeology of Frontiers and Boundaries: 14159. Studies in Archaeology. San Diego: Academic Press Inc.

Hood, M. S. F. 1965 Minoan Sites in the Far West of Crete. BSA 60: 99-113.

Hood, M. S. F. 1990a Settlers in Crete c. 3000 B.C. Cretan Studies 2: 151-58.

Hood, S. 1990b Autochthons or Settlers? Evidence for immigration at the beginning

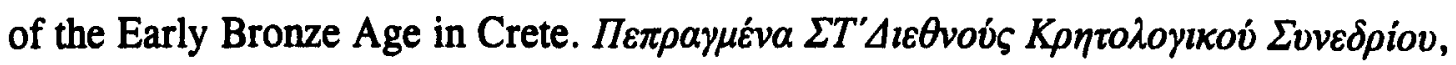
A1: 367-75. Xavió.

Hood, M. S. F., P. Warren and G. Cadogan 1964 Travels in Crete, 1962, BSA 59: 50-99. 
I.G.S.R. 1956 Geological Map of Greece: Platanias Sheet, 1:50 000. Institute for Geology and Subsurface Research. Athens.

I.G.S.R. 1969 Geological Map of Greece: Alikianou Sheet, 1:50 000. Institute for Geology and Subsurface Research. Athens.

I.G.S.R. 1970 Geological Map of Greece: Kastelli Sheet, 1:50 000. Institute for Geology and Subsurface Research. Athens.

I.G.S.R. 1971 Geological Map of Greece: Chania Sheet, 1:50 000. Institute for Geology and Subsurface Research. Athens.

Jacobshagen, V. 1979 Structure and geotectonic evolution of the Hellenides. Proceedings of the VI Colloquium on the Geology of the Aegean Region 3: 1355-67. Athens.

Jacobshagen, V. 1994 Orogenic evolution of the Hellenides: new aspects. Geologische Rundschau 83: 249-56.

Jones, R. E. 1986 Greek and Cypriot Pottery: a review of scientific studies, Fitch Laboratory Occasional Paper 1. Athens: British School at Athens.

Jones, S. 1997 The Archaeology of Ethnicity: Constructing Identities in the Past and Present. London: Routledge.

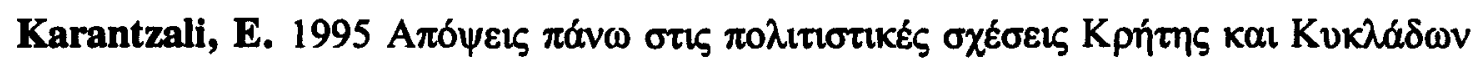

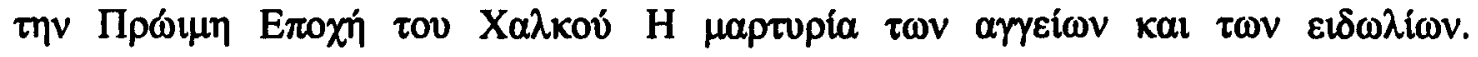

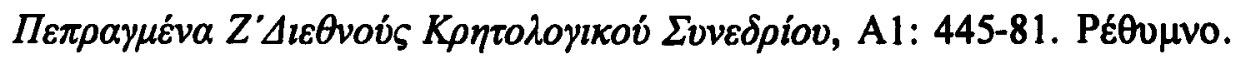

Karantzali, E. 1996 Le Bronze Ancien dans les Cyclades et en Crète. BAR International Series 631.

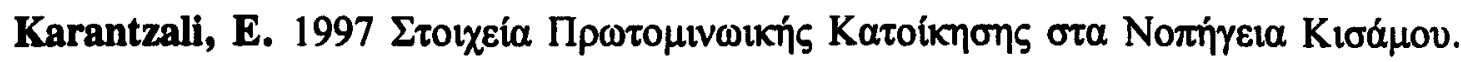

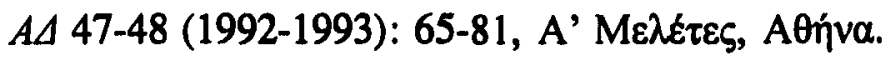

Karytinos, A. 1998 Sealstones in Cemeteries: A Display of Social Status? In K. Branigan (ed.) Cemetery and Society in the Aegean Bronze Age: 78-86. Sheffield: Sheffield Academic Press. 
Kemp, R. A. 1985 Soil Micromorphology and the Quaternary. Quaternary Research Association Technical Guides 2. Cambridge.

Kilikoglou, V. 1994 Scanning Electron Microscopy. In D. E. Wilson and P. M. Day Ceramic Regionalism in Prepalatial Central Crete: the Mesara Imports from EM IB to EM IIA Knossos, BSA 89: 70-75.

Kilikoglou, V., M. I. Karayannis and A. P. Grimanis 1990 Neutron Activation and statistical analysis of pottery from Thera, Greece, Journal of Radioanalytical and Nuclear Chemistry, Articles, vol. 141, 2: 347-55.

Kilikoglou, V. and A. P. Grimanis 1993 Chemical characterisation of Bronze Age pottery from Greek South Aegean islands by INAA, Journal of Radioanalytical and Nuclear Chemistry, Articles, vol. 168, 2: 297-306.

Kilikoglou, V. and Y. Maniatis 1993 Technological study of Neolithic ceramics from Tharounia and Psachna, Euboea. In A. Sampson (ed.) Skoteini, Tharrounia: The Cave, The Settlement and the Cemetery: 438-41. Athens.

Kilikoglou, V., G. Vekinis, Y. Maniatis and P. M. Day 1998 Mechanical performance of quartz-tempered ceramics: Part I, Strength and Toughness. Archaeometry 40, 2: 261-79.

Kiriatzi, E., S. Andreou, S. Dimitriadis and K. Kotsakis 1997 Co-existing traditions: handmade and wheelmade pottery in Later Bronze Age Central Macedonia. In R. Laffineur and P. P. Betancourt (eds.) TEXNH: Craftsmen, Craftswomen and Craftsmanship in the Aegean Bronze Age: 361-67 Aegaeum 16. Lì̀ge: Université de Liège.

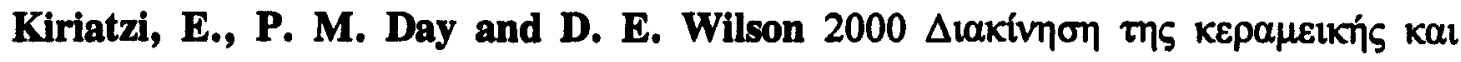

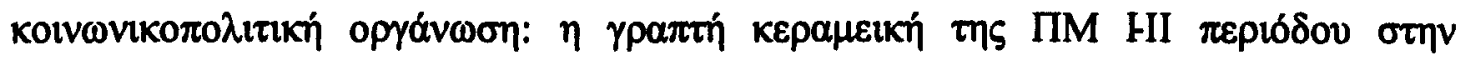

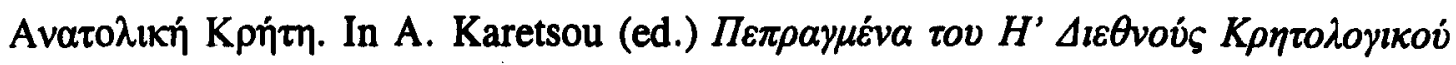

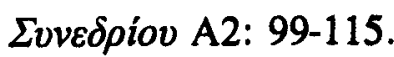


Krahl, Von J., G. Kauffmann, H. Kozur, D. Richter, O. Förster and F. Heinritzi 1983 Neue Daten zur Biostratigraphie und zur tektonischen Lagerung der PhyllitGruppe und der Trypali-Gruppe auf der Insel Kreta (Griechenland). Geologische Rundschau 72, 3: 1147-66.

Livingstone Smith, A. 2001 Bonfire II: The Return of Pottery Firing Temperatures, Journal of Archaeological Science, 28: 991-1003.

Longacre, W. A. and J. M. Skibo (eds) 1994 Kalinga Ethnoarchaeology: Expanding Archaeological Method and Theory. Washington: Smithsonian Institution Press.

Maniatis, Y. and M. Tite 1981 Technological examination of Neolithic-Bronze Age pottery from Central and South East Europe and the Near East, Journal of Archaeological Science 8: 59-76.

Mannning, S.W. 1995 The Absolute Chronology of the Aegean Early Bronze Age. Sheffield: Sheffield Academic Press.

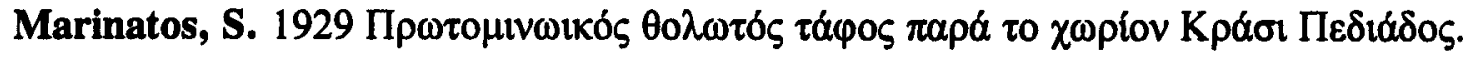
AS 12: 102-41.

Marinatos, S. 1932 Funde und Forschungen auf Kreta. Archäologischer Anzeiger (in Jahrbuch des Deutschen Archäologischen Instituts) 47: 176-7.

Matson, F. R. 1973 The Potters of Chalkis. In E. N. Borza and R. W. Carruba (eds.) Classics and the Classical Tradition: 117-42. Pennsylvania State University Press.

Matthew, A. J., A. J. Woods, and C. Oliver 1991 Spots before the eyes: new comparison charts for visual percentage estimation in archaeological material. In A. Middleton and I. Freestone (eds.) Recent Developments in Ceramic Petrology: 211-63. British Museum Occasional Papers, 81. London.

Metaxa-Muhly, P. 1984 Minoan Hearths. American Journal of Archaeology 88: 107 122.

Meulencamp, J. E. 1969 Stratigraphy of Neogene deposits in the Rethymnon province, Crete. Utrect Micropalaeontological Bulletin 2. 
Meulencamp, J. E. 1971 The Neogene in the Southern Aegean Area, in A. Strid (ed.) Evolution in the Aegean, Opera Botanica 30: 5-12.

Meulencamp, J. E., A. Jonkers and P. Spaak 1977 Late Miocene to Early Pliocene Development of Crete, VI Colloquium on the Geology of the Aegean Region, Athens I: $137-49$.

Momigliano, N. 1991 MM IA Pottery from Evans: a reassessment, $B S A$ 86: 149-271. Momigliano, N. and D. E. Wilson 1996: Knossos 1993: Excavations outside the South Front of the Palace. BSA 91: 1-57.

Mommsen, H., T. Beier and A. Hein 2002 A complete chemical grouping of the Berkeley Neutron Activation Analysis data on Mycenaean pottery. Journal of Archaeological Science, 29: 613-37.

Moody, J. A. 1985 The Development of a Bronze Age Coarse Ware Chronology for the Khania Region of West Crete. Temple University Aegean Symposium 10: 51-65.

Moody, J. A. 1987 The Environmental and Cultural Prehistory of the Khania Region of West Crete: Neolithic through Late Minoan III. Ph.D. Thesis, University of Minnesota.

Myer, G. H., K. G. McIntosh and P. P. Betancourt 1995 Definition of Pottery Fabrics by Ceramic Petrography. In P. P. Betancourt and C. Davaras (eds.) Pseira I, The Minoan Buildings on the West Side of Area A, pp. 143-153. The University Museum, University of Pennsylvania.

Mylonas, G. E. 1959 Aghios Kosmas: An Early Bronze Age Settlement and Cemetery in Attica. Princeton: Princeton University Press.

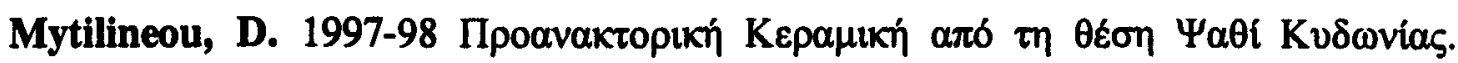

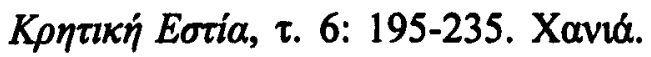

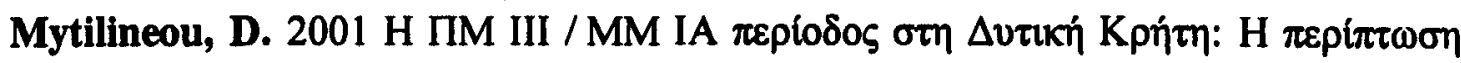

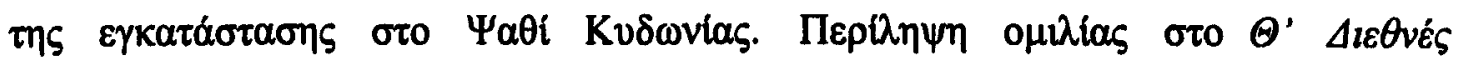

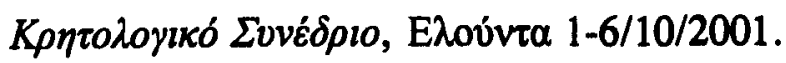


Mytilineou, D. and E. Hallager 2000 The "Mystery" of Psathi: some early Minoan strips and a sealing. Proceedings of the Danish Institute in Athens, vol. III: 51-65. Nakou, G. 1995 The cutting edge: a new look at Early Aegean metallurgy. Journal of Mediterranean Archaeology 8, 2: 1-32.

Neff, H., B. Bishop and E. V. Sayre 1988 A simulation approach to the problem of tempering in compositional studies of archaeological ceramics. Journal of Archaeological Science 15: 159-72.

Neff, H., B. Bishop and E. V. Sayre 1989 More observations on the problem of tempering in compositional studies of archaeological ceramics. Journal of Archaeological Science 16: 57-69.

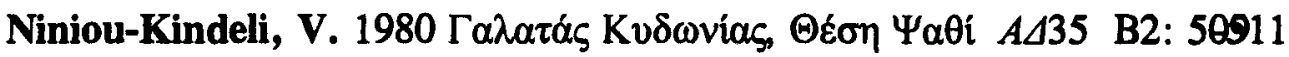

Nixon, L., J. Moody and O. Rackham 1988 Archaeological Survey in Sphakia, Crete. Echos du Monde Classique/Classical Views XXXII, n.s. 7: 159-73.

Nixon, L., J. Moody, S. Price and O. Rackham 1989 Archaeological Survey in Sphakia, Crete. Echos du Monde Classique/Classical Views XXXIII, n.s. 8: 201-15.

Nixon, L., J. Moody, V. Niniou-Kindeli and O. Rackham 1990 Archaeological Survey in Sphakia, Crete. Echos du Monde Classique/Classical Views XXXIV, n.s. 9: 213-20.

Noll, W., 1982 Mineralogie und Technik der Keramiken Altkretas. N. Jb. Miner. Abh., 142, 2: 150-99.

Noll, W., R. Holm and L. Born 1975 Painting of Ancient Ceramics. Angew. Chem. Internat. Edit. 14, 9: 602-13.

Nowicki, K. 1999 Final Neolithic Refugees or Early Bronze Age Newcomers? The Problem of Defensible Sites in Crete in the Late Fourth Millennium B.C. In P. P. Betancourt, V. Karageorghis, R. Laffineur and W.-D. Niemeier (eds.) MELETEMATA: Studies in Aegean Archaeology presented to Malcolm H. Wiener as he enters his $65^{\text {th }}$ year, vol. II: 575-81. Aegaeum 20. Liège: Université de Liège. 
Papadatos, Y. 1999 Mortuary practices and their importance for the reconstruction of society and life in Prepalatial Crete: the evidence from tholos tomb $\Gamma$, in Archanes, Phourni. Unpublished PhD Dissertation, University of Sheffield.

Papageorgiou, I., M. J. Baxter and M. A. Cau 2001 Model-based cluster analysis of artefact compositional data, Archaeometry 43, 4: 571-88.

Papamanoli-Guest, A. and A. Lambraki 1976 Les grottes de Léra et de l' Arkoudia en Crète Occidentale aux époques préhistoriques et historiques. $A \Delta 31, \mathrm{~A}, \mathrm{M} \varepsilon \lambda \hat{\varepsilon} \tau \alpha \mathrm{l}$ : 178-243.

Parker-Pearson, M. 1999 The Archaeology of Death and Burial. Stroud.

Payne, H. G. 1932 Archaeology in Greece 1931-32. Archaeological Reports, Journal of Hellenic Studies 52: 253-55.

Pendlebury, J. D. S. 1939 The Archaeology of Crete: An Introduction. London: Methuen.

Perlman, I. and F. Asaro 1969 Pottery analysis by neutron activation, Archaeometry 11: 21-52.

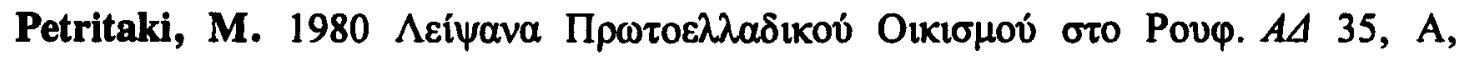

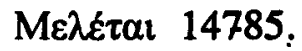

Postma, G. and W. Nemec 1990 Regressive and transgressive sequence in a raised Holocene gravelly beach, southwestern Crete. Sedimentology 37: 907-20.

Pullen, D. J. 1995 The Pottery of the Neolithic, Early Helladic I, and Early Helladic II Periods. In C. Runnels, D. J. Pullen and S. Langdon (eds.) Artifact and Assemblage: The Finds from a Regional Survey of the Southern Argolid, Greece, vol. I, The Prehistoric and Early Iron Age Pottery and the Lithic Artifacts: 6-42. Stanford, California: Stanford University Press.

Rackham, O. and J. Moody 1996 The Making of the Cretan Landscape. Manchester University Press.

Renfrew, C. 1969 The development and chronology of the Early Cycladic figurines. American Journal of Archaeology 73: 1-32. 
Renfrew, C. 1972 The Emergence of Civilisation: The Cyclades and the Aegean in the Third Millennium B.C. Methuen and Co Ltd.

Rice, P. M. 1981 Evolution of specialised pottery production: a trial model. Current Anthropology 22: 219-40.

Rice, P. M. 1987 Pottery Analysis: A Sourcebook. Chicago: University of Chicago Press.

Rice, P. M. 1991 Specialisation, standardisation and diversity: a retrospective. In R.L. Bishop and F.W. Lange (eds.) The Ceramic Legacy of Anna O. Shepard: 257-79.

Riley, J. A. 1982 The petrological analysis of Aegean ceramics. In I. Freestone, C. Johns and T. Potter (eds.) Current research in Ceramics: Thin-section studies: 1-7. British Museum Occasional Paper No 32. London.

Riley, J. A. 1983 The contribution of ceramic petrology to our understanding of Minoan Society, in O. Krzyszkowska and L. Nixon (eds.) Minoan Society, Proceedings of the Cambridge Colloquium 1981: 283-92, Bristol: Bristol Classical Press.

Rye, O. S. 1981 Pottery Technology: Principles and Reconstruction. Manuals on Archaeology 4. Taraxacum, Washington.

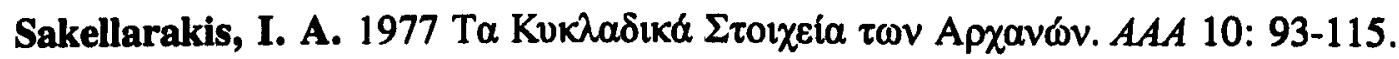

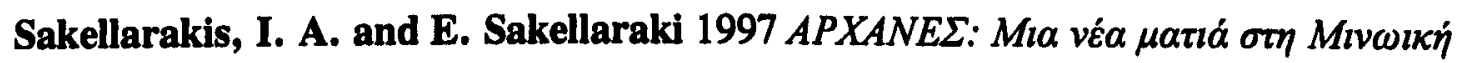
Kpírn. Athens.

Sampson A. 1985 Manika I: an Early Helladic Town in Chalkis. Athens: Etaireia Euvoikon Spoudon.

Sampson A. 1988 Manika II: the Early Helladic Settlement and Cemetery. Athens: Etaireia Euvoikon Spoudon.

Schmidt, H. 1902 Heinrich Schliemann's Sammlung trojanischer Altertïmer. Berlin Seager, R. B. 1912 Explorations in the island of Mochlos. New York. 
Seidel, E. and M. Okrusch 1976 Regional distribution of critical metamorphic minerals in the Southern Aegean, Bulletin de la Societé Géologique de France XVIII, 7: 347-50.

Shennan, S. J. 1989 Introduction: archaeological approaches to cultural identity. In J. S. Shennan (ed.) Archaeological Approaches to Cultural Identity: 1-32. London: Unwin Hyman.

Soles, J. F. 1988 Social ranking in Prepalatial cemeteries. In E. B. French and K. A. Wardle (eds.) Problems in Greek Prehistory: 49-61. Bristol

Soles, J. F. 1992 The Prepalatial Cemeteries at Mochlos and Gournia and the House Tombs of Bronze Age Crete. Hesperia Suppl. 24. Princeton.

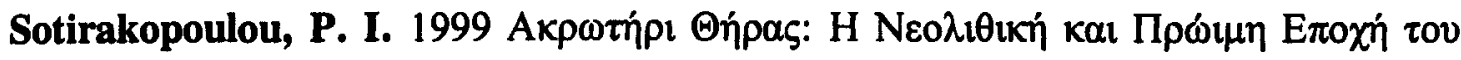

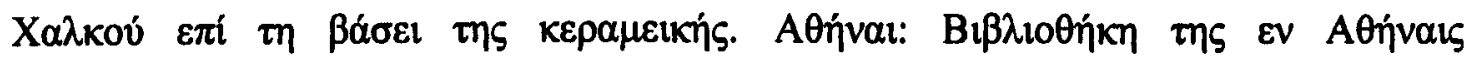

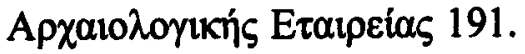

Stark M. T. 1999 Social Dimensions of Technical Choice in Kalinga Ceramic Traditions. In E. S. Chilton (ed.) Material Meanings: Critical Approaches to the Interpretation of Material Culture: 24-43. Salt Lake City: The University of Utah Press.

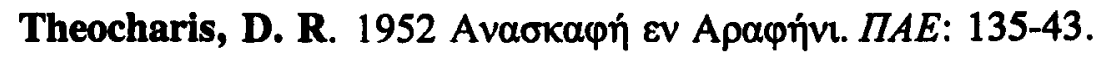

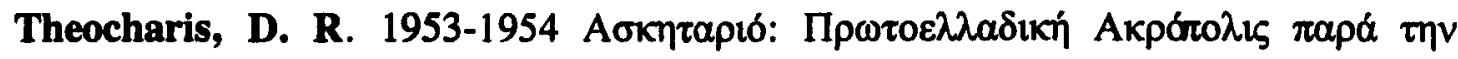

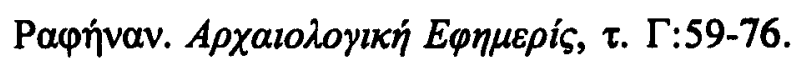

Thommeret, Y. and J., J. Laborel, L. F. Montaggioni and P. A. Pirazzoli 1981 Late Holocene shoreline changes and seismo-tectonic displacements in Western Crete (Greece). Zeitschrift für Geomorphologie N. F. Suppl. Bd. 40: 127-49.

Timpson, M. E. 1992 An Investigation of the Pedogenesis of Soils Developed in Quaternary Alluvial Deposits of Eastern Crete. Ph.D. Thesis, University of Tennessee, Knoxville.

Tomlinson, J. E. 1991 Provenance of Minoan Ceramics by multivariate analysis of Neutron Activation data. Unpublished Ph.D. diss., Univ. of Manchester. 
Tomlinson, J. E. 1995 Multivariate analysis of neutron activation data on heavy ware stirrup jars from Mycenae. In I. Tournavitou (ed.) The Ivory Houses at Mycenae: 3058. BSA Supplementary Volume. London.

Tsolakidou, A., V. Kilikoglou, E. Kiriatzi, and P. M. Day 2002 Investigating petrological and chemical groupings of Early Minoan cooking vessels. In V. Kilikoglou, A. Hein and Y. Maniatis (eds.) Modern Trends in Scientific Studies on Ancient Ceramics, Papers presented at the $5^{\text {th }}$ European Meeting on Ancient Ceramics, Athens 1999: 19-34. BAR Int. Series 1011.

Tzavella-Evjen, H. 1984 Lithares. Athens.

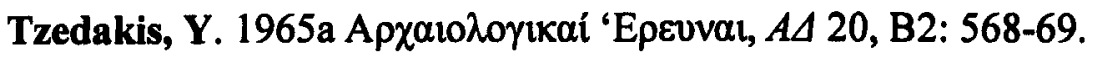

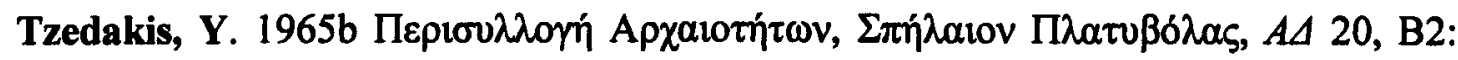
569-70.

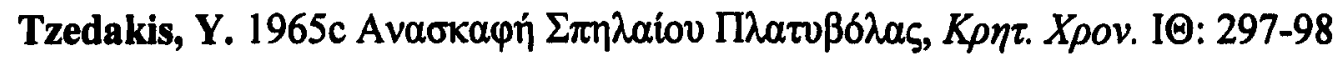

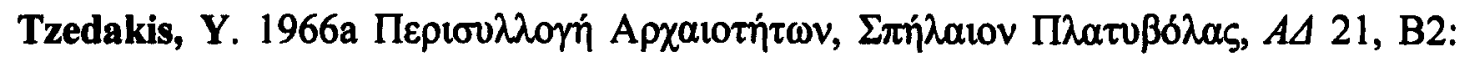
428-9.

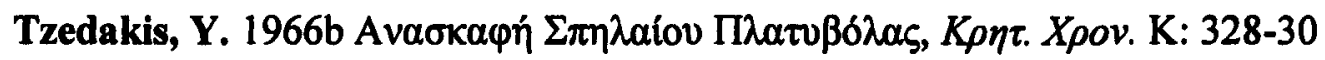

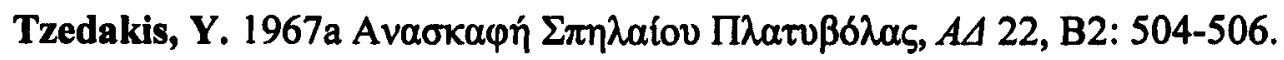

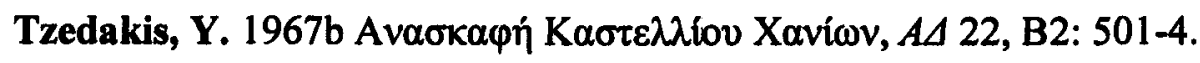

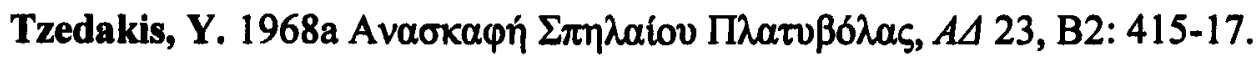

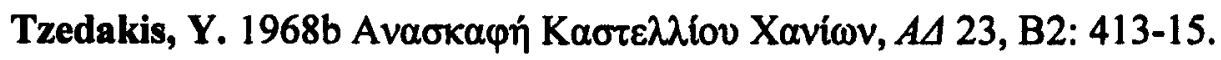

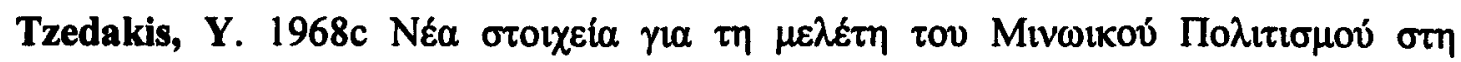

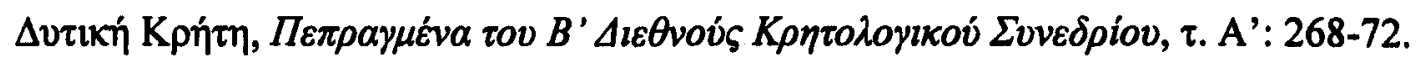

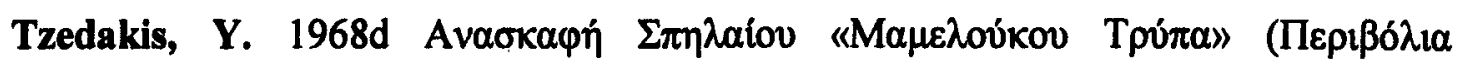

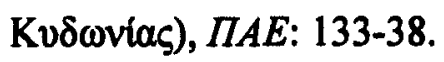

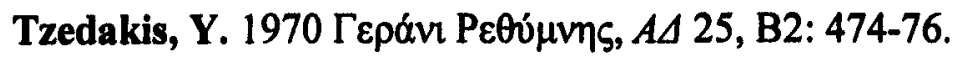

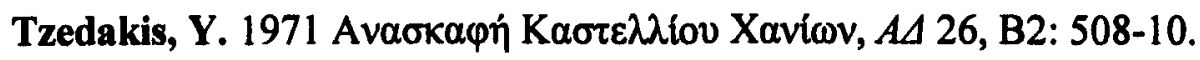




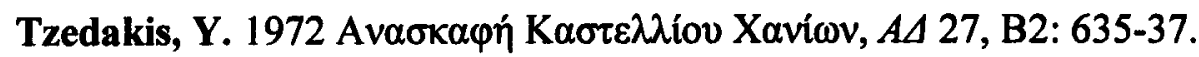

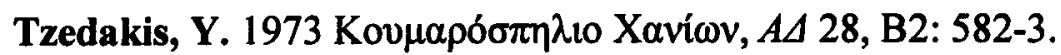

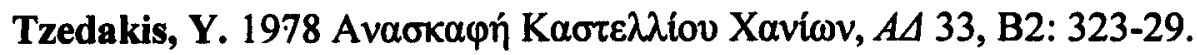

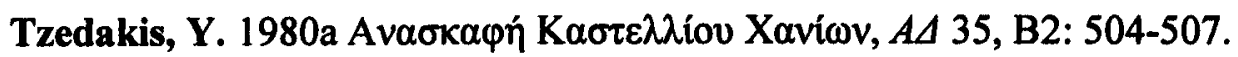

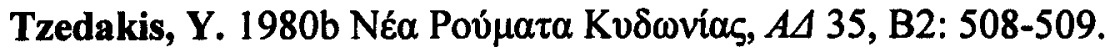

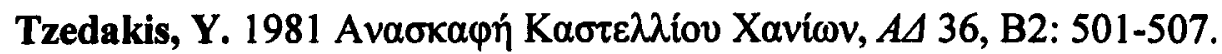

Tzedakis, Y. 1984 Le passage au Minoen Ancien en Crète Occidentale. In Hommage à Henri van Effenterre, Aux Origines de l' Héllénisme: la Crète et la Grèce: 3-7. Université Paris I: Publications de la Sorbonne.

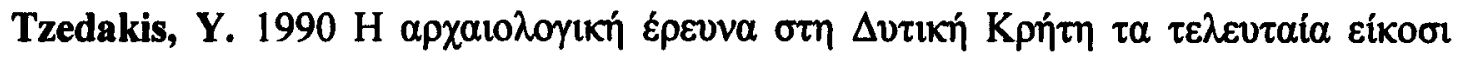

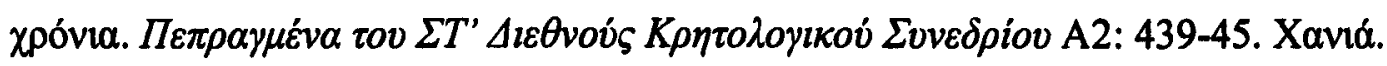

Tzedakis, Y. and E. Hallager 1983 The Greek-Swedish Excavations at Kastelli, Chania (1980), $A A A$ XVI: 9-17.

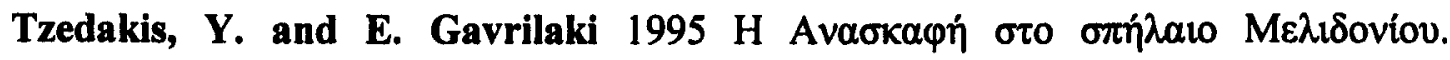

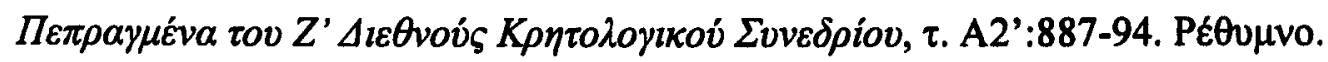

Vagnetti, L. and P. Belli 1978 Characters and Problems of the Final Neolithic in Crete. Studi Micenei ed Egeo-Anatolici, Fascicolo XIX: 125-63. Incunabula Graeca LXVIII. Roma.

Vagnetti, L. and R. E. Jones 1988 Towards the identification of local Mycenaean pottery in Italy. In E. B. French and K. A. Wardle (eds.) Problems in Greek Prehistory: 335-48. Bristol

Vagnetti, L. J. Tzedakis and A. Christopoulou 1989 Scavi a Nerokourou, Kydonias, Richerche Greco-Italiene in Creta Occidentale I, Fascicolo Primo, Roma.

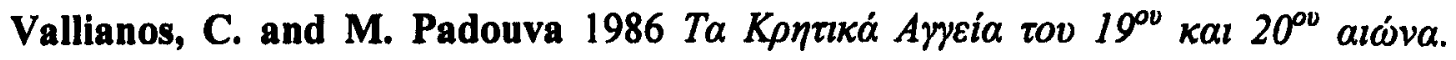

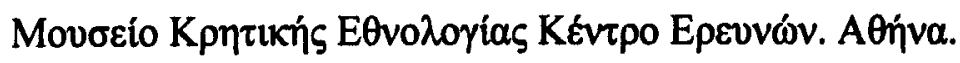


Vallianou, D. 1996 New evidence of earthquake destructions in Late Minoan Crete. In S. Stiros and R. E. Jones (eds.) Archaeoseismology: 153-67. IGME and The British School at Athens, Fitch Laboratory Occasional Paper 7.

Vekinis, G. and V. Kilikoglou 1998 Mechanical performance of quartz-tempered ceramics: Part II, Hertzian strength, wear resistance and applications to ancient ceramics. Archaeometry 40, 2: 281-92.

Venables, W. N. and B. D. Ripley 1999 Modern applied statistics with S-Plus, 3rd Edition. New York: Springer-Verlag.

Venables, W. N. and B. D. Ripley 2000 S-Programming. New York: SpringerVerlag.

Vita-Finzi, C. 1969 The Mediterranean Valleys: Geological changes in historical times. Cambridge: Cambridge University Press.

Vlasaki, M. and E. Hallager 1995 Evidence for seal use in Pre-palatial Western Crete. Corpus der Minoischen und Mykenischen Siegel, vol. 5: 251-70.

Voyatzoglou, M. 1984 Thrapsano, Village of Jar Makers. In P. P. Betancourt (ed.) East Cretan White-on-Dark Ware: Studies of a Handmade Pottery of the Early to Middle Minoan Periods: 130-42. University Museum Monograph 51, Pennsylvania.

Warren, P. (ed.) 1972 Myrtos: an Early Bronze Age settlement in Crete. British School at Athens Suppl. 7.

Warren, P. 1973 Crete, 3000-1400 B.C.: Immigration and the archaeological evidence. In R. A. Crossland and A. Birchland (eds.) Bronze Age Migrations in the Aegean: 41-50. Duckworth

Warren, P. and Y. Tzedakis, 1974 Debla, An Early Minoan Settlement in Western Crete. BSA 69: 299-342.

Warren, P. and V. Hankey 1989 Aegean Bronze Age Chronology. Bristol: Bristol Classical Press.

Watrous, L. V. 1994 Review of Aegean Prehistory III: Crete from earliest prehistory through the Protopalatial period. American Journal of Archaeology 98: 695-753. 
Watrous, L. V., D. Hatzi-Vallianou, K. Pope, N. Mourtzas, J. Shay, C. T. Shay, J. Bennet, D. Tsoungarakis, E. Angelomati-Tsoungaraki, C. Vallianos and H. Blitzer 1993 A Survey of the Western Mesara Plain in Crete: Preliminary Report. Hesperia 62, 2: 191-248.

Whitbread, I. K. 1986 The characterisation of argillaceous inclusions in ceramic thin sections, Archaeometry, 28, 1: 79-88.

Whitbread, I. K. 1989 A proposal for the systematic description of thin sections towards the study of ancient ceramic technology. In Y. Maniatis (ed.) Archaeometry: Proceedings of the 25th International Symposium: 127-138. Amsterdam: Elsevier Science Publishers.

Whitbread, I. K. 1995a We are what we study: problems in communication and collaboration between ceramologists and archaeological scientists. KVHAA Konferenser 34: 91-100.

Whitbread, I. K. 1995b Greek Transport Amphorae: A Petrological and Archaeological Study. The British School at Athens, Fitch Laboratory Occasional Paper 4.

Whitelaw, T. M. 1983 The settlement at Fournou Koryfi Myrtos and aspects of Early Minoan social organisation. In O. Krzyszkowska and L. Nixon (eds.) Minoan Society: 323-45. Bristol: Bristol Classical Press.

Whitelaw, T. M., P. M. Day, E. Kiriatzi, V. Kilikoglou and D. E. Wilson 1997 Ceramic traditions at EM IIB Myrtos Fournou Korifi. In R. Laffineur and P. P. Betancourt (eds.) TEXNH: Craftsmen, Craftswomen and Craftsmanship in the Aegean Bronze Age: 265-75 Aegaeum 16. Liège: Université de Liège.

Wiencke, M. H. 2000 The Architecture, Stratification, and Pottery of Lerna III. Lerna, a Preclassical Site in the Argolid: Results of excavations conducted by the American School of Classical Studies at Athens, vol. IV. The American School of Classical Studies at Athens, Princeton, New Jersey.

Wiessner, P. 1983 Style and social information in Kalahari San projectile points. American Antiquity 48: 253-76. 
Wiessner, P. 1984 Reconsidering the behavioural basis for style: a case study among the Kalahari San. Journal of Anthropological Archaeology 3: 190-234.

Wilson, D. E. 1984 The EM IIA West Court House at Knossos. Ph.D. Dissertation, University of Cincinnati.

Wilson, D. E. 1985 The pottery and Architecture of the EM IIA West Court House at Knossos, BSA 80: 281-364.

Wilson, D. E. 1994 Knossos before the Palaces: an overview of the Early Bronze Age (EM I- EM III), in D. Evely, H. Hughes-Brock and N. Momigliano (eds.) Knossos: A Labyrinth of History. Papers in Honour of Sinclair Hood: 23-44. London.

Wilson, D. E. 1999 Keos IX. Ayia Irini Periods I-III: The Neolithic and Early Bronze Age Settlements. Part I: The Pottery and Small Finds. Mainz on Rhine: Philipp von Zabern.

Wilson, D. E. and P. M. Day 1994 Ceramic Regionalism in Prepalatial Central Crete: the Mesara Imports from EM IB to EM IIA Knossos, BSA 89: 1-87.

Wilson, D. E. and P. M. Day 1999 EM IIB Ware Groups at Knossos: The 1907-1908 South Front Tests, BSA 94: 1-62.

Wilson, D. E. and P. M. Day 2000 EM I Chronology and Social Practice: Pottery from the Early Palace Tests at Knossos, BSA 95: 21-63.

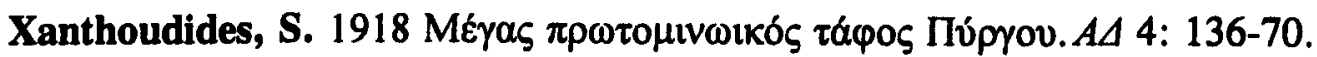

Xanthoudides, S. 1924 The Vaulted Tombs of Mesara: An Account of Some Early Cemeteries of Southern Crete. London: Hodder and Stoughton Ltd.

Zachos, K. 1996 Tracing a destructive earthquake in the Southwestern Peloponnese (Greece) during the Early Bronze Age. In S. Stiros and R. E. Jones (eds.) Archaeoseismology: 169-85. IGME and The British School at Athens, Fitch Laboratory Occásional Paper 7.

Zamani, A. and H. Maroukian 1981 A morphotectonic investigation in Northwestern Crete: The peninsula of Akrotiri. Zeitschrift fur Geomorphologie N. F. Suppl. Bd. 40: 151-64. 


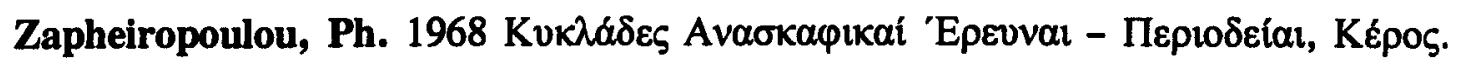
$\mathrm{A} \Delta$ 23, Xpovkкú, B2: 381.

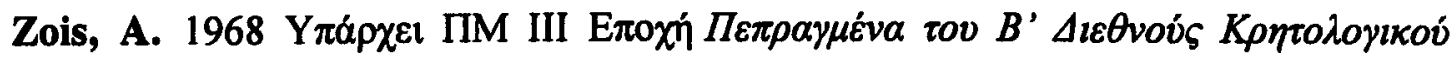

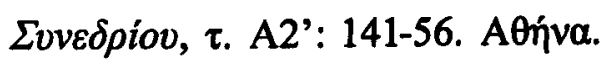

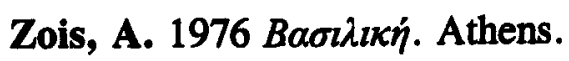

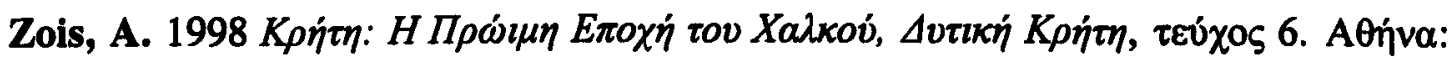
A $\pi \delta \delta \delta \varepsilon \xi ц$.

Zulauf, G., G. Kowalczyk, J. Krahl, R. Petschick and S. Schwanz 2002 The tectonometamorphic evolution of high-pressure low-temperature metamorphic rocks of eastern Crete, Greece: constraints from microfabrics, strain, illite crystallinity and palaeodifferential stress. Journal of Structural Geology 24: 1805-28. 